\title{
A breath of fear : a translational approach into the mechanisms of panic
}

Citation for published version (APA):

Leibold, N. K. (2015). A breath of fear : a translational approach into the mechanisms of panic. [Doctoral Thesis, Maastricht University]. Maastricht University. https://doi.org/10.26481/dis.20150625nl

Document status and date:

Published: 01/01/2015

DOI:

$10.26481 /$ dis.20150625nl

Document Version:

Publisher's PDF, also known as Version of record

\section{Please check the document version of this publication:}

- A submitted manuscript is the version of the article upon submission and before peer-review. There can be important differences between the submitted version and the official published version of record.

People interested in the research are advised to contact the author for the final version of the publication, or visit the DOI to the publisher's website.

- The final author version and the galley proof are versions of the publication after peer review.

- The final published version features the final layout of the paper including the volume, issue and page numbers.

Link to publication

\footnotetext{
General rights rights.

- You may freely distribute the URL identifying the publication in the public portal. please follow below link for the End User Agreement:

www.umlib.nl/taverne-license

Take down policy

If you believe that this document breaches copyright please contact us at:

repository@maastrichtuniversity.nl

providing details and we will investigate your claim.
}

Copyright and moral rights for the publications made accessible in the public portal are retained by the authors and/or other copyright owners and it is a condition of accessing publications that users recognise and abide by the legal requirements associated with these

- Users may download and print one copy of any publication from the public portal for the purpose of private study or research.

- You may not further distribute the material or use it for any profit-making activity or commercial gain

If the publication is distributed under the terms of Article $25 \mathrm{fa}$ of the Dutch Copyright Act, indicated by the "Taverne" license above, 


\section{A breath of fear}

A translational approach into

the mechanisms of panic

Nicole Leibold 
Layout and printing Ridderprint BV, Ridderkerk, the Netherlands

Cover Hans Peeters

ISBN 978-94-6299-107-1

(C) 2015 by Nicole Leibold, Maastricht, the Netherlands

All rights reserved. No part of this publication may be reproduced or used in any form or by any manner without prior written permission of the author. 


\title{
A breath of fear
}

\author{
A translational approach into \\ the mechanisms of panic
}

\author{
PROEFSCHRIFT
}

ter verkrijging van de graad van doctor

aan de Universiteit Maastricht,

op gezag van de Rector Magnificus, Prof. dr. L.L.G. Soete,

volgens het besluit van het College van Decanen,

in het openbaar te verdedigen

op donderdag 25 juni 2015 om 16.00 uur

door

Nicole Katharina Leibold 


\section{Promotor}

Prof. dr. H.W.M. Steinbusch

\section{Copromotores}

Dr. K.R.J. Schruers

Dr. D.L.A. van den Hove

\section{Beoordelingscommissie}

Prof. dr. T.A.M.J. van Amelsvoort (voorzitter)

Prof. dr. S. Claes (Katholieke Universiteit Leuven, België)

Prof. dr. K. Domschke (Julius-Maximilians-Universität Würzburg, Duitsland)

Dr. B.P. Rutten

Prof. dr. Y. Temel

The research presented in this thesis was performed at the Department of Psychiatry and Neuropsychology, School for Mental Health and Neuroscience, Maastricht University, Maastricht, the Netherlands.

Publication of this thesis was financially supported by Lundbeck B.V. and Servier Nederland Farma B.V.
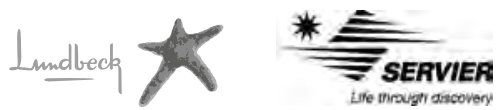

Life tirough aiscovery 

Paranimfen

Iris Lange

Sanne Peeters 


\section{Table of contents}

Chapter 1 General introduction

Panic disorder: Setting the stage

Aims and outline of this thesis

Chapter 2 The brain acid-base homeostasis and serotonin:

A perspective on the use of carbon dioxide as human and rodent experimental model of panic

Chapter 3 Carbon dioxide inhalation as a human experimental model of panic: The relationship between emotions and cardiovascular physiology

Chapter 4 Brainstem response to hypercapnia: A symptom provocation study into the pathophysiology of panic disorder

Chapter 5 Amiloride-sensitive cation channel 2 genotype affects the response to a carbon dioxide panic challenge

Chapter 6 Functional role of the 5-HT system and ASIC1a levels in $\mathrm{CO}_{2}$-induced fear-related behavior in mice

Chapter 7 The "humane" nature of euthanizing lab animals using $\mathrm{CO}_{2}$ : Cross-species panic research

Chapter 8 General discussion

Summary

Samenvatting 220

Valorization 228

Acknowledgments 237

Curriculum vitae 249

Publication list 253 


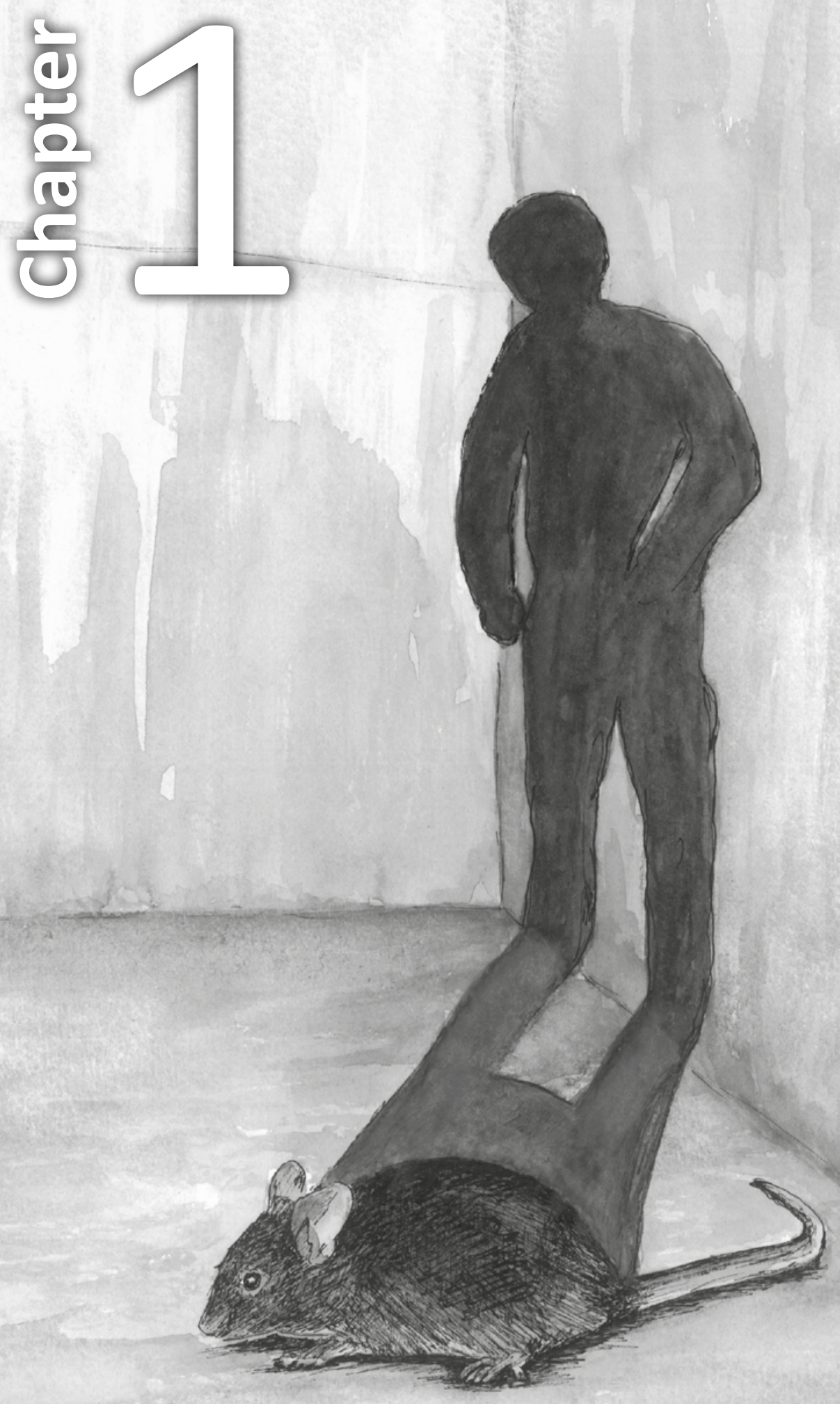


General introduction 
Chapter 1 


\section{Panic disorder: Setting the stage}

\section{Symptomatology and epidemiology}

Every fifth person in the general population experiences a panic attack (PA) at least once in life (Kessler et al., 2006). PAs are characterized by the sudden, unexpected onset of intense fear and/or discomfort, accompanied by a number of somatic and cognitive symptoms. According to the current Diagnostic and Statistical Manual of Mental Disorders (DSM)-5 (American Psychiatric Association, 2013) at least four of the following symptoms have to develop abruptly, reaching a symptomatic peak within a few minutes:

1) palpitations or accelerated heart rate

2) sweating

3) trembling or shaking

4) sensations of shortness of breath or being smothered

5) feeling of choking

6) chest pain or discomfort

7) nausea or abdominal distress

8) feeling dizzy, unsteady, lightheaded or faint

9) derealization (feelings of unreality) or depersonalization (being detached from oneself)

10) fear of losing control or going insane

11) sense of impending death

12) paresthesias (numbness or tingling sensations)

13) chills or hot flushes

Recurrent PAs represent the hallmark of panic disorder (PD), which has a prevalence of about 4\% in the general population (Norton et al., 2008; Pane-Farre et al., 2014). Women are more often affected than men (Dick et al., 1994; Gater et al., 1998) and have an earlier onset, commonly between 25 to 34 years compared to 30 to 44 years in men (Wittchen and Essau, 1993). The frequency of attacks differs considerably between patients: from a few attacks a month, periods with frequent attacks separated by weeks with few or no attacks, to experiencing several attacks every week (Faravelli and Paionni, 2001). As PAs are highly distressing periods, most patients develop anxiety about the occurrence of future attacks, which is referred to as "anticipatory anxiety". To meet the DSM-5 criteria for $\mathrm{PD}$, anticipatory anxiety and/or a significant change in behavior related to the attacks have to be present for at least one month. About one third to half of the patients start avoiding places and situations in which previous PAs occurred, in which an attack might be embarrassing (e.g., being in a restaurant) or in which it might be difficult to seek help 
(e.g., driving a car, in an elevator). This avoidance behavior ("agoraphobia") commonly develops within the first year after the first PA (White and Barlow, 2002).

\section{Diagnosis}

The diagnosis of PD is mainly based on self-reports obtained by (semi-)structured clinical interviews. As PAs do not occur exclusively in the context of PD, other potential anxiety disorders such as specific phobia and social anxiety disorder are taken into account. A distinction can be made based on the nature of the stimulus: PAs in specific phobia and social anxiety disorder are caused by a particular external stimulus such as direct exposure to the fearful stimulus, while PAs in PD occur unexpectedly and are believed to be of bodily origin. Moreover, medical conditions such as hyperthyroidism or drug abuse have to be excluded. For instance, a physical examination and the Mental International Neuropsychiatric Interview (M.I.N.I.; Sheehan et al., 1998) or the Structured Clinical Interview for DSM-IV Axis I Disorders (SCID-I; First et al., 1996) are used to determine whether the general criteria of PD with or without the presence of agoraphobia are met. The frequency and severity of PAs and agoraphobia are then further quantified by means of other questionnaires such as the Panic Disorder Severity Scale (PDSS; Shear et al., 1997) or the Panic and Agoraphobia Scale (PAS; Bandelow, 1995).

\section{Treatment}

The two main treatments for PD are cognitive behavioral therapy (CBT) and pharmacotherapy. One form of CBT is exposure therapy, in which the patient is repeatedly exposed to the frightened stimulus to experience that there are no life-threatening consequences. With regard to PAs, the focus is on provoking the arousing bodily sensations associated with the occurrence of an attack such as dizziness, palpitations, and feeling of shortness of breath. Commonly used approaches include intentional hyperventilation (Meuret et al., 2005), breathing through a straw (Lee et al., 2006), running on the spot, shaking the head from side to side, and spinning in a chair (Ito et al., 2001). All of these, however, only cause a fraction of a full-blown PA (Antony et al., 2006; Lee et al., 2006). In case of agoraphobia, patients can undergo a program in which they are exposed to situations associated with varying intensities of discomfort. Situations include, for instance, going into a small shop or a large supermarket, eating in a busy restaurant, or taking the train. In the beginning, a therapist is commonly present, who increases the physical distance to the patient in the course of the treatment until the patient is able to face the situation alone. Exposure therapies are performed until the discomfort decreases and clinically relevant effects are observed.

With regard to pharmacotherapy, the first-choice treatment represents selective serotonin 
reuptake inhibitors (SSRIs). SSRIs such as citalopram, fluoxetine, and paroxetine inhibit the serotonin transporter (5-HTT) that is located in the membrane of presynaptic serotonergic neurons and is responsible for the reuptake of serotonin (5-HT) out of the synaptic cleft. Inhibition of the 5-HTT, in turn, prolongs 5-HT neurotransmission. Based on current knowledge (Batelaan et al., 2012), in case of no clinical improvement, it is recommended to test a second SSRI before switching to tricyclic antidepressants (TCAs) such as imipramine. TCAs also inhibit the 5-HTT and additionally norepinephrine reuptake. The third option is the use of benzodiazepines (e.g., diazepam), which bind to the gamma-aminobutyric acid $A\left(G A B A_{A}\right)$ receptor, enhancing the efficiency of the inhibitory neurotransmitter GABA. The fourth choice is a monoamine oxidase-A (MAO-A) inhibitor like befloxatone. MAO-A is the enzyme that deaminates neurotransmitters such as $5-\mathrm{HT}$. Inhibition of this enzyme is thus related to a relatively longer availability of 5- $\mathrm{HT}$ in the synaptic cleft and a prolonged 5-HT signal transmission. A general difficulty in the use of pharmacotherapy is the high rate of side effects, which include, among others, headache, various types of sexual dysfunction, dry mouth, nausea, insomnia, weight changes, and mood swings (Batelaan et al., 2012; Cascade et al., 2009). In addition, the onset of antidepressants is relatively slow and several weeks are required to exert positive effects. In contrast, benzodiazepines are effective as soon as a clinically relevant dose is administered, but a major limitation in their use is the development of dependence (Batelaan et al., 2012). Furthermore, the effect is mainly on the anticipatory anxiety and less on the PAs. To effectively treat those, higher dosages are often necessary, at the cost of sedation (Griez and Schruers, 1998). Any treatment aims at achieving full symptomatic remission. However, although both exposure therapy (Craske et al., 1997) and the above mentioned medical compounds (Baldwin et al., 2014; Batelaan et al., 2012) have been shown to be clinically effective, many patients do not respond to the first-line interventions (Baldwin et al., 2014) and a number of patients remain symptomatic (Craske et al., 1997; Craske and Zucker, 2001) or relapse after treatment, particularly after drug discontinuation with relapse rates up to 70\% (Craske and Zucker, 2001).

\section{Impact on quality of life and social costs}

The sudden occurrence of symptoms such as palpitations, chest pain, feelings of shortness of breath, and dizziness is highly frightening for the individuals. When the first PAs occur, the individuals typically seek help in an emergency department because they believe that they experience a heart attack. Frequently, many extensive (cardiovascular) tests are done (Fleet et al., 1996; Katon, 1996), often without receiving an explanation or treatment. Being declared physically "healthy" and not knowing the reasons for their recurrent 
problem, is extremely frustrating for patients. Until PD is finally diagnosed, it is commonly a lengthy process and several other disorders as well as the use of substance abuse have to be excluded before the final diagnosis can be made. Further, the unpredictable onset of PAs is often associated with anticipatory anxiety and agoraphobia. These can become so severe that the patients' daily life is substantially affected by being less productive at work or not being able to leave the house anymore, resulting in missing working days, associated with financial loss for the patients as well as employers, and becoming socially isolated. In addition, even at home, severe impairments in household activities and living situation are observed (Davidoff et al., 2012). Comorbidities with other disorders, in particular depression and social phobia, constitute an additional major impairment in the daily functioning (Bonham and Uhlenhuth, 2014). Therefore, the quality of life is considerably decreased in comparison with healthy individuals (Mendlowicz and Stein, 2000). Moreover, although current treatments are effective in general, the many side effects of pharmacological interventions are frequently not well tolerated by the patients, often leading to a lower compliance of taking the medication (Batelaan et al., 2012), concomitant with high relapse rates (Craske and Zucker, 2001). Altogether, the utilization of health care services is higher in PD patients in comparison with patients of other psychiatric disorders (Deacon et al., 2008). At the population level, the costs of PD are tremendous, namely comparable to the combined costs of simple phobia, social phobia, and generalized anxiety disorder (Batelaan et al., 2007).

\section{Etiology from a biological perspective}

To improve the patients' quality of life by more effective treatment strategies, the current understanding into the pathophysiology of PD needs to be improved. A challenge is that PD is a very heterogeneous disorder: it consists of different aspects, namely PAs, anxiety in anticipation of future attacks, and often avoidance behavior, and all of these vary widely in their intensity between patients.

Nowadays, it is generally recognized that anxiety, fear, and panic are distinct entities and are subserved by divergent brain structures. A behavioral response is determined by the "defensive distance" to the threatening stimulus, such as a predator or an environmental cue (McNaughton and Corr, 2004). According to this concept, at a large distance, when a threat is potentially present, anxiety predominates, associated with activation of the frontal cortex and risk assessment as well as approach behavior. With decreasing distance, brain activation shifts to more subcortical, primordial structures, which is linked to a fast, primitive behavioral response. Thus, fear predominates at a small defensive distance with the direct presence of a threat, which relates to activation of limbic structures and the 
brainstem, and defensive avoidance as well as fight-or-flight behavior. At the smallest distance possible, which is conceptually from within the body, the triggered response is panic (PAs), associated with primarily brainstem activation.

The focus of the present thesis is on PAs and their within-body origin. Their unexpected nature makes it challenging to assess PAs in real-life, but PAs represent a rare example of a pathophysiological phenomenon that can be reliably provoked in an experimental setting. A number of methods exist (Esquivel et al., 2008), of which particularly inhalation of an excess concentration of carbon dioxide $\left(\mathrm{CO}_{2}\right)$ has a long-standing history. It represents a well-established model as it fulfills the criteria for an ideal experimental model previously proposed (Guttmacher et al., 1983). First, the use of a $\mathrm{CO}_{2}$ inhalation is safe and the effects are only short-lasting. Second, inhaling $35 \% \mathrm{CO}_{2}$ induces the majority of symptoms of a naturally occurring PA in PD patients (Nardi et al., 2006; Schruers et al., 2004). Third, there is a relatively high specificity for a heightened response to $\mathrm{CO}_{2}$ in PD patients (Griez et al., 1990; Kent et al., 2001; Perna et al., 1999; Verburg et al., 1994). Noteworthy, when using a higher $\mathrm{CO}_{2}$ concentration, a similar response can be triggered in healthy individuals (Griez et al., 2007), suggesting that basic mechanisms are involved in the panic-related sensitivity to $\mathrm{CO}_{2}$. Fourth, the clinically effective drugs like SSRIs (Bertani et al., 2001; Perna et al., 2004; Perna et al., 1997; Schruers and Griez, 2004), TCAs (Bertani et al., 1997; Perna et al., 2002; Perna et al., 1997), benzodiazepines (Nardi et al., 1999; Sanderson et al., 1994), and an MAO-A inhibitor (Perna et al., 1994) have been shown to reduce the response to a $\mathrm{CO}_{2}$ inhalation. Finally, the effects are reproducible, with good test-retest reliability (Coryell and Arndt, 1999; Verburg et al., 1998).

Interestingly, a similar approach can be applied in experimental animals. In rodents, it has been shown that exposure to $\mathrm{CO}_{2}$ decreases brain $\mathrm{pH}$ (Ziemann et al., 2009; Ziemann et al., 2008). The effective use of $\mathrm{CO}_{2}$ as human experimental panic model suggests that a disturbance in the brain acid-base homeostasis is involved in the pathophysiology of PAs. Many areas in the brain are sensitive to changes in $\mathrm{pH}$, examples are the amygdala (Ziemann et al., 2009), the hypothalamus (Johnson et al., 2012), the locus coeruleus (Biancardi et al., 2008), the nucleus tractus solitarii (Dean et al., 1990), the retrotrapezoid nucleus (Mulkey et al., 2004), the ventrolateral medulla (da Silva et al., 2010), the medullary raphe (Putnam et al., 2004; Richerson, 2004), and raphe nuclei (da Silva et al., 2011; Severson et al., 2003). There is no consensus on which brain structure should be considered as key player in detecting changes in $\mathrm{pH}$ and triggering the behavioral fear response to $\mathrm{CO}_{2}$. In a series of rodent experiments, it was shown that the amygdala was essentially involved in these processes (Ziemann et al., 2009). However, no other candidate structures were investigated and in a recent human study, involving patients with a dysfunctional amygdala 
due to Urbach-Wiethe disease who unexpectedly experienced PA-like symptoms to a 35\% $\mathrm{CO}_{2}$ inhalation (Smoller et al., 2014). This study indicates that, at least in humans, the amygdala may not be the sole player in panic-related chemosensitivity. Furthermore, another unsolved question is what molecules sense the changes in $\mathrm{pH}$ in neurons that can evoke a behavioral fear response. In rodents, the acid-sensing ion channel 1a (ASIC1a) was put forward as prime candidate (Ziemann et al., 2009). In humans, just recently, an association between the human homologue gene amiloride-sensitive cation channel 2 (ACCN2) and the diagnosis of PD has been found (Smoller et al., 2014). However, the direct link to a change in brain $\mathrm{pH}$, as evidenced by rodent studies using $\mathrm{CO}_{2}$ exposure, is missing. Therefore, whether the human ACCN2 gene is involved in differential sensitivity to $\mathrm{CO}_{2}$ remains to be elucidated.

\section{Aims and outline of this thesis}

The overall aim of this thesis was to further investigate the pathophysiology of PD, with a focus on PAs and the relationship with differential sensitivity to changes in the acid-base homeostasis. As human models are limited in their potential to provide insights into the molecular mechanisms underlying a disorder, a translational, cross-species approach was used, in which healthy individuals, PD patients, and rodents were exposed to an excess concentration of $\mathrm{CO}_{2}$. In addition, we aimed to use similar outcome measurements in both species to maximize the translation of knowledge between the two research domains.

Chapter 2 provides a literature review on the use of inhaling $\mathrm{CO}_{2}$ as experimental panic model in humans and rodents. Covered topics include methodological approaches and the cardio-respiratory response. In addition, the relationship between $\mathrm{CO}_{2}$, changes in $\mathrm{pH}$, the $5-\mathrm{HT}$ system, and adaptive responses are critically summarized. Based on this, current knowledge gaps are highlighted and future directions are discussed.

In Chapter 3, we investigated the response of healthy individuals to four concentrations of $\mathrm{CO}_{2}$. As (experimentally provoked) PAs are characterized by intense fear and discomfort as well as physiological symptoms such as palpitations, we complemented the commonly used self-reports with continuous measurements of the cardiovascular system using a novel customized computerized system. 
In Chapter 4, we assessed brain activation to inhaling $\mathrm{CO}_{2}$ in humans with differential sensitivity using functional magnetic resonance imaging (fMRI). More specifically, we explored which brain areas are activated by $\mathrm{CO}_{2}$ and whether there is a difference in activation between PD patients, healthy individuals, and experienced divers, representing three groups with descending $\mathrm{CO}_{2}$ sensitivity.

Chapter 5 addresses the effects of genetic variants in the ACCN2 gene, the human homologue of the rodent gene encoding the pH-sensitive ion channel ASIC1a, on the emotional and cardiovascular response to $\mathrm{CO}_{2}$ inhalation in healthy volunteers and PD patients.

The work described in Chapter 6 expands on the previous studies by exposing mice to $\mathrm{CO}_{2}$ using an innovative, fully controlled $\mathrm{CO}_{2}$ chamber, allowing monitoring of freely moving mice. In addition to studying the behavioral response to $\mathrm{CO}_{2}$ exposure in two tests, the cardio-respiratory response was monitored, and the roles of ASIC1a and 5-HTT were examined.

Chapter 7 presents insights from the used translational approach to judge the acceptability of euthanizing lab animals using $\mathrm{CO}_{2}$. The behavioral as well as the cardio-respiratory response to $\mathrm{CO}_{2}$ was analyzed and compared across species.

In Chapter 8, the main results of the work presented in this thesis are integrated and discussed. In addition, clinical implications and future perspectives are addressed. 


\section{References}

American Psychiatric Association, 2013. The Diagnostic and Statistical Manual of Mental Disorders (5th ed.). American Psychiatric Publishing, Arlington, VA.

Antony, M.M., Ledley, D.R., Liss, A., Swinson, R.P., 2006. Responses to symptom induction exercises in panic disorder. Behav. Res. Ther. 44, 85-98.

Baldwin, D.S., Anderson, I.M., Nutt, D.J., Allgulander, C., Bandelow, B., den Boer, J.A., Christmas, D.M., Davies, S., Fineberg, N., Lidbetter, N., Malizia, A., McCrone, P., Nabarro, D., O'Neill, C., Scott, J., van der Wee, N., Wittchen, H.U., 2014. Evidence-based pharmacological treatment of anxiety disorders, post-traumatic stress disorder and obsessive-compulsive disorder: a revision of the 2005 guidelines from the British Association for Psychopharmacology. J. Psychopharm. 28, 403-439.

Bandelow, B., 1995. Assessing the efficacy of treatments for panic disorder and agoraphobia. II. The Panic and Agoraphobia Scale. Int. Clin. Psychopharmacol. 10, 73-81.

Batelaan, N., Smit, F., de Graaf, R., van Balkom, A., Vollebergh, W., Beekman, A., 2007. Economic costs of fullblown and subthreshold panic disorder. J. Affect. Disord. 104, 127-136.

Batelaan, N.M., Van Balkom, A.J., Stein, D.J., 2012. Evidence-based pharmacotherapy of panic disorder: an update. The international journal of neuropsychopharmacology/official scientific journal of the Collegium Internationale Neuropsychopharmacologicum 15, 403-415.

Bertani, A., Caldirola, D., Bussi, R., Bellodi, L., Perna, G., 2001. The 35\% CO2 hyperreactivity and clinical symptomatology in patients with panic disorder after 1 week of treatment with citalopram: an open study. J. Clin. Psychopharmacol. 21, 262-267.

Bertani, A., Perna, G., Arancio, C., Caldirola, D., Bellodi, L., 1997. Pharmacologic effect of imipramine, paroxetine, and sertraline on $35 \%$ carbon dioxide hypersensitivity in panic patients: a double-blind, random, placebocontrolled study. J. Clin. Psychopharmacol. 17, 97-101.

Biancardi, V., Bicego, K.C., Almeida, M.C., Gargaglioni, L.H., 2008. Locus coeruleus noradrenergic neurons and CO2 drive to breathing. Pflugers Arch. 455, 1119-1128.

Bonham, C.A., Uhlenhuth, E., 2014. Disability and comorbidity: diagnoses and symptoms associated with disability in a clinical population with panic disorder. Psychiatry J 2014, 619727.

Cascade, E., Kalali, A.H., Kennedy, S.H., 2009. Real-World Data on SSRI Antidepressant Side Effects. Psychiatry 6, 16-18.

Coryell, W., Arndt, S., 1999. The 35\% CO2 inhalation procedure: test-retest reliability. Biol. Psychiatry 45, 923927.

Craske, M.G., Rowe, M., Lewin, M., Noriega-Dimitri, R., 1997. Interoceptive exposure versus breathing retraining within cognitive-behavioural therapy for panic disorder with agoraphobia. The British journal of clinical psychology / the British Psychological Society 36 (Pt 1), 85-99.

Craske, M.G., Zucker, B.G., 2001. Consideration of the APA practice guideline for the treatment of patients with panic disorder: strengths and limitations for behavior therapy. Behav. Ther. 32, 259-281.

da Silva, G.S., Giusti, H., Benedetti, M., Dias, M.B., Gargaglioni, L.H., Branco, L.G., Glass, M.L., 2011. Serotonergic neurons in the nucleus raphe obscurus contribute to interaction between central and peripheral ventilatory responses to hypercapnia. Pflugers Arch. 462, 407-418.

da Silva, G.S., Li, A., Nattie, E., 2010. High CO2/H+ dialysis in the caudal ventrolateral medulla (Loeschcke's area) increases ventilation in wakefulness. Respir. Physiol. Neurobiol. 171, 46-53.

Davidoff, J., Christensen, S., Khalili, D.N., Nguyen, J., IsHak, W.W., 2012. Quality of life in panic disorder: looking beyond symptom remission. Quality of life research : an international journal of quality of life aspects of treatment, care and rehabilitation 21, 945-959.

Deacon, B., Lickel, J., Abramowitz, J.S., 2008. Medical utilization across the anxiety disorders. J. Anxiety Disord. $22,344-350$. 
Dean, J.B., Bayliss, D.A., Erickson, J.T., Lawing, W.L., Millhorn, D.E., 1990. Depolarization and stimulation of neurons in nucleus tractus solitarii by carbon dioxide does not require chemical synaptic input. Neuroscience 36, 207-216.

Dick, C.L., Bland, R.C., Newman, S.C., 1994. Epidemiology of psychiatric disorders in Edmonton. Panic disorder. Acta Psychiatr. Scand. Suppl. 376, 45-53.

Esquivel, G., Schruers, K., Griez, E., 2008. Experimental models: panic and fear. In: Blanchard, RJ, Griebel, G, Nutt, DJ (eds), Handbook of Anxiety and Fear. Elsevier BV, Amsterdam. 413 - 435.

Faravelli, C., Paionni, A., 2001. Panic Disorder: Clinical Course, Morbidity and Comorbidity. John Wiley \& Sons, Ltd, Chicester, UK.

First, M.B., Spitzer, R.L., Gibbon, M., Williams, J.B.W., 1996. Structured Clinical Interview for DSM-IV Axis I Disorders, Clinician Version (SCID-CV). American Psychiatric Press, Inc., Washington, D.C.

Fleet, R.P., Dupuis, G., Marchand, A., Burelle, D., Arsenault, A., Beitman, B.D., 1996. Panic disorder in emergency department chest pain patients: prevalence, comorbidity, suicidal ideation, and physician recognition. The American journal of medicine 101, 371-380.

Gater, R., Tansella, M., Korten, A., Tiemens, B.G., Mavreas, V.G., Olatawura, M.O., 1998. Sex differences in the prevalence and detection of depressive and anxiety disorders in general health care settings: report from the World Health Organization Collaborative Study on Psychological Problems in General Health Care. Arch. Gen. Psychiatry 55, 405-413.

Griez, E., de Loof, C., Pols, H., Zandbergen, J., Lousberg, H., 1990. Specific sensitivity of patients with panic attacks to carbon dioxide inhalation. Psychiatry Res. 31, 193-199.

Griez, E., Schruers, K., 1998. Experimental pathophysiology of panic. J. Psychosom. Res. 45, 493-503.

Griez, E.J., Colasanti, A., van Diest, R., Salamon, E., Schruers, K., 2007. Carbon dioxide inhalation induces dosedependent and age-related negative affectivity. PLoS One 2, e987.

Guttmacher, L.B., Murphy, D.L., Insel, T.R., 1983. Pharmacologic models of anxiety. Compr. Psychiatry 24, 312-326.

Ito, L.M., de Araujo, L.A., Tess, V.L., de Barros-Neto, T.P., Asbahr, F.R., Marks, I., 2001. Self-exposure therapy for panic disorder with agoraphobia: randomised controlled study of external v. interoceptive self-exposure. The British journal of psychiatry: the journal of mental science 178, 331-336.

Johnson, P.L., Molosh, A., Fitz, S.D., Truitt, W.A., Shekhar, A., 2012. Orexin, stress, and anxiety/panic states. Prog. Brain Res. 198, 133-161.

Katon, W., 1996. Panic disorder: relationship to high medical utilization, unexplained physical symptoms, and medical costs. The Journal of clinical psychiatry 57 Suppl 10, 11-18; discussion 19-22.

Kent, J.M., Papp, L.A., Martinez, J.M., Browne, S.T., Coplan, J.D., Klein, D.F., Gorman, J.M., 2001. Specificity of panic response to $\mathrm{CO}(2)$ inhalation in panic disorder: a comparison with major depression and premenstrual dysphoric disorder. Am. J. Psychiatry 158, 58-67.

Kessler, R.C., Chiu, W.T., Jin, R., Ruscio, A.M., Shear, K., Walters, E.E., 2006. The epidemiology of panic attacks, panic disorder, and agoraphobia in the National Comorbidity Survey Replication. Arch. Gen. Psychiatry 63, 415-424.

Lee, K., Noda, Y., Nakano, Y., Ogawa, S., Kinoshita, Y., Funayama, T., Furukawa, T.A., 2006. Interoceptive hypersensitivity and interoceptive exposure in patients with panic disorder: specificity and effectiveness. BMC Psychiatry 6, 32.

McNaughton, N., Corr, P.J., 2004. A two-dimensional neuropsychology of defense: fear/anxiety and defensive distance. Neurosci. Biobehav. Rev. 28, 285-305.

Mendlowicz, M.V., Stein, M.B., 2000. Quality of life in individuals with anxiety disorders. Am. J. Psychiatry 157, 669-682.

Meuret, A.E., Ritz, T., Wilhelm, F.H., Roth, W.T., 2005. Voluntary hyperventilation in the treatment of panic disorder--functions of hyperventilation, their implications for breathing training, and recommendations for standardization. Clin. Psychol. Rev. 25, 285-306. 
Mulkey, D.K., Stornetta, R.L., Weston, M.C., Simmons, J.R., Parker, A., Bayliss, D.A., Guyenet, P.G., 2004. Respiratory control by ventral surface chemoreceptor neurons in rats. Nat. Neurosci. 7, 1360-1369.

Nardi, A.E., Valenca, A.M., Lopes, F.L., Nascimento, I., Veras, A.B., Freire, R.C., Mezzasalma, M.A., de-MeloNeto, V.L., Zin, W.A., 2006. Psychopathological profile of 35\% CO2 challenge test-induced panic attacks: a comparison with spontaneous panic attacks. Compr. Psychiatry 47, 209-214.

Nardi, A.E., Valenca, A.M., Zin, W., Nascimento, I., 1999. Carbon dioxide induced panic attacks and short term clonazepam treatment. Preliminary study. Arq. Neuropsiquiatr. 57, 361-365.

Norton, P.J., Zvolensky, M.J., Bonn-Miller, M.O., Cox, B.J., Norton, G.R., 2008. Use of the Panic Attack Questionnaire-IV to assess non-clinical panic attacks and limited symptom panic attacks in student and community samples. J. Anxiety Disord. 22, 1159-1171.

Pane-Farre, C.A., Stender, J.P., Fenske, K., Deckert, J., Reif, A., John, U., Schmidt, C.O., Schulz, A., Lang, T., Alpers, G.W., Kircher, T., Vossbeck-Elsebusch, A.N., Grabe, H.J., Hamm, A.O., 2014. The phenomenology of the first panic attack in clinical and community-based samples. J. Anxiety Disord. 28, 522-529.

Perna, G., Bertani, A., Caldirola, D., Di Pasquale, D., Migliarese, G., Bellodi, L., 2004. Modulation of hyperreactivity to $35 \% \mathrm{CO} 2$ after one week of treatment with paroxetine and reboxetine: a double-blind, randomized study. J. Clin. Psychopharmacol. 24, 277-282.

Perna, G., Bertani, A., Caldirola, D., Gabriele, A., Cocchi, S., Bellodi, L., 2002. Antipanic drug modulation of $35 \%$ CO2 hyperreactivity and short-term treatment outcome. J. Clin. Psychopharmacol. 22, 300-308.

Perna, G., Bertani, A., Gabriele, A., Politi, E., Bellodi, L., 1997. Modification of 35\% carbon dioxide hypersensitivity across one week of treatment with clomipramine and fluvoxamine: a double-blind, randomized, placebocontrolled study. J. Clin. Psychopharmacol. 17, 173-178.

Perna, G., Bussi, R., Allevi, L., Bellodi, L., 1999. Sensitivity to 35\% carbon dioxide in patients with generalized anxiety disorder. J. Clin. Psychiatry 60, 379-384.

Perna, G., Cocchi, S., Bertani, A., Arancio, C., Bellodi, L., 1994. Pharmacologic effect of toloxatone on reactivity to the $35 \%$ carbon dioxide challenge: a single-blind, random, placebo-controlled study. J. Clin. Psychopharmacol. 14, 414-418.

Putnam, R.W., Filosa, J.A., Ritucci, N.A., 2004. Cellular mechanisms involved in $\mathrm{CO}(2)$ and acid signaling in chemosensitive neurons. Am. J. Physiol. Cell Physiol. 287, C1493-1526.

Richerson, G.B., 2004. Serotonergic neurons as carbon dioxide sensors that maintain pH homeostasis. Nat. Rev. Neurosci. 5, 449-461.

Sanderson, W.C., Wetzler, S., Asnis, G.M., 1994. Alprazolam blockade of CO2-provoked panic in patients with panic disorder. Am. J. Psychiatry 151, 1220-1222.

Schruers, K., Griez, E., 2004. The effects of tianeptine or paroxetine on 35\% CO2 provoked panic in panic disorder. J. Psychopharm. 18, 553-558.

Schruers, K.R.J., Van De Mortel, H., Overbeek, T., Griez, E., 2004. Symptom profiles of natural and laboratory panic attacks. Acta Neuropsychiatr. 16, 101-106.

Severson, C.A., Wang, W., Pieribone, V.A., Dohle, C.I., Richerson, G.B., 2003. Midbrain serotonergic neurons are central pH chemoreceptors. Nat. Neurosci. 6, 1139-1140.

Shear, M.K., Brown, T.A., Barlow, D.H., Money, R., Sholomskas, D.E., Woods, S.W., Gorman, J.M., Papp, L.A., 1997. Multicenter collaborative panic disorder severity scale. The American journal of psychiatry 154, 1571-1575.

Sheehan, D.V., Lecrubier, Y., Sheehan, K.H., Amorim, P., Janavs, J., Weiller, E., Hergueta, T., Baker, R., Dunbar, G.C., 1998. The Mini-International Neuropsychiatric Interview (M.I.N.I.): the development and validation of a structured diagnostic psychiatric interview for DSM-IV and ICD-10. The Journal of clinical psychiatry 59 Suppl 20, 22-33;quiz 34-57.

Smoller, J.W., Gallagher, P.J., Duncan, L.E., McGrath, L.M., Haddad, S.A., et al., 2014. The Human Ortholog of AcidSensing Ion Channel Gene ASIC1a Is Associated with Panic Disorder and Amygdala Structure and Function. Biol. Psychiatry. 76, 902-910. 
Verburg, C., Griez, E., Meijer, J., 1994. A 35\% carbon dioxide challenge in simple phobias. Acta Psychiatr. Scand. 90, 420-423.

Verburg, K., Pols, H., de Leeuw, M., Griez, E., 1998. Reliability of the $35 \%$ carbon dioxide panic provocation challenge. Psychiatry Res. 78, 207-214.

White, K., Barlow, D., 2002. Panic disorder and agoraphobia. Guilford Press, New York.

Wittchen, H.U., Essau, C.A., 1993. Epidemiology of panic disorder: progress and unresolved issues. J. Psychiatr. Res. 27 Suppl 1, 47-68.

Ziemann, A.E., Allen, J.E., Dahdaleh, N.S., Drebot, II, Coryell, M.W., Wunsch, A.M., Lynch, C.M., Faraci, F.M., Howard, M.A., 3rd, Welsh, M.J., Wemmie, J.A., 2009. The amygdala is a chemosensor that detects carbon dioxide and acidosis to elicit fear behavior. Cell 139, 1012-1021.

Ziemann, A.E., Schnizler, M.K., Albert, G.W., Severson, M.A., Howard, M.A., 3rd, Welsh, M.J., Wemmie, J.A., 2008. Seizure termination by acidosis depends on ASIC1a. Nat. Neurosci. 11, 816-822. 

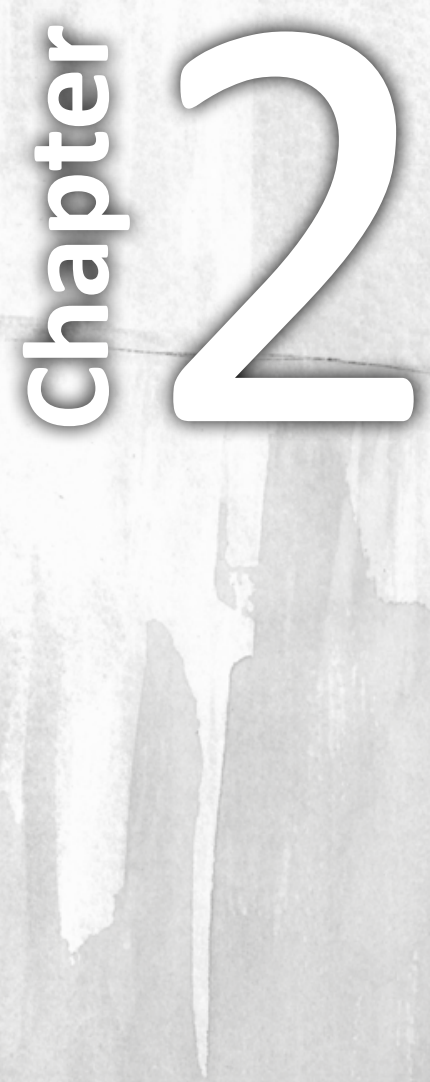


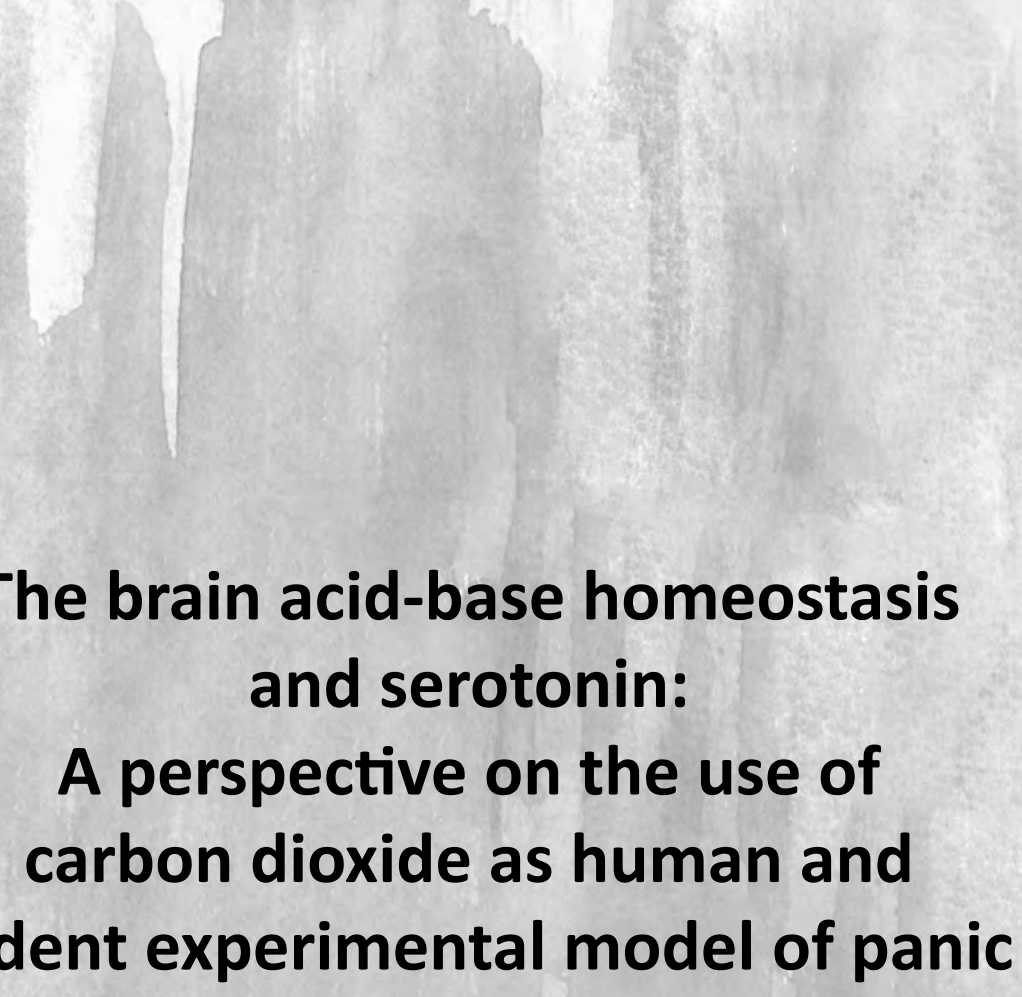

Nicole Leibold ${ }^{a, b}$, Daniel van den Hove ${ }^{a, b}$, Gabriel Esquivel ${ }^{a}$, Klara De Cort ${ }^{a}$, Liesbet Goossens ${ }^{a}$, Eveline Strackx ${ }^{c}$, Gordon Buchanan ${ }^{d}$, Harry Steinbusch ${ }^{a}$, Klaus-Peter Lesch ${ }^{a, b}$, Koen Schruers ${ }^{a, e}$

a Department of Psychiatry and Neuropsychology, Maastricht University, P.O. Box 616, 6200 MD Maastricht, the Netherlands. School for Mental Health and Neuroscience (MHeNS), Maastricht University. European Graduate School of Neuroscience (EURON), P.O. Box 616, 6200 MD Maastricht, the Netherlands

b Division of Molecular Psychiatry, Laboratory of Translational Neuroscience, Center of Mental Health, University of Wuerzburg, Fuechsleinstrasse 15, 97080 Wuerzburg, Germany

Department of Health and Technology, Leuven University College, Herestraat 49, 3000 Leuven, Belgium

d Department of Neurology, Yale University School of Medicine, P.O. Box 208018, 15 York Street, New Haven, Connecticut 06520-8018, USA

e Center for the Psychology of Learning and Experimental Psychopathology, Department of Psychology, University of Leuven, Tiensestraat 102, P.O. Box 3726, 3000 Leuven, Belgium 


\section{Abstract}

Panic attacks (PAs), the core feature of panic disorder, represent a common phenomenon in the general adult population and are associated with a considerable decrease in quality of life and high health care costs. To date, the underlying pathophysiology of PAs is not well understood. A unique feature of PAs is that they represent a rare example of a psychopathological phenomenon that can be reliably modeled in the laboratory in panic disorder patients and healthy volunteers. The most effective techniques to experimentally trigger PAs are those that acutely disturb the acid-base homeostasis in the brain: inhalation of carbon dioxide $\left(\mathrm{CO}_{2}\right)$, hyperventilation, and lactate infusion. This review particularly focuses on the use of $\mathrm{CO}_{2}$ inhalation in humans and rodents as an experimental model of panic. Besides highlighting the different methodological approaches, the cardiorespiratory and the endocrine responses to $\mathrm{CO}_{2}$ inhalation are summarized. In addition, the relationships between $\mathrm{CO}_{2}$ level, changes in brain $\mathrm{pH}$, the serotonergic system, and adaptive physiological and behavioral responses to $\mathrm{CO}_{2}$ exposure are presented. We aim to present an integrated psychological and neurobiological perspective. Remaining gaps in the literature and future perspectives are discussed. 


\section{Introduction}

Panic attacks (PAs) are common psychopathological phenomena that affect about $23 \%$ of the general population at least once in their lifetime (Kessler et al., 2006). PAs represent abrupt surges of intense fear or discomfort, even though no real danger is present, accompanied by various physical or cognitive symptoms. According to the current criteria in the Diagnostic and Statistical Manual of Mental Disorders (DSM) - 5 (American Psychiatric Association, 2013), at least four out of the following thirteen symptoms have to develop abruptly with a symptomatic peak within a few minutes after onset: palpitations or pounding heart; sweating; trembling or shaking; sensation of shortness of breath or smothering; feeling of choking; chest pain or discomfort; nausea or abdominal distress; feeling of dizziness, lightheadedness or faintness; depersonalization (feeling of being detached from oneself) or derealization (feeling of unreality); fear of losing control or going crazy; fear of dying; paresthesia (numbness or tingling sensations); and chills or hot flushes. As several symptoms closely resemble those of a cardiac arrest or acute asthma, cardiac- and/or emergency departments are frequently visited. Patients often receive costly tests such as angiography and echocardiography (Zaubler and Katon, 1998), without finding an explanation for their complaints.

PAs can occur in any anxiety or mental disorder as well as in many medical conditions (American Psychiatric Association, 2013), but are most prominent in panic disorder (PD). PD occurs in about $4 \%$ in the general population (Norton et al., 2008; Pane-Farre et al., 2014), with the onset commonly between the ages of 25 to 34 years in women and 30 to 44 years in men (Wittchen and Essau, 1993). PD has a high heritability of about 40\% (Hettema et al., 2001; Maron et al., 2010) and is characterized by PAs that occur more than once and unexpectedly (i.e., "out of the blue" and not caused by a medical condition or the use or withdrawal of a drug) (American Psychiatric Association, 2013). The frequency of the attacks can vary widely: a few attacks a month, several attacks each week or having periods with frequent attacks separated by weeks or months with less or no attack (Faravelli and Paionni, 2001). In addition to recurrent unexpected PAs, at least one of the following criteria is required for a period of at least one month: persistent concern about having additional attacks or the implications of the attack (anticipatory anxiety), and/or a significant maladaptive change in behavior related to the attacks. Frequently, patients develop agoraphobia, the avoidance of places and situations that are associated with the occurrence of previous attacks or in which having an attack may be embarrassing or in which it may be difficult to get help (for instance, being alone outside the home, being in a crowd or travelling in a bus or car). This avoidance behavior can become so severe that patients are confined to their homes. Due to the unpredictability 
of PAs, avoidance behavior, and the common comorbid anxiety disorders (Tilli et al., 2012), patients experience a marked decrease in their quality of life (Mendlowicz and Stein, 2000). Therefore, costs associated with an individual having PD are substantial (SalvadorCarulla et al., 1995). At the population level, the costs associated with PD are comparable with the combined costs associated with social phobia, simple phobia, and generalized anxiety disorder (GAD) (Batelaan et al., 2007).

\section{Etiology of panic from a neurobiological perspective: The concepts of anxiety, fear, and panic}

According to the current DSM-5 (American Psychiatric Association, 2013), PD is classified as an anxiety disorder and is characterized by unexpected PAs (including intense fear) as well as anticipatory anxiety. Research has indicated that anxiety, fear, and panic are distinct entities involving divergent brain structures and behaviors. The main factor that determines the specific behavioral response is the "defensive distance" to the threat (e.g., a predator). According to this concept, first introduced by Blanchard and Blanchard (1990), at a large defensive distance, i.e. in the presence of a potential threat, anxiety predominates and the individual displays non-defensive behavior such as complex risk assessment and approach behavior (defensive approach). In contrast, at a small defensive distance, i.e. in the direct presence of a threat, fear will be predominant, leading to a fast primitive response to avoid or leave the dangerous situation (i.e., fight-or-flight response, defensive avoidance).

Graeff (1994) mapped distinct neural structures to these concepts, primarily based on his research in small mammals. These structures were later integrated into a two-dimensional behavioral defense system model by McNaughton, Gray, and Corr (2004; 2000). A large distance to a threat is associated with more rostral, cortical brain structures, including the prefrontal cortex, to evaluate the threat. The smaller the defensive distance, the more important is a fast, primitive response, which is linked to a caudal shift to subcortical, primordial structures. Extrapolating this concept to the clinic, a large defensive distance is associated with rostral neural structures and complex anxiety as seen in obsessive compulsions and in social anxiety. In contrast, with more proximal threats, a fear response is induced, which is associated with limbic and brainstem structures. The smallest defensive distance possible, which is from within a subject's own body, is related to PAs and is likely associated with primordial brainstem structures (Figure 1).

Recently, this concept was confirmed in a seminal functional imaging study by Mobbs et al. (2007). Participants were chased in a virtual predator paradigm, in which they received either no electrical shock or a low or high intensity shock, when captured. 


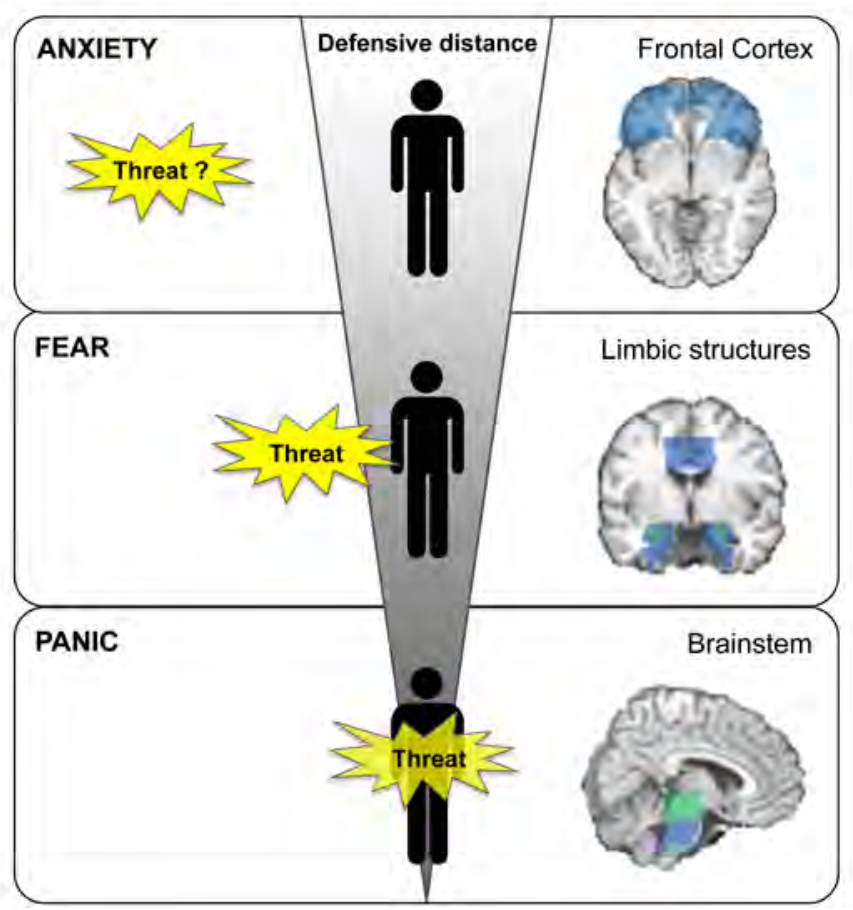

Figure 1. Schematic presentation of a two-dimensional behavioral defense system. Distinct neural structures are mapped to the defensive distance to the threat and the behavioral response (adapted from McNaughton and Gray, 2000).

Participants were informed about the condition before the trial. Results showed that as the distance to the predator shortened, brain activity shifted from the prefrontal cortex to the periaqueductal gray (PAG), particularly when a high intensity electrical shock was expected. In addition, PAG activity correlated with an increased degree of dread of being chased and decreased confidence of escape. In spite of the sophisticated approach, conceptually, this study did not model the smallest defensive distance possible and the within-body origin of PAs.

\section{Etiology of panic from a psychological perspective}

From a psychological point of view, there are at least two prominent theories regarding panic: the cognitive theory and the learning theory.

In cognitive theories such as Clark's model (1986) PAs are the result of the catastrophic misinterpretation of somatic sensations believed to signify an imminent harmful consequence. For instance, converging evidence exists for an increased interoceptive sensitivity to stimuli arising from the cardiac system in anxiety disorders (for comprehensive 
review see Domschke et al., 2010). The misinterpretation of harmless heart pounding as a heart attack can further intensify the symptoms and reinforce misinterpretation, resulting in a full-blown PA. As a consequence, the person becomes chronically hypervigilant for bodily sensations. This attentional bias towards somatic cues associated with the occurrence of a PA can make someone more prone to misinterpret somatic sensations, eventually leading to a vicious circle of misinterpretations culminating in PAs. Spontaneous catastrophic misinterpretations of bodily sensations are therefore assumed to play a major role in the transition of a PA into PD and are considered as a hallmark of PD. Several studies provide support for catastrophic misinterpretations of bodily sensations in PD, however, most of those studies are based on self-reports (Austin and Kiropoulos, 2008) that do not capture the spontaneous nature of the misinterpretations. In this view, indirect measures, such as priming paradigms, have been suggested to provide a good alternative. In such a priming paradigm, the response time can be measured to, for instance, word pairs that are either panic-related (e.g., breathlessness - suffocate; bodily PA symptom - catastrophic misinterpretation) or neutral (e.g., flowers - picking). However, the results of those studies have been inconsistent (Hermans et al., 2010; Schneider and Schulte, 2007). In a study from our group (Hermans et al., 2010), significant priming effects were not only observed in PD patients, but also in a group of mental health professionals without a history of PD. This observation raises doubts about the pathogenic nature of catastrophic misinterpretations. In addition, an important critique on cognitive theory is the observation that PAs also occur in situations in which no catastrophic misinterpretation can be identified, such as during sleep (Craske and Tsao, 2005; Freire et al., 2007; Mellman and Uhde, 1989; Sarisoy et al., 2008). Importantly, there is currently no experimental support for the hypothesized causal role of catastrophic misinterpretations in PD (De Cort et al., 2013).

In contrast to the cognitive theory that mainly explains the transition of a PA into PD, the learning theory is the first that attempts to explain the unexpected "non-clinical" PAs in the general population. It is based on the proposition that individuals can "learn" to develop certain symptoms. An early theory by Barlow (1988) is known as the "alarm theory" and distinguishes three types of alarms: true, false, and learned. A true alarm is an unconditioned fear reaction to an actual threat, whereas a false alarm is an alarm that occurs in the absence of a real threat. PAs can be true or false alarms, depending on the actual presence of a threat. The occurrence of an alarm, whether true or false, can become associated with an external or internal cue. The individuals "learn" that a specific cue is connected to the alarm and become fearful of that cue because it may be a predictor for the onset of another alarm (i.e., a PA). Consequently, they may develop anxiety and avoidance behavior regarding future attacks. In a modern learning theory account, Bouton and colleagues (2001) further specified that a false, learned alarm is not necessarily pathological. The key 
process between experiencing a PA and the progression to PD is the development of anxiety that is focused on the occurrence of the next potential PA. In this respect, it is hypothesized that interoceptive conditioning is of particular importance in the pathogenesis of PD. For instance, a bodily stimulus that preceded the onset of a previous PA (e.g., slight increase in heart rate) becomes associated with the occurrence of the PA, thereby becoming a learned stimulus that predicts intense arousal and induces anxiety. Experienced anxiety, in turn, generates more intense and additional stimuli (e.g., a further increase in heart rate, sweating), which, in turn, intensifies anxiety. This spiraling process can lead to a panic state. To date, a role of learning mechanisms in PD is supported by various experimental studies. Support is found for enhanced resistance to extinction (Michael et al., 2007), impaired discriminatory learning, and overgeneralization in PD patients (Lissek et al., 2010; Lissek et al., 2009) during fear conditioning paradigms. Recently, neural substrates were provided for alterations in PD patients during fear conditioning. Activations were found in the dorsal inferior frontal gyrus during differential conditioning and in the midbrain during safety signal processing. These results were interpreted as altered top-down and bottomup processes, reflecting changes in risk assessment/behavioral inhibition and defensive reactivity, respectively (Lueken et al., 2014). Further, increased baseline activations were found in structures such as hippocampus and amygdala in patients that did not respond to cognitive behavioral therapy. Treatment response was related to an intact inhibitory functional anterior cingulate cortex-amygdala coupling (Lueken et al., 2013). A limitation of the current studies is that they employ external cues, which do not reflect the withinbody nature of the sensations that are associated with PAs. Despite their clear relevance, interoceptive conditioning studies in the framework of PD are rather scarce. Interoceptive conditioning has recently been established in healthy volunteers through respiratory loads/breathing occlusions (Pappens et al., 2012), and inhalations of 20\% (Acheson et al., 2007) or $35 \% \mathrm{CO}_{2}$ (De Cort et al., 2012). Yet again, there is a paucity of interoceptive studies with PD patients or persons at risk for developing PD. Recently, we (De Cort et al., 2014) applied a differential interoceptive conditioning paradigm using pentagastrin and $35 \% \mathrm{CO}_{2}$ in subjects scoring low or high on anxiety sensitivity, a risk factor for PD (Naragon-Gainey, 2010). Anxiety sensitivity refers to, partially heritable (Stein et al., 1999), inter-individual differences in anxiety-related sensations that are associated with harmful consequences (McNally, 2002; Reiss, 1997). Discriminatory learning was impaired in subjects with high anxiety sensitivity, causing them to overpredict danger. Therefore, the progression from the initial insult towards the development of PD may be due to impairment in discriminatory learning and overgeneralization rather than excessive conditioning. 


\section{Experimental models of panic attacks and scope of the review}

PAs can be studied in two ways, i.e. by means of ambulatory assessment of naturally occurring PAs, or by provoking the sensations from within the body using experimental stimuli. Given the spontaneous occurrence of PA, which makes ambulatory assessment challenging, the possibility to trigger PAs in the lab has been tested using a large number of different techniques (for review see Esquivel et al., 2008b). These include $\mathrm{CO}_{2}$ exposure; hyperventilation; or administration of lactate, cholecystokinin (CCK, a peptide hormone activating CCK-B receptors), flumazenil (a benzodiazepine receptor antagonist), caffeine (an adenosine receptor antagonist), agents affecting the serotonergic (5-HT) system such as fenfluramine (acute 5-HT enhancer) and metachlorophenylpiperazine (m-CPP, primarily a $5-\mathrm{HT}_{2 \mathrm{~B} / 2 \mathrm{C}}$ receptor agonist), and agents with effects on the noradrenergic system such as yohimbine (an alpha2-antagonist) and isoproterenol (a beta-agonist).

Five criteria have been proposed that an ideal experimental model should fulfill (Guttmacher et al., 1983). First, safety is an essential consideration in any experiment involving humans. The evoked symptoms should be temporary and readily reversible, and without any predictable health risks. Second, there should be convergence (i.e. the induced symptoms should reflect the real-life ones). Third, the model should be specific and should differentiate between those with and without the disease (discrimination). Fourth, the effects should be replicable when consecutive trials are performed. Fifth, after a clinically effective treatment (e.g., drugs or cognitive behavioral therapy) individuals should respond markedly less than individuals who did not receive that treatment (clinical validation). Based on these criteria, to date, there are three models that are relatively well validated: $\mathrm{CO}_{2}$ exposure, hyperventilation, and lactate administration. All three have in common that they alter the $\mathrm{pH}$ within the body.

We have previously proposed that an acutely disturbed acid-base homeostasis, involving an entire network within the brain, underlies the occurrence of PAs (Esquivel et al., 2009). Under normal circumstances, the acid-base homeostasis is tightly regulated within a narrow range around a $\mathrm{pH}$ of 7.4. A shift out of this normal range can have a severe impact on chemical reactions and enzymatic functions, with potentially fatal consequences. Therefore, sensing a change in $\mathrm{pH}$ and triggering adaptive responses are of pivotal importance for survival. Neurons sensitive to $\mathrm{CO}_{2} / \mathrm{H}^{+}$and thus to changes in $\mathrm{pH}$ have been found in many brain regions such as the amygdala (Ziemann et al., 2009), the hypothalamus (Johnson et al., 2012a; Williams et al., 2007), and various brainstem nuclei (Biancardi et al., 2008; Dean et al., 1990; Dias et al., 2007; Mulkey et al., 2004; Putnam et al., 2004; Richerson, 2004; Severson et al., 2003). Combined with the defensive distance model proposed by McNaughton $(2004 ; 2000)$ and the functional imaging predator study by Mobbs et al. (2007), these chemosensitive brainstem regions would be of particular 


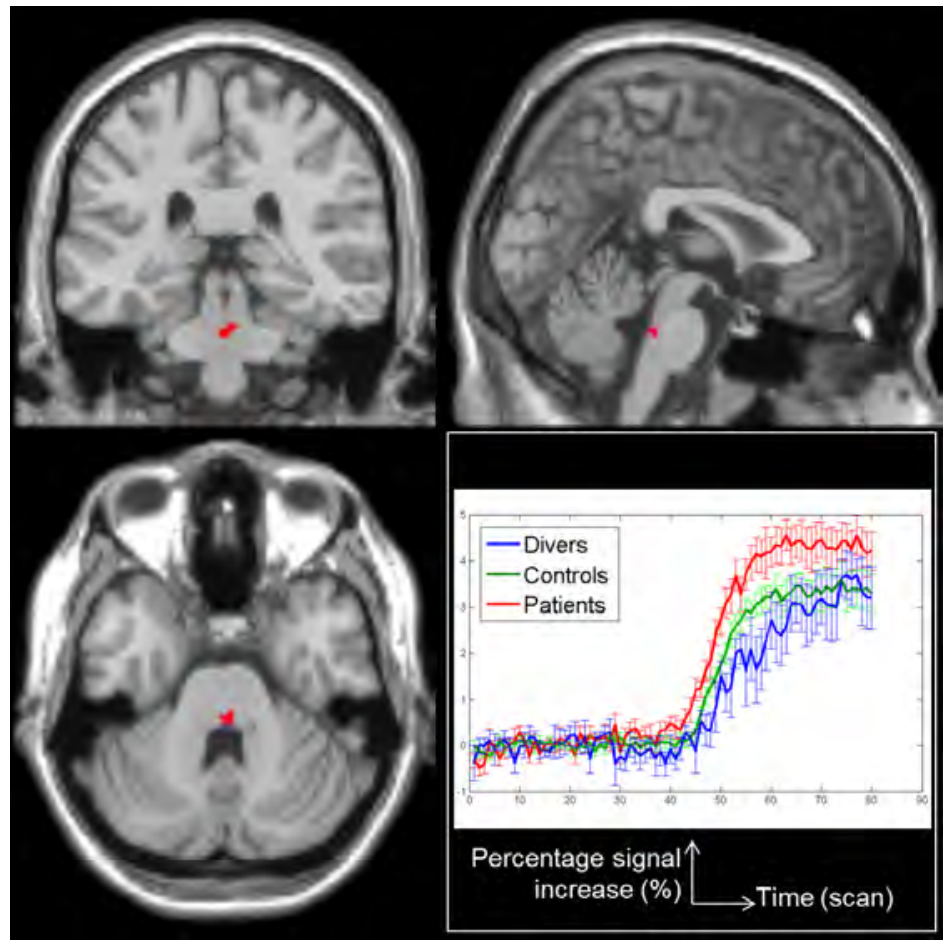

Figure 2. Brain activity in response to inhaling $\mathrm{CO}_{2} \cdot \mathrm{CO}_{2}$ activated the brainstem, particularly in panic disorder patients compared to healthy controls (Goossens et al., 2014). Copyright (C) 2014 by Sage Publications Inc. Reprinted by permission of SAGE.

interest in the pathophysiology of PAs. The only missing component to validate the brainstem model in humans was evidence of a threat stimulus originating from within the body, which would represent the most proximal defensive distance possible. We recently provided this missing component by applying $\mathrm{CO}_{2}$ inhalations to human subjects (Goossens et al., 2014), showing that breathing $\mathrm{CO}_{2}$ resulted in brainstem activation in PD patients in comparison with healthy controls (Figure 2).

To unravel the molecular mechanisms underlying such brainstem activation as well as the properties of neurons that sense changes in $\mathrm{pH}$, the number of rodent studies on panic increased over the past few years, as this concept is difficult to study in humans. Important progress has been made with regard to the PAG (Johnson et al., 2014; Paul et al., 2014), the raphe nuclei (Richerson, 2004; Severson et al., 2003), and the role of the 5 -HT system (Richerson, 2004). As the role of the PAG in relationship to panic has been elaborated extensively elsewhere (Johnson et al., 2014; Paul et al., 2014), it will not be discussed in this review. 
In the present review, we focus on $\mathrm{CO}_{2}$ as panic-provoking method in both humans and animals to discuss the relationship between $\mathrm{CO}_{2}$, changes in brain $\mathrm{pH}$, the 5 -HT system, and associated adaptive physiological and behavioral responses.

\section{$\mathrm{CO}_{2}$ exposure as experimental model of panic attacks in humans}

$\mathrm{CO}_{2}$ is an end-product of carbohydrate metabolism and is continuously produced within the body. The majority of bodily $\mathrm{CO}_{2}$ is readily processed by the bicarbonate buffering system to maintain a physiological acid-base balance. $\mathrm{CO}_{2}$ reacts with water to form carbonic acid, which in turn dissociates into hydrogen ions and bicarbonate $\left(\mathrm{CO}_{2}+\mathrm{H}_{2} \mathrm{O}\right.$ $\left.\leftrightarrow \mathrm{H}_{2} \mathrm{CO}_{3} \leftrightarrow \mathrm{H}^{+}+\mathrm{HCO}_{3}^{-}\right)$. Bicarbonate compensates the hydrogen ions. Without this buffering, hydrogen ions would accumulate, resulting in a decrease in $\mathrm{pH}$. When the $\mathrm{CO}_{2}$ concentration increases strongly, the partial pressure of $\mathrm{CO}_{2}$ increases rapidly, which is associated with a decrease in $\mathrm{pH}$. This is followed by adaptive bodily responses such as an increase in respiration rate to expirate the excess $\mathrm{CO}_{2}$, leading to respiratory alkalosis (Griez et al., 1987a).

As PAs originate within the brain, the effects of PAs or a $\mathrm{CO}_{2}$ inhalation on brain $\mathrm{pH}$ are more important than the peripheral effects. In rodents, $\mathrm{CO}_{2}$ exposure causes a decrease in brain pH (Schuchmann et al., 2006; Ziemann et al., 2009; Ziemann et al., 2008). In humans, however, studies investigating the direct link between breathing $\mathrm{CO}_{2}$ and brain $\mathrm{pH}$ are lacking. Indirect evidence for brain acidification comes from a study using intravenous infusion of bicarbonate that caused a decrease in brain $\mathrm{pH}$ as shown by magnetic resonance spectroscopy (Nakashima et al., 1996). Moreover, PD patients display a larger increase in brain lactate to visual stimuli compared to healthy subjects (Maddock et al., 2009). As work in rodents showed that an increase in lactate is associated with a decrease in $\mathrm{pH}$ (Erlichman et al., 2008), a similar effect can be expected in humans.

\section{Methodology}

\section{Procedure and assessment}

Three decades ago, Van den Hout and Griez (1984) investigated the effects of a single vital capacity breath of $35 \% \mathrm{CO}_{2}$. They showed that this $\mathrm{CO}_{2}$ concentration has panicogenic properties and proposed it as an effective tool for exposure therapy in PD patients. Later, the same research group reported that PD patients appeared to be more vulnerable to a $35 \% \mathrm{CO}_{2}$ inhalation than healthy participants, more frequently reporting fear in response to the procedure (Griez et al., 1987b). In addition, patients rated the induced symptoms as strikingly similar to the ones experienced during a naturally occurring PA. 
Following this study, $\mathrm{CO}_{2}$ inhalation became one of the most extensively used experimental models for panic. Exposure to a low concentration of $\mathrm{CO}_{2}(5-7 \%)$ for up to $20 \mathrm{~min}$, or taking a single breath of a high concentration (35\%) $\mathrm{CO}_{2}$ are widely used. To the best of our knowledge, there are no systematic studies assessing adverse effects, but in general $\mathrm{CO}_{2}$ inhalation is a safe and well-tolerated procedure, with some reports of mild headache in some individuals (criterion safety of an ideal experimental model). In addition, inhaling $35 \% \mathrm{CO}_{2}$ also does not prime individuals at risk, i.e. first-degree relatives of PD patients, to develop PD (Perna et al., 1999b). With regard to the use of a low concentration of $\mathrm{CO}_{2}$, the administration method varies between studies (Coryell et al., 2001; Kent et al., 2001). After inhalation of $35 \% \mathrm{CO}_{2}$, subjects usually hold their breath for either 4 (Schruers et al., 2011; van Beek and Griez, 2000; Verburg et al., 1995; Verschoor and Markus, 2011) or $8 \mathrm{~s}$ (Nardi et al., 2006; Valenca et al., 2002a). It was shown that particularly an inhalation of $35 \% \mathrm{CO}_{2}$ induces a response reflecting the majority of symptoms of naturally occurring PA (Nardi et al., 2006; Schruers et al., 2004), thereby fulfilling the criterion of convergence required for an ideal experimental model (Guttmacher et al., 1983).

The response to $\mathrm{CO}_{2}$ is commonly evaluated using self-reports about the presence and intensity of fear and panic symptoms in line with the DSM criteria, although there is a wide variability in the exact cut-off threshold for defining a PA (Rassovsky and Kushner, 2003). In addition, most studies use the change in reported discomfort, thus calculating the difference between post- and pre-inhalation rating, whereas others focus on post $\mathrm{CO}_{2}$ ratings (Verburg et al., 1998). Other variations in the assessment method include obtaining a direct statement regarding whether a subject had experienced a PA (Holt and Andrews, 1989) or judgment by the investigator based on observation (Gorman et al., 1994; Papp et al., 1997).

\section{Specificity of $\mathrm{CO}_{2}$ hyperreactivity in panic disorder}

The third criterion for an ideal experimental model concerns the ability to discriminate individuals affected by a disorder from those who are not affected (Guttmacher et al., 1983). It has been repeatedly shown that PD patients are responsive to a $\mathrm{CO}_{2}$ inhalation (e.g., Esquivel et al., 2008a; Nardi et al., 2006; Papp et al., 1993; Perna et al., 1995c; Schmidt et al., 1997). Compared to healthy subjects, PD patients are more sensitive to a $\mathrm{CO}_{2}$ challenge (e.g., Fyer et al., 1987; Perna et al., 1994a). Among a group of patients with mixed anxiety disorders, only patients with PD reported an increase in fear, implying that the $\mathrm{CO}_{2}$-elicited effects are independent of baseline fear (Griez et al., 1990b). Other patient groups suffering from GAD (Perna et al., 1999a; Verburg et al., 1995), animal phobia (Verburg et al., 1994), post-traumatic stress disorder (Talesnik et al., 2007), obsessivecompulsive disorder (Griez et al., 1990a; Perna et al., 1995b), and major depression (Kent 
et al., 2001; Perna et al., 1995a) responded significantly less than PD patients. However, it has to be noted that there are some exceptions to the specificity of $\mathrm{CO}_{2}$-hyperreactivity for PD. Patients with social anxiety disorder have an elevated responsivity to $\mathrm{CO}_{2}$, which is intermediate between healthy controls and patients with PD (for meta-analysis see Schutters et al., 2012). Furthermore, individuals with sporadic PAs who did not meet the DSM-III-R criteria responded comparably to PD patients, suggesting that they belonged to the same vulnerability spectrum (Perna et al., 1995c). Twin studies (Battaglia et al., 2007; Battaglia et al., 2008; Bellodi et al., 1998; Roberson-Nay et al., 2013) and assessments of familial-genetic risk (Perna et al., 1996) suggest an association between genetics and $\mathrm{CO}_{2}$ hypersensitivity. In line with this, healthy first-degree relatives of PD patients have an elevated $\mathrm{CO}_{2}$ reactivity (Coryell, 1997) that is intermediate between healthy controls without a familial PD history and PD patients (van Beek and Griez, 2000). Therefore, the specificity of heightened $\mathrm{CO}_{2}$-vulnerability is relatively high, though not absolute, for PD. It has been proposed that panic is associated with evolutionarily evolved, fundamental mechanisms (Klein, 1993) and primitive brain structures such as the periaqueductal gray (McNaughton and Corr, 2004; McNaughton and Gray, 2000). If this is in fact true, it may be expected that every individual would react to $\mathrm{CO}_{2}$ and not just patients with PD. It is likely that the response degree differs between individuals, with PD patients reacting most strongly. In accordance with this notion, it was shown that $\mathrm{CO}_{2}$ can also trigger panic in healthy volunteers (Griez et al., 2007). The adverse reaction to $\mathrm{CO}_{2}$ increases dosedependently (Griez et al., 2007; Kaye et al., 2004; Leibold et al., 2013; Schruers et al., 2011), and is especially profound with a double vital capacity breath of $35 \% \mathrm{CO}_{2}$. The double vital capacity inhalation leads to a higher concentration of $\mathrm{CO}_{2}$ within the body and effectively elicits the emotional response associated with naturally occurring PAs, thus comparable to the effects of a single breath in PD patients (Griez et al., 2007). In healthy volunteers, experimental PAs are successfully triggered in 37\% (Griez et al., 2007) to 68\% (Leibold et al., 2013) of subjects, whilst in PD patients $43 \%$ to $94 \%$ of the participants fulfill the criterion of having experienced a PA during the $\mathrm{CO}_{2}$ inhalation (for overview see Colasanti et al., 2012). Several factors are likely to explain part of this variability. For instance, study samples often differ in terms of age and sex. In healthy volunteers, it has been demonstrated that the sensitivity to $\mathrm{CO}_{2}$ decreases with increasing age (Griez et al., 2007), showing the necessity for homogeneous samples and/or large sample sizes. With regard to sex, epidemiological data imply that women are more often affected by PD than men (Dick et al., 1994; Gater et al., 1998). However, $\mathrm{CO}_{2}$ panic provocation studies did not find this sex effect consistently. Several studies did not find a sex effect (Griez et al., 2007; Leibold et al., 2013; Nardi et al., 2007; Perna et al., 2004b; Poonai et al., 2000), whereas in others a higher reactivity was observed in females (Bunaciu et al., 2012; Kelly et al., 
2006; Nillni et al., 2012). Environmental factors such as socialization processes cause women to report greater fear, whilst the expression of anxiety or fear may be inconsistent with the male role and less tolerated in men (McLean and Anderson, 2009). In addition, personality traits such as anxiety sensitivity may be associated with the response to a $\mathrm{CO}_{2}$ challenge (McNally, 2002), but were not evaluated in all studies. Furthermore, the variety in assessment methods (Rassovsky and Kushner, 2003) can result in different panic rates. In addition, most studies use the change in reported discomfort, thus calculating the difference between post- and pre-inhalation rating, whereas others solely focus on post- $\mathrm{CO}_{2}$ ratings (Verburg et al., 1998). In spite of methodological differences associated with some variability in the reported efficacy of $\mathrm{CO}_{2}$ as panic-provoking stimulus, there is a large and convincing amount of evidence that $\mathrm{CO}_{2}$ effectively triggers panic symptoms, to a different degree, in both PD patients and unaffected people, thereby supporting the postulation of a role of fundamental mechanisms in panic. Noteworthy, reactivity to a $\mathrm{CO}_{2}$ inhalation appears to be a predictor for the future development of PAs (Schmidt et al., 2007b; Schmidt and Zvolensky, 2007), but not for PD (Schmidt et al., 2007b). However, in combination with anxiety sensitivity, interactive effects were found beyond the separate effects of the two risk factors to develop an anxiety disorder, including PD (Schmidt and Zvolensky, 2007).

\section{Test-retest reliability}

Another criterion that is used to evaluate an experimental model is its ability to elicit reproducible effects (Guttmacher et al., 1983). Both in PD patients and in healthy subjects the within-subject test-retest reliability of $\mathrm{CO}_{2}$ inhalations has been assessed. With regard to lower concentrations of $\mathrm{CO}_{2}, 7 \% \mathrm{CO}_{2}$ inhalations proved to have good test-retest reliability when a second inhalation was applied one week later (Poma et al., 2005). Using a single vital capacity breath of $35 \% \mathrm{CO}_{2}$ with a week between the two inhalations showed good reliability at the level of reported subjective fear (Kaye et al., 2004; Verburg et al., 1998) as well as in panic symptoms (Verburg et al., 1998), with some variation between the distinct panic symptoms (Verburg et al., 1998). In addition, no significant habituation of psychological responses was observed (Kaye et al., 2004). Similarly, high correlations were found between the majority of individual symptom ratings obtained by a single breath of $35 \% \mathrm{CO}_{2}$ with a retest after about 29 days (Coryell and Arndt, 1999). Although repeated exposure to high concentrations of 20\% (Beck and Wolf, 2001) and 35\% (Beck and Shipherd, 1997; Beck et al., 1999; Beck et al., 1997; Griez and van den Hout, 1986; van den Hout et al., 1987) has been shown to result in desensitization to some extent, the response to a few consecutive trials with $\mathrm{CO}_{2}$ exposure shows good test-retest reliability (Kaye et al., 2004; Verburg et al., 1998). 


\section{Robustness against contextual manipulations}

The response to $\mathrm{CO}_{2}$ has been shown to be robust against contextual factors such as manipulation of safety signals (e.g. objects or persons signaling safety such as presence of a doctor), instructions or control. For instance, Rapee et al. (1991) assessed the role of safety cues in mediating the response to $\mathrm{CO}_{2}$ in PD patients. In the safety condition, a "senior" and a "professional junior experimenter" were present during the procedure and in personal contact with the patient, whilst in the non-safety condition, the "senior experimenter" was called to an emergency and only a "student" was present who left the patients alone during the experiment. No difference in panic rates was found between the two conditions. Only one study reported that absence of a "safe" person during the $\mathrm{CO}_{2}$ challenge was associated with slightly more distress and arousal in PD patients when compared to when a "safe" person was present (Carter et al., 1995). In another study (Papp et al., 1995), the instructions before the inhalation were manipulated by informing one group about the expected symptoms and the reassurance that these symptoms were caused by inhaling $\mathrm{CO}_{2}$-enriched air, whilst the second group only received an explanation about the procedure without reassurance. This manipulation did not result in any difference in subjective ratings between the two groups. Similarly, instructions such as standard information about the study in comparison with an extensive reassurance regarding any perceived dangerousness of the inhalation did not affect panic rates among PD patients and controls. In the reassurance group, less subjective breathlessness was reported, which was not reflected in the actual respiratory measurements (Welkowitz et al., 1999). Moreover, healthy volunteers scoring high in cardiac sensitivity (i.e., high cardiac concerns) experienced more fear and were more likely to panic in response to inhalation of $35 \% \mathrm{CO}_{2}$ when a cardiac defibrillator was brought into the experimental room before the inhalation (Telch et al., 2010). This is in line with a study showing that the level of anxiety sensitivity in combination with the instructional set could influence the response to $\mathrm{CO}_{2}$ to some extent (Telch et al., 2011). With regard to perceived control, patients who were told they could decrease the amount of $\mathrm{CO}_{2}$ in a $5.5 \% \mathrm{CO}_{2}$ inhalation procedure, by turning a knob, which did not actually do anything, reported less panic symptoms in terms of number and intensity, less anxiety, and were less likely to report PAs (Sanderson et al., 1989). However, this result was not replicated in a later study by another group (Welkowitz et al., 1999). Furthermore, the unpredictability of administration of $20 \% \mathrm{CO}_{2}$ did not alter subjective fear levels compared to when the administration was predictable (Yartz et al., 2008). In summary, the response to $\mathrm{CO}_{2}$ is robust against manipulations, but there are some dispositional tendencies that may potentiate or mitigate panicogenic effects. 


\section{Pharmacological manipulation with a focus on the serotonergic system}

The first-line pharmacological treatment, selective serotonin reuptake inhibitors (SSRIs), aims at normalizing the $5-\mathrm{HT}$ neurotransmitter system. 5- $\mathrm{HT}$ is a monoamine that is involved in a large number of functions within the brain (Lesch and Waider, 2012). Its principal source is a brainstem cluster of nine nuclei of 5-HT neurons (Lesch and Waider, 2012). The rostral subdivision, consisting of the dorsal and the median raphe nucleus, projects primarily to the forebrain, thereby mediating emotional states, circadian rhythms, sleep-wake regulation, food intake, and cognition. The caudal subdivision, comprising the raphe pallidus, the raphe obscurus, and the raphe magnus, projects to the spinal cord and cerebellum, and is involved in motor activity and regulation of the autonomic nervous system (Lesch et al., 2012). 5-HT is synthesized from the amino acid tryptophan, which is an essential amino acid. Most tryptophan is protein-bound, only about $5 \%$ is free and transported across the blood-brain barrier (Bell et al., 2001). Within the brain, tryptophan is further processed to 5-hydroxy-tryptophan by the enzyme tryptophan hydroxylase 2 (TPH2), followed by the conversion to $5-\mathrm{HT}$ by the enzyme amino acid decarboxylase. In this metabolic pathway, the TPH2-mediated step is the rate-limiting step (Lesch et al., 2012).

Studies during the past two decades frequently used tryptophan depletion to assess 5-HT-related mechanisms in the pathophysiology of panic (e.g., Goddard et al., 1994; Miller et al., 2000; Schruers et al., 2000). Tryptophan depletion is a method to acutely deplete dietary tryptophan leading to a pronounced reduction in plasma tryptophan and, therefore, reduced 5-HT production and release within the brain (Bell et al., 2001). The most effective method to reduce tryptophan is to consume a drink containing other amino acids such as valine, leucine, isoleucine, phenylalanine, and tyrosine. These five amino acids compete with tryptophan for transport across the blood-brain barrier, thereby limiting the entry of tryptophan into the brain. In addition, the drink stimulates protein synthesis in the liver, which depletes tryptophan that is already present in the plasma (Bell et al., 2001). In PD patients, tryptophan depletion alone failed to have panicogenic effects (Goddard et al., 1994). However, in combination with $\mathrm{CO}_{2}$ as panic-provoking stimulus, it enhanced the panic response (Miller et al., 2000; Schruers et al., 2000) and led to a higher rate of PAs during the $\mathrm{CO}_{2}$ inhalation (Miller et al., 2000). Moreover, we showed that acute administration of the 5-HT precursor L-5-hydroxytryptophan, leading to increased brain 5- $\mathrm{HT}$ levels, reduced the panic response triggered by a $\mathrm{CO}_{2}$ inhalation (Schruers et al., 2002). In healthy volunteers, in combination with a $\mathrm{CO}_{2}$ inhalation, an increase in neurovegetative symptoms was found (Klaassen et al., 1998), which, however was not replicated in later studies (e.g., Hood et al., 2006), and even a blunted response to $\mathrm{CO}_{2}$ was reported by others (Colasanti et al., 2011). The varying results between 
studies may be due to differences in methodology such as the exact tryptophan depletion mixture (Sobczak and Schruers, 2014). For instance, Klaassen et al. (1998) used a mixture consisting of various amino acids excluding tryptophan, whilst a gelatin-based mixture was used by Colasanti et al. (2011). Therefore, depending on the exact composition, the efficacy of the drink to deplete central tryptophan is likely to vary. In addition, changes in the tryptophan metabolism may also interfere with neurotransmitter systems such as glutamate or gamma-aminobutyric acid (GABA). Therefore, future studies should use a more standardized approach to confirm that depletion of tryptophan, and hence 5-HT, enhances the panicogenic effects of $\mathrm{CO}_{2}$.

SSRIs target the 5-HT transporter (5-HTT) (Ravindran and Stein, 2010), which normally transports extracellular 5-HT back into the presynaptic neuron, thereby terminating the action of 5-HT in the synaptic cleft. As such, inhibition of the 5-HTT leads to a prolonged availability of $5-\mathrm{HT}$ in the synaptic cleft. SSRIs markedly attenuated the $\mathrm{CO}_{2}$ reactivity after a short treatment of seven days (Bertani et al., 2001; Bertani et al., 1997; Perna et al., 2004a; Perna et al., 2002; Perna et al., 1997) as well as after a longer treatment for up to 4 - 6 weeks (Perna et al., 2002; Pols et al., 1996; Schruers and Griez, 2004). Interestingly, the decrease in $\mathrm{CO}_{2}$ reactivity after one week of SSRI treatment, thus before full therapeutic efficacy is obtained, predicted the clinical outcome after one month of treatment (Perna et al., 2002). Noteworthy, genetic variants in the gene encoding the 5-HTT have been shown to naturally influence the availability of extracellular 5-HT by altering the expression, and/or regulation of 5-HTT. A well-described functional variant is a length polymorphism in the promoter region of the 5-HTT gene, referred to as the 5-HTT gene-linked polymorphic region (5-HTTLPR) (Lesch et al., 1996). When the 5-HTTLPR was discovered, two variants were described influencing the transcriptional activity of the 5-HTT gene: a long (L)-allele with 16 repeats and a short (S)-allele with 14 repeats. The L-allele is associated with an about two times higher 5-HTT expression relative to the $\mathrm{S}$-allele as shown by in vitro studies. Only a few years later, a third variant was reported (Nakamura et al., 2000), which is a single nucleotide substitution of A to $G$ in the L-allele and is associated with gene expression levels similar to the one of the S-allele (Hu et al., 2006). To date, genetic studies assessing the effects of the 5-HTTLPR on $\mathrm{CO}_{2}$-induced panic yielded inconsistent results. In a study in healthy volunteers, homozygous L-allele carriers were hyperreactive to a single breath of $35 \% \mathrm{CO}_{2}$ in comparison with S-allele carriers (Schmidt et al., 2000). In line with this and using a larger sample, we showed that the fear reaction to $\mathrm{aCO}_{2}$ inhalation is dose-dependent and moderated by the 5-HTTLPR (Schruers et al., 2011). More specifically, homozygous carriers of the L-allele reported the strongest fear, particularly at an intermediate dosage of $17.5 \% \mathrm{CO}_{2}$. In contrast, in a sample of PD patients, no relationship between the 5 -HTTLPR polymorphism and $\mathrm{CO}_{2}$-reactivity could 
be found (Perna et al., 2004c). However, the same group reported a better treatment response to the SSRI paroxetine for homo- and heterozygous female L-allele carriers, supporting a role of the $5-\mathrm{HT}$ system in PD.

Similarly to the effects of SSRIs, a reduced reactivity to $\mathrm{CO}_{2}$ was observed after treatment with tricyclic antidepressants (Bertani et al., 1997; Perna et al., 2002; Perna et al., 1997), the reversible monoamine oxidase type A inhibitor toloxatone (Perna et al., 1994b), and the 5-HT-norepinephrine reuptake inhibitor venlafaxine (Bertani et al., 2003). Panicolytic effects were also reported for benzodiazepines (Beckett et al., 1986; Nardi et al., 1999; Pols et al., 1991; Sanderson et al., 1994; Valenca et al., 2000; Valenca et al., 2002b), which are used in the daily clinic when the earlier treatment options have failed (Baldwin et al., 2014). In contrast, acute administration of drugs without clinical efficacy such as propranolol, hydroxyzine, and flupentixol did not reduce the reactivity to $\mathrm{CO}_{2}$ (Papadopoulos et al., 2010). Therefore, $\mathrm{CO}_{2}$ exposure fulfills the criterion of clinical validation of a good experimental model (Guttmacher et al., 1983).

\section{Hypothalamo-pituitary-adrenal axis and physiological response Lack of hypothalamo-pituitary-adrenal axis activation in $\mathrm{CO}_{2}$-induced panic attacks}

PAs are associated with high levels of subjective distress and are generally believed to be an expression of a dysfunctional, hypersensitive fear system. Therefore, it can be expected that the stress experienced during a PA activates the hypothalamo-pituitary-adrenal (HPA) axis. The HPA axis is a central endocrine system that consists of three secretional levels (Kandel et al., 2012). In the hypothalamus, the paraventricular nucleus secretes vasopressin and corticotrophin-releasing hormone, which binds to specific receptors on the anterior pituitary and stimulates the release of adrenocorticotropic hormone into the blood stream. Adrenocorticotropic hormone, in turn, stimulates the adrenal cortex to synthesize and secrete glucocorticoids. This end-product of the HPA axis, cortisol in humans and corticosterone in rodents, induces a variety of acute adaptive changes such as increasing heart rate and mobilizing energy resources to ensure an appropriate response to the stressful situation. Under normal conditions, cortisol is secreted in a pulsatile fashion as its secretion is regulated by negative feedback systems to keep the levels within a physiological range (Lightman and Conway-Campbell, 2010). To activate the negative feedback, cortisol binds to glucocorticoid receptors located in the anterior pituitary gland, the hypothalamus, and the hippocampus, thereby downregulating the further release. However, stress can override the feedback mechanisms leading to increased cortisol secretion.

Cortisol is the hormone that has been most commonly measured as an index of the HPA axis activity. Due to the spontaneous nature of naturally occurring PAs, only a few studies 
have assessed cortisol levels outside the laboratory. In those studies, elevated cortisol levels were found during the PA (Bandelow et al., 2000; Cameron et al., 1987; Woods et al., 1987). However, some methodological considerations such as small sample size (Cameron et al., 1987) or triggering the PA in phobic situations (Bandelow et al., 2000) limit the generalizability of these results. Given that PAs occur unpredictably, and that there is circadian variability of the HPA axis, most studies have focused on experimentally induced PAs. Several studies applying a low concentration of $5 \% \mathrm{CO}_{2}$ in patients with PD and/or healthy subjects did not find significant increases in cortisol levels after the inhalation compared to baseline (Coplan et al., 2002; Kaye et al., 2004; Woods et al., 1988). One study reported a decreased cortisol level in panicking PD patients during the $\mathrm{CO}_{2}$ inhalation phase compared to room air inhalation (Sinha et al., 1999). No prior baseline difference was found between patients who panicked, patients who were not sensitive to $\mathrm{CO}_{2}$, and healthy controls. However, after administration of a higher dosage of $7.5 \% \mathrm{CO}_{2}$, a slight increase in cortisol levels was observed in healthy subjects (Woods et al., 1988). Therefore, it was proposed that a higher percentage of $\mathrm{CO}_{2}$ would be needed to sufficiently activate the HPA axis (Argyropoulos et al., 2002). Based on the wide-spread use of $35 \% \mathrm{CO}_{2}$ as a panic-provoking stimulus, this concentration has been applied in a number of studies to assess HPA axis reactivity. In healthy subjects, a single vital capacity breath resulted in an increase in cortisol, with the most robust effect after 15 min compared to baseline values (Kaye et al., 2004) or after 20 min compared to room air inhalation (Argyropoulos et al., 2002). However, the invasive nature of blood sampling and the methodological design in the second study (i.e. always performing the $\mathrm{CO}_{2}$ inhalation 40 min after the air inhalation) does not allow differentiation of the effects of the $\mathrm{CO}_{2}$ inhalation from the effects of the prolonged experimental procedure. Mixed results were obtained by Wetherell et al. (2006). They observed an increase in cortisol levels in six healthy subjects, but no response or negative reactivity in ten other healthy subjects. Responders experienced a $\mathrm{CO}_{2}$-induced increase in negative feelings to a greater extent than non-responders, possibly contributing to the differences between the individuals. Other studies failed to replicate the $\mathrm{CO}_{2}$-induced HPA axis activation (Brambilla et al., 2013; Meiri et al., 2001; van Duinen et al., 2004a, b; Verschoor and Markus, 2011). In general, use of a randomized order design for administering $\mathrm{CO}_{2}$ and placebo air inhalations is most preferable to prevent order effects (Meiri et al., 2001; van Duinen et al., 2004a). In addition, the timing of sample collection is important in studies examining the stress response given the time delay for a stressful event to induce a measurable change in cortisol excretion. Based on the studies by Kaye et al. (2004) and Argyropoulos et al. (2002) 15 - 20 min seem to be most appropriate. Similarly to healthy subjects, results are contradictory in patients with PD as shown by a series of experiments performed by 
our research group. In the first study (van Duinen et al., 2004b), no cortisol increase was found after inhaling $35 \% \mathrm{CO}_{2}$ compared to baseline. In a follow-up study (van Duinen et al., 2005), a second baseline sample was obtained directly before the $\mathrm{CO}_{2}$ inhalation in addition to the one sampled $30 \mathrm{~min}$ before. All subjects started the trial at the same day to control for circadian variation in cortisol secretion. These methodological improvements facilitated evaluation of the direct effects of the $\mathrm{CO}_{2}$ exposure and revealed a small, but statistically significant cortisol increase in response to $\mathrm{CO}_{2}$. However, it has been proposed that PD patients may be hyperreactive to novelty cues and that the experimental context stimulates the HPA axis in patients, which may explain the positive findings in some studies (Abelson et al., 2007). In a follow-up study comparing PD patients with healthy controls, inhaling $35 \% \mathrm{CO}_{2}$ increased cortisol levels in both groups to a similar small extent (van Duinen et al., 2007). No distinction of the two groups was possible based on the neuroendocrinological response to $\mathrm{CO}_{2}$.

Despite that experiencing panic is a very stressful period accompanied by marked sympathetic activation, it is not necessarily associated with a strong activation of the HPA axis. This contradicts the notion that, in general, stress stimulates the HPA axis. However, it is in line with the earlier introduced model by McNaughton and Corr (2004) stating that panic is associated with a fast response caused by a threat coming from the smallest distance possible, which is in this case from within the body. PAs occur spontaneously and are accompanied by an immediate bodily response. The HPA axis, in contrast, is not immediately activated. Based on these considerations, the general lack of HPA axis activation by the panicogenic stimulus $\mathrm{CO}_{2}$ can be considered as consistent with McNaugthon and Corr's defense model. In addition, it was suggested that the HPA axis activation may be suppressed as acute activation would counterproductively increase catabolic activity and oxygen demand (Preter and Klein, 2008). In contrast to PAs, anticipatory anxiety may activate the HPA axis (Graeff and Zangrossi, 2010). As PD patients often fear the occurrence of the next PA it seems logical that patients may have chronically increased cortisol levels. In this respect, baseline differences between patients and controls have been investigated, showing that some, but not all patients have elevated levels (for overview see Wedekind et al., 2000). To conclude, in contrast to anticipatory anxiety, (experimentally-induced) PAs are generally not accompanied by a strong HPA axis activation.

\section{Cardio-respiratory response to a $\mathrm{CO}_{2}$ inhalation}

Human studies mostly rely on self-reports to study the response to $\mathrm{CO}_{2}$. Some components of PAs such as the experienced fear can be best assessed by reports of the individual, but PAs are also accompanied by physiological symptoms. Previously, we have proposed 
(in line with Denton, 2006; Denton et al., 2009) that PAs can be considered an instance of primal emotion aimed at protecting an individual against a vital threat. In general, emotions consist of two elements: sensation and intention. The conscious perception of a disturbed bodily function is referred to as sensation, whilst intention is an adaptive response to restore the homeostasis. Maintaining the internal milieu is essential for bodily well-being and normal functioning. When a survival-threatening disturbance occurs and the sensation is triggered interoceptively, the emotion can merge into the stream of conscious awareness as primal emotion. In this respect, PAs may be rooted in primitive, instinctual behavior associated with an immediate threat to the individual's existence. A metabolic disturbance within the brain may spread from subcortical regions such as the brainstem into higher cortical areas, including regions involved in affective responses. Thus, it permeates into conscious awareness of a full-blown emotion (Colasanti et al., 2012). Considering that PAs are an instance of a primal emotion and that PAs are subjective experiences associated with profound physiological symptoms, we believe that assessing either biological or psychological measurements does not capture the entire phenomenon. Therefore, to complement self-reports about the fear and panic symptoms felt during the experiment physiological parameters such blood pressure, heart rate, and respiratory parameters are also worth measuring.

\section{Activation of the cardiovascular system}

The interest in the cardiovascular system is based on the observation that PAs are discrete episodes of autonomic arousal. This is supported by ambulatory assessment studies of naturally occurring PAs (Freedman et al., 1985; Taylor et al., 1986). However, due to the unexpected nature of PAs, ambulatory studies are relatively scarce. Given the close resemblance of real-life and $\mathrm{CO}_{2}$-induced PAs, several studies studied the cardiovascular response to $\mathrm{CO}_{2}$ inhalation.

Early provocation studies conducted more than two decades ago, demonstrated that administration of $5 \% \mathrm{CO}_{2}$ for an extended time period could to affect the cardiovascular system. More specifically, a PA induced by inhaling $\mathrm{CO}_{2}$ was associated with an increase in diastolic blood pressure (Gorman et al., 1988). Another study demonstrated an increase in heart rate in subjects who panicked during the $5 \% \mathrm{CO}_{2}$ inhalation (Sasaki et al., 1996). A later study reported an increase in systolic and diastolic blood pressure and in heart rate in panic patients and healthy controls when inhaling $5 \%$ and $7 \% \mathrm{CO}_{2}$ (Martinez et al., 1998). In line with this, Woods et al. (1988) reported a dose-related increase in blood pressure and heart rate in a healthy sample. Similarly, other research groups reported a $\mathrm{CO}_{2}$-induced stimulation of systolic blood pressure (Bailey et al., 2005), the diastolic blood pressure (Bailey et al., 2007), and heart rate (Bailey et al., 2005; Gregor and Zvolensky, 
2008; Nillni et al., 2012; Papadopoulos et al., 2010). No effect of treatment with the SSRI paroxetine for 21 days was found on any cardiovascular measurement in response to $7.5 \%$ $\mathrm{CO}_{2}$ in healthy subjects (Bailey et al., 2007). A direct comparison of panic patients and controls showed that patients had a tendency towards a higher heart rate during eight inhalations of $20 \% \mathrm{CO}_{2}$ (Blechert et al., 2010). Yet other studies failed to find an effect in patients (Bystritsky and Shapiro, 1992) and healthy subjects (Kaye et al., 2004). In addition to studying a mere increase in a specific outcome parameter, also the variability/variation of that parameter may be of interest (e.g., Bystritsky et al., 2000; Bystritsky and Shapiro, 1992). In this respect, it was reported that PD patients had high blood pressure variability, particularly in the diastolic blood pressure. The pattern and the degree of fluctuations differed depending on the severity of the PA (Bystritsky and Shapiro, 1992). Patients who panicked during the $\mathrm{CO}_{2}$-inhalation already had a significantly different baseline blood pressure variability compared to non-panicking patients as well as controls (Bystritsky et al., 2000). Reviewing those studies, it becomes clear that PAs seem to affect the cardiovascular system, but there is no consistent pattern in the cardiovascular response to low concentrations of $\mathrm{CO}_{2}$. Similarly, studying the effects of a relatively high concentration of $\mathrm{CO}_{2}(35 \%)$ on the cardiovascular system also did not result in a consistent pattern to date. Some groups reported an (overall) reduction in heart rate (Argyropoulos et al., 2002; Kaye et al., 2004; Wetherell et al., 2006), whilst others observed an increase in heart rate (Poonai et al., 2000; Richey et al., 2010). In addition, no difference was found between PD patients and healthy volunteers (Fleet et al., 2014).

Evidently, there is some variability in the observed responses to $\mathrm{CO}_{2}$. In part, this may be explained by limitations of the technical devices used in the past; however, more advanced technical equipment has become available. We recently exposed healthy volunteers to four concentrations of $\mathrm{CO}_{2}\left(0 \%, 9 \%, 17.5 \%\right.$, and $\left.35 \% \mathrm{CO}_{2}\right)$, and for the first time continuously measured the heart rate and blood pressure response to all four concentrations (Leibold et al., 2013). We used a customized computer system including a cardiovascular monitor and capnography that allowed a detailed analysis of the bodily response to $\mathrm{CO}_{2}$. In our study, heart rate was hardly affected by $\mathrm{CO}_{2}$. It appeared that instead of an increase or decrease in frequency, mainly the variation, thus fluctuations in heart rate, correlated with fear, discomfort, and panic symptom ratings. With regard to blood pressure, we observed a dosedependent increase. The systolic blood pressure, however, reached a plateau at $17.5 \% \mathrm{CO}_{2}$. In contrast, the diastolic blood pressure was the most sensitive parameter to discriminate between the concentrations. In addition, it reflected the dose-dependent increase in the emotional response. A robust increase in systolic (Richey et al., 2010; Wetherell et al., 2006) as well as diastolic (Richey et al., 2010) blood pressure is in line with previous studies, confirming a strong stimulation of the autonomic nervous system during $\mathrm{CO}_{2}$ exposure. 
Most studies to date have focused on the immediate effects of $\mathrm{CO}_{2}$ on the cardiovascular system. Detailed assessment of the recovery period (for instance, $10-20 \mathrm{~min}$ ) after a $\mathrm{CO}_{2}$ inhalation is very scarce. In a small study evaluating the effects of $5.5 \% \mathrm{CO}_{2}$, no difference between panic patients and controls was found (Bystritsky and Shapiro, 1992). However, with a larger sample size the same research group observed that patients had a slower heart rate recovery after breathing $5 \% \mathrm{CO}_{2}$ for 20 min (Bystritsky et al., 2000). In line with this, a tendency towards higher heart rates and a prolonged recovery time was also observed in patients after taking a single breath of $35 \% \mathrm{CO}_{2}$ (Niccolai et al., 2008).

In sum, the majority of studies in the past, reporting inconsistent findings, made use of technologies that were limited in their resolution in addition to methodological variability in $\mathrm{CO}_{2}$ concentrations, analysis strategies (e.g., calculating means over various time periods), and recruited samples (e.g., age and sex). However, the more technologically sophisticated approaches indicate that $\mathrm{CO}_{2}$ inhalation induces a general activation of the autonomic nervous system in a dose-dependent manner.

\section{Activation of the respiratory system}

The respiratory system plays a key role in maintaining the partial pressure of $\mathrm{CO}_{2}\left(\mathrm{pCO}_{2}\right), \mathrm{O}_{2}$, and the $\mathrm{pH}$ within a narrow physiological range in the body. An increase in $\mathrm{pCO}_{2}$ is the most robust stimulant for respiration under normal circumstances in mammals. Sensitive central chemoreceptors are widely located in the brain and by increasing respiration the excess of $\mathrm{CO}_{2}$ is exhaled, lowering the $\mathrm{pCO}_{2}$ level. To a lesser extent, also peripheral chemoreceptors are sensitive to $\mathrm{pCO}_{2}$ (Rassovsky and Kushner, 2003). Peripheral chemoreceptors are located in the carotid body near the bifurcation of carotid arteries and in aortic bodies and primarily detect arterial hypoxemia (Nattie, 2006), which, however, hardly affects respiration (Rassovsky and Kushner, 2003). PAs can be experimentally triggered by some respiratory challenges such as $\mathrm{CO}_{2}$ inhalation, suggesting a link between respiration and PAs.

Respiratory symptoms such as breathlessness and air hunger are components of most PAs. Given the unexpected nature of PAs and the limited likelihood to occur during the assessment period in the lab, it is difficult to study PAs under normal conditions. Therefore, examining baseline respiration (for recent meta-analysis see Grassi et al., 2013) or the respiratory response to $\mathrm{CO}_{2}$, to which $\mathrm{PD}$ patients are particularly vulnerable, has become of interest. Despite the increased lifetime prevalence of respiratory disorders in PD patients and a certain degree of phenomenological overlap, there is no causal relationship between a history of respiratory conditions and $\mathrm{CO}_{2}$ reactivity (van Beek et al., 2003). However, evidence suggests the existence of a PD subtype, characterized by a relatively high number of pronounced respiratory symptoms during a PA and a higher reactivity to $\mathrm{CO}_{2}$ (Freire and Nardi, 2012). 
To assess the respiratory response to $\mathrm{CO}_{2}$-induced PAs in more detail, various parameters have been investigated. In an early study, no difference in respiration rate, defined as the number of breaths per minute, to a $35 \% \mathrm{CO}_{2}$ inhalation was observed compared to a room air inhalation in PD patients and healthy volunteers (Gorman et al., 1990). Tidal volume (the amount of gas displaced with each breath during rest) and minute ventilation (the volume inhaled per minute) significantly increased in both groups, with no difference between the groups. However, binning data into 15 -s epochs may mask small, transient fluctuations. Others (Bystritsky and Shapiro, 1992) reported that inhaling low concentrations of $\mathrm{CO}_{2}$ increased the respiration rate in PD patients, with the most pronounced effect in patients who panicked (Sasaki et al., 1996). In addition, PD patients had a higher variability in respiration rate and irregular breathing patterns with frequent pauses (Bystritsky and Shapiro, 1992). A more detailed analysis by another research group (Papp et al., 1997) showed that healthy controls and PD patients who did not panic mainly responded to the $\mathrm{CO}_{2}$ inhalation by increasing their tidal volume, whilst patients who panicked had a blunted tidal volume response and an exaggerated respiration rate. More specifically, the breathing frequency in patients who panicked rose rapidly, with an increase observed within the first $5 \mathrm{~min}$. Subjects who panicked also had a continued rise in end-tidal $\mathrm{CO}_{2}$ $\left(\mathrm{EtCO}_{2}\right.$, the concentration of $\mathrm{CO}_{2}$ at the end of an exhaled breath), while $\mathrm{EtCO}_{2}$ stabilized quickly in those that did not panic and control subjects. Of note, both patient groups had a lower baseline $\mathrm{EtCO}_{2}$ than controls. Low $\mathrm{EtCO}_{2}$ and high minute ventilation variance at baseline predicted the occurrence of a PA during the $5 \% \mathrm{CO}_{2}$ inhalation (Papp et al., 1997). Further, increased tidal volume was also observed after repeated inhalations of $20 \% \mathrm{CO}_{2}$ (Blechert et al., 2010). Controls habituated to some extent across inhalations, which did not occur in patients with PD. The authors suggested a respiratory hypersensitivity in PD patients. In healthy volunteers, exposure to $\mathrm{CO}_{2}$ was associated with an increase in respiration rate in "responders", defined by an increase of at least one point for at least four symptoms of the panic symptom list (Poma, et al., 2005) and additionally an increase of at least $25 \%$ in the visual analogue scale rating in a later study (Poma et al., 2013). In that particular subgroup, $7 \% \mathrm{CO}_{2}$ significantly increased respiratory rate, tidal volume, minute ventilation, and $\mathrm{EtCO}_{2}$. After discontinuation of $\mathrm{CO}_{2}, \mathrm{EtCO}_{2}$ and minute volume returned to baseline within a few minutes (Poma et al., 2005). Further, PD patients had an increased variability in the respiration rate as well as in the partial pressure of $\mathrm{CO}_{2}$ compared to healthy controls during the recovery period after inhaling $\mathrm{CO}_{2}$ (Niccolai et al., 2008). In addition, in patients with PD, the tidal volume remained elevated for a longer period of time in comparison with controls (Papp et al., 1997). It has been suggested that the homeostatic control of the physiological equilibrium, which becomes disrupted by inhaling $\mathrm{CO}_{2}$, is less effective in PD patients than in healthy subjects (Niccolai et al., 2008). 
Studies assessing the effects of 5- $\mathrm{HT}$ agents on the respiratory response to a $\mathrm{CO}_{2}$ inhalation are relatively scarce. Treatment with anti-panic medication for 2 (Coryell and Rickels, 2009) to 12 weeks (Gorman et al., 2004) did not alter the respiratory response to a $\mathrm{CO}_{2}$ inhalation. However, methodological drawbacks such as the short administration time, in which SSRIs do not yet exert clinical benefits, and a small sample as well as the use of several medications in the second study limit drawing general conclusions regarding the role of the 5 -HT system in $\mathrm{CO}_{2}$-induced discomfort.

To conclude, current data imply that $\mathrm{CO}_{2}$-induced PAs are associated with alterations in the respiratory system to restore the acid-base homeostasis. Patients with PD may need more time to recover from an acute disruption of their homeostasis. Factors with the potential to influence respiration, such as anxiety sensitivity (Blechert et al., 2013), should be taken into account in future studies.

\section{Conclusion panic provocation in humans via disturbance of brain $\mathrm{pH}$}

In conclusion, studying PAs seems the most efficient using brief inhalations of $35 \%$ $\mathrm{CO}_{2}$, though also exposure to a low concentration of $\mathrm{CO}_{2}$ for a prolonged period elicits experimental PAs. Based on the criteria proposed by Guttmacher et al. (1983) 35\% $\mathrm{CO}_{2}$ can be considered a good experimental model. It is a relatively easy, non-invasive technique that reliably triggers a transient, intense emotional response and symptoms resembling naturally occurring PAs in patients with PD. These symptoms are also elicited in healthy volunteers, when using a high dosage of $35 \% \mathrm{CO}_{2}$. It proved to have good testretest reliability and also fulfills the criterion of pharmacological validation. However, as the onset of effects occurs rapidly, no behavioral measurements can be taken over time. For this, voluntary hyperventilation and particularly lactate administration, two additional models influencing the acid-base homeostasis (for review see Esquivel et al., 2008b), may be more suitable.

\section{$\mathrm{CO}_{2}$ exposure in rodents as panic model affecting acid-base homeostasis}

Human models are limited in their potential to investigate the molecular mechanisms underlying a disorder. Animal research is a valuable tool in this respect. Similar to the human panic models, two models affecting the acid-base homeostasis have been applied in rodents: exposure to $\mathrm{CO}_{2}$ and lactate administration. In contrast to human studies, selfreports about the presence and intensity of emotions and symptoms cannot be obtained in rodents. Therefore, the traditional outcome parameter in animals is the behavioral response in anxiety- and fear-related tasks in relation to molecular mechanisms of interest. 
In contrast to the study of PD in human subjects where $\mathrm{CO}_{2}$ exposure has been used for over three decades, significant progress with the use of $\mathrm{CO}_{2}$ inhalation for the study of panic in rodent models has been made only recently (Johnson et al., 2005; Ziemann et al., 2009).

\section{Methodology}

Since rodents cannot be instructed to take one or two vital capacity breaths of $\mathrm{CO}_{2}$, as is done in humans, animals are commonly exposed to a lower concentration of $\mathrm{CO}_{2}$ for a prolonged period of time. In an early study in 1981 (Elam et al.), 3 - 20\% CO was supplied for 1 min using a funnel that was placed in front of a tracheal cannula. However, since methods like this may be associated with stress, non-invasive approaches are preferable. Few early panic-related studies used a hermetically closed box to expose rodents to 35\% for 1 min (Barbaccia et al., 1994; Concas et al., 1993; Cuccheddu et al., 1995; Sanna et al., 1992). To date, to allow studying real-time behavioral performance during $\mathrm{CO}_{2}$ exposure, over a prolonged time period, it is more common to use chronic exposure to more moderate $\mathrm{CO}_{2}$ concentrations as elegantly done by two groups (Johnson et al., 2005; Ziemann et al., 2009). Compared to the tracheal cannula approach, the major advantages of using $\mathrm{CO}_{2}$-filled compartments are the non-invasiveness and that animals can move freely allowing real-time behavioral assessment. Therefore, anxiety- and fear-related behavior in response to $\mathrm{CO}_{2}$ can be studied whilst minimizing confounding effects. Animals are placed into a box before infusing the hypercapnic gas mixture (Johnson et al., 2011; Johnson et al., 2005; Johnson et al., 2012b) or into a pre-filled box (Ziemann et al., 2009). In previous studies, the behavioral response was examined either during the hypercapnic exposure in a large Plexiglas box (Ziemann et al., 2009) or immediately after exposure in flow cages (Johnson et al., 2011; Johnson et al., 2012b). Results showed that exposure to $10 \%$ and $20 \% \mathrm{CO}_{2}$ for 20 min increased anxiety- and fear-related behavior, as indicated by less activity in the center zone of the open field arena (Ziemann et al., 2009). Similarly, rodents tested directly after a 5 min infusion of $20 \% \mathrm{CO}_{2}$, leading to a gradual increase in $\mathrm{CO}_{2}$ reaching $20 \%$ at the end of the period associated with an arterial $\mathrm{pH}$ of 7.01 (Johnson et al., 2012b), also showed an increase in negative affect. Animals spent more time in the outer (Johnson et al., 2011) or middle (Johnson et al., 2012b) wall zone of the open field arena compared to animals previously exposed to room air control gas. To evaluate the aversive effects of $\mathrm{CO}_{2}$, mice are placed in a testing box divided into two chambers, one filled with air and one with $\mathrm{CO}_{2}$. The two chambers are connected by a swinging door to allow free crossing, whilst limiting gas mixing (Ziemann et al., 2009). When one chamber was filled with $10 \% \mathrm{CO}_{2}$ mice avoided that chamber and spent more than $90 \%$ of the time in the chamber filled with air. The same research group also assessed freezing, which 
is defined as the absence of any movements apart from respiration and is considered as a correlate of fear and panic in mice. Breathing $10 \% \mathrm{CO}_{2}$ for $10 \mathrm{~min}$ elicited a robust freezing response, whilst no effect was observed after $5 \% \mathrm{CO}_{2}$ (Ziemann et al., 2009). Evidently, exposure to $\mathrm{CO}_{2}$ elicits a marked behavioral fear response in rodents. However, it is difficult to translate the exact level of distress the animals experience to the human perspective. Observed behavior in rodents is not interchangeable with verbal self-reports in humans. In this respect, heart rate, blood pressure, and respiration rate are promising complements to the behavioral assessment as those parameters can be measured in both humans and rodents to facilitate comparison.

\section{Cardio-respiratory response to $\mathrm{CO}_{2}$ exposure and link to the serotonergic system}

To date, the cardio-respiratory response to $\mathrm{CO}_{2}$ has been studied only rarely in the direct framework of panic. For instance, in rats, exposure to a hypercapnic gas mixture of $5 \%$ $\mathrm{CO}_{2}$ increased respiration rate, tidal volume, and minute volume (Annerbrink et al., 2003). This increase was dose-dependent, an effect that was attenuated by treatment with the SSRI paroxetine for 15 weeks (Olsson et al., 2004). In addition, when rats were treated with the 5-HT synthesis inhibitor parachlorophenylalanine, tidal volume variability and minute volume variability were significantly higher at baseline and during $\mathrm{CO}_{2}$ exposure than in untreated control rats (Annerbrink et al., 2003). Furthermore, recordings of the phrenic nerve, important in breathing, of anesthetized rats with a mean arterial blood $\mathrm{pH}$ of 7.22, showed an increase in amplitude (Dumont et al., 2011). In addition, the mean blood pressure and heart rate were also increased. Decreasing the $\mathrm{pH}$ even more to 7.01 (at the end of the $\mathrm{CO}_{2}$ exposure period) was associated with an elevation in respiration rate and mean arterial blood pressure, and decreased heart rate in conscious rats, whilst under anesthesia respiration rate decreased (Johnson et al., 2012b). This difference may be explained by a combined effect of the anesthetic ketamine on the arousal system, opioid systems, and anxiety circuits.

\section{Conclusion panic induction in rodents via disturbance of brain $\mathrm{pH}$}

To conclude, $\mathrm{CO}_{2}$ is known to affect behavior and breathing and important insights into the involved mechanisms and the disease entities to which they are relevant (e.g., Li and Nattie, 2008) have been gained. However, in rodents, the cardio-respiratory response to $\mathrm{CO}_{2}$-induced panic has not been assessed as extensively as done in human studies of $\mathrm{CO}_{2}$ induced panic, and pharmacological validation is mostly lacking. The translation between human and animal research is often hampered by the differences in outcome measures (i.e., verbal self-reports in humans compared to observed behavioral response in rodents). To maximize translation of knowledge and thereby making rodent research more efficient, 
experiments in humans and rodents should be performed as similar as possible. In this respect, assessing the same outcome measurements in both species such as the cardiorespiratory response in addition to the classical behavioral measurements and combining the data may be a promising approach for future studies.

\section{Integrating animal and human data: The link between brain acidosis, the serotonergic system, and adaptive responses}

\section{The brainstem as important structure in sensing changes in $\mathbf{p H}$}

There are a number of neurons having properties consistent with being chemoreceptors. Neurons sensitive to $\mathrm{CO}_{2} / \mathrm{pH}$ are found in the amygdala of mice (Ziemann et al., 2009), in the hypothalamus (Johnson et al., 2012a; Williams et al., 2007), and in rodent brainstem nuclei such as the locus coeruleus (Biancardi et al., 2008; Filosa et al., 2002; Oyamada et al., 1998; Pineda and Aghajanian, 1997), the nucleus tractus solitarii (Dean et al., 1990), the retrotrapezoid nucleus (Mulkey et al., 2004), the ventrolateral medulla (da Silva et al., 2010), the medullary raphe (Putnam et al., 2004; Richerson, 2004), the dorsal raphe (Severson et al., 2003), and other subsets of the raphe nuclei (da Silva et al., 2011; Dias et al., 2007).

The key neuroanatomical brain areas involved in PAs are still under discussion (Dresler et al., 2013; Johnson et al., 2014), but given that respiratory symptoms are a cardinal feature in PAs, it can be assumed that there is an overlap between neurons involved in a defensive/panic response and neurons stimulating respiration. Based on previous research in humans and mice, the amygdala has been a highly promising candidate in the past few years (Pfleiderer et al., 2007; Ziemann et al., 2009). However, a recent landmark study in humans produced contradictory findings. The sensitivity to a $35 \% \mathrm{CO}_{2}$ inhalation was tested in patients with a bilaterally damaged amygdala due to Urbach-Wiethe disease (Feinstein et al., 2013). This is an extremely rare disease associated with an infiltration of a hyaline (lipoid) material into skin, membranes, and organs including the brain. Considering the amygdala as key player and its dysfunctionality in those patients, it was hypothesized that they would show a blunted response to $\mathrm{CO}_{2}$. However, unexpectedly, all patients experienced a PA. This study shows that the $\mathrm{CO}_{2}$-induced effects are, at least in part, attributable to structures other than the amygdala, but as this study focused on the behavioral response to $\mathrm{CO}_{2}$ no candidate structures were suggested. More recently, we used a functional imaging study (Goossens et al., 2014), in which healthy volunteers and PD patients breathed $\mathrm{CO}_{2}$ within a magnetic resonance imaging scanner. Activation of the right anterior insula correlated with a subjective feeling of breathlessness. With regard to chemosensitive areas, we observed that breathing $\mathrm{CO}_{2}$ activates the brainstem, 
an effect that was more pronounced in PD patients than in healthy subjects (see Figure 3 for overview). Considering $\mathrm{CO}_{2}$ as a stimulus that induces adverse effects from within the body, brainstem activation is consistent with the two-dimensional defense model by McNaughton (2000). However, due to the limited spatial resolution of the used functional imaging scanner it remains to be determined which brainstem nuclei are activated in response to $\mathrm{CO}_{2}$.

In rodents, a hypercapnic gas exposure with up to $20 \% \mathrm{CO}_{2}$ induced a functional cellular response (i.e., induction of c-fos, an inducible transcription factor encoded by an immediate early gene) in various structures such as the medulla (Okada et al., 2002), the nucleus tractus solitaries (Pete et al., 2002; Teppema et al., 1997), the PAG (Johnson et al., 2011), and the raphe nucleus (Johnson et al., 2005; Niblock et al., 2010; Pete et al., 2002). Interestingly, there is a fair similarity to the structures activated after exposing rodents to cat odor, an unconditioned fear-provoking stimulus (Dielenberg et al., 2001). Therefore, $\mathrm{CO}_{2}$ activates brain areas that are involved in unconditioned, stress-related behavioral responses. Given the symptomatology of PAs, the PAG and the raphe nuclei are of particular interest in this respect. The role of the PAG has been extensively elaborated elsewhere (Johnson et al., 2014; Paul et al., 2014). Therefore, in the present review, the role of the raphe nuclei in relationship to chemosensitivity is discussed.

\section{The role of the serotonergic system in brainstem chemosensitivity}

\section{Medullary serotonergic raphe neurons mediate the respiratory response to $\mathrm{CO}_{2}$}

In vitro studies in cultured rat brain slices and isolated tissue showed that a subset of medullary raphe neurons (i.e., about 15-20\%) is highly sensitive to changes in $\mathrm{CO}_{2}$ (Richerson, 1995; Wang et al., 1998) and that the mean increase in firing rate is about $300 \%$ when the $\mathrm{pH}$ drops from 7.40 to 7.19 (Wang et al., 1998). In a later study, the same research group proved that all acidosis-stimulated neurons of the medullary raphe were serotonergic, whilst this was not the case for another subset of neurons that was inhibited by $\mathrm{CO}_{2}$ (Wang et al., 2001). To prevent synaptically-mediated effects of $\mathrm{CO}_{2}$, ionotropic GABAergic and glutamatergic receptors were blocked (Wang et al., 2001). In addition, the cells were microdissected and physically isolated, which implies that 5-HT cells are intrinsically chemosensitive and not dependent on input from other brain regions.

Intriguingly, 5-HT neurons are tightly juxtaposed to large medullary arteries, with neuronal processes wrapping around those arteries, coming for up to $2 \mu \mathrm{m}$ within the vessel lumen (Bradley et al., 2002). This proximity to arteries makes them ideally situated for accurately monitoring arterial blood $\mathrm{CO}_{2}$ levels. Neurons in the medullary raphe project to major respiratory nuclei such as hypoglossal and phrenic motor neurons (Corcoran et al., 2009) and have been associated with driving respiratory adaptations to restore the 
disturbed $\mathrm{pH} / \mathrm{CO}_{2}$ homeostasis (Richerson, 2004) (see Figure 3 for overview). In line with this, exposure to $10 \% \mathrm{CO}_{2}$ for 20 min strongly stimulated breathing in rats as shown by an increase of $256 \%$ in minute ventilation (Kondo et al., 2000). In addition, focal acidosis in the raphe induced by microinjection of acetazolamide (Bernard et al., 1996), a carbonic anhydrase inhibitor, or microdialysis using artificial cerebrospinal fluid equilibrated with $25 \% \mathrm{CO}_{2}$ (Nattie and $\mathrm{Li}, 2001$ ) stimulated ventilation, with an increase in frequency by 15 - 20\% in rats (Nattie and Li, 2001). A non-specific lesion of neurons in the medullary raphe caused by ibotenic acid reduced the ventilatory response to $\mathrm{CO}_{2}$ in rats (Dias et al., 2007) and by $26.8 \%$ three to seven days post treatment in goats (Hodges et al., 2004). Moreover, disruption of 5-HT neurons has been shown to alter the hypercapnic ventilatory response. For instance, a saporin-induced reduction of nearly $30 \%$ of 5 - HT neurons was associated with a decreased ventilatory response to $7 \% \mathrm{CO}_{2}$ exposure (Nattie et al., 2004). After treatment with the 5-HT neuron-selective toxin 5,7-dihydroxytryptamine (5,7-DHT) in neonatal rats, these animals had a blunted ventilatory response to $\mathrm{CO}_{2}$ in adulthood (Mueller et al., 1984). Further support for an important role of 5-HT neurons in stimulating breathing is provided by an optogenetics study showing that selectively stimulating medullary raphe 5-HT neurons induces a large increase in respiratory frequency in mice (Depuy et al., 2011).

\section{Midbrain serotonergic raphe neurons mediate the behavioral and emotional response to $\mathrm{CO}_{2}$}

Similarly to medullary 5-HT neurons acting as central chemoreceptors, a high percentage of midbrain raphe neurons are highly chemosensitive (i.e., acidosis-stimulated increase in firing rate of about $400 \%$ ) and serotonergic as shown by their electrophysiological properties (Severson et al., 2003). In line with this, exposure to hypercapnia led to an increase in c-fos in various rodent brain structures. It was shown that c-fos immunoreactivity was present in cells positively stained for tryptophan hydroxylase (TPH), indicating c-fos expression in 5-HT neurons (Johnson et al., 2005). Furthermore, as it is the case in the medulla, a large proportion of those 5-HT neurons are located next to large arteries in the midline, allowing to monitor the acid/base status of blood (Severson et al., 2003). In contrast to medullary raphe neurons, midbrain neurons project rostrally, thereby possibly mediating non-respiratory related responses such as arousal (from sleep), an intense feeling of anxiety, and alterations in cerebrovascular tone (Richerson, 2004).

Genetically modified rodents: Further support for a role of the serotonergic system in mediating adaptive responses to $\mathrm{CO}_{2}$

Experiments in genetically modified rodents provided further evidence for a role of 5-HT 
a
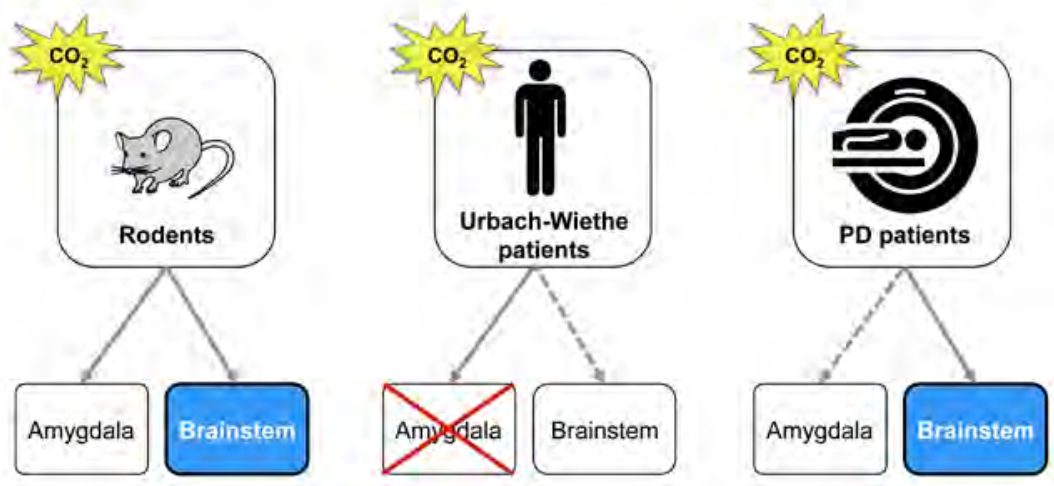

Experimental evidence available

... No experimental evidence available

b

\section{Brainstem}
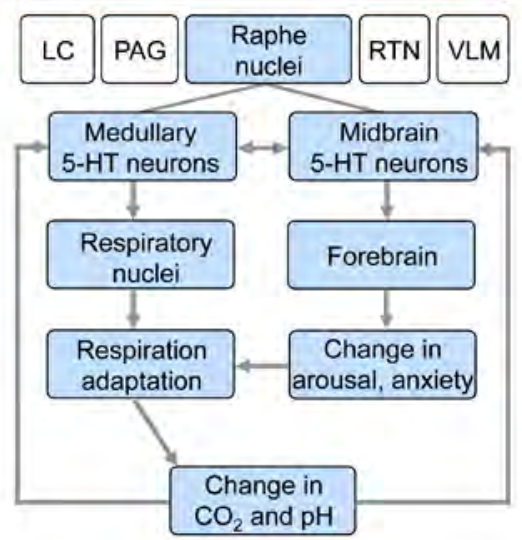

Figure 3. Schematic representation of integrating rodent and human research regarding sensing changes in brain $\mathrm{CO}_{2}$ and $\mathrm{pH}$ and adaptive responses. a) $\mathrm{CO}_{2}$ exposure in rodents provided evidence for chemosensitive neurons located in the amygdala and the brainstem. Recently, it was reported that a $\mathrm{CO}_{2}$ inhalation unexpectedly induced panic attacks in Urbach-Wiethe patients, who have a bilaterally dysfunctional amygdala. This study suggests that the amygdala is not essentially involved in $\mathrm{CO}_{2}$-induced fear and panic attacks. A more recent functional imaging study by our group showed that inhaling $\mathrm{CO}_{2}$ activates the brainstem in PD patients. Altogether, current evidence points towards the brainstem as important structure in sensing changes in $\mathrm{pH}$ and triggering adaptive responses. b) An increase in $\mathrm{CO}_{2}$ associated with a decrease in $\mathrm{pH}$ activates medullary and midbrain 5- $\mathrm{HT}$ neurons to restore the acid-base homeostasis. Medullary 5-HT neurons project to respiratory nuclei such as hypoglossal and phrenic motor neurons, thereby driving respiratory adaptations. Midbrain 5-HT neurons project to the forebrain, mediating emotional states such as arousal and anxiety. $\mathrm{CO}_{2}$, carbon dioxide; $\mathrm{fMRI}$, functional magnetic resonance imaging; LC, locus coeruleus; PAG, periaqueductal gray; PD, panic disorder; RTN, retrotrapezoid nucleus; VLM, ventrolateral medulla; $5-\mathrm{HT}$, serotonin. 
neurons in responding to changes in $\mathrm{CO}_{2} / \mathrm{pH}$ and driving physiological adjustments to restore the homeostasis. Pheochromocytoma 12 ETS factor-1 (Pet-1) is a transcription factor that is selectively expressed in 5-HT neurons and is proposed to be a key factor in the development of the 5-HT system (Hendricks et al., 2003). Mice lacking Pet-1 exhibit a $70 \%$ loss of $5-\mathrm{HT}$ immunoreactive neurons (Hendricks et al., 1999). Male mice had normal resting ventilation, but showed a significant deficit in the breathing response to hypercapnia, which was not observed in females (Hodges et al., 2011). Knock-out of the transcription factor LIM homeobox transcription factor 1 beta (Lmx1b), which is also considered to be a major factor in the development of 5-HT neurons, in Pet-1 expressing $5-\mathrm{HT}$ neurons results in a loss of more than $99 \%$ of central $5-\mathrm{HT}$ neurons (Zhao et al., 2006). The hypercapnic ventilatory response in these genetically altered mice was markedly blunted by up to $50 \%$ compared to wildtype animals (Hodges et al., 2008). Notably, this deficit was rescued by intracerebroventricular infusion of 5-HT (Hodges et al., 2008). In addition, the response to a hypoxic challenge was not dependent on the genotype, implying a specific effect for $\mathrm{CO}_{2}$. Moreover, these mice showed a strongly increased arousal latency (i.e., transition from sleep to wakefulness), with some animals not waking up during a 10 min period of exposure to $10 \% \mathrm{CO}_{2}$, an effect that was not observed in wildtype mice (Buchanan and Richerson, 2010). 5-HT is, therefore, not only strongly involved in breathing, but also in arousal and wakefulness.

Another interesting rodent strain concerns the 5-HTT. Homozygous 5- $\mathrm{Htt}$ knock-out mice have a $66 \%$ reduction in the spontaneous firing rate of dorsal raphe neurons, while heterozygous knock-out mice have a reduction of $35 \%$ in comparison with wildtype animals (Gobbi et al., 2001). It was shown that deletion of the 5-HTT is associated with a reduced breathing response to a hypercapnic challenge. In that study (Li and Nattie, 2008), the response was markedly reduced in knock-out mice compared to wildtypes, with a more pronounced effect in males. Notably, this deficit was already present at postnatal days 15 and 25 , which may explain the blunted $\mathrm{CO}_{2}$ response in later life. Mice lacking the 5-HTT are characterized by an increased extracellular concentration of 5-HT within the brain. In particular, homozygous knock-out mice have an enhanced synaptic availability of 5-HT at somatodendritic $5-\mathrm{HT}_{1 \mathrm{~A}}$ autoreceptors that provide negative feedback to downregulate the firing activity of 5-HT neurons. Thereby, these mice may have impaired ventilatory drive. However, in another study (Gobbi et al., 2001), desensitization of the autoreceptors was observed in hetero- and homozygous $5-\mathrm{Htt}$ knock-out mice. Thus, although the exact mechanisms are not yet fully understood, genetic deletion of the 5-HTT accompanied by alterations in the 5-HT system seems to be associated with a reduced breathing response to $\mathrm{CO}_{2}$ exposure. 


\section{Potential candidate molecules acting as chemoreceptors}

A large amount of research demonstrates that 5-HT cells have chemosensitive properties and may play an important role in eliciting physiological as well as defensive behavioral responses. The mechanism of how the cells sense changes in extracellular $\mathrm{pH}$ is still to be revealed. A large variety of molecules have the potential to sense $\mathrm{pH}$ fluctuations within the brain (Wemmie, 2011). Two may be of particular interest and are elaborated upon here.

In a seminal series of studies, Ziemann et al. (2009) showed that exposure to $\mathrm{CO}_{2}$-enriched air induces fear-related behavior in mice. Using various approaches including genetic deletion and pharmacological intervention, they demonstrated that the behavioral effect was strongly dependent on acid-sensing ion channels, especially acid-sensing ion channel 1a (ASIC1a). In general, ASICs are voltage-independent, proton-gated channels that belong to the degenerin/epithelial sodium channel family (Sherwood et al., 2012) and are permeable to sodium and calcium (Xiong et al., 2004; Yermolaieva et al., 2004). The ASIC1a subtype becomes activated half-maximally when the extracellular $\mathrm{pH}$ drops to 6.5 - 5.9 (Kellenberger and Schild, 2002). In their study, Ziemann et al. (2009) demonstrated that $\mathrm{CO}_{2}$-induced fear-related behavior was dependent on ASIC1a located within the amygdala. However, ASIC1 is widely expressed throughout the entire brain (Wemmie et al., 2003) including 5-HT-rich cell regions such as the brainstem (Price et al., 2014), which may underlie the link between $5-\mathrm{HT}$ cells and their function as chemoreceptors. Genetic deletion of ASIC1 did not affect the arousal response (transition from sleep to wakefulness) to $7 \% \mathrm{CO}_{2}$ (Price et al., 2014), which was markedly blunted in animals lacking central 5-HT neurons (Buchanan and Richerson, 2010). Nevertheless, ASIC1 seems to be involved in innate fear-like behavior as shown by a blunted freezing response during exposure to fox feces in mice with a genetic deletion of ASIC1 (Price et al., 2014). Recently, the human homologue gene, amiloride-sensitive cation channel 2 (ACCN2), has been highlighted as new prime candidate gene (Smoller et al., 2014) in PD. In that study, variants in the ACCN2 gene were associated with PD, and in healthy volunteers with amygdala volume and function to visual presentation of emotional faces, leading to the conclusion that the association might reflect enhanced sensitivity to reduced $\mathrm{pH}$ secondary to neuronal activity. In this study, no stimulus was employed acting directly on chemosensitive receptors, however. Future studies should incorporate such a stimulus. For this, $\mathrm{CO}_{2}$ is a logical candidate.

Another molecule that is a likely candidate to be involved in chemosensitivity is the TWIK-related acid sensitive $\mathrm{K}^{+}$channel (TASK). TASK is a two-pore domain channel that helps to maintain the resting membrane potential and is sensitive to small fluctuations in the extracellular pH in a narrow physiological range (Enyedi and Czirjak, 2010). A small 
$\mathrm{pH}$ reduction of 0.1 is sufficient to inhibit the TASK-1 subtype channels, thereby leading to an increase in the electrical membrane potential and the likelihood of generating action potentials (Buckler, 2010). Contrary to this, alkalosis excites TASK and reduces the likelihood of membrane depolarization (Enyedi and Czirjak, 2010). Interestingly, in motor neurons, it has been shown that TASK-1 is inhibited by various neurotransmitters including 5-HT (Talley et al., 2000). The exact mechanism is largely unknown, but might involve interaction with $5-\mathrm{HT}_{2 \mathrm{C}}$ receptors. Another link to the $5-\mathrm{HT}$ system is the spatial expression of the channels. In addition the lateral lemniscal region, the intertrigeminal region, TASK2 is expressed in the dorsal raphe nucleus (Gestreau et al., 2010). In contrast to TASK-2 expression that is limited to specific brainstem nuclei, TASK-1 and TASK-3 are expressed throughout the brain including the brainstem (Talley et al., 2001). It was demonstrated that the latter channels are expressed in the majority of dorsal and caudal raphe 5-HT neurons (Washburn et al., 2002). Knock-out of TASK-1 and TASK-3 in mice abolished the pH-sensitivity of 5-HT raphe neurons, but not in the retrotrapezoid nucleus. However, the ventilatory response to $3 \%, 5 \%$, and $10 \% \mathrm{CO}_{2}$ was fully retained in those mice and no difference in $\mathrm{CO}_{2}$-sensitivity was found compared to control mice, questioning an essential role of TASK channels in central respiratory chemosensitivity (Mulkey et al., 2007). In fact, TASK-1 deficiency strongly reduces the carotid sinus nerve chemoafferent discharge to $\mathrm{CO}_{2}$ in the carotid body, implying a role of TASK-1 in peripheral rather than central chemosensitivity (Trapp et al., 2008).

\section{Conclusion section integrating human and animal data}

Taken together, there is accumulating and convincing evidence that, in humans, the brainstem plays a major role in chemosensitivity and that the chemosensitive properties of brainstem 5-HT neurons are intrinsic in nature. However, most research has not been done in the direct framework of panic. Combining human and animal research in this respect could advance the current insights into the underlying pathophysiology of PD. This is supported by the finding that the chemoreceptive properties of 5-HT neurons seem not be specific for rodents, but to exist across species (e.g., Larnicol et al., 1994; Veasey et al., $1995,1997)$. Therefore, 5 -HT cells may play a key role in the inborn central suffocation detection system. In this respect, also the specific roles the $\mathrm{pH}$-sensitive molecules remain to be investigated.

\section{Discussion and future perspectives}

PD is a prevalent disabling condition that is associated with a considerable decrease in quality of life and accounts for a large amount of health care costs. It consists of two 
main components: panic and (anticipatory) anxiety. The underlying etiology is not well understood, but both neurobiological models (McNaughton and Corr, 2004) and modern learning theories (Bouton et al., 2001) make a clear distinction between these two components. Anxiety is associated with more distant threats and higher cortical processing, whilst panic is triggered by a threat coming from the most proximal distance possible - the subject's own body. After experiencing a PA, (anticipatory) anxiety is believed to play a major role in the progression to PD (Bouton et al., 2001). In the hierarchical model, panic is a distinct primitive defensive reaction associated with activation of subcortical, primordial brain structures. This concept is in line with human functional imaging data (Mobbs et al., 2007), showing that a decreasing distance to a virtual predator was associated with brain activity shifts from the prefrontal cortex to the PAG. Additional evidence comes from a recent study by our group (Goossens et al., 2014), in which we demonstrated that $\mathrm{CO}_{2}$, causing a threat stimulus from within the body, activates the brainstem in healthy volunteers and to a greater extent in PD patients. In accordance with previous studies in our lab, showing that $\mathrm{CO}_{2}$ induces a dose-dependent increase in fear in healthy volunteers (Griez et al., 2007; Leibold et al., 2013; Schruers et al., 2011), this study suggests the existence of a $\mathrm{CO}_{2}$-sensitivity continuum.

Compatible with these models and observations is a theory by Klein (1993), in which he proposed that every individual is equipped with an evolutionarily evolved brain alarm system that detects metabolic threats from bodily origin. For instance, changes in $\mathrm{CO}_{2}$ levels and associated changes in $\mathrm{pH}$ alert individuals of imminent asphyxia by activating their suffocation detection system, causing an emotional and behavioral response such as acute panic. A dysfunctional system, however, may erroneously be activated without the presence of a real vital threat, eventually triggering a PA. The neural basis for Klein's suffocation monitor is not known to date.

In recent years, progress has been made in understanding central chemosensitivity at the cellular and functional level using various technical approaches. The amygdala has been considered to have a key role in sensing changes in $\mathrm{pH}$ and eliciting the adaptive behavioral fear response (Ziemann et al., 2009). However, there is convincing evidence that brainstem cells mediate the adaptive physiological and emotional response to $\mathrm{CO}_{2}$ (Richerson, 2004; Severson et al., 2003). How can these findings be reconciled? Neurons sensitive to $\mathrm{CO}_{2} / \mathrm{pH}$ are located throughout the brain (Biancardi et al., 2008; Dean et al., 1990; Richerson, 2004; Severson et al., 2003; Ziemann et al., 2009) and seminal evidence against the amygdala as sole key structure in chemosensitivity in humans was recently provided (Feinstein et al., 2013). In that study, patients with a bilaterally damaged amygdala unexpectedly experienced a robust fear response to $\mathrm{CO}_{2}$ inhalation. However, as no functional imaging was included no other candidate structures were suggested. We 
(Goossens et al., 2014) recently demonstrated brainstem activation during inhalation of $\mathrm{CO}_{2}$. Combined with the great deal of evidence that 5-HT raphe neurons have intrinsic chemosensitive properties and elicit various adaptive responses such as changes in respiration and arousal state (Richerson, 2004; Severson et al., 2003), the brainstem may be the most important brain region involved in chemosensitivity in humans. Therefore, PAs may originate in the brainstem and the 5-HT system may be one of the key players involved. In this respect, 5-HT cells may represent the neural basis for the oversensitive central suffocation alarm system, which was previously proposed to underlie PAs (Klein, 1993; Preter and Klein, 2008). The remaining question is how do 5-HT neurons sense changes in $\mathrm{pH}$, and which chemoreceptors are involved? Previously, it was shown that $\mathrm{CO}_{2}$-induced fear-related behavior is dependent on ASIC1a within the amygdala (Ziemann et al., 2009). Since ASIC1a is not exclusively expressed within the amygdala, but also in brainstem nuclei (Price et al., 2014), this ion channel is a likely candidate to be located in 5-HT raphe cells. However, experimental evidence for this notion and its contribution to physiological and behavioral adaptive response is lacking to date. Use of e.g. spatial conditional genetically modified mice and pharmacological manipulations regarding potential molecules such as ASIC1a and the 5-HT system may shed more light into the molecular mechanisms that are implicated in chemosensitivity. This is particularly important as extending our understanding of the pathophysiology in $\mathrm{pH}$ disturbances associated with changes in respiration and arousal states is not exclusively relevant for panic, but also for other disorders such as sudden infant death syndrome, sleep apnea, and possibly sudden unexpected death in epilepsy (Richerson and Buchanan, 2011).

The current main treatment options for PD consist of pharmacological interventions such as SSRIs and exposure therapy, a form of cognitive behavioral therapy. In addition, studies suggest breathing training as another treatment option. Exposure therapy is based on the repeated exposure to the frightened stimulus to experience that the sensations are not associated with life-threatening consequences. In PD, approaches such as hyperventilation (Meuret et al., 2005), spinning in a chair, shaking the head from side to side, or running on a spot (Ito et al., 2001) induce some PA symptoms, but only a fraction of a full-blown PA (Antony et al., 2006; Lee et al., 2006). $\mathrm{CO}_{2}$ inhalation with its efficacy to induce the emotional and panic symptom response might provide a powerful alternative here. Breathing training is used to normalize respiratory patterns that are associated with symptoms such as breathlessness during a PA. By receiving auditory and visual feedback via a capnographic biofeedback system patients become aware of the impact of changes in breathing and learn to adapt, for instance, their breathing frequencies (Meuret et al., 2001). The limited number of studies to date does not allow drawing final conclusions on the efficacy of that technique, but current studies show promising potential as therapeutic 
intervention (Meuret et al., 2010; Meuret et al., 2003, 2008). Most panic research and assessments of the potential of intervention strategies have been performed in PD patients. However, given the previously described $\mathrm{CO}_{2}$-sensitivity spectrum, important insights into the fundamental mechanisms underlying chemosensitivity and related PAs can also be gained by studying healthy volunteers, which has a number of advantages. Healthy volunteers not taking medication can be sampled to ensure that no effects are masked by medication, which may be the case in PD patients. In addition, larger samples can be studied in a relatively short period of time, and PD patients do not have to undergo the burden of experiencing experimentally what they are most afraid of, i.e. PAs. Moreover, interestingly, it was shown that the sensitivity to a $\mathrm{CO}_{2}$ inhalation predicts the onset of PAs later in life (Schmidt et al., 2007b; Schmidt and Zvolensky, 2007), though not for PD (Schmidt et al., 2007b). However, in combination with anxiety sensitivity interactive effects were found beyond the effects of the two factors separately to develop an anxiety disorder, including PD (Schmidt and Zvolensky, 2007). Therefore, the combination might represent a biomarker for future psychopathology. This provides the opportunity for early preventive interventions in subjects at high risk, i.e. individuals with a strong reactivity to $\mathrm{CO}_{2}$ and a high anxiety sensitivity level. It is shown that anxiety sensitivity is not stable over time (Maltby et al., 2005) and can be decreased by targeted interventions such as providing educational information about the benign nature of stress and the effects on the body, and behavioral exercises (e.g. spinning or breathing through a straw) focusing on reducing interoceptive conditioning to bodily cues by repeated exposure to the fear provoking sensations (Schmidt et al., 2007a). Targeted interventions decreasing anxiety sensitivity showed positive effects on the likelihood of anxiety pathology, including PAs and PD (Gardenswartz and Craske, 2001; Schmidt et al., 2007a).

While human research (healthy subjects or PD patients) and experimental models can further extend our understanding of the pathophysiology underlying panic and chemosensitivity by for instance assessing gene - environmental interactions, they are limited in their potential to examine the neurobiological mechanisms underlying a disorder. Animal research is an important approach in this respect. To be able to translate the knowledge between human and animal research, the comparison of aspects between the two research domains has to be maximized. In contrast to the long-standing use of $\mathrm{CO}_{2}$ as panic-provoking agent in humans, comparable animal models are relatively scarce. There are some studies that used the same stimulus, $\mathrm{CO}_{2}$. However, the main outcome parameter in those studies, the behavioral response, is difficult to compare with the main outcome parameter in human panic studies, i.e. self-reports about the experienced discomfort. Therefore, the field would greatly benefit from adding outcome parameters that can be obtained in both humans and rodents. In this respect, careful assessment of, for instance, parameters with regard 


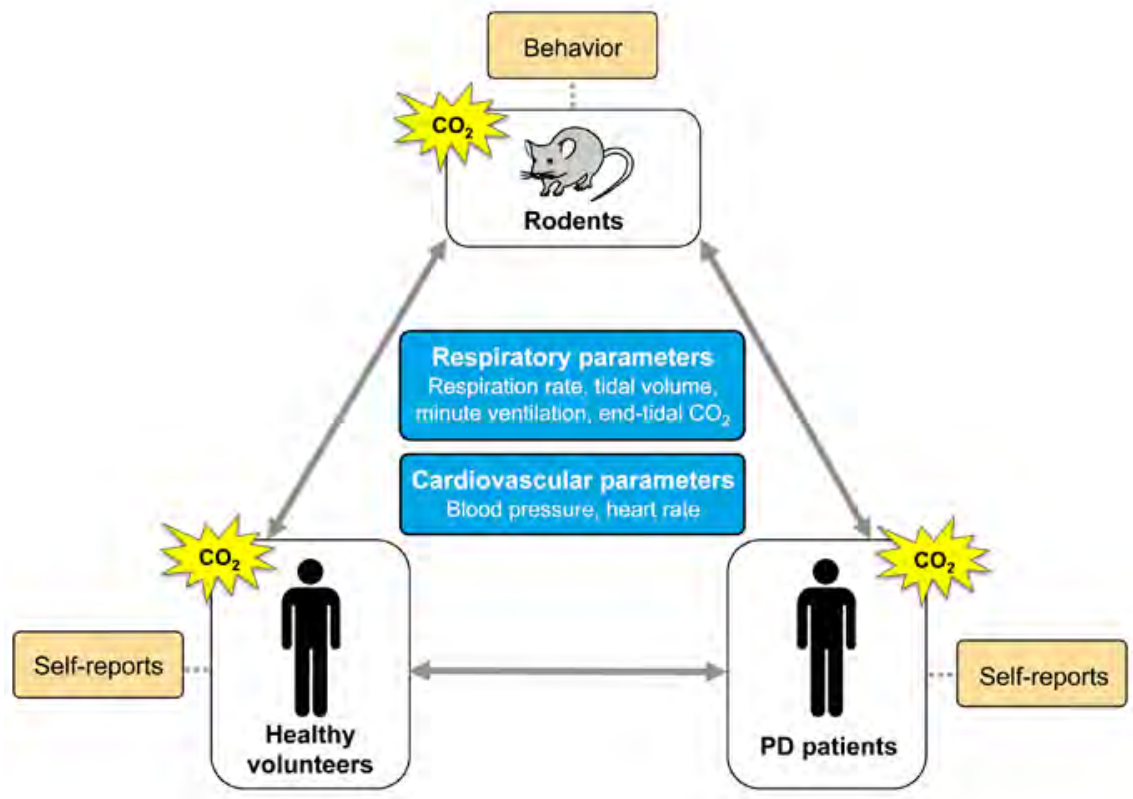

Figure 4. Proposed translational, cross-species approach. Applying the same experimental stimulus (e.g., $\mathrm{CO}_{2}$ ) and obtaining the same outcome measurements (e.g., physiology such as cardio-respiratory parameters) in addition to the commonly used behavioral assessments will improve the translation of knowledge between research domains. $\mathrm{CO}_{2}$ reactivity in rodents can then be used as model for humans and the $\mathrm{CO}_{2}$ reactivity in healthy volunteers serves as model for the $\mathrm{CO}_{2}$ reactivity in panic disorder (PD) patients.

to the cardiovascular and respiratory system may be a useful scientific addition to the presently employed behavioral tests (Figure 4). In healthy subjects, these measurements can be easily incorporated using existing technical devices as previously done (e.g., Blechert et al., 2013; Leibold et al., 2013). Cardiovascular parameters such as blood pressure and heart rate can be assessed non-invasively using a finger cuff and respiratory parameters such as respiration rate using a mask connected to a capnograph. In PD patients, obtaining respiratory parameters may be more difficult as wearing a mask throughout the entire inhalation period may not be accepted or could cause strong discomfort that could interfere with the parameters of interest. In rodents, devices for measuring blood pressure, heart rate, and respiration in freely moving animals are also available. Regarding sodium lactate infusion, a number of rodent studies have incorporated physiological measurements (e.g., Johnson et al., 2013; Johnson et al., 2008). However, rodent $\mathrm{CO}_{2}$ studies with physiological measurements in the direct framework of panic are still largely missing. Particularly obtaining the same physiological measurements in response to the same stimulus in both humans and rodents is highly useful for a direct translation. 
When the same experimental stimuli such as $\mathrm{CO}_{2}$ and outcome measures are combined, the $\mathrm{CO}_{2}$ reactivity in rodents can be used as model for humans and new pharmacological treatments may be identified. The current pharmacological first-line treatment SSRIs are accompanied by many side effects (Cascade et al., 2009). In addition, new drugs frequently fail in the clinical phase. This is, in part, due to the divergence of animal and human models for a disease. However, when using the same stimulus and outcomes in both rodents and humans, the likelihood of obtaining an effective drug in humans based on a promising one in the rodent model will significantly increase. New drugs and decreasing the time to test them is of pivotal importance for patients to return to a normal daily life, which also has a large impact on society and the costs associated with the disorder. In addition, given the spectrum of $\mathrm{CO}_{2}$ reactivity and to reduce the burden for patients with $\mathrm{PD}$, the $\mathrm{CO}_{2}$ reactivity in healthy subjects can be used as model for the reactivity in PD patients. The potency of new therapeutics can thus be evaluated in healthy subjects before testing in patients.

To conclude, despite considerable progress that research has made during the past few years, the exact pathophysiology underlying PD and PAs is still largely unknown. Accumulating evidence supports the hierarchical defense model. First, growing evidence indicates PAs are associated with primitive brain structures and originating in the brainstem. Second, PAs seem to occur at the most proximal distance, which is in this case from within the body. As an acute disturbance in brain $\mathrm{pH}$ can be life-threatening, $\mathrm{CO}_{2}$ triggers negative affect, which can culminate in panic, in most individuals. Further, $\mathrm{CO}_{2}$ also triggers fear-related behavior in rodents. Therefore, rodent models can extend our understanding of the molecular mechanisms underlying $\mathrm{CO}_{2}$-induced fear and PAs such as the role of the $5-\mathrm{HT}$ system and $\mathrm{pH}$-sensitive ion channels like ASIC1a. In this respect, conditional genetically modified rodents and advanced techniques such as optogenetics are also highly useful to modulate specific systems, whilst in humans, studies focusing on gene - environmental interactions can further shed light into the complex pathophysiology of panic. The most powerful approach, however, will be when animal and human studies are combined. To accomplish this, the field would greatly benefit from interdisciplinary and more translational approaches. Using the same experimental stimulus (e.g., $\mathrm{CO}_{2}$ ) and same outcome measurements (e.g., physiology) will greatly improve the translation and application of knowledge between the different species. Then the reactivity to $\mathrm{CO}_{2}$ in rodents can be used as model for humans and the reactivity to $\mathrm{CO}_{2}$ in healthy volunteers can be used as model for the reactivity in PD patients. Altogether, this approach can extend our understanding of the etiological mechanisms, aiding to a revised definition of PAs depending on the etiological basis and will contribute to the development and testing of new therapeutic options for this incapacitating and highly prevalent condition. 


\section{Acknowledgments}

This work was supported by the Deutsche Forschungsgemeinschaft (DFG) Sonderforschungsbereich Transregio (SFB TRR) 58, Sonderforschungsbereich (SFB) 58/A1 and A5 to K-PL and DvdH. 


\section{References}

Abelson, J.L., Khan, S., Liberzon, I., Young, E.A., 2007. HPA axis activity in patients with panic disorder: review and synthesis of four studies. Depress. Anxiety 24, 66-76.

Acheson, D.T., Forsyth, J.P., Prenoveau, J.M., Bouton, M.E., 2007. Interoceptive fear conditioning as a learning model of panic disorder: an experimental evaluation using $20 \% \mathrm{CO}(2)$-enriched air in a non-clinical sample. Behav. Res. Ther. 45, 2280-2294.

American Psychiatric Association, 2013. The Diagnostic and Statistical Manual of Mental Disorders (5th ed.). American Psychiatric Publishing, Arlington, VA.

Annerbrink, K., Olsson, M., Melchior, L.K., Hedner, J., Eriksson, E., 2003. Serotonin depletion increases respiratory variability in freely moving rats: implications for panic disorder. Int. J. Neuropsychopharmacol. 6, 51-56.

Antony, M.M., Ledley, D.R., Liss, A., Swinson, R.P., 2006. Responses to symptom induction exercises in panic disorder. Behav. Res. Ther. 44, 85-98.

Argyropoulos, S.V., Bailey, J.E., Hood, S.D., Kendrick, A.H., Rich, A.S., Laszlo, G., Nash, J.R., Lightman, S.L., Nutt, D.J., 2002. Inhalation of $35 \% \mathrm{CO}(2)$ results in activation of the HPA axis in healthy volunteers. Psychoneuroendocrinology 27, 715-729.

Austin, D., Kiropoulos, L., 2008. An Internet-based investigation of the catastrophic misinterpretation model of panic disorder. J. Anxiety Disord. 22, 233-242.

Bailey, J.E., Argyropoulos, S.V., Kendrick, A.H., Nutt, D.J., 2005. Behavioral and cardiovascular effects of $7.5 \% \mathrm{CO} 2$ in human volunteers. Depress. Anxiety 21, 18-25.

Bailey, J.E., Kendrick, A., Diaper, A., Potokar, J.P., Nutt, D.J., 2007. A validation of the $7.5 \%$ CO2 model of GAD using paroxetine and lorazepam in healthy volunteers. $J$ Psychopharmacol 21, 42-49.

Baldwin, D.S., Anderson, I.M., Nutt, D.J., Allgulander, C., Bandelow, B., den Boer, J.A., Christmas, D.M., Davies, S., Fineberg, N., Lidbetter, N., Malizia, A., McCrone, P., Nabarro, D., O'Neill, C., Scott, J., van der Wee, N., Wittchen, H.U., 2014. Evidence-based pharmacological treatment of anxiety disorders, post-traumatic stress disorder and obsessive-compulsive disorder: a revision of the 2005 guidelines from the British Association for Psychopharmacology. J. Psychopharm. 28, 403-439.

Bandelow, B., Wedekind, D., Pauls, J., Broocks, A., Hajak, G., Ruther, E., 2000. Salivary cortisol in panic attacks. Am. J. Psychiatry 157, 454-456.

Barbaccia, M.L., Roscetti, G., Trabucchi, M., Cuccheddu, T., Concas, A., Biggio, G., 1994. Neurosteroids in the brain of handling-habituated and naive rats: effect of CO2 inhalation. Eur. J. Pharmacol. 261, 317-320.

Barlow, D., 1988. Anxiety and its disorders: The nature and treatment of anxiety and panic. New York: Guilford Press.

Batelaan, N., Smit, F., de Graaf, R., van Balkom, A., Vollebergh, W., Beekman, A., 2007. Economic costs of fullblown and subthreshold panic disorder. J. Affect. Disord. 104, 127-136.

Battaglia, M., Ogliari, A., Harris, J., Spatola, C.A., Pesenti-Gritti, P., Reichborn-Kjennerud, T., Torgersen, S., Kringlen, E., Tambs, K., 2007. A genetic study of the acute anxious response to carbon dioxide stimulation in man. J. Psychiatr. Res. 41, 906-917.

Battaglia, M., Pesenti-Gritti, P., Spatola, C.A., Ogliari, A., Tambs, K., 2008. A twin study of the common vulnerability between heightened sensitivity to hypercapnia and panic disorder. Am. J. Med. Genet. B Neuropsychiatr. Genet. 147B, 586-593.

Beck, J.G., Shipherd, J.C., 1997. Repeated exposure to interoceptive cues: does habituation of fear occur in panic disorder patients? A preliminary report. Behav. Res. Ther. 35, 551-557.

Beck, J.G., Shipherd, J.C., Read, J., 1999. Response patterns to repeated CO2 inhalation in individuals with high anxiety sensitivity. Behav. Res. Ther. 37, 1073-1089.

Beck, J.G., Shipherd, J.C., Zebb, B.J., 1997. How does interoceptive exposure for panic disorder work? An uncontrolled case study. J. Anxiety Disord. 11, 541-556. 
Beck, J.G., Wolf, M.S., 2001. Response to repeated CO2 in individuals with elevated anxiety sensitivity: replication with 20\% CO2. J. Behav. Ther. Exp. Psychiatry 32, 1-16.

Beckett, A., Fishman, S.M., Rosenbaum, J.F., 1986. Clonazepam blockade of spontaneous and CO2 inhalationprovoked panic in a patient with panic disorder. J. Clin. Psychiatry 47, 475-476.

Bell, C., Abrams, J., Nutt, D., 2001. Tryptophan depletion and its implications for psychiatry. The British journal of psychiatry : the journal of mental science 178, 399-405.

Bellodi, L., Perna, G., Caldirola, D., Arancio, C., Bertani, A., Di Bella, D., 1998. CO2-Induced Panic Attacks: A Twin Study. Am J Psychiatr 155, 1184-1188.

Bernard, D.G., Li, A., Nattie, E.E., 1996. Evidence for central chemoreception in the midline raphe. J. Appl. Physiol. 80, 108-115.

Bertani, A., Bellodi, L., Bussi, R., Caldirola, D., Cucchi, M., Perna, G., 2003. The effect of one-week treatment with venlafaxine on 35\% CO2 hyperreactivity in patients with panic disorder: an open study. J. Clin. Psychopharmacol. 23, 106-108.

Bertani, A., Caldirola, D., Bussi, R., Bellodi, L., Perna, G., 2001. The 35\% CO2 hyperreactivity and clinical symptomatology in patients with panic disorder after 1 week of treatment with citalopram: an open study. J. Clin. Psychopharmacol. 21, 262-267.

Bertani, A., Perna, G., Arancio, C., Caldirola, D., Bellodi, L., 1997. Pharmacologic effect of imipramine, paroxetine, and sertraline on $35 \%$ carbon dioxide hypersensitivity in panic patients: a double-blind, random, placebocontrolled study. J. Clin. Psychopharmacol. 17, 97-101.

Biancardi, V., Bicego, K.C., Almeida, M.C., Gargaglioni, L.H., 2008. Locus coeruleus noradrenergic neurons and CO2 drive to breathing. Pflugers Arch. 455, 1119-1128.

Blanchard, R.J., Blanchard, D.C., 1990. An ethoexperimental analysis of defense, fear and anxiety. Otago University Press, Dunedin.

Blechert, J., Wilhelm, F.H., Meuret, A.E., Wilhelm, E.M., Roth, W.T., 2010. Respiratory, autonomic, and experiential responses to repeated inhalations of $20 \% \mathrm{CO}(2)$ enriched air in panic disorder, social phobia, and healthy controls. Biol. Psychol. 84, 104-111.

Blechert, J., Wilhelm, F.H., Meuret, A.E., Wilhelm, E.M., Roth, W.T., 2013. Experiential, autonomic, and respiratory correlates of $\mathrm{CO}$ reactivity in individuals with high and low anxiety sensitivity. Psychiatry Res.

Bouton, M.E., Mineka, S., Barlow, D.H., 2001. A modern learning theory perspective on the etiology of panic disorder. Psychol. Rev. 108, 4-32.

Bradley, S.R., Pieribone, V.A., Wang, W., Severson, C.A., Jacobs, R.A., Richerson, G.B., 2002. Chemosensitive serotonergic neurons are closely associated with large medullary arteries. Nat. Neurosci. 5, 401-402.

Brambilla, F., Perini, G., Serra, M., Pisu, M.G., Zanone, S., Toffanin, T., Milleri, S., Garcia, C.S., Biggio, G., 2013. Changes in neuroactive steroid secretion associated with $\mathrm{CO}$-induced panic attacks in normal individuals. Psychoneuroendocrinology 38, 2234-2242.

Buchanan, G.F., Richerson, G.B., 2010. Central serotonin neurons are required for arousal to CO2. Proc. Natl. Acad. Sci. U. S. A. 107, 16354-16359.

Buckler, K.J., 2010. Two-pore domain k(+) channels and their role in chemoreception. Adv. Exp. Med. Biol. 661, 15-30.

Bunaciu, L., Feldner, M.T., Babson, K.A., Zvolensky, M.J., Eifert, G.H., 2012. Biological sex and panic-relevant anxious reactivity to abrupt increases in bodily arousal as a function of biological challenge intensity. $J$. Behav. Ther. Exp. Psychiatry 43, 526-531.

Bystritsky, A., Craske, M., Maidenberg, E., Vapnik, T., Shapiro, D., 2000. Autonomic reactivity of panic patients during a $\mathrm{CO} 2$ inhalation procedure. Depress. Anxiety 11, 15-26.

Bystritsky, A., Shapiro, D., 1992. Continuous physiological changes and subjective reports in panic patients: a preliminary methodological report. Biol. Psychiatry 32, 766-777.

Cameron, O.G., Lee, M.A., Curtis, G.C., McCann, D.S., 1987. Endocrine and physiological changes during "spontaneous" panic attacks. Psychoneuroendocrinology 12, 321-331. 
Carter, M.M., Hollon, S.D., Carson, R., Shelton, R.C., 1995. Effects of a safe person on induced distress following a biological challenge in panic disorder with agoraphobia. J. Abnorm. Psychol. 104, 156-163.

Cascade, E., Kalali, A.H., Kennedy, S.H., 2009. Real-World Data on SSRI Antidepressant Side Effects. Psychiatry 6, 16-18.

Clark, D.M., 1986. A cognitive approach to panic. Behav. Res. Ther. 24, 461-470.

Colasanti, A., Esquivel, G., den Boer, E., Horlings, A., Dandachi, A., Oostwegel, J.L., van Donkelaar, E.L., Griez, E.J., Schruers, K., 2011. Effects of tryptophan depletion and tryptophan loading on the affective response to high-dose CO2 challenge in healthy volunteers. Psychopharmacology (Berl.) 215, 739-748.

Colasanti, A., Esquivel, G., Schruers, K.J., Griez, E.J., 2012. On the psychotropic effects of carbon dioxide. Curr. Pharm. Des. 18, 5627-5637.

Concas, A., Sanna, E., Cuccheddu, T., Mascia, M.P., Santoro, G., Maciocco, E., Biggio, G., 1993. Carbon dioxide inhalation, stress and anxiogenic drugs reduce the function of GABAA receptor complex in the rat brain. Prog. Neuropsychopharmacol. Biol. Psychiatry 17, 651-661.

Coplan, J.D., Moreau, D., Chaput, F., Martinez, J.M., Hoven, C.W., Mandell, D.J., Gorman, J.M., Pine, D.S., 2002. Salivary cortisol concentrations before and after carbon-dioxide inhalations in children. Biol. Psychiatry 51, 326-333.

Corcoran, A.E., Hodges, M.R., Wu, Y., Wang, W., Wylie, C.J., Deneris, E.S., Richerson, G.B., 2009. Medullary serotonin neurons and central CO2 chemoreception. Respir. Physiol. Neurobiol. 168, 49-58.

Coryell, W., 1997. Hypersensitivity to carbon dioxide as a disease-specific trait marker. Biol. Psychiatry 41, $259-263$.

Coryell, W., Arndt, S., 1999. The 35\% CO2 inhalation procedure: test-retest reliability. Biol. Psychiatry 45, 923-927.

Coryell, W., Fyer, A., Pine, D., Martinez, J., Arndt, S., 2001. Aberrant respiratory sensitivity to $\mathrm{CO}(2)$ as a trait of familial panic disorder. Biol. Psychiatry 49, 582-587.

Coryell, W., Rickels, H., 2009. Effects of escitalopram on anxiety and respiratory responses to carbon dioxide inhalation in subjects at high risk for panic disorder: a placebo-controlled, crossover study. J. Clin. Psychopharmacol. 29, 174-178.

Craske, M.G., Tsao, J.C., 2005. Assessment and treatment of nocturnal panic attacks. Sleep Med. Rev. 9, 173-184.

Cuccheddu, T., Floris, S., Serra, M., Porceddu, M.L., Sanna, E., Biggio, G., 1995. Proconflict effect of carbon dioxide inhalation in rats. Life Sci. 56, PL321-324.

da Silva, G.S., Giusti, H., Benedetti, M., Dias, M.B., Gargaglioni, L.H., Branco, L.G., Glass, M.L., 2011. Serotonergic neurons in the nucleus raphe obscurus contribute to interaction between central and peripheral ventilatory responses to hypercapnia. Pflugers Arch. 462, 407-418.

da Silva, G.S., Li, A., Nattie, E., 2010. High CO2/H+ dialysis in the caudal ventrolateral medulla (Loeschcke's area) increases ventilation in wakefulness. Respir. Physiol. Neurobiol. 171, 46-53.

De Cort, K., Griez, E., Buchler, M., Schruers, K., 2012. The role of "interoceptive" fear conditioning in the development of panic disorder. Behav. Ther. 43, 203-215.

De Cort, K., Hermans, D., Noortman, D., Arends, W., Griez, E.J., Schruers, K.R., 2013. The weight of cognitions in panic: the link between misinterpretations and panic attacks. PLoS One 8, e70315.

De Cort, K., Van Diest, I., Schroijen, M., Hurlemann, R., Claassen, S., Hoogenhout, J., Van Den Bergh, O., Goossens, L., Schruers, K., 2014. The first steps towards panic. Interoceptive fear conditioning with lowdose pentagastrin and 35\% CO2 as experimental model for the initial development of panic disorder EABCT 2014, The Hague, The Netherlands.

Dean, J.B., Bayliss, D.A., Erickson, J.T., Lawing, W.L., Millhorn, D.E., 1990. Depolarization and stimulation of neurons in nucleus tractus solitarii by carbon dioxide does not require chemical synaptic input. Neuroscience $36,207-216$

Denton, D., 2006. The primordial emotions: The dawning of consciousness. Oxford University Press.

Denton, D.A., McKinley, M.J., Farrell, M., Egan, G.F., 2009. The role of primordial emotions in the evolutionary origin of consciousness. Conscious. Cogn. 18, 500-514. 
Depuy, S.D., Kanbar, R., Coates, M.B., Stornetta, R.L., Guyenet, P.G., 2011. Control of breathing by raphe obscurus serotonergic neurons in mice. The Journal of neuroscience : the official journal of the Society for Neuroscience 31, 1981-1990.

Dias, M.B., Nucci, T.B., Margatho, L.O., Antunes-Rodrigues, J., Gargaglioni, L.H., Branco, L.G., 2007. Raphe magnus nucleus is involved in ventilatory but not hypothermic response to CO2. J Appl Physiol (1985) 103, 1780-1788.

Dick, C.L., Bland, R.C., Newman, S.C., 1994. Epidemiology of psychiatric disorders in Edmonton. Panic disorder. Acta Psychiatr. Scand. Suppl. 376, 45-53.

Dielenberg, R.A., Hunt, G.E., McGregor, I.S., 2001. "When a rat smells a cat": the distribution of Fos immunoreactivity in rat brain following exposure to a predatory odor. Neuroscience 104, 1085-1097.

Domschke, K., Stevens, S., Pfleiderer, B., Gerlach, A.L., 2010. Interoceptive sensitivity in anxiety and anxiety disorders: an overview and integration of neurobiological findings. Clin. Psychol. Rev. 30, 1-11.

Dresler, T., Guhn, A., Tupak, S.V., Ehlis, A.C., Herrmann, M.J., Fallgatter, A.J., Deckert, J., Domschke, K., 2013. Revise the revised? New dimensions of the neuroanatomical hypothesis of panic disorder. J. Neural Transm. 120, 3-29.

Dumont, F.S., Biancardi, V., Kinkead, R., 2011. Hypercapnic ventilatory response of anesthetized female rats subjected to neonatal maternal separation: insight into the origins of panic attacks? Respir. Physiol. Neurobiol. 175, 288-295.

Elam, M., Yao, T., Thoren, P., Svensson, T.H., 1981. Hypercapnia and hypoxia: chemoreceptor-mediated control of locus coeruleus neurons and splanchnic, sympathetic nerves. Brain Res. 222, 373-381.

Enyedi, P., Czirjak, G., 2010. Molecular background of leak K+ currents: two-pore domain potassium channels. Physiol. Rev. 90, 559-605.

Erlichman, J.S., Hewitt, A., Damon, T.L., Hart, M., Kurascz, J., Li, A., Leiter, J.C., 2008. Inhibition of monocarboxylate transporter 2 in the retrotrapezoid nucleus in rats: a test of the astrocyte-neuron lactate-shuttle hypothesis. The Journal of neuroscience : the official journal of the Society for Neuroscience 28, 4888-4896.

Esquivel, G., Diaz-Galvis, J., Schruers, K., Berlanga, C., Lara-Munoz, C., Griez, E., 2008a. Acute exercise reduces the effects of a $35 \%$ CO2 challenge in patients with panic disorder. J. Affect. Disord. 107, 217-220.

Esquivel, G., Schruers, K., Griez, E., 2008b. Experimental models: panic and fear. In: Blanchard, RJ, Griebel, G, Nutt, DJ (eds), Handbook of Anxiety and Fear. Elsevier BV, Amsterdam. 413 - 435.

Esquivel, G., Schruers, K.R., Maddock, R.J., Colasanti, A., Griez, E.J., 2009. Acids in the brain: a factor in panic? J Psychopharmacol 24, 639-647.

Faravelli, C., Paionni, A., 2001. Panic Disorder: Clinical Course, Morbidity and Comorbidity. John Wiley \& Sons, Ltd, Chicester, UK.

Feinstein, J.S., Buzza, C., Hurlemann, R., Follmer, R.L., Dahdaleh, N.S., Coryell, W.H., Welsh, M.J., Tranel, D., Wemmie, J.A., 2013. Fear and panic in humans with bilateral amygdala damage. Nat. Neurosci. 16, $270-272$.

Filosa, J.A., Dean, J.B., Putnam, R.W., 2002. Role of intracellular and extracellular pH in the chemosensitive response of rat locus coeruleus neurones. J. Physiol. 541, 493-509.

Fleet, R., Foldes-Busque, G., Gregoire, J., Harel, F., Laurin, C., Burelle, D., Lavoie, K., 2014. A study of myocardial perfusion in patients with panic disorder and low risk coronary artery disease after $35 \% \mathrm{CO} 2$ challenge. $J$. Psychosom. Res. 76, 41-45.

Freedman, R.R., lanni, P., Ettedgui, E., Puthezhath, N., 1985. Ambulatory monitoring of panic disorder. Arch. Gen. Psychiatry 42, 244-248.

Freire, R.C., Nardi, A.E., 2012. Panic disorder and the respiratory system: clinical subtype and challenge tests. Revista brasileira de psiquiatria 34 Suppl 1, S32-41.

Freire, R.C., Valenca, A.M., Nascimento, I., Lopes, F.L., Mezzasalma, M.A., Zin, W.A., Nardi, A.E., 2007. Clinical features of respiratory and nocturnal panic disorder subtypes. Psychiatry Res. 152, 287-291.

Fyer, M.R., Uy, J., Martinez, J., Goetz, R., Klein, D.F., Fyer, A., Liebowitz, M.R., Gorman, J., 1987. CO2 challenge of patients with panic disorder. Am. J. Psychiatry 144, 1080-1082. 
Gardenswartz, C.A., Craske, M.G., 2001. Prevention of panic disorder. Behav. Ther. 32, 725-737.

Gater, R., Tansella, M., Korten, A., Tiemens, B.G., Mavreas, V.G., Olatawura, M.O., 1998. Sex differences in the prevalence and detection of depressive and anxiety disorders in general health care settings: report from the World Health Organization Collaborative Study on Psychological Problems in General Health Care. Arch. Gen. Psychiatry 55, 405-413.

Gestreau, C., Heitzmann, D., Thomas, J., Dubreuil, V., Bandulik, S., Reichold, M., Bendahhou, S., Pierson, P., Sterner, C., Peyronnet-Roux, J., Benfriha, C., Tegtmeier, I., Ehnes, H., Georgieff, M., Lesage, F., Brunet, J.F., Goridis, C., Warth, R., Barhanin, J., 2010. Task2 potassium channels set central respiratory CO2 and 02 sensitivity. Proc. Natl. Acad. Sci. U. S. A. 107, 2325-2330.

Gobbi, G., Murphy, D.L., Lesch, K., Blier, P., 2001. Modifications of the serotonergic system in mice lacking serotonin transporters: an in vivo electrophysiological study. J. Pharmacol. Exp. Ther. 296, 987-995.

Goddard, A.W., Sholomskas, D.E., Walton, K.E., Augeri, F.M., Charney, D.S., Heninger, G.R., Goodman, W.K., Price, L.H., 1994. Effects of tryptophan depletion in panic disorder. Biol. Psychiatry 36, 775-777.

Goossens, L., Leibold, N., Peeters, R., Esquivel, G., Knuts, I., Backes, W., Marcelis, M., Hofman, P., Griez, E., Schruers, K., 2014. Brainstem response to hypercapnia: A symptom provocation study into the pathophysiology of panic disorder. J Psychopharmacol.

Gorman, J.M., Fyer, M.R., Goetz, R., Askanazi, J., Liebowitz, M.R., Fyer, A.J., Kinney, J., Klein, D.F., 1988. Ventilatory physiology of patients with panic disorder. Arch. Gen. Psychiatry 45, 31-39.

Gorman, J.M., Martinez, J., Coplan, J.D., Kent, J., Kleber, M., 2004. The effect of successful treatment on the emotional and physiological response to carbon dioxide inhalation in patients with panic disorder. Biol. Psychiatry 56, 862-867.

Gorman, J.M., Papp, L.A., Coplan, J.D., Martinez, J.M., Lennon, S., Goetz, R.R., Ross, D., Klein, D.F., 1994. Anxiogenic effects of $\mathrm{CO} 2$ and hyperventilation in patients with panic disorder. Am. J. Psychiatry 151, 547553.

Gorman, J.M., Papp, L.A., Martinez, J., Goetz, R.R., Hollander, E., Liebowitz, M.R., Jordan, F., 1990. High-dose carbon dioxide challenge test in anxiety disorder patients. Biol. Psychiatry 28, 743-757.

Graeff, F.G., 1994. Neuroanatomy and neurotransmitter regulation of defensive behaviors and related emotions in mammals. Braz. J. Med. Biol. Res. 27, 811-829.

Graeff, F.G., Zangrossi, H., 2010. The hypothalamic-pituitary-adrenal axis in anxiety and panic. Psychol. Neurosci. 3.

Grassi, M., Caldirola, D., Vanni, G., Guerriero, G., Piccinni, M., Valchera, A., Perna, G., 2013. Baseline respiratory parameters in panic disorder: a meta-analysis. J. Affect. Disord. 146, 158-173.

Gregor, K.L., Zvolensky, M.J., 2008. Anxiety sensitivity and perceived control over anxiety-related events: evaluating the singular and interactive effects in the prediction of anxious and fearful responding to bodily sensations. Behav. Res. Ther. 46, 1017-1025.

Griez, E., de Loof, C., Pols, H., Zandbergen, J., Lousberg, H., 1990a. Specific sensitivity of patients with panic attacks to carbon dioxide inhalation. Psychiatry Res. 31, 193-199.

Griez, E., van denGriez, E., van den Hout, M.A., Verstappen, F., 1987a. Body fluids after CO2 inhalation: insight into panic mechanisms? Eur. Arch. Psychiatry Neurol. Sci. 236, 369-371.

Griez, E., Zandbergen, J., Pols, H., de Loof, C., 1990b. Response to 35\% CO2 as a marker of panic in severe anxiety. Am. J. Psychiatry 147, 796-797.

Griez, E.J., Colasanti, A., van Diest, R., Salamon, E., Schruers, K., 2007. Carbon dioxide inhalation induces dosedependent and age-related negative affectivity. PLoS One 2, e987.

Griez, E.J., Lousberg, H., van den Hout, M.A., van der Molen, G.M., 1987b. CO2 vulnerability in panic disorder. Psychiatry Res. 20, 87-95.

Guttmacher, L.B., Murphy, D.L., Insel, T.R., 1983. Pharmacologic models of anxiety. Compr. Psychiatry 24, 312326. 
Hendricks, T., Francis, N., Fyodorov, D., Deneris, E.S., 1999. The ETS domain factor Pet-1 is an early and precise marker of central serotonin neurons and interacts with a conserved element in serotonergic genes. $J$. Neurosci. 19, 10348-10356.

Hendricks, T.J., Fyodorov, D.V., Wegman, L.J., Lelutiu, N.B., Pehek, E.A., Yamamoto, B., Silver, J., Weeber, E.J., Sweatt, J.D., Deneris, E.S., 2003. Pet-1 ETS gene plays a critical role in 5-HT neuron development and is required for normal anxiety-like and aggressive behavior. Neuron 37, 233-247.

Hermans, D., De Cort, K., Noortman, D., Vansteenwegen, D., Beckers, T., Spruyt, A., Schruers, K., 2010. Priming associations between bodily sensations and catastrophic misinterpretations: Specific for panic disorder? Behav. Res. Ther. 48, 900-908.

Hettema, J.M., Neale, M.C., Kendler, K.S., 2001. A review and meta-analysis of the genetic epidemiology of anxiety disorders. The American journal of psychiatry 158, 1568-1578.

Hodges, M.R., Best, S., Richerson, G.B., 2011. Altered ventilatory and thermoregulatory control in male and female adult Pet-1 null mice. Respir. Physiol. Neurobiol. 177, 133-140.

Hodges, M.R., Opansky, C., Qian, B., Davis, S., Bonis, J., Bastasic, J., Leekley, T., Pan, L.G., Forster, H.V., 2004. Transient attenuation of $\mathrm{CO} 2$ sensitivity after neurotoxic lesions in the medullary raphe area of awake goats. J. Appl. Physiol. 97, 2236-2247.

Hodges, M.R., Tattersall, G.J., Harris, M.B., McEvoy, S.D., Richerson, D.N., Deneris, E.S., Johnson, R.L., Chen, Z.F., Richerson, G.B., 2008. Defects in breathing and thermoregulation in mice with near-complete absence of central serotonin neurons. J. Neurosci. 28, 2495-2505.

Holt, P.E., Andrews, G., 1989. Provocation of panic: three elements of the panic reaction in four anxiety disorders. Behav. Res. Ther. 27, 253-261.

Hood, S.D., Hince, D.A., Robinson, H., Cirillo, M., Christmas, D., Kaye, J.M., 2006. Serotonin regulation of the human stress response. Psychoneuroendocrinology 31, 1087-1097.

Hout, M.A., 1986. CO2 inhalation in the treatment of panic attacks. Behav. Res. Ther. 24, 145-150.

Hu, X.Z., Lipsky, R.H., Zhu, G., Akhtar, L.A., Taubman, J., Greenberg, B.D., Xu, K., Arnold, P.D., Richter, M.A., Kennedy, J.L., Murphy, D.L., Goldman, D., 2006. Serotonin transporter promoter gain-of-function genotypes are linked to obsessive-compulsive disorder. Am. J. Hum. Genet. 78, 815-826.

Ito, L.M., de Araujo, L.A., Tess, V.L., de Barros-Neto, T.P., Asbahr, F.R., Marks, I., 2001. Self-exposure therapy for panic disorder with agoraphobia: randomised controlled study of external v. interoceptive self-exposure. The British journal of psychiatry : the journal of mental science 178, 331-336.

Johnson, P.L., Federici, L.M., Shekhar, A., 2014. Etiology, triggers and neurochemical circuits associated with unexpected, expected, and laboratory-induced panic attacks. Neurosci. Biobehav. Rev.

Johnson, P.L., Fitz, S.D., Engleman, E.A., Svensson, K.A., Schkeryantz, J.M., Shekhar, A., 2013. Group II metabotropic glutamate receptor type 2 allosteric potentiators prevent sodium lactate-induced panic-like response in panic-vulnerable rats. J. Psychopharm. 27, 152-161.

Johnson, P.L., Fitz, S.D., Hollis, J.H., Moratalla, R., Lightman, S.L., Shekhar, A., Lowry, C.A., 2011. Induction of c-Fos in 'panic/defence'-related brain circuits following brief hypercarbic gas exposure. J Psychopharmacol 25, 26-36.

Johnson, P.L., Hollis, J.H., Moratalla, R., Lightman, S.L., Lowry, C.A., 2005. Acute hypercarbic gas exposure reveals functionally distinct subpopulations of serotonergic neurons in rats. J Psychopharmacol 19, 327-341.

Johnson, P.L., Molosh, A., Fitz, S.D., Truitt, W.A., Shekhar, A., 2012a. Orexin, stress, and anxiety/panic states. Prog. Brain Res. 198, 133-161.

Johnson, P.L., Samuels, B.C., Fitz, S.D., Lightman, S.L., Lowry, C.A., Shekhar, A., 2012b. Activation of the orexin 1 receptor is a critical component of CO2-mediated anxiety and hypertension but not bradycardia. Neuropsychopharmacology 37, 1911-1922.

Johnson, P.L., Truitt, W.A., Fitz, S.D., Lowry, C.A., Shekhar, A., 2008. Neural pathways underlying lactate-induced panic. Neuropsychopharmacology: official publication of the American College of Neuropsychopharmacology 33, 2093-2107. 
Kandel, E.R., Schwartz, J.H., Jessell, T.M., Siegelbaum, S.A., Hudspeth, A.J., 2012. Principles of Neural Science (Fifth edition). Mcgraw-Hill Companies, Inc.

Kaye, J., Buchanan, F., Kendrick, A., Johnson, P., Lowry, C., Bailey, J., Nutt, D., Lightman, S., 2004. Acute carbon dioxide exposure in healthy adults: evaluation of a novel means of investigating the stress response. $J$. Neuroendocrinol. 16, 256-264.

Kellenberger, S., Schild, L., 2002. Epithelial sodium channel/degenerin family of ion channels: a variety of functions for a shared structure. Physiol. Rev. 82, 735-767.

Kelly, M.M., Forsyth, J.P., Karekla, M., 2006. Sex differences in response to a panicogenic challenge procedure: an experimental evaluation of panic vulnerability in a non-clinical sample. Behav. Res. Ther. 44, 1421-1430.

Kent, J.M., Papp, L.A., Martinez, J.M., Browne, S.T., Coplan, J.D., Klein, D.F., Gorman, J.M., 2001. Specificity of panic response to $\mathrm{CO}(2)$ inhalation in panic disorder: a comparison with major depression and premenstrual dysphoric disorder. Am. J. Psychiatry 158, 58-67.

Kessler, R.C., Chiu, W.T., Jin, R., Ruscio, A.M., Shear, K., Walters, E.E., 2006. The epidemiology of panic attacks, panic disorder, and agoraphobia in the National Comorbidity Survey Replication. Arch. Gen. Psychiatry 63, 415-424.

Klaassen, T., Klumperbeek, J., Deutz, N.E., van Praag, H.M., Griez, E., 1998. Effects of tryptophan depletion on anxiety and on panic provoked by carbon dioxide challenge. Psychiatry Res. 77, 167-174.

Klein, D.F., 1993. False suffocation alarms, spontaneous panics, and related conditions. An integrative hypothesis. Arch. Gen. Psychiatry 50, 306-317.

Kondo, T., Kumagai, M., Ohta, Y., Bishop, B., 2000. Ventilatory responses to hypercapnia and hypoxia following chronic hypercapnia in the rat. Respir. Physiol. 122, 35-43.

Larnicol, N., Wallois, F., Berquin, P., Gros, F., Rose, D., 1994. c-fos-like immunoreactivity in the cat's neuraxis following moderate hypoxia or hypercapnia. J. Physiol. Paris $88,81-88$.

Lee, K., Noda, Y., Nakano, Y., Ogawa, S., Kinoshita, Y., Funayama, T., Furukawa, T.A., 2006. Interoceptive hypersensitivity and interoceptive exposure in patients with panic disorder: specificity and effectiveness. BMC Psychiatry 6, 32.

Leibold, N.K., Viechtbauer, W., Goossens, L., De Cort, K., Griez, E.J., Myin-Germeys, I., Steinbusch, H.W., van den Hove, D.L., Schruers, K.R., 2013. Carbon dioxide inhalation as a human experimental model of panic: the relationship between emotions and cardiovascular physiology. Biol. Psychol. 94, 331-340.

Lesch, K.P., Araragi, N., Waider, J., van den Hove, D., Gutknecht, L., 2012. Targeting brain serotonin synthesis: insights into neurodevelopmental disorders with long-term outcomes related to negative emotionality, aggression and antisocial behaviour. Philos. Trans. R. Soc. Lond. B Biol. Sci. 367, 2426-2443.

Lesch, K.P., Bengel, D., Heils, A., Sabol, S.Z., Greenberg, B.D., Petri, S., Benjamin, J., Muller, C.R., Hamer, D.H., Murphy, D.L., 1996. Association of anxiety-related traits with a polymorphism in the serotonin transporter gene regulatory region. Science 274, 1527-1531.

Lesch, K.P., Waider, J., 2012. Serotonin in the modulation of neural plasticity and networks: implications for neurodevelopmental disorders. Neuron 76, 175-191.

Li, A., Nattie, E., 2008. Serotonin transporter knockout mice have a reduced ventilatory response to hypercapnia (predominantly in males) but not to hypoxia. J. Physiol. 586, 2321-2329.

Lightman, S.L., Conway-Campbell, B.L., 2010. The crucial role of pulsatile activity of the HPA axis for continuous dynamic equilibration. Nat. Rev. Neurosci. 11, 710-718.

Lissek, S., Rabin, S., Heller, R.E., Lukenbaugh, D., Geraci, M., Pine, D.S., Grillon, C., 2010. Overgeneralization of conditioned fear as a pathogenic marker of panic disorder. Am. J. Psychiatry 167, 47-55.

Lissek, S., Rabin, S.J., McDowell, D.J., Dvir, S., Bradford, D.E., Geraci, M., Pine, D.S., Grillon, C., 2009. Impaired discriminative fear-conditioning resulting from elevated fear responding to learned safety cues among individuals with panic disorder. Behav. Res. Ther. 47, 111-118. 
Lueken, U., Straube, B., Konrad, C., Wittchen, H.U., Strohle, A., Wittmann, A., Pfleiderer, B., Uhlmann, C., Arolt, V., Jansen, A., Kircher, T., 2013. Neural substrates of treatment response to cognitive-behavioral therapy in panic disorder with agoraphobia. The American journal of psychiatry 170, 1345-1355.

Lueken, U., Straube, B., Reinhardt, I., Maslowski, N.I., Wittchen, H.U., Strohle, A., Wittmann, A., Pfleiderer, B., Konrad, C., Ewert, A., Uhlmann, C., Arolt, V., Jansen, A., Kircher, T., 2014. Altered top-down and bottom-up processing of fear conditioning in panic disorder with agoraphobia. Psychol. Med. 44, 381-394.

Maddock, R.J., Buonocore, M.H., Copeland, L.E., Richards, A.L., 2009. Elevated brain lactate responses to neural activation in panic disorder: a dynamic $1 \mathrm{H}-\mathrm{MRS}$ study. Mol. Psychiatry 14, 537-545.

Maltby, N., Mayers, M.F., Allen, G.J., Tolin, D.F., 2005. Anxiety sensitivity: stability in prospective research. J. Anxiety Disord. 19, 708-716.

Maron, E., Hettema, J.M., Shlik, J., 2010. Advances in molecular genetics of panic disorder. Mol. Psychiatry 15, 681-701.

Martinez, J.M., Coplan, J.D., Browne, S.T., Goetz, R., Welkowitz, L.A., Papp, L.A., Klein, D.F., Gorman, J.M., 1998. Hemodynamic response to respiratory challenges in panic disorder. J. Psychosom. Res. 44, 153-161.

McLean, C.P., Anderson, E.R., 2009. Brave men and timid women? A review of the gender differences in fear and anxiety. Clin. Psychol. Rev. 29, 496-505.

McNally, R.J., 2002. Anxiety sensitivity and panic disorder. Biol. Psychiatry 52, 938-946.

McNaughton, N., Corr, P.J., 2004. A two-dimensional neuropsychology of defense: fear/anxiety and defensive distance. Neurosci. Biobehav. Rev. 28, 285-305.

McNaughton, N., Gray, J.A., 2000. Anxiolytic action on the behavioural inhibition system implies multiple types of arousal contribute to anxiety. J. Affect. Disord. 61, 161-176.

Meiri, G., Ben-Zion, I.Z., Greenberg, B.D., Murphy, D.L., Benjamin, J., 2001. Influence of the serotonin antagonist, metergoline, on the anxiogenic effects of carbon dioxide, and on heart rate and neuroendocrine measures, in healthy volunteers. Hum Psychopharmacol 16, 237-245.

Mellman, T.A., Uhde, T.W., 1989. Electroencephalographic sleep in panic disorder. A focus on sleep-related panic attacks. Arch. Gen. Psychiatry 46, 178-184.

Mendlowicz, M.V., Stein, M.B., 2000. Quality of life in individuals with anxiety disorders. Am. J. Psychiatry 157, 669-682.

Meuret, A.E., Ritz, T., Wilhelm, F.H., Roth, W.T., 2005. Voluntary hyperventilation in the treatment of panic disorder--functions of hyperventilation, their implications for breathing training, and recommendations for standardization. Clin. Psychol. Rev. 25, 285-306.

Meuret, A.E., Rosenfield, D., Seidel, A., Bhaskara, L., Hofmann, S.G., 2010. Respiratory and cognitive mediators of treatment change in panic disorder: evidence for intervention specificity. J. Consult. Clin. Psychol. 78, 691-704.

Meuret, A.E., Wilhelm, F.H., Ritz, T., Roth, W.T., 2003. Breathing training for treating panic disorder. Useful intervention or impediment? Behav. Modif. 27, 731-754.

Meuret, A.E., Wilhelm, F.H., Ritz, T., Roth, W.T., 2008. Feedback of end-tidal pCO2 as a therapeutic approach for panic disorder. J. Psychiatr. Res. 42, 560-568.

Meuret, A.E., Wilhelm, F.H., Roth, W.T., 2001. Respiratory biofeedback-assisted therapy in panic disorder. Behav. Modif. 25, 584-605.

Michael, T., Blechert, J., Vriends, N., Margraf, J., Wilhelm, F.H., 2007. Fear conditioning in panic disorder: Enhanced resistance to extinction. J. Abnorm. Psychol. 116, 612-617.

Miller, H.E., Deakin, J.F., Anderson, I.M., 2000. Effect of acute tryptophan depletion on CO2-induced anxiety in patients with panic disorder and normal volunteers. Br. J. Psychiatry 176, 182-188.

Mobbs, D., Petrovic, P., Marchant, J.L., Hassabis, D., Weiskopf, N., Seymour, B., Dolan, R.J., Frith, C.D., 2007. When fear is near: threat imminence elicits prefrontal-periaqueductal gray shifts in humans. Science 317, 1079-1083. 
Mueller, R.A., Towle, A.C., Breese, G.R., 1984. Supersensitivity to the respiratory stimulatory effect of TRH in 5,7-dihydroxytryptamine-treated rats. Brain Res. 298, 370-373.

Mulkey, D.K., Stornetta, R.L., Weston, M.C., Simmons, J.R., Parker, A., Bayliss, D.A., Guyenet, P.G., 2004. Respiratory control by ventral surface chemoreceptor neurons in rats. Nat. Neurosci. 7, 1360-1369.

Mulkey, D.K., Talley, E.M., Stornetta, R.L., Siegel, A.R., West, G.H., Chen, X., Sen, N., Mistry, A.M., Guyenet, P.G., Bayliss, D.A., 2007. TASK channels determine $\mathrm{pH}$ sensitivity in select respiratory neurons but do not contribute to central respiratory chemosensitivity. The Journal of neuroscience : the official journal of the Society for Neuroscience 27, 14049-14058.

Nakamura, M., Ueno, S., Sano, A., Tanabe, H., 2000. The human serotonin transporter gene linked polymorphism (5-HTTLPR) shows ten novel allelic variants. Mol. Psychiatry 5, 32-38.

Nakashima, K., Yamashita, T., Kashiwagi, S., Nakayama, N., Kitahara, T., Ito, H., 1996. The effect of sodium bicarbonate on CBF and intracellular pH in man: stable Xe-CT and 31P-MRS. Acta Neurol. Scand. Suppl. 166, 96-98.

Naragon-Gainey, K., 2010. Meta-analysis of the relations of anxiety sensitivity to the depressive and anxiety disorders. Psychol. Bull. 136, 128-150.

Nardi, A.E., Valenca, A.M., Lopes, F.L., de-Melo-Neto, V.L., Freire, R.C., Veras, A.B., Nascimento, I., King, A.L., Soares-Filho, G.L., Mezzasalma, M.A., Zin, W.A., 2007. Caffeine and 35\% carbon dioxide challenge tests in panic disorder. Hum Psychopharmacol 22, 231-240.

Nardi, A.E., Valenca, A.M., Lopes, F.L., Nascimento, I., Veras, A.B., Freire, R.C., Mezzasalma, M.A., de-MeloNeto, V.L., Zin, W.A., 2006. Psychopathological profile of $35 \% \mathrm{CO} 2$ challenge test-induced panic attacks: a comparison with spontaneous panic attacks. Compr. Psychiatry 47, 209-214.

Nardi, A.E., Valenca, A.M., Zin, W., Nascimento, I., 1999. Carbon dioxide induced panic attacks and short term clonazepam treatment. Preliminary study. Arq. Neuropsiquiatr. 57, 361-365.

Nattie, E., 2006. Why do we have both peripheral and central chemoreceptors? J. Appl. Physiol. 100, 9-10.

Nattie, E.E., Li, A., 2001. CO2 dialysis in the medullary raphe of the rat increases ventilation in sleep. J. Appl. Physiol. 90, 1247-1257.

Nattie, E.E., Li, A., Richerson, G.B., Lappi, D.A., 2004. Medullary serotonergic neurones and adjacent neurones that express neurokinin-1 receptors are both involved in chemoreception in vivo. J. Physiol. 556, 235-253.

Niblock, M.M., Gao, H., Li, A., Jeffress, E.C., Murphy, M., Nattie, E.E., 2010. Fos-Tau-LacZ mice reveal sex differences in brainstem c-fos activation in response to mild carbon dioxide exposure. Brain Res. 1311, 51-63.

Niccolai, V., van Duinen, M.A., Griez, E.J., 2008. Objective and subjective measures in recovery from a $35 \%$ carbon dioxide challenge. Can. J. Psychiatry. 53, 737-744.

Nillni, Y.I., Berenz, E.C., Rohan, K.J., Zvolensky, M.J., 2012. Sex differences in panic-relevant responding to a $10 \%$ carbon dioxide-enriched air biological challenge. J. Anxiety Disord. 26, 165-172.

Norton, P.J., Zvolensky, M.J., Bonn-Miller, M.O., Cox, B.J., Norton, G.R., 2008. Use of the Panic Attack Questionnaire-IV to assess non-clinical panic attacks and limited symptom panic attacks in student and community samples. J. Anxiety Disord. 22, 1159-1171.

Okada, Y., Chen, Z., Jiang, W., Kuwana, S., Eldridge, F.L., 2002. Anatomical arrangement of hypercapnia-activated cells in the superficial ventral medulla of rats. J. Appl. Physiol. 93, 427-439.

Olsson, M., Annerbrink, K., Bengtsson, F., Hedner, J., Eriksson, E., 2004. Paroxetine influences respiration in rats: implications for the treatment of panic disorder. Eur. Neuropsychopharmacol. 14, 29-37.

Oyamada, Y., Ballantyne, D., Muckenhoff, K., Scheid, P., 1998. Respiration-modulated membrane potential and chemosensitivity of locus coeruleus neurones in the in vitro brainstem-spinal cord of the neonatal rat. $J$. Physiol. 513 ( Pt 2), 381-398.

Pane-Farre, C.A., Stender, J.P., Fenske, K., Deckert, J., Reif, A., John, U., Schmidt, C.O., Schulz, A., Lang, T., Alpers, G.W., Kircher, T., Vossbeck-Elsebusch, A.N., Grabe, H.J., Hamm, A.O., 2014. The phenomenology of the first panic attack in clinical and community-based samples. J. Anxiety Disord. 28, 522-529. 
Papadopoulos, A., Rich, A., Nutt, D.J., Bailey, J.E., 2010. The effects of single dose anxiolytic medication on the $\mathrm{CO} 2$ models of anxiety: differentiation of subjective and objective measures. J Psychopharmacol 24, 649656.

Papp, L.A., Klein, D.F., Martinez, J., Schneier, F., Cole, R., Liebowitz, M.R., Hollander, E., Fyer, A.J., Jordan, F., Gorman, J.M., 1993. Diagnostic and substance specificity of carbon-dioxide-induced panic. Am. J. Psychiatry $150,250-257$.

Papp, L.A., Martinez, J.M., Klein, D.F., Coplan, J.D., Norman, R.G., Cole, R., de Jesus, M.J., Ross, D., Goetz, R., Gorman, J.M., 1997. Respiratory psychophysiology of panic disorder: three respiratory challenges in 98 subjects. Am. J. Psychiatry 154, 1557-1565.

Papp, L.A., Welkowitz, L.A., Martinez, J.M., Klein, D.F., Browne, S., Gorman, J.M., 1995. Instructional set does not alter outcome of respiratory challenges in panic disorder. Biol. Psychiatry 38, 826-830.

Pappens, M., Smets, E., Vansteenwegen, D., Van Den Bergh, O., Van Diest, I., 2012. Learning to fear suffocation: a new paradigm for interoceptive fear conditioning. Psychophysiology 49, 821-828.

Paul, E.D., Johnson, P.L., Shekhar, A., Lowry, C.A., 2014. The Deakin/Graeff hypothesis: Focus on serotonergic inhibition of panic. Neurosci. Biobehav. Rev.

Perna, G., Barbini, B., Cocchi, S., Bertani, A., Gasperini, M., 1995a. 35\% CO2 challenge in panic and mood disorders. J. Affect. Disord. 33, 189-194.

Perna, G., Battaglia, M., Garberi, A., Arancio, C., Bertani, A., Bellodi, L., 1994a. Carbon dioxide/oxygen challenge test in panic disorder. Psychiatry Res. 52, 159-171.

Perna, G., Bertani, A., Arancio, C., Ronchi, P., Bellodi, L., 1995b. Laboratory response of patients with panic and obsessive-compulsive disorders to 35\% CO2 challenges. Am. J. Psychiatry 152, 85-89.

Perna, G., Bertani, A., Caldirola, D., Bellodi, L., 1996. Family history of panic disorder and hypersensitivity to CO2 in patients with panic disorder. Am. J. Psychiatry 153, 1060-1064.

Perna, G., Bertani, A., Caldirola, D., Di Pasquale, D., Migliarese, G., Bellodi, L., 2004a. Modulation of hyperreactivity to $35 \% \mathrm{CO} 2$ after one week of treatment with paroxetine and reboxetine: a double-blind, randomized study. J. Clin. Psychopharmacol. 24, 277-282.

Perna, G., Bertani, A., Caldirola, D., Gabriele, A., Cocchi, S., Bellodi, L., 2002. Antipanic drug modulation of 35\% CO2 hyperreactivity and short-term treatment outcome. J. Clin. Psychopharmacol. 22, 300-308.

Perna, G., Bertani, A., Gabriele, A., Politi, E., Bellodi, L., 1997. Modification of 35\% carbon dioxide hypersensitivity across one week of treatment with clomipramine and fluvoxamine: a double-blind, randomized, placebocontrolled study. J. Clin. Psychopharmacol. 17, 173-178.

Perna, G., Bussi, R., Allevi, L., Bellodi, L., 1999a. Sensitivity to 35\% carbon dioxide in patients with generalized anxiety disorder. J. Clin. Psychiatry 60, 379-384.

Perna, G., Caldirola, D., Namia, C., Cucchi, M., Vanni, G., Bellodi, L., 2004b. Language of dyspnea in panic disorder. Depress. Anxiety 20, 32-38.

Perna, G., Cocchi, S., Allevi, L., Bussi, R., Bellodi, L., 1999b. A long-term prospective evaluation of first-degree relatives of panic patients who underwent the 35\% CO2 challenge. Biol. Psychiatry 45, 365-367.

Perna, G., Cocchi, S., Bertani, A., Arancio, C., Bellodi, L., 1994b. Pharmacologic effect of toloxatone on reactivity to the $35 \%$ carbon dioxide challenge: a single-blind, random, placebo-controlled study. J. Clin. Psychopharmacol. 14, 414-418.

Perna, G., di Bella, D., Favaron, E., Cucchi, M., Liperi, L., Bellodi, L., 2004c. Lack of relationship between CO2 reactivity and serotonin transporter gene regulatory region polymorphism in panic disorder. Am. J. Med. Genet. B Neuropsychiatr. Genet. 129B, 41-43.

Perna, G., Gabriele, A., Caldirola, D., Bellodi, L., 1995c. Hypersensitivity to inhalation of carbon dioxide and panic attacks. Psychiatry Res. 57, 267-273.

Pete, G., Mack, S.O., Haxhiu, M.A., Walbaum, S., Gauda, E.B., 2002. CO(2)-induced c-Fos expression in brainstem preprotachykinin mRNA containing neurons. Respir. Physiol. Neurobiol. 130, 265-274. 
Pfleiderer, B., Zinkirciran, S., Arolt, V., Heindel, W., Deckert, J., Domschke, K., 2007. fMRI amygdala activation during a spontaneous panic attack in a patient with panic disorder. The world journal of biological psychiatry : the official journal of the World Federation of Societies of Biological Psychiatry 8, 269-272.

Pineda, J., Aghajanian, G.K., 1997. Carbon dioxide regulates the tonic activity of locus coeruleus neurons by modulating a proton- and polyamine-sensitive inward rectifier potassium current. Neuroscience 77, 723743.

Pols, H., Zandbergen, J., de Loof, C., Griez, E., 1991. Attenuation of carbon dioxide-induced panic after clonazepam treatment. Acta Psychiatr. Scand. 84, 585-586.

Pols, H.J., Hauzer, R.C., Meijer, J.A., Verburg, K., Griez, E.J., 1996. Fluvoxamine attenuates panic induced by $35 \%$ CO2 challenge. J. Clin. Psychiatry 57, 539-542.

Poma, S.Z., Merlo-Pich, E., Bettica, P., Bani, M., Fina, P., Ziviani, L., Milleri, S., 2013. Anxiolytic effects of vestipitant in a sub-group of healthy volunteers known to be sensitive to $\mathrm{CO} 2$ challenge. J. Psychopharm.

Poma, S.Z., Milleri, S., Squassante, L., Nucci, G., Bani, M., Perini, G.I., Merlo-Pich, E., 2005. Characterization of a $7 \%$ carbon dioxide ( $\mathrm{CO} 2$ ) inhalation paradigm to evoke anxiety symptoms in healthy subjects. $J$ Psychopharmacol 19, 494-503.

Poonai, N., Antony, M.M., Binkley, K.E., Stenn, P., Swinson, R.P., Corey, P., Silverman, F.S., Tarlo, S.M., 2000. Carbon dioxide inhalation challenges in idiopathic environmental intolerance. J. Allergy Clin. Immunol. 105, 358-363.

Preter, M., Klein, D.F., 2008. Panic, suffocation false alarms, separation anxiety and endogenous opioids. Prog. Neuropsychopharmacol. Biol. Psychiatry 32, 603-612.

Price, M.P., Gong, H., Parsons, M.G., Kundert, J.R., Reznikov, L.R., Bernardinelli, L., Chaloner, K., Buchanan, G.F., Wemmie, J.A., Richerson, G.B., Cassell, M.D., Welsh, M.J., 2014. Localization and behaviors in null mice suggest that ASIC1 and ASIC2 modulate responses to aversive stimuli. Genes, brain, and behavior 13, 179194.

Putnam, R.W., Filosa, J.A., Ritucci, N.A., 2004. Cellular mechanisms involved in $\mathrm{CO}(2)$ and acid signaling in chemosensitive neurons. Am. J. Physiol. Cell Physiol. 287, C1493-1526.

Rapee, R.M., Telfer, L.A., Barlow, D.H., 1991. The role of safety cues in mediating the response to inhalations of CO2 in agoraphobics. Behav. Res. Ther. 29, 353-355.

Rassovsky, Y., Kushner, M.G., 2003. Carbon dioxide in the study of panic disorder: issues of definition, methodology, and outcome. J. Anxiety Disord. 17, 1-32.

Ravindran, L.N., Stein, M.B., 2010. The pharmacologic treatment of anxiety disorders: a review of progress. The Journal of clinical psychiatry 71, 839-854.

Reiss, S., 1997. Trait anxiety: it's not what you think it is. J. Anxiety Disord. 11, 201-214.

Richerson, G.B., 1995. Response to CO2 of neurons in the rostral ventral medulla in vitro. J. Neurophysiol. 73, 933-944.

Richerson, G.B., 2004. Serotonergic neurons as carbon dioxide sensors that maintain pH homeostasis. Nat. Rev. Neurosci. 5, 449-461.

Richerson, G.B., Buchanan, G.F., 2011. The serotonin axis: Shared mechanisms in seizures, depression, and SUDEP. Epilepsia 52 Suppl 1, 28-38.

Richey, J.A., Schmidt, N.B., Hofmann, S.G., Timpano, K.R., 2010. Temporal and structural dynamics of anxiety sensitivity in predicting fearful responding to a 35\% CO2 challenge. J. Anxiety Disord. 24, 423-432.

Roberson-Nay, R., Moruzzi, S., Ogliari, A., Pezzica, E., Tambs, K., Kendler, K.S., Battaglia, M., 2013. Evidence for distinct genetic effects associated with response to 35\% CO(2). Depress. Anxiety 30, 259-266.

Salvador-Carulla, L., Segui, J., Fernandez-Cano, P., Canet, J., 1995. Costs and offset effect in panic disorders. The British journal of psychiatry. Supplement, 23-28.

Sanderson, W.C., Rapee, R.M., Barlow, D.H., 1989. The influence of an illusion of control on panic attacks induced via inhalation of 5.5\% carbon dioxide-enriched air. Arch. Gen. Psychiatry 46, 157-162. 
Sanderson, W.C., Wetzler, S., Asnis, G.M., 1994. Alprazolam blockade of CO2-provoked panic in patients with panic disorder. Am. J. Psychiatry 151, 1220-1222.

Sanna, E., Cuccheddu, T., Serra, M., Concas, A., Biggio, G., 1992. Carbon dioxide inhalation reduces the function of GABAA receptors in the rat brain. Eur. J. Pharmacol. 216, 457-458.

Sarisoy, G., Boke, O., Arik, A.C., Sahin, A.R., 2008. Panic disorder with nocturnal panic attacks: symptoms and comorbidities. European psychiatry : the journal of the Association of European Psychiatrists 23, 195-200.

Sasaki, I., Akiyoshi, J., Sakurai, R., Tsutsumi, T., Ono, H., Yamada, K., Fujii, I., 1996. Carbon dioxide induced panic attack in panic disorder in Japan. Prog. Neuropsychopharmacol. Biol. Psychiatry 20, 1145-1157.

Schmidt, N.B., Eggleston, A.M., Woolaway-Bickel, K., Fitzpatrick, K.K., Vasey, M.W., Richey, J.A., 2007a. Anxiety Sensitivity Amelioration Training (ASAT): a longitudinal primary prevention program targeting cognitive vulnerability. J. Anxiety Disord. 21, 302-319.

Schmidt, N.B., Maner, J.K., Zvolensky, M.J., 2007b. Reactivity to challenge with carbon dioxide as a prospective predictor of panic attacks. Psychiatry Res. 151, 173-176.

Schmidt, N.B., Storey, J., Greenberg, B.D., Santiago, H.T., Li, Q., Murphy, D.L., 2000. Evaluating gene x psychological risk factor effects in the pathogenesis of anxiety: a new model approach. J. Abnorm. Psychol. 109, 308-320.

Schmidt, N.B., Trakowski, J.H., Staab, J.P., 1997. Extinction of panicogenic effects of a $35 \% \mathrm{CO} 2$ challenge in patients with panic disorder. J. Abnorm. Psychol. 106, 630-638.

Schmidt, N.B., Zvolensky, M.J., 2007. Anxiety sensitivity and CO2 challenge reactivity as unique and interactive prospective predictors of anxiety pathology. Depress. Anxiety 24, 527-536.

Schneider, R., Schulte, D., 2007. Panic patients reveal idiographic associations between anxiety symptoms and catastrophes in a semantic priming task. Behav. Res. Ther. 45, 211-223.

Schruers, K., Esquivel, G., van Duinen, M., Wichers, M., Kenis, G., Colasanti, A., Knuts, I., Goossens, L., Jacobs, N., van Rozendaal, J., Smeets, H., van Os, J., Griez, E., 2011. Genetic moderation of CO2-induced fear by 5-HTTLPR genotype. J Psychopharmacol 25, 37-42.

Schruers, K., Griez, E., 2004. The effects of tianeptine or paroxetine on 35\% CO2 provoked panic in panic disorder. J. Psychopharm. 18, 553-558.

Schruers, K., Klaassen, T., Pols, H., Overbeek, T., Deutz, N.E., Griez, E., 2000. Effects of tryptophan depletion on carbon dioxide provoked panic in panic disorder patients. Psychiatry Res. 93, 179-187.

Schruers, K., van de Mortel, H., Overbeek, T., Griez, E., 2004. Symptom profiles of natural and laboratory panic attacks. Acta Neuropsychiatr 16, 101-106.

Schruers, K., van Diest, R., Overbeek, T., Griez, E., 2002. Acute L-5-hydroxytryptophan administration inhibits carbon dioxide-induced panic in panic disorder patients. Psychiatry Res. 113, 237-243.

Schuchmann, S., Schmitz, D., Rivera, C., Vanhatalo, S., Salmen, B., Mackie, K., Sipila, S.T., Voipio, J., Kaila, K., 2006. Experimental febrile seizures are precipitated by a hyperthermia-induced respiratory alkalosis. Nat. Med. $12,817-823$.

Schutters, S.I., Viechtbauer, W., Knuts, I.J., Griez, E.J., Schruers, K.R., 2012. 35\% CO2 sensitivity in social anxiety disorder. J Psychopharmacol 26, 479-486.

Severson, C.A., Wang, W., Pieribone, V.A., Dohle, C.I., Richerson, G.B., 2003. Midbrain serotonergic neurons are central pH chemoreceptors. Nat. Neurosci. 6, 1139-1140.

Sherwood, T.W., Frey, E.N., Askwith, C.C., 2012. Structure and activity of the acid-sensing ion channels. Am. J. Physiol. Cell Physiol. 303, C699-710.

Sinha, S.S., Coplan, J.D., Pine, D.S., Martinez, J.A., Klein, D.F., Gorman, J.M., 1999. Panic induced by carbon dioxide inhalation and lack of hypothalamic-pituitary-adrenal axis activation. Psychiatry Res. 86, 93-98.

Smoller, J.W., Gallagher, P.J., Duncan, L.E., McGrath, L.M., Haddad, S.A., et al., 2014. The Human Ortholog of AcidSensing Ion Channel Gene ASIC1a Is Associated with Panic Disorder and Amygdala Structure and Function. Biol. Psychiatry. 76, 902-910. 
Sobczak, S., Schruers, K., 2014. Can formulation affect tryptophan depletion results? Hints from studies in experimental panic. J. Psychopharm. 28, 486-490.

Stein, M.B., Jang, K.L., Livesley, W.J., 1999. Heritability of anxiety sensitivity: a twin study. The American journal of psychiatry 156, 246-251.

Talesnik, B., Berzak, E., Ben-Zion, I., Kaplan, Z., Benjamin, J., 2007. Sensitivity to carbon dioxide in drug-naive subjects with post-traumatic stress disorder. J. Psychiatr. Res. 41, 451-454.

Talley, E.M., Lei, Q., Sirois, J.E., Bayliss, D.A., 2000. TASK-1, a two-pore domain K+ channel, is modulated by multiple neurotransmitters in motoneurons. Neuron 25, 399-410.

Talley, E.M., Solorzano, G., Lei, Q., Kim, D., Bayliss, D.A., 2001. Cns distribution of members of the two-poredomain (KCNK) potassium channel family. The Journal of neuroscience : the official journal of the Society for Neuroscience 21, 7491-7505.

Taylor, C.B., Sheikh, J., Agras, W.S., Roth, W.T., Margraf, J., Ehlers, A., Maddock, R.J., Gossard, D., 1986. Ambulatory heart rate changes in patients with panic attacks. The American journal of psychiatry 143, 478-482.

Telch, M.J., Harrington, P.J., Smits, J.A., Powers, M.B., 2011. Unexpected arousal, anxiety sensitivity, and their interaction on $\mathrm{CO}(2)$-induced panic: further evidence for the context-sensitivity vulnerability model. $J$. Anxiety Disord. 25, 645-653.

Telch, M.J., Smits, J.A., Brown, M., Dement, M., Powers, M.B., Lee, H., Pai, A., 2010. Effects of threat context and cardiac sensitivity on fear responding to a $35 \% \mathrm{CO} 2$ challenge: a test of the context-sensitivity panic vulnerability model. J. Behav. Ther. Exp. Psychiatry 41, 365-372.

Teppema, L.J., Veening, J.G., Kranenburg, A., Dahan, A., Berkenbosch, A., Olievier, C., 1997. Expression of c-fos in the rat brainstem after exposure to hypoxia and to normoxic and hyperoxic hypercapnia. The Journal of comparative neurology 388, 169-190.

Tilli, V., Suominen, K., Karlsson, H., 2012. Panic disorder in primary care: comorbid psychiatric disorders and their persistence. Scand. J. Prim. Health Care 30, 247-253.

Trapp, S., Aller, M.I., Wisden, W., Gourine, A.V., 2008. A role for TASK-1 (KCNK3) channels in the chemosensory control of breathing. The Journal of neuroscience : the official journal of the Society for Neuroscience 28, 8844-8850.

Valenca, A.M., Nardi, A.E., Nascimento, I., Mezzasalma, M.A., Lopes, F.L., Zin, W., 2000. Double-blind clonazepam vs placebo in panic disorder treatment. Arq. Neuropsiquiatr. 58, 1025-1029.

Valenca, A.M., Nardi, A.E., Nascimento, I., Zi, W.A., Versiani, M., 2002a. Respiratory panic disorder subtype and sensitivity to the carbon dioxide challenge test. Braz. J. Med. Biol. Res. 35, 783-788.

Valenca, A.M., Nardi, A.E., Nascimento, I., Zin, W.A., Versiani, M., 2002b. Carbon dioxide test as an additional clinical measure of treatment response in panic disorder. Arq. Neuropsiquiatr. 60, 358-361.

van Beek, N., Griez, E., 2000. Reactivity to a 35\% CO2 challenge in healthy first-degree relatives of patients with panic disorder. Biol. Psychiatry 47, 830-835.

van Beek, N., Perna, G., Schruers, K., Verburg, K., Cucchi, M., Bellodi, L., Griez, E., 2003. Vulnerability to $35 \%$ CO2 of panic disorder patients with a history of respiratory disorders. Psychiatry Res. 120, 125-130.

van den Hout, M.A., Griez, E., 1984. Panic symptoms after inhalation of carbon dioxide. Br. J. Psychiatry 144, 503-507.

van den Hout, M.A., van der Molen, G.M., Griez, E., Lousberg, H., Nansen, A., 1987. Reduction of CO2-induced anxiety in patients with panic attacks after repeated CO2 exposure. Am. J. Psychiatry 144, 788-791.

van Duinen, M.A., Schruers, K.R., Jaegers, E., Maes, M., Griez, E.J., 2004a. Hypothalamic-pituitary-adrenal axis function following a 35\% CO2 inhalation in healthy volunteers. Prog. Neuropsychopharmacol. Biol. Psychiatry 28, 279-283.

van Duinen, M.A., Schruers, K.R., Jaegers, E., Maes, M., Griez, E.J., 2004b. Salivary cortisol in panic: are males more vulnerable? Neuro Endocrinol. Lett. 25, 386-390. 
van Duinen, M.A., Schruers, K.R., Maes, M., Griez, E.J., 2005. CO2 challenge results in hypothalamic-pituitaryadrenal activation in healthy volunteers. J Psychopharmacol 19, 243-247.

van Duinen, M.A., Schruers, K.R., Maes, M., Griez, E.J., 2007. CO2 challenge induced HPA axis activation in panic. Int. J. Neuropsychopharmacol. 10, 797-804.

Veasey, S.C., Fornal, C.A., Metzler, C.W., Jacobs, B.L., 1995. Response of serotonergic caudal raphe neurons in relation to specific motor activities in freely moving cats. J. Neurosci. 15, 5346-5359.

Veasey, S.C., Fornal, C.A., Metzler, C.W., Jacobs, B.L., 1997. Single-unit responses of serotonergic dorsal raphe neurons to specific motor challenges in freely moving cats. Neuroscience 79, 161-169.

Verburg, C., Griez, E., Meijer, J., 1994. A 35\% carbon dioxide challenge in simple phobias. Acta Psychiatr. Scand. 90, 420-423.

Verburg, K., Griez, E., Meijer, J., Pols, H., 1995. Discrimination between panic disorder and generalized anxiety disorder by 35\% carbon dioxide challenge. Am. J. Psychiatry 152, 1081-1083.

Verburg, K., Pols, H., de Leeuw, M., Griez, E., 1998. Reliability of the 35\% carbon dioxide panic provocation challenge. Psychiatry Res. 78, 207-214.

Verschoor, E., Markus, C.R., 2011. Physiological and affective reactivity to a $35 \% \mathrm{CO}(2)$ inhalation challenge in individuals differing in the 5-HTTLPR genotype and trait neuroticism. Eur. Neuropsychopharmacol.

Wang, W., Pizzonia, J.H., Richerson, G.B., 1998. Chemosensitivity of rat medullary raphe neurones in primary tissue culture. J. Physiol. 511 ( Pt 2), 433-450.

Wang, W., Tiwari, J.K., Bradley, S.R., Zaykin, R.V., Richerson, G.B., 2001. Acidosis-stimulated neurons of the medullary raphe are serotonergic. J. Neurophysiol. 85, 2224-2235.

Washburn, C.P., Sirois, J.E., Talley, E.M., Guyenet, P.G., Bayliss, D.A., 2002. Serotonergic raphe neurons express TASK channel transcripts and a TASK-like $\mathrm{pH}$ - and halothane-sensitive $\mathrm{K}+$ conductance. The Journal of neuroscience : the official journal of the Society for Neuroscience 22, 1256-1265.

Wedekind, D., Bandelow, B., Broocks, A., Hajak, G., Ruther, E., 2000. Salivary, total plasma and plasma free cortisol in panic disorder. J. Neural Transm. 107, 831-837.

Welkowitz, L.A., Papp, L., Martinez, J., Browne, S., Gorman, J.M., 1999. Instructional set and physiological response to $\mathrm{CO} 2$ inhalation. Am. J. Psychiatry 156, 745-748.

Wemmie, J.A., 2011. Neurobiology of panic and $\mathrm{pH}$ chemosensation in the brain. Dialogues in clinical neuroscience $13,475-483$.

Wemmie, J.A., Askwith, C.C., Lamani, E., Cassell, M.D., Freeman, J.H., Jr., Welsh, M.J., 2003. Acid-sensing ion channel 1 is localized in brain regions with high synaptic density and contributes to fear conditioning. $J$. Neurosci. 23, 5496-5502.

Wetherell, M.A., Crown, A.L., Lightman, S.L., Miles, J.N., Kaye, J., Vedhara, K., 2006. The four-dimensional stress test: psychological, sympathetic-adrenal-medullary, parasympathetic and hypothalamic-pituitary-adrenal responses following inhalation of 35\% CO2. Psychoneuroendocrinology 31, 736-747.

Williams, R.H., Jensen, L.T., Verkhratsky, A., Fugger, L., Burdakov, D., 2007. Control of hypothalamic orexin neurons by acid and CO2. Proc. Natl. Acad. Sci. U. S. A. 104, 10685-10690.

Wittchen, H.U., Essau, C.A., 1993. Epidemiology of panic disorder: progress and unresolved issues. J. Psychiatr. Res. 27 Suppl 1, 47-68.

Woods, S.W., Charney, D.S., Goodman, W.K., Heninger, G.R., 1988. Carbon dioxide-induced anxiety. Behavioral, physiologic, and biochemical effects of carbon dioxide in patients with panic disorders and healthy subjects. Arch. Gen. Psychiatry 45, 43-52.

Woods, S.W., Charney, D.S., McPherson, C.A., Gradman, A.H., Heninger, G.R., 1987. Situational panic attacks. Behavioral, physiologic, and biochemical characterization. Arch. Gen. Psychiatry 44, 365-375.

Xiong, Z.G., Zhu, X.M., Chu, X.P., Minami, M., Hey, J., Wei, W.L., MacDonald, J.F., Wemmie, J.A., Price, M.P., Welsh, M.J., Simon, R.P., 2004. Neuroprotection in ischemia: blocking calcium-permeable acid-sensing ion channels. Cell 118, 687-698. 
Yartz, A.R., Zvolensky, M.J., Bernstein, A., Bonn-Miller, M.O., Lejuez, C.W., 2008. Panic-relevant predictability preferences: a laboratory test. J. Abnorm. Psychol. 117, 242-246.

Yermolaieva, O., Leonard, A.S., Schnizler, M.K., Abboud, F.M., Welsh, M.J., 2004. Extracellular acidosis increases neuronal cell calcium by activating acid-sensing ion channel 1a. Proc. Natl. Acad. Sci. U. S. A. 101, 6752-6757.

Zaubler, T.S., Katon, W., 1998. Panic disorder in the general medical setting. J. Psychosom. Res. 44, 25-42.

Zhao, Z.Q., Scott, M., Chiechio, S., Wang, J.S., Renner, K.J., Gereau, R.W.t., Johnson, R.L., Deneris, E.S., Chen, Z.F., 2006. Lmx1b is required for maintenance of central serotonergic neurons and mice lacking central serotonergic system exhibit normal locomotor activity. J. Neurosci. 26, 12781-12788.

Ziemann, A.E., Allen, J.E., Dahdaleh, N.S., Drebot, II, Coryell, M.W., Wunsch, A.M., Lynch, C.M., Faraci, F.M., Howard, M.A., 3rd, Welsh, M.J., Wemmie, J.A., 2009. The amygdala is a chemosensor that detects carbon dioxide and acidosis to elicit fear behavior. Cell 139, 1012-1021.

Ziemann, A.E., Schnizler, M.K., Albert, G.W., Severson, M.A., Howard, M.A., 3rd, Welsh, M.J., Wemmie, J.A., 2008. Seizure termination by acidosis depends on ASIC1a. Nat. Neurosci. 11, 816-822. 
The brain acid-base homeostasis and serotonin 


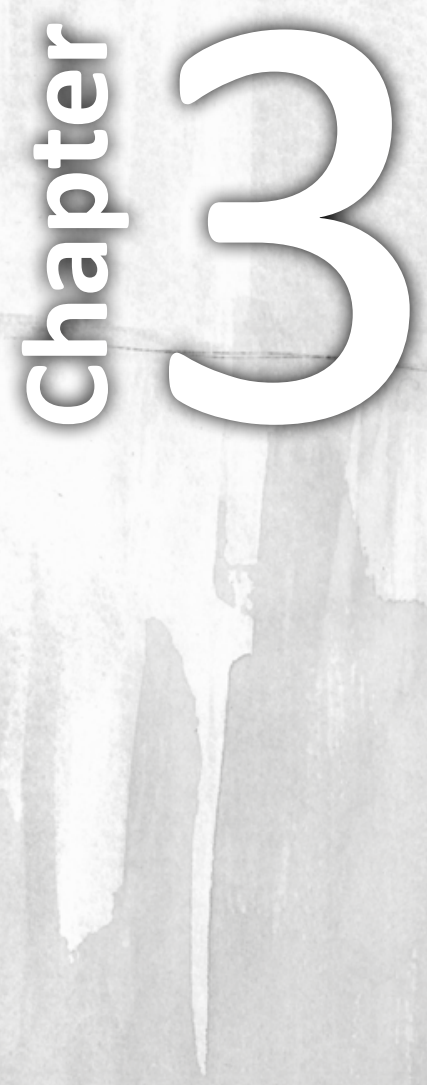




\title{
Carbon dioxide inhalation as a human experimental model of panic: The relationship between emotions and cardiovascular physiology
}

\author{
Nicole Leibold ${ }^{a}$, Wolfgang Viechtbauer ${ }^{a}$, Liesbet Goossens ${ }^{a}$, Eric Griez ${ }^{a}$, Inez Myin-Germeys ${ }^{a}$, \\ Harry Steinbusch", Daniel van den Hovea, ${ }^{a, b}$ Koen Schruers ${ }^{a, c}$
}

a Department of Psychiatry and Neuropsychology, Maastricht University, P.O. Box 616, 6200 MD Maastricht, the Netherlands. School for Mental Health and Neuroscience, Maastricht University. European Graduate School of Neuroscience (EURON), P.O. Box 616, 6200 MD Maastricht, the Netherlands

b Department of Psychiatry and Psychotherapy, Laboratory of Translational Neuroscience, University of Wuerzburg, Fuechsleinstrasse 15, 97080 Wuerzburg, Germany

Center for the Psychology of Learning and Experimental Psychopathology, Department of Psychology, University of Leuven, Tiensestraat 102, P.O. Box 3726, 3000 Leuven, Belgium 


\section{Abstract}

Inhaling carbon dioxide $\left(\mathrm{CO}_{2}\right)$-enriched air induces fear and panic symptoms resembling real-life panic attacks, the hallmark of panic disorder. The present study aimed to describe the emotional and cardiovascular effects evoked by inhaling $\mathrm{CO}_{2}$, taking shortcomings of previous studies into account. Healthy volunteers underwent a double inhalation of 0 , $9,17.5$, and $35 \% \mathrm{CO}_{2}$, according to a randomized, cross-over design. In addition to fear, discomfort, and panic symptom ratings, blood pressure and heart rate were continuously monitored. Results showed a dose-dependent increase in all self-reports. Systolic and diastolic blood pressure rose with increasing $\mathrm{CO}_{2}$ concentration, whereas heart rate results were less consistent. Diastolic blood pressure and heart rate variation correlated with fear and discomfort. Based on this relationship and the observation that the diastolic blood pressure most accurately mimicked the degree of self-reported emotions, it might serve as a putative biomarker to assess the $\mathrm{CO}_{2}$-reactivity in the future. 


\section{Introduction}

About $23 \%$ of the general population experiences a panic attack (PA) at least once in their lives (Kessler et al., 2006). PAs are spontaneous periods of irrational intense fear and/or discomfort accompanied by respiratory, neurovegetative and cognitive symptoms such as shortness of breath, choking, dizziness, palpitations, chest pain, paresthesia, fear of losing control, and derealization. The symptomatic peak is reached within 10 minutes after onset of the attack.

Recurrent PAs form the core of panic disorder (PD). In addition to PAs, PD is characterized by concerns about future attacks or concomitant consequences, often accompanied by behavioral changes (American Psychiatric Association, 2000). PD has a prevalence of about $4 \%$ in the general population (Weissman et al., 1997) and is accompanied by a considerable decrease in quality of life and high health care costs (Andlin-Sobocki and Wittchen, 2005; Olesen et al., 2012). In spite of a large amount of research into the underlying mechanisms of panic, there is still no scientific consensus on its pathogenesis. From a biological point of view, converging evidence points towards a role of chemosensitivity in the pathophysiology of PAs. An early theory was postulated by Klein (1993; Preter and Klein, 2008), stating that every individual is equipped with a phylogenetically evolved suffocation alarm system that is sensitive to metabolic threats from bodily origin (e.g., carbon dioxide $\left(\mathrm{CO}_{2}\right)$ levels and $\mathrm{CO}_{2}$-induced changes in $\mathrm{pH}$ ). When activated, the individual is alerted of imminent asphyxia, leading to an emotional and behavioral response such as acute panic. An erroneous triggering of the alarm system, however, signals a vital threat without the presence of a real danger. In other words, according to Klein's theory, PAs are false alarms due to a dysfunctional suffocation detection. However, a neural substrate for that suffocation detector system remains to be elucidated.

On a molecular level, it has been shown that brainstem serotonergic cells act as chemosensors that detect a decrease in $\mathrm{pH}$ due to an increased concentration of $\mathrm{CO}_{2}$ (Corcoran et al., 2009; Richerson, 2004; Severson et al., 2003). These serotonergic cells are closely associated with large arteries, thereby being ideally situated to sense arterial blood $\mathrm{CO}_{2}$ levels and to initiate behavioral and autonomic responses aimed at maintaining pH homeostasis (Bradley et al., 2002). As projection areas of these cells include the limbic system, it has been suggested that these serotonergic cells are involved in the affective response to $\mathrm{CO}_{2}$. In this respect, these cells may mediate arousal and feelings of anxiety and suffocation to $\mathrm{CO}_{2}$ (Richerson, 2004).

A recent study further increased the insights into the mechanisms underlying the effects of $\mathrm{CO}_{2}$. In this rodent study, it was demonstrated that the acid-sensing ion channel 1a (ASIC1a) also detects changes in $\mathrm{pH}$. Exposure to $\mathrm{CO}_{2}$ was shown to reduce 
the $\mathrm{pH}$ within the amygdala, which activates amygdalar ASIC1a that, in turn, is strongly involved in triggering fear behavior (Ziemann et al., 2009). These data are in accordance with a previous hypothesis that PAs might involve an acute disturbance in the acid-base balance in certain brain areas (Esquivel et al., 2010).

We have previously proposed (in line with Denton 2006; 2009) that PAs can be considered as the expression of an emotion aimed at maintaining the individual's homeostasis. In this view, emotions consist of two components, namely sensation and intention. Sensation is the conscious perception of disturbed bodily functions, stimulating an adaptive response (intention). When the sensation is evoked by internal body states (i.e., interoceptor driven) and is linked to survival, thus signaling that the organism's existence is instantly threatened, the emotion may pervade the conscious awareness as primal emotion (Colasanti et al., 2012; Denton, 2006; Denton et al., 2009). In this respect, we believe that PAs are rooted in instinctual behavior and are an instance of primal emotion to protect the individual against a vital threat. Therefore, it would be meaningless to assess PAs using exclusively biological or psychological measures.

PAs can be reliably provoked in the laboratory. Numerous pharmacological substances and other techniques have been used (for review see Esquivel et al., 2008), of which some influence the acid-base homeostasis: voluntary hyperventilation, lactate infusions, and $\mathrm{CO}_{2}$ inhalations.

When comparing the different methods, it is apparent that $\mathrm{CO}_{2}$ inhalation has a number of advantages, which made it an often applied and well-established experimental model for human panic during the last few decades. $\mathrm{CO}_{2}$ inhalation is a relatively easy, noninvasive, safe, and reliable technique to trigger intense, but short-lasting, fear and panic symptoms in PD patients (e.g. Nardi et al., 2006; Perna et al., 2004b; Verburg et al., 1995; Verburg et al., 1998). These sensations closely resemble the symptomatology of naturally occurring PAs (Nardi et al., 2006; Schruers et al., 2004). Over the last few years, it has been shown that panic can also be induced in healthy subjects by inhaling $\mathrm{CO}_{2}$. More specifically, $\mathrm{CO}_{2}$ dose-dependently elicits negative affect, provoking the emotional and physical sensations of a PA in accordance with the formal DSM-IV criteria, particularly when using a double vital capacity breath of $35 \% \mathrm{CO}_{2}$ (Colasanti et al., 2008; Griez et al., 2007; Schruers et al., 2011). These studies demonstrate that panic symptoms can, to a differing extent, be triggered in most individuals, depending on the concentration of $\mathrm{CO}_{2}$ used. This implies the existence of a $\mathrm{CO}_{2}$-reactivity continuum and that the response to $\mathrm{CO}_{2}$ is based on a common mechanism. Therefore, studying healthy volunteers can provide important insights into the fundamental mechanisms underlying $\mathrm{CO}_{2}$-reactivity. Additional reasons to investigate the basic mechanisms of panic in healthy volunteers are the high comorbidity with other psychiatric disorders 
and the frequent use of medication by PD patients, both of which may mask the effects of interest.

The response to $\mathrm{CO}_{2}$ is commonly measured using self-reports on the presence and intensity of fear and panic symptoms. PAs are accompanied by profound physiological symptoms that are also classically assessed by self-reports. A primal emotion consists of the conscious perception of disturbed bodily function as well as an adaptive homeostatic response. The former can be reported by the individual, whereas the latter is not completely covered by self-reports. Therefore, focusing on the classical selfreports seems too narrow to examine a PA in all its aspects. Incorporating physiological measures may be an important approach to assess the homeostatic response and to complement self-ratings, thereby refining the assessment and diagnosis of PAs. In recent years, various (psycho)physiological parameters have been increasingly included (e.g., Bailey et al., 2005; Blechert et al., 2010, 2013; Bystritsky et al., 2000; Gorman et al., 2001; Papadopoulos et al., 2010; Pappens et al., 2012; Poma et al., 2005).

When focusing on the cardiovascular system, blood pressure and heart rate are the parameters of interest. More than two decades ago, some attempts were already made to include those measurements to assess the cardiovascular response to a $\mathrm{CO}_{2}$-inhalation. For instance, in PD patients and controls, Gorman et al. (1990) did not find any significant alteration in blood pressure after inhaling $35 \% \mathrm{CO}_{2}$. Similarly, Bystritsky and Shapiro (1992) did not observe any blood pressure response in healthy subjects, when inhaling a low dosage of $5.5 \% \mathrm{CO}_{2}$. However, small sample sizes and analyzing means over prolonged periods of time (Gorman et al., 1990) limit the generalizability of these results. Using larger samples, other research groups did report $\mathrm{CO}_{2}$-induced increases in blood pressure (Martinez et al., 1998) and heart rate (Martinez et al., 1998; Poonai et al., 2000). Using more advanced beatto-beat monitoring revealed that $35 \% \mathrm{CO}_{2}$ elicited a relative rise in systolic blood pressure, whereas heart rate was not affected, when comparing the change between $10 \mathrm{~s}$ before to $10 \mathrm{~s}$ after the $\mathrm{CO}_{2}$ inhalation. Analyzing the first post-inhalation minute showed a relative $\mathrm{CO}_{2}$-induced rise of the systolic blood pressure, concomitant with an overall decrease of heart rate, possibly compensatory to the elevated blood pressure (Argyropoulos et al., 2002). A correlation analysis on these data yielded no significant relationship between cardiovascular parameters and self-reported fear (Bailey et al., 2003). Further, in other studies, an increase in systolic (Bailey et al., 2005; Kaye et al., 2004; Wetherell et al., 2006), but not diastolic (Bailey et al., 2005; Kaye et al., 2004), blood pressure was reported after inhaling $\mathrm{CO}_{2}$-enriched air. Assessing heart rate yielded inconsistent results in these studies, with reports on a positive (Bailey et al., 2005) and negative (Kaye et al., 2004; Wetherell et al., 2006) effect of a $\mathrm{CO}_{2}$-inhalation. In contrast, more recent studies observed an increase in heart rate (Nillni et al., 2012; Papadopoulos et al., 2010; Richey et al., 2010), but diverge 
regarding the effects of $\mathrm{CO}_{2}$ on blood pressure. Papadopoulus et al. (2010) did not find any effect caused by inhaling $7.5 \% \mathrm{CO}_{2}$, whereas Richey et al. (2010) reported an increase in systolic as well as diastolic blood pressure after taking a single breath of $35 \% \mathrm{CO}_{2}$.

Taken together, the results of studies assessing the cardiovascular physiology in response to a $\mathrm{CO}_{2}$-inhalation are fairly inconsistent, which may be explained by several identifiable variations and shortcomings in terms of methodology, technical equipment, and performed analyses. For instance, an insufficient number of measurements over time accompanied by analyzing overall means or means over several seconds (e.g., Gorman et al., 1990) masks time courses and brief fluctuations, which are of importance to gain more insight into a short-lived phenomenon such as panic. Similarly to early studies, more recent studies employing beat-to-beat measurements frequently used small sample sizes and/or focused on a single concentration of $\mathrm{CO}_{2}$ (e.g., Argyropoulos et al., 2002; Bailey et al., 2005; Bailey et al., 2003; Papadopoulos et al., 2010). In addition to methodological issues, confounders may also contribute to varying results. For instance, it has been reported that the $\mathrm{CO}_{2}$-reactivity decreases with age (Griez et al., 2007), indicating the importance of a large sample size and/ or restriction of the sample's age range. Other possible confounders include, for instance, smoking (Abrams et al., 2008; Knuts et al., 2010), caffeine intake (Nardi et al., 2007; Vilarim et al., 2011), alcohol use (Cosci et al., 2005; Kushner et al., 1996), and physical exercise (Esquivel et al., 2012; Smits et al., 2009).

The objective of the present study was to describe the emotional and cardiovascular response to $\mathrm{CO}_{2}$ to assess the psychobiological phenomenon PA in all its aspects, taking the abovementioned identifiable shortcomings of previous studies into account, and thereby refining the assessment of PAs. Accordingly, to investigate the response to $\mathrm{CO}_{2}$ in more detail, we challenged 120 healthy volunteers with four different $\mathrm{CO}_{2}$ concentrations that have been proven to evoke a dose-dependent increase in negative affect. In addition to the commonly used self-reports, we used a computerized system that allowed continuous and accurate monitoring of the physiological parameters blood pressure and heart rate throughout the entire procedure. Of note, both parameters were previously validated in a pilot study. We hypothesized that the cardiovascular measures would mimic the degree of self-reported fear, discomfort, and panic symptoms. 


\section{Materials and Methods}

\section{Subjects}

One hundred and twenty healthy volunteers participated in this study (35 males, 85 females, mean age 24.01 years, $S D=7.24)$. Subjects were recruited via advertisements at Maastricht University, the Netherlands, to ensure a homogenous sample in terms of age (Griez et al., 2007). All potential subjects were screened by an experienced psychiatrist or psychologist using a routine medical examination and the Mini International Neuropsychiatric Interview (M.I.N.I., Sheehan et al., 1998). Inclusion criteria were age between 18 and 65 years, and a good past and present physical as well as mental condition. Exclusion criteria were current or past pulmonary or cardiovascular disease, current hypertension (systolic $>170 \mathrm{mmHg}$, diastolic $>100 \mathrm{mmHg}$ ), cerebral aneurysm, pregnancy, epilepsy, excessive smoking (>15 cigarettes/day), use of adrenergic receptor blockers or psychotropic medication, and having a first-degree relative suffering from PD. Subjects were instructed to refrain from coffee on the test days. Each subject gave written informed consent according to the principles of the Declaration of Helsinki. A financial compensation was paid for participation. The study was approved by the Medical Ethics Committee of Maastricht University and the Maastricht University Hospital.

\section{Procedure}

The study was performed as previously described (Griez et al., 2007; Schruers et al., 2011; Verburg et al., 2001) and extended by physiological measurements (see Cardiovascular measures). Using a randomized, cross-over design, subjects underwent a standardized double inhalation of four $\mathrm{CO}_{2}$ concentrations: $0 \%$ (room air), $9 \%, 17.5 \%$ and $35 \% \mathrm{CO}_{2}$. Each mixture also contained $20 \% \mathrm{O}_{2}$ and $80 \%, 71 \%, 62.5 \%$, or $55 \% \mathrm{~N}_{2}$, respectively. Subjects were seated in a comfortable armchair during the entire procedure. A soft plastic nasaloral mask, connected to a capnograph (medair, Delsbo, Sweden) and a computer, was fixed to the subjects' head. First, the vital capacity of a double breath was measured using a flowmeter. Subjects were instructed to exhale to the maximum, to inhale as much as possible, to exhale and inhale to the maximum again, and to hold their breath for $4 \mathrm{~s}$ (to increase alveolar gas exchange). Subsequently, the $\mathrm{CO}_{2}$ inhalation took place. Subjects were told that the following breath of the $\mathrm{CO}_{2}$ mixture may cause effects, ranging from some vague sensations up to fear, depending on the $\mathrm{CO}_{2}$ concentration and the individual susceptibility. However, all sensations would be short-lived. The words "panic attack" were not mentioned to avoid cognitive bias due to expectation. The inhalation procedure was identical to the one previously used for assessing the double breath vital capacity, including the use of the same flowmeter to motivate the subjects to inhale at least $80 \%$ of 
the measured vital capacity. Inhalations took place on four separate days, each day at the same time for each subject, to avoid effects of fluctuations in circadian rhythms.

\section{Self-report measures}

Self-reports were assessed in accordance with the DSM-IV criteria, which define a PA as "a discrete period of intense fear or discomfort", accompanied by at least 4 out of 13 defined symptoms that develop abruptly and reach a peak within 10 min after onset (American Psychiatric Association, 2000). In line with this definition, subjects were asked to evaluate their subjective feeling of fear and discomfort by means of a Visual Analogue Scale (VASFear and VAS-Discomfort, respectively). The scale consists of a horizontal line of 100 $\mathrm{mm}$ length and ranges from 0 (not at all) to 100 (the worst imaginable). Panic symptoms were evaluated using the Panic Symptom List (PSL)-IV, which lists the 13 symptoms characterizing a PA according to the DSM-IV criteria such as palpitations, shortness of breath, feeling of chocking, dizziness, and fear of losing control or of dying. The list ranges from 0 (absent) to 4 (very intense).

Self-reports were obtained immediately before (how the subjects felt at that particular moment) and immediately after the $\mathrm{CO}_{2}$ inhalation (how the subjects felt at the worst moment of the inhalation) (Schruers et al., 2011). An increase of at least 25 in the fear or discomfort rating in combination with an increase of at least four points in the panic symptom rating was defined as occurrence of a PA (Esquivel et al., 2012).

\section{Cardiovascular measures}

Blood pressure and heart rate were continuously measured throughout the entire procedure (baseline, $\mathrm{CO}_{2}$ inhalation, recovery) using a computerized system (Carbon Dioxide Tolerance Tester, CTT, Maastricht Instruments B.V., Maastricht, the Netherlands). A finger cuff was attached to the mid-phalanx of the third finger of the non-dominant hand and was connected to a cardiovascular monitor (Nexfin, BMEYE B.V., Amsterdam, the Netherlands) and a computer equipped with the software $\mathrm{CO}_{2}$ Challenge (IDEEQ, Maastricht Instruments B.V., Maastricht, the Netherlands). All measurements were calibrated and subsequently recorded using a sampling rate of $2 \mathrm{~Hz}$. To minimize movements, the hand rested on the arm of the chair.

The parameters of interest were chosen based on a previous pilot study (unpublished data), in which we assessed blood pressure, heart rate, various respiratory parameters, skin conductance, and pupil diameter in response to inhaling $35 \% \mathrm{CO}_{2}$. Blood pressure and heart rate appeared to be the most sensitive outcome parameters (in addition to respiration rate and end-tidal $\mathrm{CO}_{2}$, which were also measured but will be discussed in a separate paper) and were incorporated in a customized computerized system prior to this study. 


\section{Statistical analysis}

Due to technical failure in the physiological monitoring in at least one of the four $\mathrm{CO}_{2}$ concentrations, 16 subjects were excluded. The final sample for all analyses with regard to physiology consisted, therefore, of 104 subjects ( 30 males, mean age 24.57 years, SD=7.21; 74 females mean age 23.20 years, $S D=6.01$ ). Changes (pre-score subtracted from postscore) in fear, discomfort, and panic symptoms across the four $\mathrm{CO}_{2}$ concentration levels were examined by means of multilevel models (with the four responses nested within subjects) with an unstructured variance-covariance matrix to account for the fact that the same subjects were tested under all four conditions. A significant overall test suggesting differences between at least two of the four $\mathrm{CO}_{2}$ concentration levels was followed up by tests of all pairwise differences using Holm's method to control the familywise error rate (Holm, 1979).

Physiological measures were analyzed in terms of systolic and diastolic blood pressure and heart rate. To reduce the amount of data, we first used locally weighted polynomial regression (Cleveland and Devlin, 1988) for the data of each subject in order to avoid strong effects of outliers. Based on the smoothed data, we then calculated the area under the curve (AUC), peak, and range (peak minus minimum) within the first $60 \mathrm{~s}$ after inhaling the second breath of $\mathrm{CO}_{2}$ (see Supplementary Figure 1 for an illustration of the outcomes). In addition, the amount of fluctuations around the smoothed data (standard deviation, SD) was calculated. To avoid confusion with the term "heart rate variability", which is usually assessed by means of spectrum or spectral analysis, fluctuations are denoted as "variation". These derived outcomes were then again analyzed with multilevel models as described previously. A log transformation was applied to the outcome variation to obtain residual distributions closer to normality.

Effect sizes (Cohen's d) were calculated using standardized mean gains, indicating the change in the mean standardized by the standard deviation of the scores for the lower $\mathrm{CO}_{2}$ concentration (Becker, 1988).

To assess the proportion of subjects who did not recover, that is, who did not return to a stable blood pressure or heart rate within $60 \mathrm{~s}$ after inhaling $\mathrm{CO}_{2}$, we fitted rolling regression models to the data with a $20 \mathrm{~s}$ window. Within each time window, the slope of the regression line and the residual standard deviation were obtained. Stability was defined as the first $20 \mathrm{~s}$ window, in which the slope was below 0.10 in absolute value and the residual SD below 5.0 (see Supplementary Figure 1). Then, Cox proportional hazard models were applied, in which robust estimators of the standard errors were used to account for the fact that subjects were measured in all four $\mathrm{CO}_{2}$ concentrations. When significant, main effects were further analyzed by means of pairwise comparisons using Holm's method. 
Correlation analyses between the change in self-reports and the derived cardiovascular outcome measures were performed using a permutation test, which accounts for the fact that each subject took part in all four $\mathrm{CO}_{2}$ inhalations, thereby leading to dependent values. First, the blocks of four values belonging to the same subjects were permutated. Subsequently, the four values were permutated within each block for each subject. This process was repeated 100,000 times, after which the proportion of correlations that were more extreme than the observed correlation was calculated.

To examine whether the presence of any carry-over effects may have influenced the conclusions of the previous analyses, a four-level factor was coded that indicated the sequence of treatment given (Senn, 2002). This factor was included in the model together with its interaction with the factor of the actual $\mathrm{CO}_{2}$ concentration.

All presented p-values are already adjusted for multiple testing. For all analyses, significance was set at $p<0.05$. Statistical analyses were performed using the software $\mathrm{R}$ (version 2.14.0, 2011, R Development Core Team, Vienna/Austria). For the multilevel models, the $n / m e$ package was used (version 3.1-102).

\section{Results}

\section{Effects of $\mathrm{CO}_{2}$ on self-report measures}

A significant main effect of $\mathrm{CO}_{2}$ concentration on subjective fear, discomfort, and panic symptoms $(p<0.001)$ was present. The $\mathrm{CO}_{2}$-induced increase in all self-report measures was strongly dose-dependent $(p<0.001$, except for fear and discomfort when comparing $9 \%$ to $0 \%: p=0.006$ and $p=0.015$, respectively) (Figure 1). There was no effect of sex on self-report measures. The panic rates, defined as an increase of at least 25 in fear or discomfort in addition to an increase of at least four points on the panic symptom scale, were $46.67 \%$ and $67.5 \%$ for fear and discomfort, respectively.

\section{Effects of $\mathrm{CO}_{2}$ on cardiovascular measures}

A variety of outcome measures of the systolic and diastolic blood pressure as well as heart rate was analyzed in response to $0 \%, 9 \%, 17.5 \%$, and $35 \% \mathrm{CO}_{2}$ (Supplement, Figure 1, one subject for illustration). In general, with regard to both systolic and diastolic blood pressure, the AUC, peak and time needed to return to a stable level increased dose-dependently. In contrast, only minor effects of $\mathrm{CO}_{2}$ concentration on heart rate were observed. The results of the group means with regard to the AUC, peak, range, and proportion of subjects that did not recover as well as variation within a $60 \mathrm{~s}$ phase after the $\mathrm{CO}_{2}$ inhalation are presented in the following subsections. Women had a lower blood pressure after inhaling $0 \% \mathrm{CO}_{2}$. However, since the increases in response to $\mathrm{CO}_{2}$-enriched air were not statistically 
different between women and men, the physiological effects are not presented per sex. Analyses of carry-over effects did not indicate any significant effects.
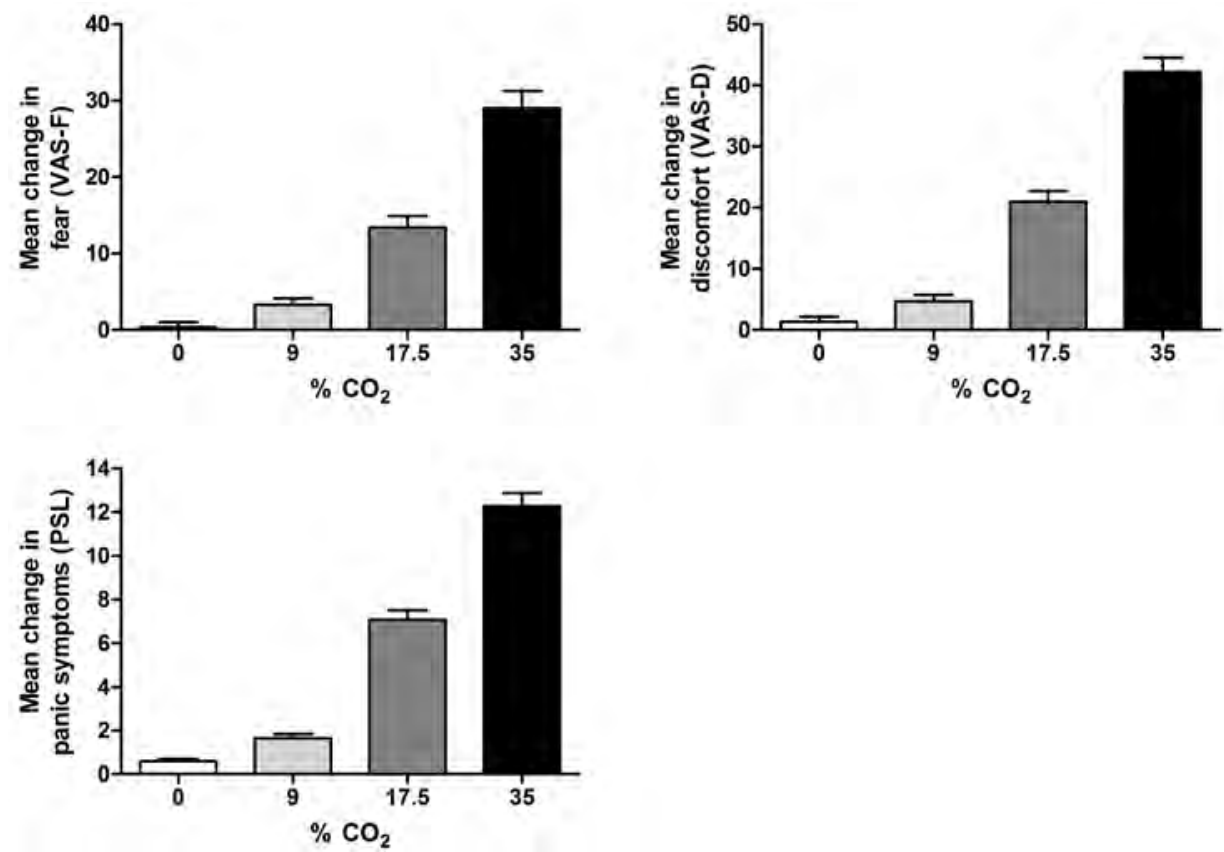

Figure 1. Effects of increasing $\mathrm{CO}_{2}$ concentrations on the change in fear (VAS-F, top left), discomfort (VAS-D, top right) and panic symptoms (PSL, bottom). A main effect of $\mathrm{CO}_{2}$ concentration on fear, discomfort and panic symptoms was observed ( $p<0.001$, Multilevel models). $\mathrm{CO}_{2}$ increased both emotions and panic symptoms dose-dependently $(p<0.001$, except for fear and discomfort when comparing $9 \%$ to $0 \%, p=0.006$ and $p=0.015$, respectively; pairwise comparisons using Holm's method, corrected for multiple testing). Bars represent mean change + standard error of the mean.

\section{Systolic blood pressure}

Effects of increasing $\mathrm{CO}_{2}$ concentrations on group means of the systolic blood pressure over time (means per second) are depicted in Figure 2 (top panel), showing that $\mathrm{CO}_{2}$ induced a brief drop in the first seconds, followed by a rise and another brief drop. Approximately 8 $\mathrm{s}$ after inhaling $\mathrm{CO}_{2}$ an abrupt rise occurred, reaching a peak, followed by quickly declining levels until stability was reached. These effects were dose-dependent until $17.5 \% \mathrm{CO}_{2}$. However, the time to return to a stable systolic blood pressure was longer in the $35 \% \mathrm{CO}_{2}$ condition in comparison with all other $\mathrm{CO}_{2}$ dosages.

Analysis of the derived cardiovascular outcomes (based on the 60 s recovery phase starting immediately after the second breath of $\mathrm{CO}_{2}$ ) revealed a main effect of $\mathrm{CO}_{2}$ concentration 
on the systolic AUC $(p<0.001)$ and the $\mathrm{CO}_{2}$-induced peak $(p<0.001)$. The increase in the systolic AUC as well as the peak was dose-dependent until $17.5 \% \mathrm{CO}_{2}$, indicating reaching a plateau (see Table 1 for means and Table 2 for all p-values and effect sizes). Further, an overall effect of $\mathrm{CO}_{2}$ dosage was observed concerning the range of the systolic blood pressure $(p<0.001)$. Multiple comparisons revealed that $0 \%$ and $9 \%$, not different from one another $(p=0.833)$, induced a significantly smaller range than $17.5 \%$ (both $p<0.001$ ) and $35 \% \mathrm{CO}_{2}$ (both $\mathrm{p}<0.001$ ). The proportion of subjects who did not recover within 60 $s$ after the $\mathrm{CO}_{2}$ inhalation was also dependent on the $\mathrm{CO}_{2}$ concentration (main effect $p<0.001$ ) (Supplement, Figure 2, top panel, left). The highest proportions, i.e. the lowest number of subjects who did not recover within the $60 \mathrm{~s}$ time window, were observed after inhaling $17.5 \%$ and $35 \% \mathrm{CO}_{2}$ (Supplement, see Table 1 for means and Table 2 for $\mathrm{p}$-values). Similarly to the previous analyses, a main effect of $\mathrm{CO}_{2}$ concentration on variation was observed $(p<0.001)$, with a relative increase in variation with increasing dosage of $\mathrm{CO}_{2}$ dosage.

Table 1. Effects of increasing $\mathrm{CO}_{2}$ concentrations on the mean peak, range, and on the variation of the systolic as well as diastolic blood pressure and heart rate within the $60 \mathrm{~s}$ after the inhalation. Values represent means over the entire analyzed $60 \mathrm{~s}$ phase.

\begin{tabular}{|c|c|c|c|c|}
\hline & $\% \mathrm{CO}_{2}$ & $\begin{array}{l}\text { Systolic } \\
\text { blood pressure }\end{array}$ & $\begin{array}{l}\text { Diastolic } \\
\text { blood pressure }\end{array}$ & Heart rate \\
\hline \multirow{4}{*}{ Peak } & 0 & 135 & 83 & 109 \\
\hline & 9 & 146 & 89 & 109 \\
\hline & 17.5 & 156 & 97 & 108 \\
\hline & 35 & 156 & 100 & 107 \\
\hline \multirow{4}{*}{ Range } & 0 & 44 & 32 & 43 \\
\hline & 9 & 45 & 29 & 45 \\
\hline & 17.5 & 55 & 37 & 48 \\
\hline & 35 & 57 & 42 & 49 \\
\hline \multirow{4}{*}{ Variation } & 0 & 0.16 & -0.15 & 0.23 \\
\hline & 9 & 0.39 & 0.11 & 0.58 \\
\hline & 17.5 & 0.45 & 0.30 & 0.78 \\
\hline & 35 & 0.62 & 0.51 & 1.03 \\
\hline
\end{tabular}



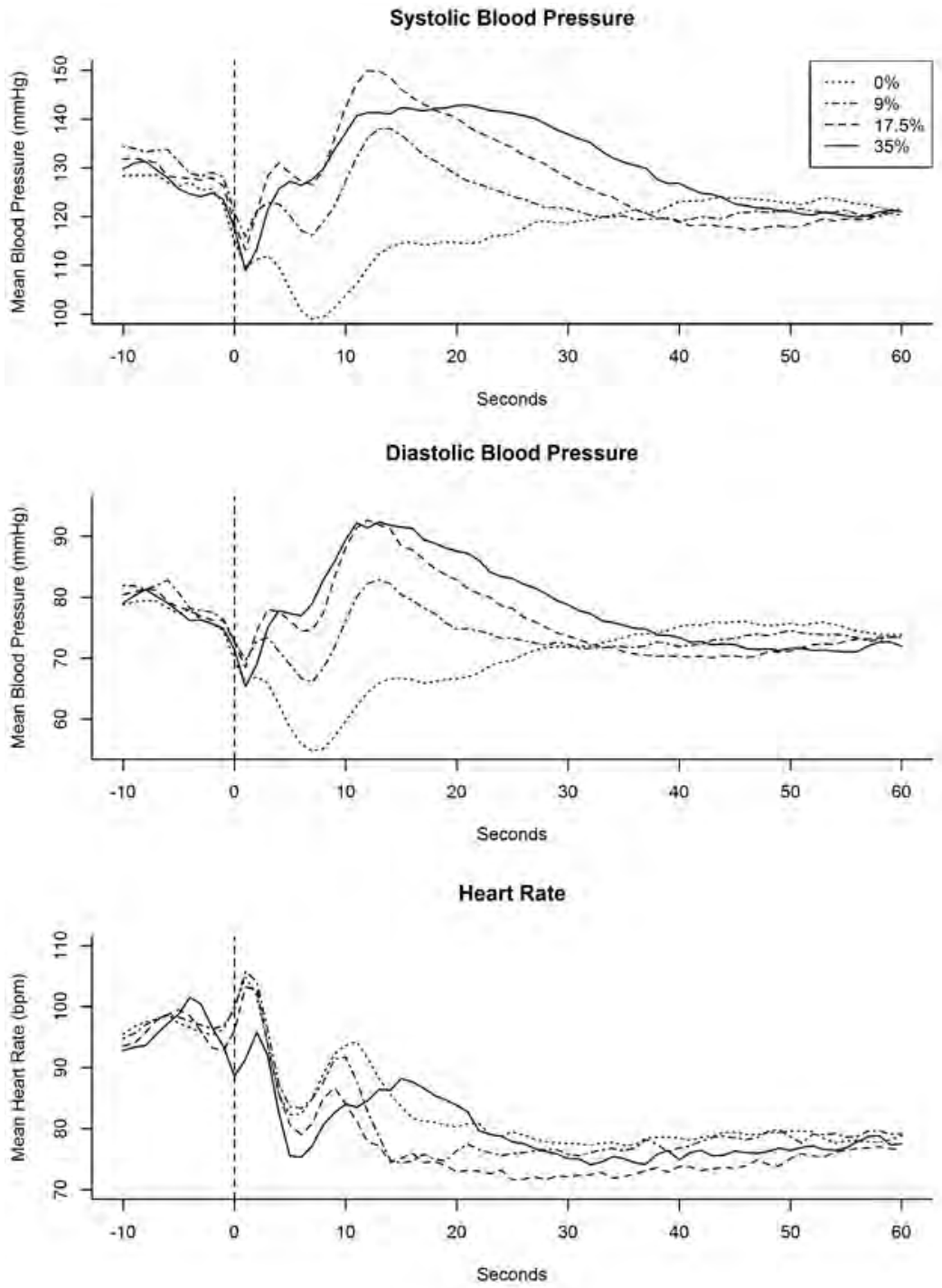

Figure 2. Effects of increasing concentrations of $\mathrm{CO}_{2}$ on mean systolic blood pressure (top panel), diastolic blood pressure (middle panel), and heart rate (bottom panel) over time (means per second). The dashed line indicates the end of a double breath of $\mathrm{CO}_{2}$. Top panel: Inhaling $\mathrm{CO}_{2}$ induced two brief decreases in systolic blood pressure, after which a rise could be observed, followed by a recovery phase in which the blood pressure returned to stable levels. The effect of $\mathrm{CO}_{2}$ was dose-dependently, with the exception of $35 \% \mathrm{CO}_{2}$, which caused a lower systolic blood pressure peak than $17.5 \% \mathrm{CO}_{2}$. However, at $35 \%$, the systolic blood pressure took longer to return to a stable level compared to the other $\mathrm{CO}_{2}$ concentrations. Middle panel: $\mathrm{CO}_{2}$ induced two short decreases in diastolic blood pressure, after which the levels increased dose-dependently until reaching a peak, similar to the systolic blood pressure. Subsequently, the diastolic blood pressure decreased again, eventually reaching stable levels again. Bottom panel: $\mathrm{CO}_{2}$ induced a short steep rise in mean heart rate, after which a drop, followed by second, longer rise could be observed. Subsequently, heart rate quickly returned to a stable level. $\mathrm{CO}_{2}$-induced alterations in heart rate were not dose-dependent. 


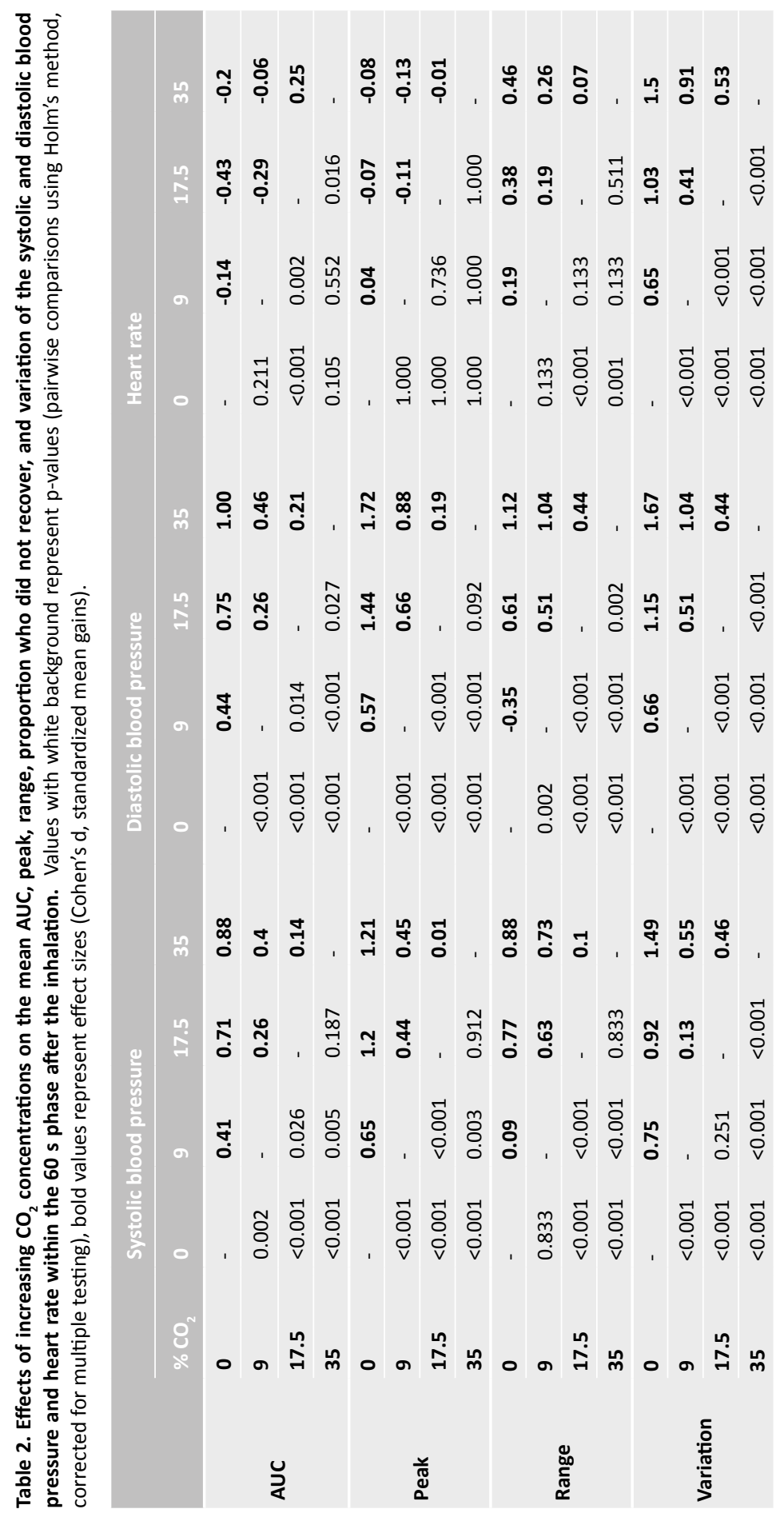




\section{Diastolic blood pressure}

Effects of increasing $\mathrm{CO}_{2}$ concentrations on group means (per second) of the diastolic blood pressure are shown in Figure 2 (middle panel). Similar to the systolic blood pressure, $\mathrm{CO}_{2}$ caused two brief declines within the first $8 \mathrm{~s}$, after which a steep dose-dependent rise eventually reaching a peak was observed. This was followed by a decrease until stable levels were reached. In addition, after inhaling $35 \% \mathrm{CO}_{2}$, it took longer to return to a stable level compared to lower $\mathrm{CO}_{2}$ concentrations.

Within the $60 \mathrm{~s}$ recovery phase after the double breath of $\mathrm{CO}_{2}$, an overall effect of $\mathrm{CO}_{2}$ concentration on the AUC of the diastolic blood pressure $(p<0.001)$ and on the $\mathrm{CO}_{2}$-elicited peak was observed $(p<0.001) . \mathrm{CO}_{2}$ caused a dose-dependent rise in the diastolic AUC and peak. However, with respect to the peak, a plateau was reached at $17.5 \% \mathrm{CO}_{2}$ (see Table 1 for means and Table 2 for $p$-values and effect sizes). A main effect of $\mathrm{CO}_{2}$ was also observed in the range of the diastolic blood pressure $(p<0.001)$, with an increase in the range when inhaling higher concentrations of $\mathrm{CO}_{2}$. In addition, all ranges differed significantly from one another. Further, analysis of the proportion of subjects that did not recover within $60 \mathrm{~s}$ after inhaling $\mathrm{CO}_{2}$ (overall effect $\mathrm{p}<0.001$ ) revealed that most of the subjects did return to a stable diastolic blood pressure after inhaling $0 \%$ and $9 \% \mathrm{CO}_{2}$ (Supplement, Figure 2, top panel, right). This proportion was strongly reduced after inhaling $17.5 \%$ and particularly $35 \% \mathrm{CO}_{2}$ (Supplement, see Table 1 for means and Table 2 for $\mathrm{p}$-values). An overall effect of $\mathrm{CO}_{2}$ concentration was also present on the variation of the diastolic blood pressure $(p<0.001)$. The rise in variation showed a distinct dose-dependent pattern (all $p<0.001)$.

\section{Heart rate}

Effects of increasing $\mathrm{CO}_{2}$ concentrations on mean heart rate before, during, and after the $\mathrm{CO}_{2}$ inhalation (mean per second) are illustrated in Figure 2 (bottom panel). $\mathrm{CO}_{2}$ caused a brief rise for about $3 \mathrm{~s}$, followed by a drop and another, though slightly longer, rise after about 9-16 s. Subsequently, heart rate promptly returned to a stable level. In contrast to blood pressure, no dose-dependent relationship was present.

With regard to the analysis of the $60 \mathrm{~s}$ phase after inhaling $\mathrm{CO}_{2}$, the observed main effect of $\mathrm{CO}_{2}$ concentration on the AUC of the heart rate was highly significant $(p<0.001)$. Interestingly, inhaling $17.5 \% \mathrm{CO}_{2}$ showed the smallest AUC compared to all other $\mathrm{CO}_{2}$ concentrations (see Table 1 for means and Table 2 for $p$-values and effect sizes). No significant overall effect regarding a $\mathrm{CO}_{2}$-elicited heart rate peak was present. With respect to the range of the heart rate, a main effect of $\mathrm{CO}_{2}$ dosage was observed $(p<0.001)$. Pairwise comparisons using Holm's method revealed that inhalation of the two highest $\mathrm{CO}_{2}$ concentrations, i.e. $17.5 \%$ and $35 \%$, was associated with an increased range compared to $0 \% \mathrm{CO}_{2}$ ( $p<0.001$ and $\mathrm{p}=0.001$, respectively). A main effect was also present regarding 
the proportion of subjects that did not recover within $60 \mathrm{~s}$ after the inhalation $(p=0.001)$ (Supplement, Figure 2, bottom panel), indicating that all $\mathrm{CO}_{2}$ concentrations resulted in a larger proportion compared to the $0 \%$ condition (Supplement, see Table 1 for means and Table 2 for $p$-values). Furthermore, an overall effect of $\mathrm{CO}_{2}$ dosage on heart rate variation was found $(p<0.001)$, with a dose-dependent rise in variation. Effects of all $\mathrm{CO}_{2}$ dosages differed significantly from one another (all $p<0.001$ ).

Table 3. Correlations (represented as R-values) and corresponding p-values (permutation test) between mean change in fear (VAS-F), discomfort (VAS-D), and panic symptoms (PSL) and the outcome measures of the diastolic cardiovascular outcome measures as well as heart rate.

\begin{tabular}{|c|c|c|c|c|c|}
\hline & & & $\begin{array}{l}\text { Mean change } \\
\text { in VAS-F }\end{array}$ & $\begin{array}{l}\text { Mean change } \\
\text { in VAS-D }\end{array}$ & $\begin{array}{l}\text { Mean change } \\
\text { in PSL }\end{array}$ \\
\hline \multirow{8}{*}{$\begin{array}{l}\text { Systolic blood } \\
\text { pressure }\end{array}$} & \multirow{2}{*}{ AUC } & $\mathbf{R}$ & 0.22 & 0.19 & 0.19 \\
\hline & & p-value & $0.009 * *$ & 0.069 & 0.098 \\
\hline & \multirow{2}{*}{ Peak } & $\mathbf{R}$ & 0.24 & 0.19 & 0.22 \\
\hline & & p-value & $0.013^{*}$ & 0.190 & 0.139 \\
\hline & \multirow{2}{*}{ Range } & $\mathbf{R}$ & 0.21 & 0.19 & 0.26 \\
\hline & & p-value & 0.053 & 0.163 & $0.047^{*}$ \\
\hline & \multirow{2}{*}{ Variation } & $\mathbf{R}$ & 0.16 & 0.23 & 0.26 \\
\hline & & p-value & 0.138 & 0.074 & $0.036^{*}$ \\
\hline \multirow{8}{*}{$\begin{array}{l}\text { Diastolic blood } \\
\text { pressure }\end{array}$} & \multirow{2}{*}{ AUC } & $\mathbf{R}$ & 0.24 & 0.25 & 0.23 \\
\hline & & p-value & $0.006 * *$ & $0.013^{*}$ & 0.066 \\
\hline & \multirow{2}{*}{ Peak } & $\mathbf{R}$ & 0.34 & 0.31 & 0.33 \\
\hline & & p-value & $0.002 * *$ & 0.037 & 0.065 \\
\hline & \multirow{2}{*}{ Range } & $\mathbf{R}$ & 0.29 & 0.29 & 0.36 \\
\hline & & p-value & $0.021^{*}$ & 0.078 & $0.023^{*}$ \\
\hline & \multirow{2}{*}{ Variation } & $\mathbf{R}$ & 0.32 & 0.36 & 0.39 \\
\hline & & p-value & 0.016 & 0.012 & $0.013^{*}$ \\
\hline \multirow{8}{*}{ Heart rate } & \multirow{2}{*}{ AUC } & $\mathbf{R}$ & 0.04 & -0.07 & -0.03 \\
\hline & & p-value & 0.56 & 0.38 & 0.69 \\
\hline & \multirow{2}{*}{ Peak } & $\mathbf{R}$ & 0.06 & -0.03 & 0.00 \\
\hline & & p-value & 0.21 & 0.47 & 0.96 \\
\hline & \multirow{2}{*}{ Range } & $\mathbf{R}$ & 0.13 & 0.14 & 0.18 \\
\hline & & p-value & 0.051 & $0.050 *$ & $0.007^{* *}$ \\
\hline & \multirow{2}{*}{ Variation } & $\mathbf{R}$ & 0.34 & 0.39 & 0.43 \\
\hline & & p-value & $0.006^{* *}$ & $0.003^{* *}$ & $<0.001 * * *$ \\
\hline \multicolumn{6}{|l|}{$* p<0.05$} \\
\hline \multicolumn{6}{|l|}{$* * p<0.01$} \\
\hline$* * * p<0.001$ & & & & & \\
\hline
\end{tabular}




\section{Correlation analyses between self-reports and cardiovascular outcomes}

Correlation analyses between the change in fear, discomfort, and panic symptoms, and the cardiovascular outcomes revealed several significant correlations (see Table 3 for an overview). Both the AUC and the peak of the systolic blood pressure were significantly correlated with fear only $(R=0.22, p=0.009$ and $R=0.24, p=0.013$, respectively). The range as well as the variation in systolic blood pressure was correlated with panic symptoms $(R=0.26$, $p=0.047$ and $R=0.26, p=0.036$, respectively). Additionally, all outcomes of the diastolic blood pressure were significantly correlated with fear, in particular the AUC and the peak diastolic blood pressure $(R=0.24, p=0.006$ and $R=0.34, p=0.002$, respectively). Moreover, most outcomes of the diastolic blood pressure also correlated with discomfort. With regard to heart rate, strong correlations were found between the heart rate variation and fear $(R=0.34$, $p=0.006)$, discomfort $(R=0.39, p=0.003)$, as well as panic symptoms $(R=0.43, p<0.001)$.

\section{Discussion}

In the present study we aimed to describe the emotional and cardiovascular effects provoked by four different concentrations of $\mathrm{CO}_{2}$, ranging from $0 \%$ (room air) to $35 \% \mathrm{CO}_{2}$, in a large sample of healthy volunteers. In addition to replicating a dose-dependent fear response to $\mathrm{CO}_{2}$, we substantially extended our previous studies by including continuous monitoring of cardiovascular effects. The results show $\mathrm{CO}_{2}$-induced increases in most outcomes of the blood pressure, with highest discriminability for the diastolic blood pressure. Heart rate was mainly affected in terms of variation. Correlation analyses revealed a significant relationship between fear and heart rate variation as well as several outcome measures of the diastolic blood pressure.

\section{Effects of $\mathrm{CO}_{2}$ on self-reports}

$\mathrm{CO}_{2}$ proved to provoke an immediate dose-dependent increase of fear, discomfort, and panic symptoms. This observation is consistent with previous studies by our group, demonstrating that increasing concentrations of $\mathrm{CO}_{2}$ are associated with increased negative affect in healthy subjects. Particularly $35 \% \mathrm{CO}_{2}$ has been shown to be an effective dosage to induce the emotions and symptoms associated with naturally occurring PAs in PD patients, conforming to the DSM-IV criteria for PAs (Griez et al., 2007; Schruers et al., 2011). In this respect, this study corroborates the use of $\mathrm{CO}_{2}$ as a reliable, fast, and relatively simple laboratory model for PAs.

Further, no sex differences were found. This result diverges from epidemiological data showing that women are more often affected by PD than men (Dick et al., 1994; Gater et al., 1998). Previous research failed to show consistent results with regard to sex differences 
in $\mathrm{CO}_{2}$-reactivity. While some research groups did report more fear and panic (Kelly et al., 2006), stronger increases in anxiety (Bunaciu et al., 2012) or higher levels of panic symptoms (Nillni et al., 2012) in women compared to men, others did not find a sex effect (Griez et al., 2007; Nardi et al., 2007; Perna et al., 2004a; Poonai et al., 2000). It has been proposed that environmental factors such as socializing may prime women to be more likely to report distress, whilst fearful behavior may be less accepted in men (McLean and Anderson, 2009). Other factors such as anxiety sensitivity (Schmidt and Zvolensky, 2007), which were not assessed in the present study, may also play a confounding role.

\section{Effects of $\mathrm{CO}_{2}$ on cardiovascular outcomes}

In the present study, an immediate activation of the autonomic nervous system in response to $\mathrm{CO}_{2}$ was observed, with a rapid increase in both systolic and diastolic blood pressure. Except for variation, the outcome measures of the systolic blood pressure showed no statistical difference between $17.5 \%$ and $35 \% \mathrm{CO}_{2}$, though subjective emotions and panic symptoms increased dose-dependently, which was well mimicked by the diastolic blood pressure. These diverging results may be explained by a ceiling effect in the case of the systolic blood pressure. Further, these observations also imply that diastolic blood pressure has a better discriminability and higher sensitivity compared to systolic blood pressure and is therefore preferable in analyzing the reactivity to $\mathrm{CO}_{2}$. Notably, no carry-over effects were present for any outcome measure, implying that the effects of the $\mathrm{CO}_{2}$ concentrations were not affected by the order given.

Since this is the first study that assessed both the emotional and cardiovascular response to $0 \%, 9 \%, 17.5 \%$, and $35 \% \mathrm{CO}_{2}$, and analyzed a variety of physiological outcomes, we are unable to directly compare these outcome measures with previous studies. However, general effects of $\mathrm{CO}_{2}$ inhalations have been described previously. The $35 \% \mathrm{CO}_{2}$-induced rise in systolic blood pressure is consistent with previous studies (Argyropoulos et al., 2002; Griez and Van den Hout, 1983; Kaye et al., 2004; Kaye et al., 2006; Richey et al., 2010; Shufflebotham et al., 2009; Wetherell et al., 2006). With regard to the diastolic blood pressure, an immediate $\mathrm{CO}_{2}$-induced increase has also been reported previously in some (Griez and Van den Hout, 1983; Kaye et al., 2006; Richey et al., 2010), but not all studies (Argyropoulos et al., 2002; Bailey et al., 2005; Bailey et al., 2007; Kaye et al., 2004; Papadopoulos et al., 2010). The discrepancies between our results and those of other studies might be explained by differential methodology. For instance, a single vital capacity breath of $35 \% \mathrm{CO}_{2}$ (Argyropoulos et al., 2002; Kaye et al., 2004), in contrast to a double vital capacity breath in the present study, exposure to lower $\mathrm{CO}_{2}$ concentrations such as 7.5\% for 20 min (Bailey et al., 2005; Bailey et al., 2007; Papadopoulos et al., 2010), and differences in terms of sample size (Argyropoulos et al., 2002; Bailey et al., 2005), 
as well as methods of analysis (Gorman et al., 1990) can contribute to varying results. In comparison with these other studies the present study has several advantages. Since it has been shown that in healthy volunteers specifically a double breath of $35 \% \mathrm{CO}_{2}$ provokes emotions and panic symptoms resembling a real-life PA (Griez et al., 2007; Schruers et al., 2011), our approach may be seen as more robust to induce a panic response with a rapid onset. Moreover, our large sample size on top of measuring the effects of four concentrations of $\mathrm{CO}_{2}$ in each subject presumably yielded more reliable results. In addition, analytical methods such as calculating averages over 15 s intervals (Gorman et al., 1990) can mask small and brief fluctuations, resulting in a possibly inappropriate interpretation of the results. This emphasizes the need for continuous monitoring and analysis of the data obtained in short time frame such as twice per second as in the present study.

With regard to heart rate, contrary to our hypothesis, the outcome measures did not increase in a dose-dependent manner and were, in general, hardly affected by any $\mathrm{CO}_{2}$ concentration. More specifically, the AUC of the heart rate decreased with increasing $\mathrm{CO}_{2}$ concentration, with the strongest effect in the $17.5 \% \mathrm{CO}_{2}$ condition. This effect might be compensatory to the increased blood pressure and was also observed in previous studies using a single (Argyropoulos et al., 2002; Kaye et al., 2004; Shufflebotham et al., 2009; Wetherell et al., 2006) and double vital breath of $35 \% \mathrm{CO}_{2}$ (Verschoor and Markus, 2011). However, other studies reported an increase in heart rate (Bailey et al., 2005; Poonai et al., 2000; Richey et al., 2010; Sasaki et al., 1996) or did not find any effect (Bailey et al., 2007; Bystritsky and Shapiro, 1992). These discrepancies may be again explained by differential methodology as previously described. Interestingly, a clear dose-dependent increase in the heart rate variation was observed, i.e. the level of heart rate fluctuations increased with a rising dosage of $\mathrm{CO}_{2}$. This observation suggests that panic symptoms such as palpitations may be more related to fluctuations in heart rate rather than to a mere increase in frequency.

In the present study, the increases in blood pressure and heart rate were comparable in men and women in all $\mathrm{CO}_{2}$-enriched air conditions. Similarly, Kelly et al. (2006) failed to reliably discriminate between men and women when assessing the response to 12 inhalations of $20 \% \mathrm{CO}_{2}$ for $20 \mathrm{~s}$. However, this result is not uniform as some other studies did report sex differences in the physiological response to inhaling $\mathrm{CO}_{2}$. For instance, in a recent study by Nillni et al. (2012), when administering $10 \% \mathrm{CO}_{2}$ for $4 \mathrm{~min}$, women had higher heart rate levels during the inhalation when compared to men, an effect which could not be attributed to baseline differences in heart rate. This result is in line with a previous study using the same concentration of $\mathrm{CO}_{2}$ and administration time (Gregor and Zvolensky, 2008). Taken together, future research should further clarify whether women are more physiologically reactive to laboratory-induced PAs than men. 


\section{Correlations between self-reports and cardiovascular outcome measures}

Correlation analyses between self-report measures and cardiovascular outcomes revealed the most significant relationship between fear and heart rate variation. As previously mentioned, this observation may imply that fluctuations caused by a homeostatic disturbance play a more important role in $\mathrm{CO}_{2}$-induced fear than, e.g., an increase in heart rate itself. In addition to heart rate, fear and discomfort were associated with most of the outcomes of the diastolic blood pressure, particularly the AUC and the $\mathrm{CO}_{2}$-induced peak. Correlation analysis of a previous study by Bailey et al. (2003) did not reveal any relationship between blood pressure or heart rate and fear. Evidently, analyzing several outcome measures such as the AUC, peak, and variation in distinct cardiovascular parameters in a temporal manner gives a more detailed view into the complex relationship between physiology and panic, thereby revealing correlations that might not be detected when focusing on, for instance, the mean blood pressure and heart rate alone.

Regarding the systolic blood pressure, fewer correlations with self-reports were present. This result, in combination with the observation that the diastolic blood pressure mimicked the degree of fear, discomfort, and panic symptoms, suggests that the diastolic blood pressure is the most favorable parameter to assess the physiological response to $\mathrm{CO}_{2}$.

\section{Limitations}

Various factors are known to have a potential influence on the individual response to inhaling $\mathrm{CO}_{2}$. In the present study, several confounding effects were minimized using strict exclusion criteria. For instance, heavy smokers (Abrams et al., 2008; Knuts et al., 2010), alcohol users (Cosci et al., 2005; Kushner et al., 1996) and users of drugs/medications that are considered to have an effect on the nervous or cardiovascular system were excluded during the screening procedure. In addition, subjects were instructed to refrain from coffee on all test days to avoid possible anxiogenic effects of caffeine (Nardi et al., 2007; Vilarim et al., 2011). However, other potential confounders such as anxiety sensitivity (Blechert et al., 2013; Schmidt and Zvolensky, 2007) and physical activity (Esquivel et al., 2012; Smits et al., 2009) were not assessed. Moreover, due to practical reasons, we also did not control for menstrual cycle phase (Perna et al., 1995). Including those measurements would improve the study design and may increase the reliability of the results.

\section{Panic as an instance of a primal emotion}

We have previously proposed (in line with Denton et al. 2006; 2009) that PAs are the expression of a primal emotion (Colasanti et al., 2012). The interoceptor-driven sensation of a bodily disturbance linked to immediate threat of the individual leads to a compelling intention (i.e., adaptive homeostatic response) to protect the individual against that 
vital threat. In accordance with this notion, we showed in the present study that selfreports, representing sensations that emerge into consciousness, and the physiological response to $\mathrm{CO}_{2}$ are closely related. The present results are in accordance with previous data showing that neuronal activation of (para)limbic brain areas and deactivation of other areas in response to $\mathrm{CO}_{2}$ are congruent with the pattern observed with a subjective experience of other primal emotions such as extreme thirst, hunger or pain (Liotti et al., 2001). Together, the close relationship of self-reports and physiology in the present study as well as the congruency of (de)activation of brain structures in response to $\mathrm{CO}_{2}$ in other primal emotions supports our proposition that PAs are an instance of a primal emotion.

\section{Clinical implications and future perspectives}

The symptoms experienced during a PA such as palpitations, chest pain, breathing difficulties, and dizziness are not specific or automatically attributable to a PA. Up to $20 \%$ of patients suffering from chest pain and seeking help in emergency departments meet the official criteria for PD (Huffman and Pollack, 2003). This observation emphasizes the need for a fast and refined assessment of PAs.

In the present study, the overall heart rate response to inhaling $\mathrm{CO}_{2}$ was not strongly affected. The variation in heart rate, however, increased dose-dependently. This may indicate that panic symptoms such as palpitations are associated with heart rate fluctuations (i.e. brief disturbances in the homeostasis) rather than, for instance, a mere increase in frequency. Furthermore, among the assessed cardiovascular parameters, the diastolic blood pressure appears to be the most sensitive and robust measure, deeming it a putative biomarker for (experimentally induced) panic. Therefore, we propose that diastolic blood pressure measurements should be included in future studies to complement other measures such as self-reports.

It has been previously demonstrated that $\mathrm{CO}_{2}$ inhalation is a reliable technique to provoke intense, but transient, fear and/or discomfort and various sensations in PD patients as well as healthy subjects. These sensations closely resemble the symptomatology of reallife PAs. In PD patients, a single vital capacity breath of $35 \% \mathrm{CO}_{2}$ is sufficient, whereas in healthy subjects, a double breath of $35 \% \mathrm{CO}_{2}$ is particularly effective in triggering those symptoms. These observations suggest the existence of a $\mathrm{CO}_{2}$-reactivity continuum based on a common mechanism, thereby opening the possibility of referring to healthy subjects for the study of panic, which has several advantages. First, patients do not need to be burdened unnecessarily. Second, the potency of new therapies to modulate the response to $\mathrm{CO}_{2}$ can also be evaluated in healthy volunteers before eventually testing promising interventions in patients with PD. Third, sampling and testing healthy volunteers provides insights into the fundamental mechanisms underlying $\mathrm{CO}_{2}$-reactivity and panic, without 
possible masking effects of comorbidity and medication.

Bouton et al. (2001) proposed that conditioned anxiety about future PAs in response to extero- or interoceptive cues is a key process in the progression of PAs into PD. This process can also be best modeled in healthy subjects, because PD patients have progressed beyond the initial conditioning. Experimentally, the use of interoceptive cues is challenging given their internal nature. As inhaling $35 \% \mathrm{CO}_{2}$ reliably causes an immediate intense emotional response, we recently used $\mathrm{CO}_{2}$ inhalation as unconditioned stimulus to examine selective interoceptive conditioning (De Cort et al., 2012). In that study, we showed that $\mathrm{CO}_{2}$ may be a valuable agent for establishing an effective interoceptive cue in conditioning research. This is particularly interesting to investigate the role of interoceptive conditioning in the development from spontaneous PAs to PD. In future studies, it would be therefore worthwhile to also study patients with anxiety disorders to examine the difference between the adaptive nature of fear conditioning and the dysfunctional nature of anxiety disorders (Beckers et al., 2013).

Furthermore, the use of $\mathrm{CO}_{2}$ as an interoceptive cue may be a promising technique in the treatment of PD. In spite of its effectiveness (Sanchez-Meca et al., 2010), interoceptive exposure is not yet commonly used in daily practice. When it is included in therapy, symptom induction exercises such as hyperventilation or spinning are most often used. However, these exercises only induce a fraction of the panic symptoms (Antony et al., 2006; Lee et al., 2006). Therefore, we propose to include $35 \% \mathrm{CO}_{2}$ inhalation in interoceptive exposure therapy. The congruency with naturally occurring PAs will putatively increase the learning of how to deal with future PAs and thereby improve the effectiveness of cognitive behavioral therapies.

While $\mathrm{CO}_{2}$ inhalation in humans is a well-established experimental model for panic and increased the knowledge about that psychobiological phenomenon, it is limited in its potential to contribute to molecular insights. These can be better assessed in animal research. In a recent rodent study (Ziemann et al., 2009), it was shown that exposure to $\mathrm{CO}_{2}$ also triggers fear behavior in mice. Various techniques were used to provide a molecular substrate for this effect. It was demonstrated that the fear response is dependent on the $\mathrm{pH}$-sensitive ion channel ASIC1a located within the amygdala. More specifically, $\mathrm{CO}_{2}$ reduces the $\mathrm{pH}$ within the amygdala, thereby stimulating amygdalar ASIC1a and triggering fear behavior. Knockout of the gene encoding ASIC1a blunted this particular effect. Main outcome measures in this study were a series of behavioral tests. In order to be relevant for translation into a human perspective, animal studies should ideally use stimuli and outcome measures that are as similar as possible to those of human studies. In most human panic provocation studies, symptom reports are used as outcome. It is obvious that observed behavior in animals and symptom reports in humans are not interchangeable. 
Physiology, however, is measureable in both rodents and humans, which makes it a valuable addition to assess the response to $\mathrm{CO}_{2}$ in different species. We therefore propose to extend the methods from the present study to animal studies, where physiological outcome measures are not yet commonly used. Thereby, the comparability between animal and human research can be considerably improved, thus contributing to a better translation of knowledge gained in the laboratory back to the clinic.

\section{Conclusion}

In sum, the present study addressed identifiable shortcomings in previous studies such as small sample sizes, and methodological as well as technical limitations, to comprehensively investigate the reactivity to $\mathrm{CO}_{2}$ in healthy volunteers. The results show a dose-dependent subjective emotional and panic symptom response to $\mathrm{CO}_{2}$. This pattern was best represented by the diastolic blood pressure, indicating a better sensitivity and discriminability compared to the systolic blood pressure and heart rate. Further, particularly significant correlations were found between self-reports and heart rate variation as well as several outcome measures of the diastolic blood pressure. These results indicate that the combination of both subjective self-reports and cardiovascular measures is a promising method to obtain a more refined and reliable assessment of PAs and to assess PAs in all its aspects as an instance of a primal emotion. Particularly the diastolic blood pressure appears to be a robust and putative biomarker to assess the reactivity to $\mathrm{CO}_{2}$ in future studies. 


\section{References}

Abrams, K., Zvolensky, M.J., Dorflinger, L., Galatis, A., Blank, M., Eissenberg, T., 2008. Fear reactivity to bodily sensations among heavy smokers and nonsmokers. Exp Clin Psychopharmacol 16, 230-239.

American Psychiatric Association, 2000. Diagnostic and Statistical Manual of Mental Disorders: DSM-IV-TR, 4th edn. Washington, DC: American Psychiatric Association.

Andlin-Sobocki, P., Wittchen, H.U., 2005. Cost of anxiety disorders in Europe. Eur J Neurol 12 Suppl 1, 39-44.

Antony, M.M., Ledley, D.R., Liss, A., Swinson, R.P., 2006. Responses to symptom induction exercises in panic disorder. Behav Res Ther 44, 85-98.

Argyropoulos, S.V., Bailey, J.E., Hood, S.D., Kendrick, A.H., Rich, A.S., Laszlo, G., Nash, J.R., Lightman, S.L., Nutt, D.J., 2002. Inhalation of $35 \% \mathrm{CO}(2)$ results in activation of the HPA axis in healthy volunteers. Psychoneuroendocrinology 27, 715-729.

Bailey, J.E., Argyropoulos, S.V., Kendrick, A.H., Nutt, D.J., 2005. Behavioral and cardiovascular effects of $7.5 \% \mathrm{CO} 2$ in human volunteers. Depress Anxiety 21, 18-25.

Bailey, J.E., Argyropoulos, S.V., Lightman, S.L., Nutt, D.J., 2003. Does the brain noradrenaline network mediate the effects of the CO2 challenge? J Psychopharmacol 17, 252-259.

Bailey, J.E., Papadopoulos, A., Lingford-Hughes, A., Nutt, D.J., 2007. D-Cycloserine and performance under different states of anxiety in healthy volunteers. Psychopharmacology (Berl) 193, 579-585.

Becker, B.J., 1988. Synthesizing standardized mean-change measures. Br J Math Stat Psych 41, 257-278.

Beckers, T., Krypotos, A.M., Boddez, Y., Effting, M., Kindt, M., 2013. What's wrong with fear conditioning? Biol Psychol 92, 90-96.

Blechert, J., Wilhelm, F.H., Meuret, A.E., Wilhelm, E.M., Roth, W.T., 2010. Respiratory, autonomic, and experiential responses to repeated inhalations of $20 \% \mathrm{CO}(2)$ enriched air in panic disorder, social phobia, and healthy controls. Biol Psychol 84, 104-111.

Blechert, J., Wilhelm, F.H., Meuret, A.E., Wilhelm, E.M., Roth, W.T., 2013. Experiential, autonomic, and respiratory correlates of CO reactivity in individuals with high and low anxiety sensitivity. Psychiatry Res. 209, 556-573.

Bouton, M.E., Mineka, S., Barlow, D.H., 2001. A modern learning theory perspective on the etiology of panic disorder. Psychol Rev 108, 4-32.

Bradley, S.R., Pieribone, V.A., Wang, W., Severson, C.A., Jacobs, R.A., Richerson, G.B., 2002. Chemosensitive serotonergic neurons are closely associated with large medullary arteries. Nat Neurosci 5, 401-402.

Bunaciu, L., Feldner, M.T., Babson, K.A., Zvolensky, M.J., Eifert, G.H., 2012. Biological sex and panic-relevant anxious reactivity to abrupt increases in bodily arousal as a function of biological challenge intensity. J Behav Ther Exp Psychiatry 43, 526-531.

Bystritsky, A., Craske, M., Maidenberg, E., Vapnik, T., Shapiro, D., 2000. Autonomic reactivity of panic patients during a CO2 inhalation procedure. Depress Anxiety 11, 15-26.

Bystritsky, A., Shapiro, D., 1992. Continuous physiological changes and subjective reports in panic patients: a preliminary methodological report. Biol Psychiatry 32, 766-777.

Cleveland, W.S., Devlin, S.J., 1988. Locally weighted regression: An approach to regression analysis by local fitting. J Am Statist Assoc 83, 596-610.

Colasanti, A., Esquivel, G., Schruers, K.J., Griez, E.J., 2012. On the psychotropic effects of carbon dioxide. Curr Pharm Des 18, 5627-5637.

Colasanti, A., Salamon, E., Schruers, K., van Diest, R., van Duinen, M., Griez, E.J., 2008. Carbon dioxide-induced emotion and respiratory symptoms in healthy volunteers. Neuropsychopharmacology 33, 3103-3110.

Corcoran, A.E., Hodges, M.R., Wu, Y., Wang, W., Wylie, C.J., Deneris, E.S., Richerson, G.B., 2009. Medullary serotonin neurons and central CO2 chemoreception. Respir Physiol Neurobiol 168, 49-58.

Cosci, F., De Gooyer, T., Schruers, K., Faravelli, C., Griez, E., 2005. The influence of ethanol infusion on the effects of $35 \%$ CO2 challenge. A study in panic disorder patients and healthy volunteers. Eur Psychiatry 20, 299-303. 
De Cort, K., Griez, E., Buchler, M., Schruers, K., 2012. The role of „interoceptive“ fear conditioning in the development of panic disorder. Behav Ther 43, 203-215.

Denton, D., 2006. The primordial emotions: The dawning of consciousness. Oxford University Press.

Denton, D.A., McKinley, M.J., Farrell, M., Egan, G.F., 2009. The role of primordial emotions in the evolutionary origin of consciousness. Conscious Cogn 18, 500-514.

Dick, C.L., Bland, R.C., Newman, S.C., 1994. Epidemiology of psychiatric disorders in Edmonton. Panic disorder. Acta Psychiatr Scand Suppl 376, 45-53.

Esquivel, G., Dandachi, A., Knuts, I., Goossens, L., Griez, E., Schruers, K., 2012. Effects of acute exercise on CO(2) -induced fear. Depress Anxiety 29, 155-158.

Esquivel, G., Schruers, K., Griez, E., 2008. Experimental models: panic and fear. In: Blanchard, RJ, Griebel, G, Nutt, DJ (eds), Handbook of Anxiety and Fear. Elsevier BV, Amsterdam. 413 - 435.

Esquivel, G., Schruers, K.R., Maddock, R.J., Colasanti, A., Griez, E.J., 2010. Acids in the brain: a factor in panic? J Psychopharmacol 24, 639-647.

Gater, R., Tansella, M., Korten, A., Tiemens, B.G., Mavreas, V.G., Olatawura, M.O., 1998. Sex differences in the prevalence and detection of depressive and anxiety disorders in general health care settings: report from the World Health Organization Collaborative Study on Psychological Problems in General Health Care. Arch Gen Psychiatry 55, 405-413.

Gorman, J.M., Kent, J., Martinez, J., Browne, S., Coplan, J., Papp, L.A., 2001. Physiological changes during carbon dioxide inhalation in patients with panic disorder, major depression, and premenstrual dysphoric disorder: evidence for a central fear mechanism. Arch Gen Psychiatry 58, 125-131.

Gorman, J.M., Papp, L.A., Martinez, J., Goetz, R.R., Hollander, E., Liebowitz, M.R., Jordan, F., 1990. High-dose carbon dioxide challenge test in anxiety disorder patients. Biol Psychiatry 28, 743-757.

Gregor, K.L., Zvolensky, M.J., 2008. Anxiety sensitivity and perceived control over anxiety-related events: evaluating the singular and interactive effects in the prediction of anxious and fearful responding to bodily sensations. Behav Res Ther 46, 1017-1025.

Griez, E., Van den Hout, M.A., 1983. Carbon dioxide and anxiety: cardiovascular effects of a single inhalation. J Behav Ther Exp Psychiatry 14, 297-304.

Griez, E.J., Colasanti, A., van Diest, R., Salamon, E., Schruers, K., 2007. Carbon dioxide inhalation induces dosedependent and age-related negative affectivity. PLoS One 2, e987.

Holm, S., 1979. A simple sequentially rejective multiple test procedure. Scand J Statist 6, 65-70.

Huffman, J.C., Pollack, M.H., 2003. Predicting panic disorder among patients with chest pain: an analysis of the literature. Psychosomatics 44, 222-236.

Kaye, J., Buchanan, F., Kendrick, A., Johnson, P., Lowry, C., Bailey, J., Nutt, D., Lightman, S., 2004. Acute carbon dioxide exposure in healthy adults: evaluation of a novel means of investigating the stress response. $J$ Neuroendocrinol 16, 256-264.

Kaye, J.M., Young, T.M., Mathias, C.J., Watson, L., Lightman, S.L., 2006. Neuroendocrine and behavioural responses to $\mathrm{CO} 2$ inhalation in central versus peripheral autonomic failure. Clin Auton Res 16, 121-129.

Kelly, M.M., Forsyth, J.P., Karekla, M., 2006. Sex differences in response to a panicogenic challenge procedure: an experimental evaluation of panic vulnerability in a non-clinical sample. Behav Res Ther 44, 1421-1430.

Kessler, R.C., Chiu, W.T., Jin, R., Ruscio, A.M., Shear, K., Walters, E.E., 2006. The epidemiology of panic attacks, panic disorder, and agoraphobia in the National Comorbidity Survey Replication. Arch Gen Psychiatry 63, 415-424.

Klein, D.F., 1993. False suffocation alarms, spontaneous panics, and related conditions. An integrative hypothesis. Arch Gen Psychiatry 50, 306-317.

Knuts, I.J., Cosci, F., Esquivel, G., Goossens, L., van Duinen, M., Bareman, M., Overbeek, T., Griez, E.J., Schruers, K.R., 2010. Cigarette smoking and 35\% CO(2) induced panic in panic disorder patients. J Affect Disord 124, 215-218. 
Kushner, M.G., Mackenzie, T.B., Fiszdon, J., Valentiner, D.P., Foa, E., Anderson, N., Wangensteen, D., 1996. The effects of alcohol consumption on laboratory-induced panic and state anxiety. Arch Gen Psychiatry 53, 264270.

Lee, K., Noda, Y., Nakano, Y., Ogawa, S., Kinoshita, Y., Funayama, T., Furukawa, T.A., 2006. Interoceptive hypersensitivity and interoceptive exposure in patients with panic disorder: specificity and effectiveness. BMC Psychiatry 6, 32.

Liotti, M., Brannan, S., Egan, G., Shade, R., Madden, L., Abplanalp, B., Robillard, R., Lancaster, J., Zamarripa, F.E., Fox, P.T., Denton, D., 2001. Brain responses associated with consciousness of breathlessness (air hunger). Proc Natl Acad Sci U S A 98, 2035-2040.

Martinez, J.M., Coplan, J.D., Browne, S.T., Goetz, R., Welkowitz, L.A., Papp, L.A., Klein, D.F., Gorman, J.M., 1998. Hemodynamic response to respiratory challenges in panic disorder. J Psychosom Res 44, 153-161.

McLean, C.P., Anderson, E.R., 2009. Brave men and timid women? A review of the gender differences in fear and anxiety. Clin Psychol Rev 29, 496-505.

Nardi, A.E., Valenca, A.M., Lopes, F.L., de-Melo-Neto, V.L., Freire, R.C., Veras, A.B., Nascimento, I., King, A.L., Soares-Filho, G.L., Mezzasalma, M.A., Zin, W.A., 2007. Caffeine and 35\% carbon dioxide challenge tests in panic disorder. Hum Psychopharmacol 22, 231-240.

Nardi, A.E., Valenca, A.M., Lopes, F.L., Nascimento, I., Veras, A.B., Freire, R.C., Mezzasalma, M.A., de-MeloNeto, V.L., Zin, W.A., 2006. Psychopathological profile of 35\% CO2 challenge test-induced panic attacks: a comparison with spontaneous panic attacks. Compr Psychiatry 47, 209-214.

Nillni, Y.I., Berenz, E.C., Rohan, K.J., Zvolensky, M.J., 2012. Sex differences in panic-relevant responding to a $10 \%$ carbon dioxide-enriched air biological challenge. J Anxiety Disord 26, 165-172.

Olesen, J., Gustavsson, A., Svensson, M., Wittchen, H.U., Jonsson, B., 2012. The economic cost of brain disorders in Europe. Eur J Neurol 19, 155-162.

Papadopoulos, A., Rich, A., Nutt, D.J., Bailey, J.E., 2010. The effects of single dose anxiolytic medication on the CO2 models of anxiety: differentiation of subjective and objective measures. J Psychopharmacol 24, 649656.

Pappens, M., De Peuter, S., Vansteenwegen, D., Van den Bergh, O., Van Diest, I., 2012. Psychophysiological responses to $\mathrm{CO}(2)$ inhalation. Int J Psychophysiol 84, 45-50.

Perna, G., Brambilla, F., Arancio, C., Bellodi, L., 1995. Menstrual cycle-related sensitivity to $35 \%$ CO2 in panic patients. Biol Psychiatry 37, 528-532.

Perna, G., Caldirola, D., Namia, C., Cucchi, M., Vanni, G., Bellodi, L., 2004a. Language of dyspnea in panic disorder. Depress Anxiety 20, 32-38.

Perna, G., di Bella, D., Favaron, E., Cucchi, M., Liperi, L., Bellodi, L., 2004b. Lack of relationship between CO2 reactivity and serotonin transporter gene regulatory region polymorphism in panic disorder. $A m \mathrm{~J} M e d$ Genet B Neuropsychiatr Genet 129B, 41-43.

Poma, S.Z., Milleri, S., Squassante, L., Nucci, G., Bani, M., Perini, G.I., Merlo-Pich, E., 2005. Characterization of a $7 \%$ carbon dioxide (CO2) inhalation paradigm to evoke anxiety symptoms in healthy subjects. $J$ Psychopharmacol 19, 494-503.

Poonai, N., Antony, M.M., Binkley, K.E., Stenn, P., Swinson, R.P., Corey, P., Silverman, F.S., Tarlo, S.M., 2000. Carbon dioxide inhalation challenges in idiopathic environmental intolerance. J Allergy Clin Immunol 105, 358-363.

Preter, M., Klein, D.F., 2008. Panic, suffocation false alarms, separation anxiety and endogenous opioids. Prog Neuropsychopharmacol Biol Psychiatry 32, 603-612.

Richerson, G.B., 2004. Serotonergic neurons as carbon dioxide sensors that maintain pH homeostasis. Nat Rev Neurosci 5, 449-461.

Richey, J.A., Schmidt, N.B., Hofmann, S.G., Timpano, K.R., 2010. Temporal and structural dynamics of anxiety sensitivity in predicting fearful responding to a 35\% CO2 challenge. J Anxiety Disord 24, 423-432. 
Sanchez-Meca, J., Rosa-Alcazar, A.I., Marin-Martinez, F., Gomez-Conesa, A., 2010. Psychological treatment of panic disorder with or without agoraphobia: a meta-analysis. Clin Psychol Rev 30, 37-50.

Sasaki, I., Akiyoshi, J., Sakurai, R., Tsutsumi, T., Ono, H., Yamada, K., Fujii, I., 1996. Carbon dioxide induced panic attack in panic disorder in Japan. Prog Neuropsychopharmacol Biol Psychiatry 20, 1145-1157.

Schmidt, N.B., Zvolensky, M.J., 2007. Anxiety sensitivity and CO2 challenge reactivity as unique and interactive prospective predictors of anxiety pathology. Depress Anxiety 24, 527-536.

Schruers, K., Esquivel, G., van Duinen, M., Wichers, M., Kenis, G., Colasanti, A., Knuts, I., Goossens, L., Jacobs, N., van Rozendaal, J., Smeets, H., van Os, J., Griez, E., 2011. Genetic moderation of CO2-induced fear by 5-HTTLPR genotype. J Psychopharmacol 25, 37-42.

Schruers, K., van de Mortel, H., Overbeek, T., Griez, E., 2004. Symptom profiles of natural and laboratory panic attacks. Acta Neuropsychiatr 16, 101-106.

Senn, S.S., 2002. Cross-over trials in clinical research (2nd ed.). John Wiley \& Sons Ltd, Chichester, England.

Severson, C.A., Wang, W., Pieribone, V.A., Dohle, C.I., Richerson, G.B., 2003. Midbrain serotonergic neurons are central pH chemoreceptors. Nat Neurosci 6, 1139-1140.

Sheehan, D.V., Lecrubier, Y., Sheehan, K.H., Amorim, P., Janavs, J., Weiller, E., 1998. The Mini-International Neuropsychiatric Interview (M.I.N.I.): the development and validation of a structured diagnostic psychiatric interview for DSM-IV and ICD-10. J Clin Psychiatry 59 Suppl 20, 22-33.

Shufflebotham, J., Wetherell, M.A., Hince, D., Hood, S., Lightman, S., Nutt, D., Probert, C., Potokar, J., 2009. Women with diarrhoea-predominant irritable bowel syndrome show an increased pressure response to $35 \%$ carbon dioxide stress challenge. Stress 12, 30-36.

Smits, J.A., Meuret, A.E., Zvolensky, M.J., Rosenfield, D., Seidel, A., 2009. The effects of acute exercise on CO(2) challenge reactivity. J Psychiatr Res 43, 446-454.

Verburg, K., Griez, E., Meijer, J., Pols, H., 1995. Discrimination between panic disorder and generalized anxiety disorder by $35 \%$ carbon dioxide challenge. Am J Psychiatry 152, 1081-1083.

Verburg, K., Perna, G., Griez, E.J.L., 2001. A case study of the 35\% CO2 challenge, in: Griez EJL, F.C., Nutt D, Zohar J (Ed.), Anxiety Disorders. An Introduction to Clinical Management and Research, Wiley, Chichester, pp. 341-357.

Verburg, K., Pols, H., de Leeuw, M., Griez, E., 1998. Reliability of the 35\% carbon dioxide panic provocation challenge. Psychiatry Res 78, 207-214.

Verschoor, E., Markus, C.R., 2011. Physiological and affective reactivity to a $35 \% \mathrm{CO}(2)$ inhalation challenge in individuals differing in the 5-HTTLPR genotype and trait neuroticism. Eur Neuropsychopharmacol. 22, 546554.

Vilarim, M.M., Rocha Araujo, D.M., Nardi, A.E., 2011. Caffeine challenge test and panic disorder: a systematic literature review. Expert Rev Neurother 11, 1185-1195.

Weissman, M.M., Bland, R.C., Canino, G.J., Faravelli, C., Greenwald, S., Hwu, H.G., Joyce, P.R., Karam, E.G., Lee, C.K., Lellouch, J., Lepine, J.P., Newman, S.C., Oakley-Browne, M.A., Rubio-Stipec, M., Wells, J.E., Wickramaratne, P.J., Wittchen, H.U., Yeh, E.K., 1997. The cross-national epidemiology of panic disorder. Arch Gen Psychiatry 54, 305-309.

Wetherell, M.A., Crown, A.L., Lightman, S.L., Miles, J.N., Kaye, J., Vedhara, K., 2006. The four-dimensional stress test: psychological, sympathetic-adrenal-medullary, parasympathetic and hypothalamic-pituitary-adrenal responses following inhalation of 35\% CO2. Psychoneuroendocrinology 31, 736-747.

Ziemann, A.E., Allen, J.E., Dahdaleh, N.S., Drebot, II, Coryell, M.W., Wunsch, A.M., Lynch, C.M., Faraci, F.M., Howard, M.A., 3rd, Welsh, M.J., Wemmie, J.A., 2009. The amygdala is a chemosensor that detects carbon dioxide and acidosis to elicit fear behavior. Cell 139, 1012-1021. 


\section{Supplement}

Systolic Blood Pressure $(\mathrm{mmHg})$

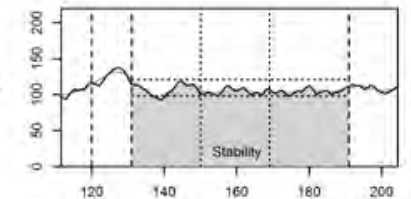

$9 \%$

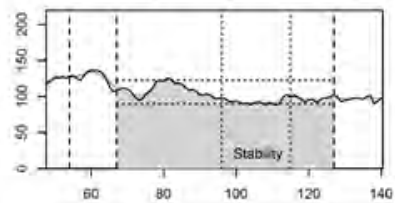

$17.5 \%$

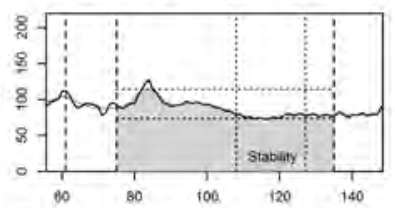

$35 \%$

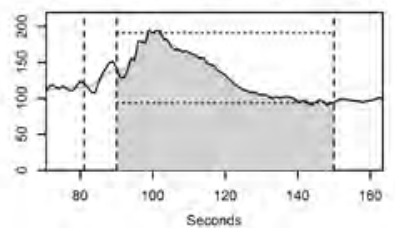

Diastolic Blood Pressure $(\mathrm{mmHg})$
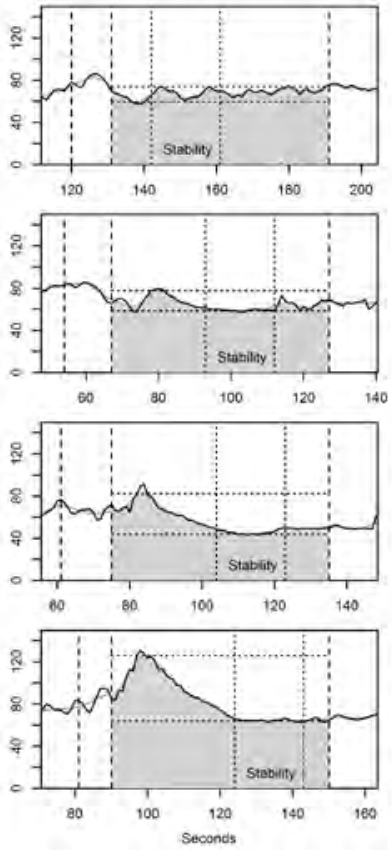

Heart Rate (bpm)
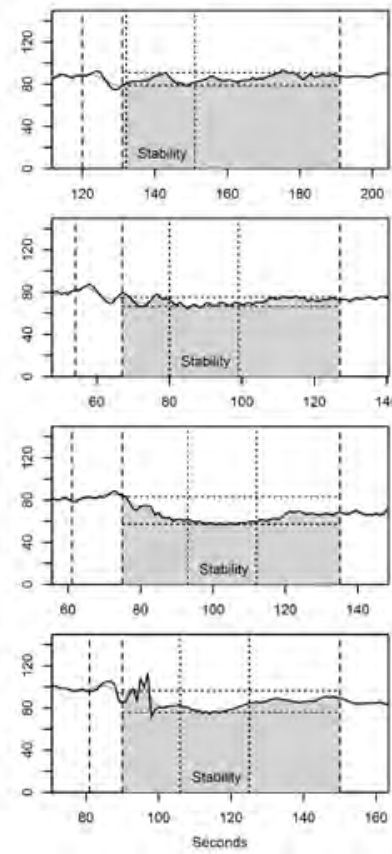

Figure 1. Example profiles of one subject for the analysis of cardiovascular measurements (left: systolic, middle: diastolic blood pressure, right: heart rate). From upper to lower panel: $0 \%, 9 \%, 17.5 \%$, and $35 \% \mathrm{CO}_{2}$. Indicated are (from left to right within one plot): the baseline phase, inhalation phase (first two vertical dashed lines), recovery phase (60 s) after inhalation, end of recovery phase (right-most dashed line), AUC (gray area), peak (top horizontal dotted line), minimum (bottom horizontal dotted line), and the time window in which stability is reached (two vertical dotted lines; only indicated when stability is actually reached, i.e. when the subject recovered). Regarding blood pressure, the peak and AUC increase the higher the $\mathrm{CO}_{2}$ dosage, with a shift to the right of reaching a stable value within $60 \mathrm{~s}$. Heart rate was affected to a lesser extent, showing no large alterations with increasing $\mathrm{CO}_{2}$ dosage. 

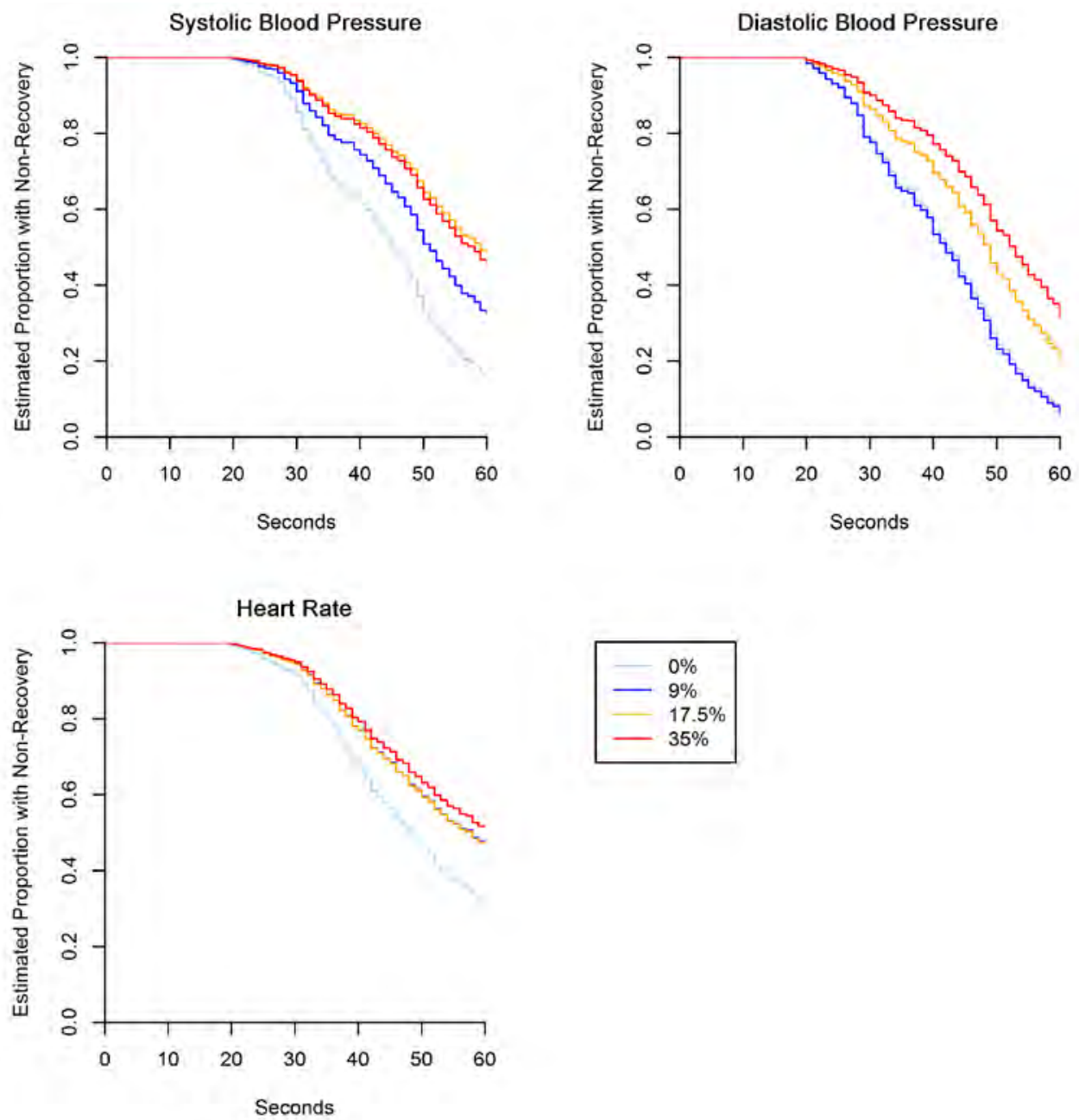

Figure 2. Proportion of subjects that did not recover regarding systolic blood pressure (top panel, left), diastolic blood pressure (top panel, right), and heart rate (bottom panel) within $60 \mathrm{~s}$ after the $\mathrm{CO}_{2}$ inhalation. Top panel, left: Regarding systolic blood pressure, the proportion of subjects increased with higher $\mathrm{CO}_{2}$ concentrations, though statistical significance was only reached for increased $\mathrm{CO}_{2}$ concentrations compared to $0 \% \mathrm{CO}_{2}$, and $9 \%$ compared to $17.5 \%$. Top panel, right: Concerning diastolic blood pressure, the proportion of subjects increased with gradually increasing $\mathrm{CO}_{2}$ concentrations. However, $9 \%$ did not differ from $0 \% \mathrm{CO}_{2}$. Bottom panel: All administered $\mathrm{CO}_{2}$ concentrations resulted in higher proportions who did not recover within 60 $\mathrm{s}$ compared to $0 \% \mathrm{CO}_{2}$. The effects of $\mathrm{CO}_{2}$ itself was comparable in all concentrations. For $\mathrm{p}$-values see Table 2 in publication (pairwise comparisons using Holm's method, adjusted for multiple testing). 
Table 1. Effects of increasing $\mathrm{CO}_{2}$ concentrations on the proportion of subjects who did not recover (compared to $0 \% \mathrm{CO}_{2}$ ) regarding the systolic as well as diastolic blood pressure and heart rate within the $60 \mathrm{~s}$ after the inhalation. Values represent means over the entire analyzed $60 \mathrm{~s}$ phase.

\begin{tabular}{|c|c|c|c|c|}
\hline & $\% \mathrm{CO}_{2}$ & $\begin{array}{l}\text { Systolic blood } \\
\text { pressure }\end{array}$ & $\begin{array}{l}\text { Diastolic blood } \\
\text { pressure }\end{array}$ & Heart rate \\
\hline \multirow{4}{*}{$\begin{array}{l}\text { Proportion non-recovery } \\
\text { (compared to } 0 \% \mathrm{CO}_{2} \text { ) }\end{array}$} & 0 & - & - & - \\
\hline & 9 & 1.6 & 1.0 & 1.5 \\
\hline & 17.5 & 2.5 & 1.7 & 1.5 \\
\hline & 35 & 2.3 & 2.3 & 1.7 \\
\hline
\end{tabular}


The relationship between emotions and cardiovascular physiology

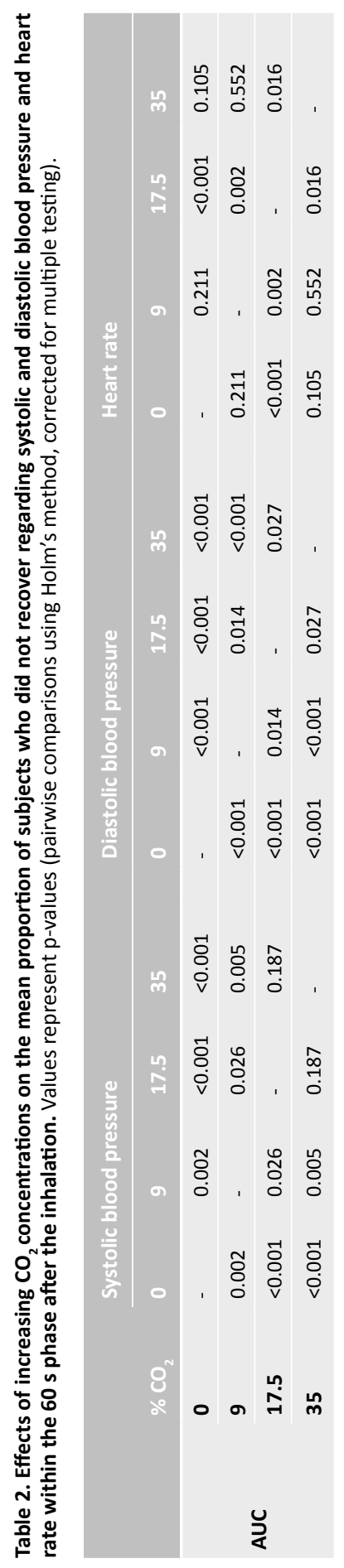




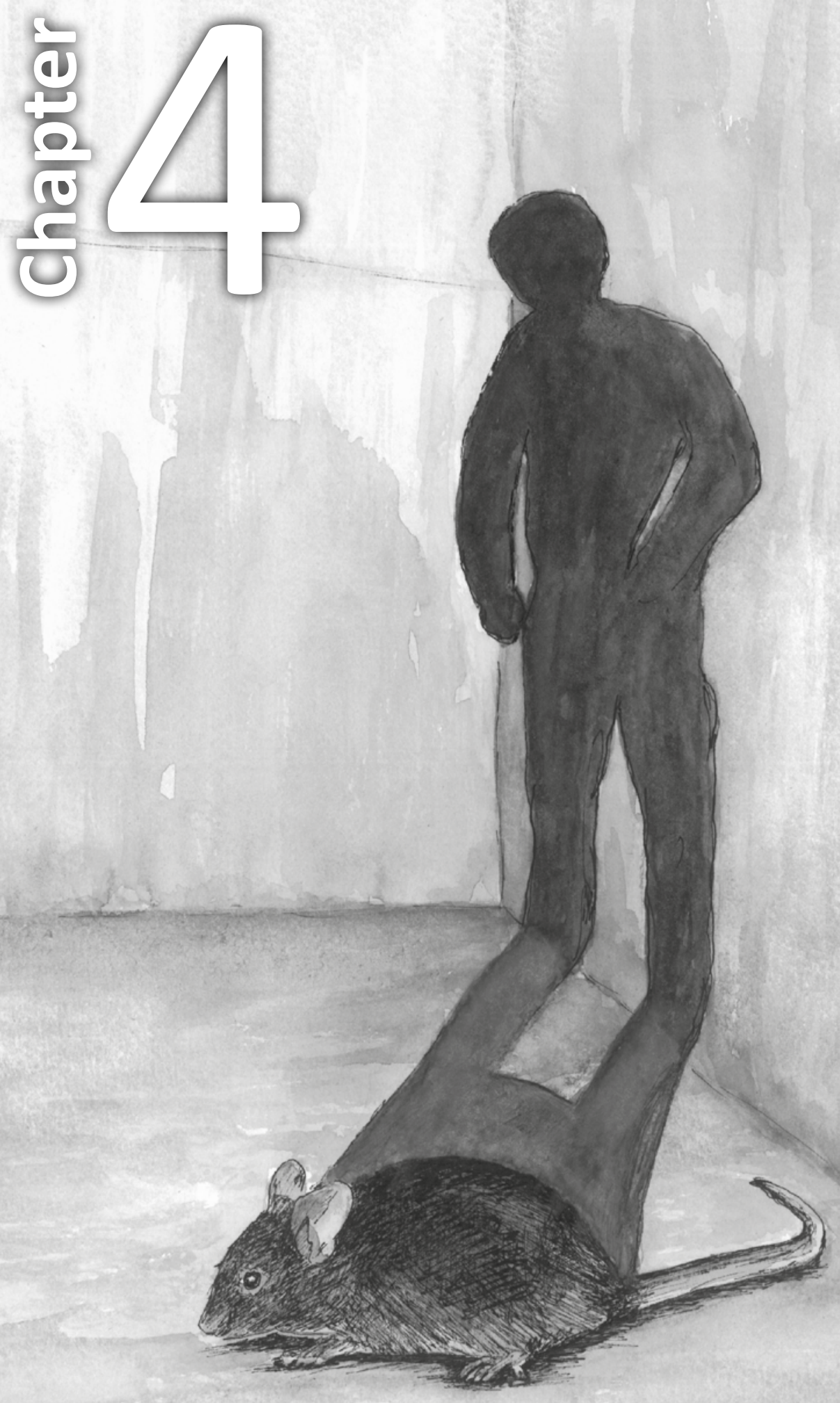




\section{Brainstem response to hypercapnia: A symptom provocation study into the pathophysiology of panic disorder}

Liesbet Goossens ${ }^{a}$, Nicole Leibold ${ }^{a}$, Ronald Peeters ${ }^{b}$, Gabriel Esquivel ${ }^{a}$, Inge Knuts ${ }^{\mathrm{a}, \mathrm{d}}$, Walter Backesc, Machteld Marcelis ${ }^{\mathrm{a}}$, Paul Hofmanc, Eric Griez ${ }^{\mathrm{a}}$, Koen Schruers ${ }^{\mathrm{a}, \mathrm{d}, \mathrm{e}}$

a Department of Psychiatry and Neuropsychology, European Graduate School of Neuroscience (EURON), Maastricht University, the Netherlands

b Department of Radiology, University Hospitals of Leuven, Belgium

c Department of Radiology, Maastricht University Medical Center, the Netherlands

d Academic Anxiety Center, Mondriaan Mental Health Center, Maastricht, the Netherlands

e Center for the Psychology of Learning and Experimental Psychopathology, Catholic University Leuven, Belgium 


\section{Abstract}

Background: The biological basis of uncued panic attacks is not yet understood. An important theory concerning the nature and cause of panic disorder is the "suffocation false alarm theory". This alarm is supposed to be over-sensitive in panic disorder patients and can be triggered by $\mathrm{CO}_{2}$. No neurobiological substrate has been identified for such an alarm. The present study investigates differences in brain activation in panic patients, healthy individuals and experienced divers in response to $\mathrm{CO}_{2}$, representing three groups with descending sensitivity to $\mathrm{CO}_{2}$.

Method: Brain activation was measured with functional magnetic resonance imaging. Subjects breathed through a mouthpiece delivering a continuous flow of $100 \%$ oxygen for $2 \mathrm{~min}$, followed by a hypercapnic gas mixture $\left(7 \% \mathrm{CO}_{2}\right)$ the next $2 \mathrm{~min}$. Statistical analysis was performed using SPM8.

Results: There was a significant main effect of group in response to the $\mathrm{CO}_{2}$. Patients show increased brainstem activation in response to hypercapnia compared to controls and divers. Subjective feelings of breathing discomfort were positively correlated with brain activation in the anterior insula in all groups.

Conclusion: This is the first study showing that the behavioral response to $\mathrm{CO}_{2}$ that characterizes panic disorder patients is likely due to increased neural sensitivity to $\mathrm{CO}_{2}$ at brainstem level. 


\section{Introduction}

The biological basis of uncued panic attacks, a core and unique part of panic disorder (PD), is not yet fully understood. Two decades ago, Klein (1993) proposed that these attacks occur when a brain suffocation monitor erroneously signals a lack of useful air. According to this theory, this monitor is present in everyone but is over-sensitive in PD patients. Triggering causes a physical and psychological state of alarm (panic) in situations where there is no actual risk for suffocation. To date, no neurobiological substrate has been identified for such a monitor.

It has been proposed that spontaneous panic attacks are the result of an oversensitive $\mathrm{pH}$-monitoring network (Esquivel et al., 2009). Given that respiratory symptoms such as feelings of suffocation or choking are cardinal features of spontaneous panic attacks, it is plausible that a degree of overlap exists between the chemosensitive neurons that serve respiration and those that are involved in triggering panic (Colasanti et al., 2008). Accordingly, challenge tests involving breathing of excess concentrations of $\mathrm{CO}_{2}$ are an established experimental model to elicit panic in the laboratory.

Detection of carbon dioxide and the accompanying changes in $\mathrm{pH}$ occurs mainly in brainstem regions (Esquivel et al., 2009). Several of these same structures have also been implicated in defensive behavior, including panic (Bailey et al., 2003).

Imaging studies involving $\mathrm{CO}_{2}$ in the light of panic are very scarce. However, there have been functional imaging studies administering gas mixtures with an elevated $\mathrm{CO}_{2}$ concentration in the framework of breathing research. As predicted from chemosensitivity studies in animals, breathing research confirms brainstem involvement in the human response to hypercapnia (Gozal et al., 1994, Brannan et al., 2001). Brannan and colleagues (Liotti et al., 2001) further report that primarily limbic and paralimbic brain regions are associated with consciousness of breathlessness. Breathlessness, or shortness of breath, is a key feature in dyspnea (subjective experience of breathing discomfort that subsumes qualitatively distinct sensations with variable intensity), which in turn is a core symptom of a panic attack (Perna et al., 2004). Several studies point to the insular cortex as the internal monitor of the subjective feeling of breathing discomfort/dyspnea (Banzett et al., 2000, Craig, 2002, Von Leupoldt et al., 2008).

Given the hypothesis of an oversensitive $\mathrm{pH}$-monitoring network and the availability of $\mathrm{CO}_{2}$-inhalation as a well-established panic provocation procedure, it is a logical step to study brain activation in response to $\mathrm{CO}_{2}$ in $\mathrm{PD}$ patients. The present study seeks to explore the neurobiology of panic attacks, which constitute the core phenomenon at the onset of the disorder. In line with this emphasis on the attacks and the abovementioned importance of chemoreceptive brain regions therein, the present study focused on the brainstem. Three brainstem regions in particular have been proposed to be involved in 
both panic and chemosensitivity: the periaqueductal gray (PAG), the raphe nuclei (RN) and the locus coeruleus (LC). The effects of $\mathrm{CO}_{2}$ have been proposed to be mediated via the noradrenaline network. In vitro and animal studies suggest that $\mathrm{CO}_{2}$ may directly activate neurons in the LC (Bailey et al., 2003), although direct in vivo evidence in humans is lacking up to date. Serotonin producing cells in the raphe have also been identified as $\mathrm{CO}_{2}$ sensors, acting to maintain $\mathrm{pH}$ homeostasis and have been proposed to form the cellular basis of the link between serotonin, chemoreception and panic (Richerson, 2004). The RN have strong projections to the PAG and a sizeable portion of the efferent projections of the LC, mainly from the A1 and A5 cell groups, also reach the PAG (Nieuwenhuys et al., 2008). The PAG has been implicated in the origin of panic since the observation that electrical stimulation of this structure in awake patients undergoing a neurosurgical procedure caused symptoms remarkably similar to those reported by PD patients during their panic attacks (Del-Ben et al., 2009). Functional neuroimaging confirms an increasingly important role for the PAG in responses towards threats as they approach the subject (Mobbs et al., 2010).

Recently, a dose-response relationship to $\mathrm{CO}_{2}$ has been demonstrated in healthy volunteers: depending on individual vulnerability, experimental panic occurs at high dosages (Griez et al., 2007). These data support the hypothesis of individual sensitivity to increasing concentrations $\mathrm{CO}_{2}$ as a continuously distributed trait (Klein, 1993, Pine et al., 2000) and point to the existence of a response spectrum, with PD patients at the highest end of the spectrum. At the other end are individuals with a low sensitivity to $\mathrm{CO}_{2}$, such as individuals suffering from "congenital central hypoventilation syndrome" (CCHS). These patients have a deficient response to hypercapnia. When exposed to elevated levels of $\mathrm{CO}_{2}$, CCHS patients do not feel discomfort or the need to breathe (Harper et al., 2005). Similarly, divers also show a decreased sensitivity to $\mathrm{CO}_{2}$ (Delapille et al., 2001).

In order to use the full spectrum of $\mathrm{CO}_{2}$ sensitivity, the present study involved a group of experienced divers, next to PD patients and normal healthy volunteers. Based on the above-mentioned studies we hypothesized increased $\mathrm{CO}_{2}$-induced brainstem activation in PD patients, but decreased activation in the divers, both versus normal controls.

\section{Methods}

\section{Subjects}

Fifteen PD patients (seven males; mean age: 38.3 years, standard deviation (SD): 10.4; for details on clinical characteristics see Table 1) visiting the outpatient clinic of the Academic Anxiety Center in Maastricht, meeting the Diagnostic and Statistical Manual of Mental Disorders (DSM) criteria (APA, 2000) for PD (with or without agoraphobia), 
were recruited for this study. Patients were excluded if they had any current comorbid axis I diagnosis. Patients on any psychotropic medication underwent a washout period and were medication free for at least 4 weeks before inclusion. Twelve healthy control subjects (seven males; mean age: 38.7 years, SD: 10.9) were matched in age and sex to the patients. Healthy controls were free of any psychopathology. Control subjects were excluded if they had a positive result on the $35 \% \mathrm{CO}_{2}$-inhalation test. A second control group of 15 experienced divers ( 9 males, mean age: 47.6 years, SD: 6.5) participated in the study. Divers were free of any psychopathology and had an experience of at least 200 diving hours.

Psychiatric diagnosis (or absence thereof) in patients, controls and divers was assessed by a structured psychiatric interview (Mini International Neuropsychiatric Interview, M.I.N.I.; Sheehan et al., 1998). Written informed consent was obtained from each participant before the experiment. The study was approved by the local ethics committee.

Table 1. Clinical characteristics of the panic disorder patients.

\begin{tabular}{|c|c|c|c|c|c|c|}
\hline Patient & MADRS & STAI I & STAI II & FQ tot & PAS & Duration (years) \\
\hline 1 & 2 & 41 & 35 & 20 & 19 & 2 \\
\hline 2 & 10 & 45 & 39 & 28 & 26 & n.k. \\
\hline 5 & 0 & 33 & 37 & 28 & 21 & 4 \\
\hline 6 & 17 & 55 & 61 & 6 & 16 & 6 \\
\hline 7 & 6 & 46 & 42 & 6 & 19 & 3 \\
\hline 8 & 5 & 53 & 37 & 4 & 13 & 13 \\
\hline 9 & 8 & 46 & 38 & 44 & 28 & 4 \\
\hline 10 & 6 & 43 & 54 & 53 & 23 & 3 \\
\hline 11 & 7 & 42 & 42 & 40 & 14 & 28 \\
\hline 12 & 6 & 38 & 38 & 27 & 19 & 4 \\
\hline 13 & 15 & 53 & 49 & 51 & 26 & 7 \\
\hline 14 & 9 & 47 & 54 & 29 & 19 & 1 \\
\hline Mean & 7.58 & 45.17 & 43.83 & 28 & 20.25 & 4.7 \\
\hline SEM & 1.39 & 1.86 & 2.46 & 4.9 & 1.38 & 1.03 \\
\hline
\end{tabular}

FQ: Fear Questionnaire; MADRS: Montgomery Asberg Depression Rating Scale; n.k.: not known; PAS: Panic and Agoraphobic Scale; SEM: standard error of the mean; STAI: State-Trait Anxiety Inventory.

\section{$\mathrm{CO}_{2}$ set-up}

The set-up was adapted from van der Zande et al. (2005). The gas mixture was released in an open circuit at a rate of $15 \mathrm{~L} / \mathrm{min}$, designed to allow ad libitum breathing with minimal positive pressure or resistance. Subjects were instructed to breathe normally. Compliance was monitored by capnometry (Normocap 200, Datex, Helsinki, Finland) at the mouthpiece 


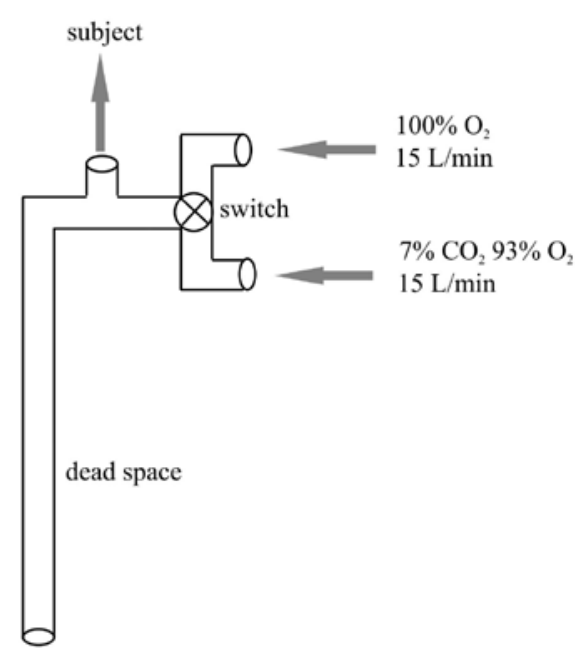

Figure 1. The breathing device. Schematic drawing of the breathing device.

level, which shows the amount of $\mathrm{CO}_{2}$ in the system. A researcher was always present in the scanning room to ensure continuous breathing through the mouthpiece. A schematic of the breathing device can be found in Figure 1.

\section{Procedure}

All subjects underwent a $35 \% \mathrm{CO}_{2}$ challenge on the screening day. The inhalation apparatus and the general procedures used in our laboratory have been described in detail elsewhere (Verburg et al., 2001). A positive response was defined by an increase of $20 \mathrm{~mm}$ or more on the visual analogue scale of fear (VAS-F) and a rise of at least 4 symptoms on the panic symptom list (PSL).

On the test day, all subjects were familiarized with the breathing procedure before the start of the scan session, with the table positioned outside the magnet bore. Subjects underwent three consecutive scanning runs of 4 min during which they breathed through the mouthpiece. The 4 min were divided in a two-minute continuous flow of $100 \%$ oxygen followed by two-minute flow of a high $\mathrm{CO}_{2}$ gas mixture $\left(7 \% \mathrm{CO}_{2}, 93 \% \mathrm{O}_{2}\right)$. A fitted nose clip ensured that the subject breathed through the mouthpiece. Subjects inserted the mouthpiece immediately before the start of the functional scan. Subjects were allowed to remove the mouthpiece between runs and scanning would proceed at the subject's own pace. The reactivity to $\mathrm{CO}_{2}$ was assessed with the increments of subjective symptoms registered on the PSL, VAS-F and a visual analogue scale for discomfort (VAS-D). The PSL and both scales were administered twice: immediately before scanning and directly after, asking to score the worst moment. 


\section{Image acquisition}

Brain images were acquired using a 3.0 Tesla Philips Achieva scanner equipped with an 8-element receive-only head coil. For functional images, $80 \mathrm{~T} 2 *$-weighted echoplanar images with blood-oxygenation level-dependent (BOLD) contrast were acquired three times for each subject [echo time $=33 \mathrm{~ms}$, repetition time $=3000 \mathrm{~ms}$, flip angle $=90^{\circ}$, slice thickness $4.0 \mathrm{~mm}$, interslice gap $0 \mathrm{~mm}$, field of view $=230 \times 230 \times 136 \mathrm{~mm}$, matrix size $80 \times 80$, in-plane resolution $=2.88 \times 2.88 \mathrm{~mm}$ ]. Thirty-four sagittal slices per volume were positioned at an angle between the line crossing the anterior and posterior commissure (AC-PC line) and a line paralleling the medial tentorium cerebelli in order to reduce susceptibility artifacts. In addition, a high-resolution T1 anatomical image was obtained for each subject using a standard 3D magnetization-prepared rapid acquisition gradient echo (MP RAGE) sequence with $1 \mathrm{~mm}^{3}$ isotropic voxels.

\section{fMRI Data Analysis}

Data quality assurance consisted of visual inspection of the raw and pre-processed data for susceptibility artifacts and other global aspects (e.g. lines in scans, artifacts in the brainstem). Furthermore, data sets were excluded when head movement exceeded $3 \mathrm{~mm}$ in either direction ( $x, y$, or $z$ axis). In total, 7 subjects were excluded from further image processing ( 3 patients, 1 control subject, and 3 divers). A final sample 35 subjects was included in the imaging analyses: 12 patients, 11 controls and 12 divers.

The functional images were realigned to the first volume of the time series to correct for head movements (four dummy images at the beginning of each time series were discarded for further analysis). After co-registering functional images to the anatomical image, they were spatially normalized to the standard space of the Montreal Neurological Institute brain (MNI brain). All functional images were sub-sampled to a voxel size of $2 \times 2 \times 2 \mathrm{~mm}$. Normalized images were smoothed with a Gaussian kernel of $6 \mathrm{~mm}$ full width at half maximum.

First-level statistical analysis was done for all subjects in the context of the General Linear Model. The $7 \% \mathrm{CO}_{2}$ condition was modeled as a boxcar epoch-related function. The model was convolved with a hemodynamic response function and its time derivatives in the general linear model. Movement parameters were included as a null regressor. Temporal filtering was not done due to the potential confound between linear drift and $\mathrm{CO}_{2}$ induced activation. For the same reason, global BOLD signal correction was not employed. Individual contrast images were used in a second-level random effects analysis, which accounts for both scan-to-scan and subject-to-subject variability, to determine $\mathrm{CO}_{2}$-specific regional responses for within- and between-group statistical comparisons.

Because of our a priori hypothesis regarding the response in the brainstem, a region of 
interest (ROI) analysis was conducted. The ROI comprised the LC, the PAG and the RN. The LC ROI was based on Keren et al. (2009). ROIs for the PAG and the rostral RN were drawn on the basis of Duvernoy's atlas of the human brainstem and cerebellum (Naidich et al., 2009). The three ROls were combined to a single continuous volume consisting of 504 voxels $\left(4032 \mathrm{~mm}^{3}\right)$. The significance level was set at $\mathrm{p}<0.05$, and corrected for multiple comparisons using the family-wise error rate.

The subjective feeling of respiratory distress during the $7 \%$ challenge was correlated with brain activation to $\mathrm{CO}_{2}$ by means of a second-level multiple regression analysis in SPM8. The subjective feeling of respiratory distress was composed by the delta scores on items of the PSL that characterize the respiratory component of a panic attack, namely "sensation of shortness of breath" and "feeling of choking". We have previously shown that this component is the best predictor of the subjective distress in experimentally provoked panic attacks (Colasanti et al., 2008). The significance level of the regression analyses was set at $p<0.05$, and corrected for multiple comparisons using the family-wise error rate for the insula (4188 voxels).

\section{Global BOLD signal}

Average values from all voxels were calculated for each image volume in the first run, resulting in a time course of the global signal during the first challenge for each subject. Signal intensities were normalised against the first five scans, i.e. each volume in a series was scaled to a percentage of the mean volume intensity of the first five images. The resulting global time series were analysed using repeated measures analysis of variance (ANOVA) to determine differences in response between patients, controls, and divers.

\section{Statistical analysis on behavioral and capnometric data}

The within-group pre- and post-challenge scores on the PSL, VAS-F, and VAS-D were analyzed with the Wilcoxon Signed Ranks test. The difference in delta scores between groups was analyzed by the Kruskal-Wallis test. Post-hoc testing was done by MannWhitney $U$ tests.

The mean percentage of end-tidal $\mathrm{CO}_{2}\left(\mathrm{PET}-\mathrm{CO}_{2}\right)$ and the respiratory rate (RR) were extracted from the capnometric data employing the software $R$ (version 2.14.0, 2011, $R$ Development Core Team, Vienna, Austria). A repeated measures ANOVA with run (1/2/3) and condition $\left(\mathrm{CO}_{2} / \mathrm{O}_{2}\right)$ as within-subject factors, and group as between-subject factor was used to analyse differences in PET- $\mathrm{CO}_{2}$ and $\mathrm{RR}$. 


\section{Results}

\section{Behavioral and capnometric data}

The $35 \% \mathrm{CO}_{2}$ challenge during the screening interview induced a significant increase in subjective fear and panic symptoms in all three groups as measured with the VAS-F (patients: $z=-2.93, p=0.003$; controls: $z=-2.81, p=0.005$; divers: $z=-2.23, p=0.026$ ) and the PSL (patients: $z=-2.93, p=0.03$; controls: $z=-2.81, p=0.005$; divers: $z=-3.07, p=0.002$ ). As expected, the delta VAS-F was significantly higher in the patient group than in controls $(z=-3.43, p<0.001)$ and divers $(z=-4.11, p<0.001)$. The controls scored significantly higher on the VAS-F than the divers ( $z=-2.67, p=0.007)$.

The $7 \%$ challenge inside the scanner evoked higher fear scores in the patients than in the controls $(z=-2.53, p=0.01)$ and the divers $(z=-3.00, p=0.002)$. However, the VAS-F scores did not differ between controls and divers during the 7\%-challenge. In contrast with $7 \%$ VAS-F score, the amount of symptoms experienced during the $7 \%$-challenge differed only significantly between the patients and the divers $(z=-3.00 p=0.002)$. There is a significant

Table 2. Descriptive data. Mean and standard error of the mean (SEM) values of behavioral data.

\begin{tabular}{|c|c|c|c|c|c|c|c|c|c|}
\hline \multicolumn{10}{|c|}{$35 \% \mathrm{CO}_{2}$ Challenge } \\
\hline & \multicolumn{3}{|l|}{ PSL } & \multicolumn{6}{|l|}{ VAS-F } \\
\hline & pre & post & delta & pre & post & delta & & & \\
\hline Patients & $3.7(1.1)$ & $21.9(3.3)$ & $13.3(3.8)$ & $24.1(6.6)$ & $80.4(6.5)$ & 42.9 (9.7) & & & \\
\hline Controls & $0.6(0.3)$ & $8.5(2.1)$ & $2.8(0.9)$ & $3.3(1.7)$ & $15.7(5.2)$ & $2.6(0.9)$ & & & \\
\hline Divers & $0.8(0.3)$ & $7.5(1.2)$ & $6.2(1.2)$ & $1.8(0.9)$ & $5.3(2.2)$ & $3.2(2.0)$ & & & \\
\hline \multicolumn{10}{|c|}{$7 \% \mathrm{CO}_{2}$ Challenge } \\
\hline & \multicolumn{3}{|l|}{ PSL } & \multicolumn{3}{|l|}{ VAS-F } & \multicolumn{3}{|l|}{ VAS-D } \\
\hline & pre & post & delta & pre & post & delta & pre & post & delta \\
\hline Patients & $3.7(1.6)$ & $15.0(2.7)$ & $7.5(2.7)$ & $14.2(3.6)$ & $46.0(8.4)$ & $31.7(6.5)$ & 17.00 (4.9) & $57.2(8.7)$ & $40.2(7.6)$ \\
\hline Controls & $0.3(0.2)$ & $4.4(1.0)$ & $3.0(1.0)$ & $3.2(1.4)$ & $13.1(4.5)$ & $9.9(3.6)$ & $7.0(1.6)$ & $35.6(8.2)$ & $28.6(7.2)$ \\
\hline Divers & $0.3(0.2)$ & $3.3(0.9)$ & $2.7(3.0)$ & $0.6(0.3)$ & $4.5(2.1)$ & $3.9(2.1)$ & $1.5(0.6)$ & $10.07(3.5)$ & $9.2(3.9)$ \\
\hline
\end{tabular}

Table 3. Capnometric data. Mean and standard error of the mean (SEM) values of behavioral data.

\begin{tabular}{|c|c|c|c|}
\hline & & \multicolumn{2}{|c|}{ CONDITION } \\
\hline & & $\mathrm{O}_{2}$ & $\mathrm{CO}_{2}$ \\
\hline \multirow{3}{*}{ PET-CO ${ }_{2}(\%)$} & Patients & $4.12(0.87)$ & $6.21(0.58)$ \\
\hline & Controls & $4.38(0.62)$ & $6.25(0.36)$ \\
\hline & Divers & $4.72(0.76)$ & $6.39(0.39)$ \\
\hline \multirow{3}{*}{$\begin{array}{l}\text { Respiratory rate } \\
\text { (breaths/minute) }\end{array}$} & Patients & $14.75(2.44)$ & $14.08(2.03)$ \\
\hline & Controls & $12.79(1.80)$ & $13.00(1.51)$ \\
\hline & Divers & $12.19(1.32)$ & $12.22(1.61)$ \\
\hline
\end{tabular}


increase in discomfort in all three groups during the scanning test. There is only a significant difference between the delta VAS-D scores of patients and divers $(z=-3.00, p=0.002)$. Descriptive data of the behavioral measures are depicted in Table 2; capnometric data are displayed in Table 3.

As expected, the $7 \% \mathrm{CO}_{2}$ challenge induced a significant increase in $\mathrm{PET}-\mathrm{CO}_{2}$ in all groups (main effect of condition: $F=101.72, p<0.001$ ). There was no main effect of group, nor a significant group by condition interaction (Main effect of group: $F=1.61, p=0.23$; group $x$ condition interaction: $\mathrm{F}=0.42, \mathrm{p}=0.67)$. Hence, there was no baseline difference in PET$\mathrm{CO} 2$ between the groups, and the induced rise in PET- $\mathrm{CO}_{2}$ did not differ between groups. The ANOVA for the RR did not yield significant results. There were no baseline differences

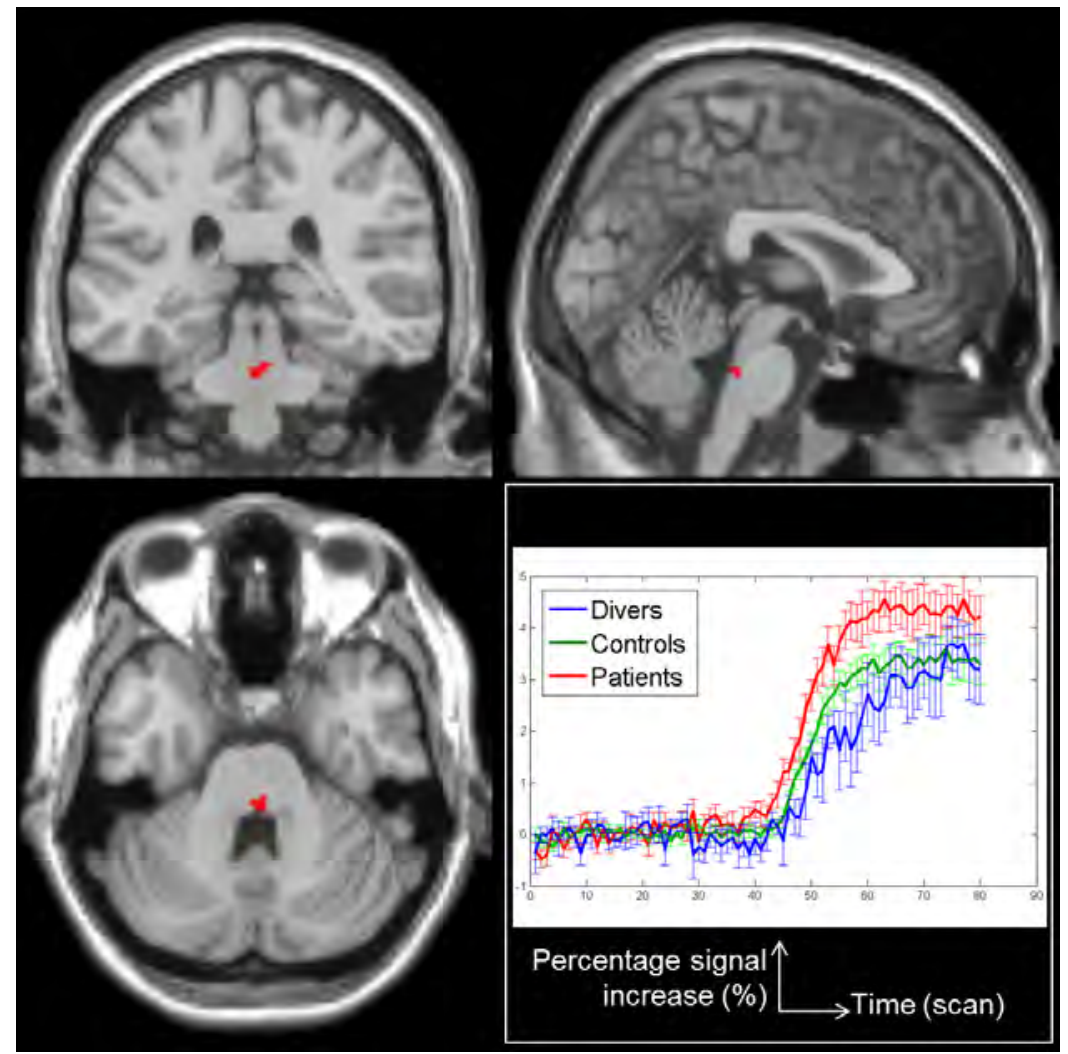

Figure 2. Main effect of group. Top and bottom left: Activation maps showing the main effect of group in the brainstem. Bottom right: The graph displays the mean percentage of signal increase for each group in the brainstem cluster (standard error of the mean (SEM) error bars). The activation maps show the voxels with a significant main effect of group overlaid on a template T1 image. The graph shows the mean percentage of BOLD signal increase in these voxels for the three different groups. 
present between groups. The $7 \% \mathrm{CO}_{2}$ challenge did not induce a significant increase in breathing frequency.

\section{Global BOLD signal}

The increase in global BOLD signal was not significantly different between groups $(F=0.281$, $p=0.76)$.

\section{Imaging data}

The ROI analysis revealed a significant main effect of group in the brainstem (MNI coordinates and statistical values of peak activation: $[2-32-30], F(2,32)=9.59, P_{F W E}=0.043$ ) (Figure 2). Post-hoc two-sample t-tests showed significantly higher brain activation at the above cluster in patients compared to the controls ( $\mathrm{MNI}$ coordinates and statistical values of peak activation: [4 -34 -28], $\mathrm{t}=3.10, \mathrm{P}_{\mathrm{FWE}}=0.012$ ) and divers ( $\mathrm{MNI}$ coordinates and statistical values of peak activation: $[4-30-28], t=3.99, P_{F W E}=0.002$ ).

A correlation analysis between brain activation and the subjective ratings of the respiratory cluster of PSL symptoms was significantly positive in all three groups with brain activation in the right anterior insula ( $\mathrm{MNI}$ coordinates and statistical values of peak activation: [34 8 18], $t=4.68, P_{F W E}=0.033, r=0.66$ ) (Figure 3).

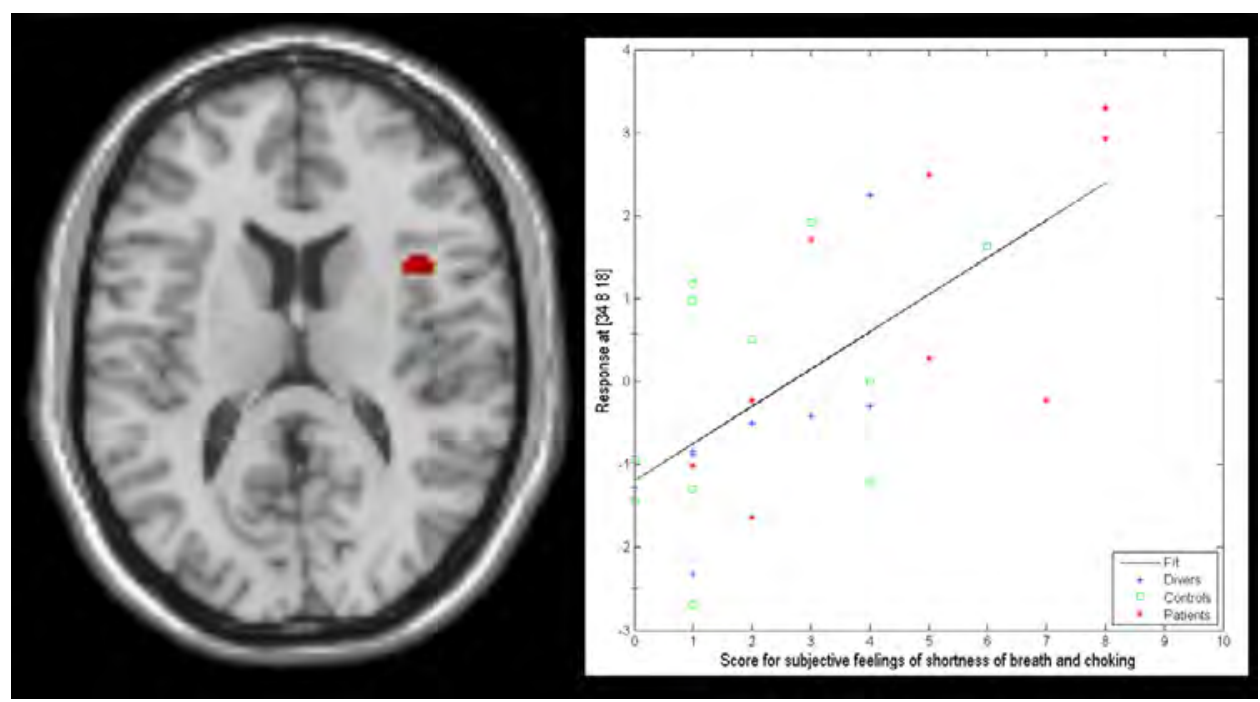

Figure 3. Positive correlation at the anterior insula with the subjective score of feelings of shortness of breath and choking. Left: Activation map showing voxels in the anterior insula significantly correlated the subjective score. Right: Graph depicting the positive correlation at the most significant voxel. 


\section{Discussion}

The present study is the first to show increased brainstem activation in response to hypercapnia in PD patients compared to normal controls. A second comparison group of experienced divers displayed a decreased response in comparison to the normal controls. Subjective feelings of shortness of breath and choking were positively correlated with brain activation in the anterior insula in all three groups: the higher the increase in the subjective feelings, the higher the activity in the anterior insula.

The brainstem finding is consistent with our hypothesis. The identified cluster is situated in the rostral dorsal pons and located in the rostral raphe ROI of our brainstem mask. Previously, the administration of increased $\mathrm{CO}_{2}$ during functional magnetic resonance imaging (fMRI) was used to study CCHS (Harper et al., 2005). CCHS patients show a lack of fear and breathlessness in response to hypercapnia. Accordingly, results of that study revealed clusters of decreased response to $\mathrm{CO}_{2}$, extending from the thalamus through the midbrain to the dorsolateral pons. The data from the present study are in line with these findings: In participants displaying a decreased behavioral response to $\mathrm{CO}_{2}$ (divers) a decreased activation of an overlapping part of the brainstem was demonstrated, while in those who show an increased behavioral response to $\mathrm{CO}_{2}$ (PD patients), an increased activation occurred.

The rostral raphe nuclei have widespread axonal projections to limbic structures implicated in comprehensive neuroanatomical models of PD such as the amygdala, prefrontal cortex and anterior cingulate cortex (Hornung, 2003). Serotonergic neurons are the major constituents of the RN. There is a large body of evidence implicating serotonin in the neurobiology of PD. For instance, combining tryptophan depletion, lowering serotonin availability to the brain, with a $35 \% \mathrm{CO}_{2}$ panic challenge results in an increased panic response in PD patients (Schruers et al., 2000). Conversely, increasing serotonin availability through administration of its precursor 5-hydroxy-tryptamine blocks the panic response (Schruers et al., 2002). Further pointing to a 5-HT-related dysfunction in PD patients, positron emission tomography (PET) imaging studies show reduced binding to the $5-\mathrm{HT}_{1 \mathrm{~A}}$ receptor in the raphe region (Nash et al., 2008).

Furthermore, a chemosensitive function has been ascribed to midbrain serotonergic neurons (Severson et al., 2003). The authors proposed that midbrain raphe neurons are responsible for non-respiratory related effects of carbon dioxide, such as arousal and fear. This proposal provides an essential link between serotonin and panic: serotonergic neurons in the rostral raphe nuclei can account for oversensitive central chemoreception leading to a "false suffocation alarm".

While activation of the raphe nuclei seems the most parsimonious explanation of the current data, other possibilities have to be taken into account since categorical statements 
about the precise anatomical location of brainstem activations cannot be made with the current spatial resolution of $\mathrm{fMRI}$. A similar brainstem cluster was also found in studies into functional neuroanatomy of the brainstem respiratory control network, using inhalation of $\mathrm{CO}_{2}$ (Brannan et al., 2001, Pattinson et al., 2009). The authors interpret the findings as due to activity in the parabrachial Kölliker-Fuse complex. From animal studies it is known that this complex plays an essential role in respiratory modulation. However, it has also been shown in rats that this complex has strong connections with the limbic system, including the insula (Pattinson et al., 2009).

Neuroanatomical models of PD as a whole, of which panic attacks are only one part, proposed the involvement of several other brain structures in addition to the brainstem such as the prefrontal cortex, amygdala, anterior cingulate cortex (ACC) (Esquivel et al., 2009), thereby putatively accounting for symptoms such as anticipatory anxiety and avoidance behavior as well. The distinction between panic attacks on one hand and anticipatory anxiety on the other in PD is comparable to the way ethoexperimental analyses of defense strategies divide defensive behavior into fear and anxiety (Mcnaughton et al., 2004). This theory, mainly based on animal models, distinguishes different types of defensive strategies depending on the distance to a (potential) threat. In this view, panic (attacks) can be regarded as a primal defensive reaction towards the most proximal form of threat, originating from within one's own body. Accordingly, a recent seminal study by Feinstein et al. (2013) showed that the amygdala is not necessary for fear/panic evoked by a $\mathrm{CO}_{2}$ inhalation. Despite the widely accepted view that the amygdala is essential for fear, three patients with focal bilateral amygdala lesions, due to Urbach-Wiethe disease, did experience a panic attack following a $\mathrm{CO}_{2}$ challenge.

Activity in the right anterior insula was positively correlated with subjective feelings of respiratory distress experienced during the challenge inside the scanner. The more breathing distress people sensed, the higher their activity in the anterior insula was.

Our observation is in line with studies explicitly examining dyspnea. Two former studies made use of a resistive load which elicits a sensation of uncomfortable or difficult breathing (Peiffer et al., 2001, Von Leupoldt et al., 2008), while others stimulate breathing via chemosensitive pathways, comparable to the present study (Banzett et al., 2000, Liotti et al., 2001). Right anterior insula activation was prominent in all of these studies.

These findings are consistent with current theories on interoception, the processing of internal bodily signals. The anterior insula is seen as the site of conscious awareness of "how you feel" (Craig, 2004). The posterior insula, in contrast, is regarded as the primary interoceptive cortex. Putatively, in the context of the present study, the internal sensation caused by different levels of $\mathrm{CO}_{2}$ would be represented in this part of the brain. We detected no differences in activity in the posterior insula, consistent with the fact that the 
same amount of $\mathrm{CO}_{2}$ was administered to each subject. However, the same amount of $\mathrm{CO}_{2}$ apparently resulted in different levels of subjective discomfort, represented by differential activation of the anterior insula.

Very strict criteria were used for inclusion of PD patients in the present study regarding comorbidity and medication use. As comorbidity, mainly with anxiety and mood disorders, is very common in PD patients with agoraphobia (PDA), the present sample may not be entirely representative for daily clinical practice. However, because of the study focus on underlying neurobiology of the panic attacks, we preferred to select a "pure" sample of PDA patients. To elaborate this further, future studies with a similar focus might consider including patients with (predominantly) nightly panic attacks, as this might represent a "core panic" subtype due to the presence of mainly uncued panic attacks (Uhde, 2000).

MRI scanning involves placing people in the confined space of the magnet bore. PDA patients are typically afraid in situations where escape is difficult in the event of a panic attack and therefore the scanning procedure could lead to more stress and concomitant movement artifacts. However, image quality appeared similar between all three groups in this study. A previous study did report a slightly lower image quality in PD patients. The authors traced this back to claustrophobic anxiety of the participants. But also in this study, this did not lead to higher dropout rates in the patient group (Lueken et al., 2011). Interpreting the results, one has to take into consideration that only experienced divers were included in the study. Divers had to meet the criterion of more than 200 hours of diving experience, which led to a significantly higher age in this study group. Changes in cerebral blood flow have been reported with age. However, age-related reductions in perfusions were mainly found in cortical areas, while subcortical CBF was relatively preserved in aging (Chen et al., 2011)

The limitation of poor signal to noise in the brainstem should also be taken into account while interpreting the results of the present study. This part of the brain is particularly susceptible to respiratory noise due to magnetic field changes caused by the varying lung volume during the respiratory cycle (Windischberger et al., 2002), and cardiac noise, due to varying effects of blood and cerebrospinal fluid flow during the cardiac cycle (Dagli et al., 1999). Future studies might reduce this noise by using the recently proposed advanced $\mathrm{fMRI}$ sequences, optimized for brainstem imaging such as cardiac-gated dualecho EPI (Beissner et al., 2011). Image quality in the brainstem is also influenced by natural elongation and contraction movements of the anatomically nearby glottis. Debriefing of subjects of the present study revealed that the feeling of a "dry mouth" probably caused extra swallowing. This is a limitation inherent to the present breathing device set-up. Future studies might consider moisturizing the inhaled air mixture.

The present study made use of a hyperoxic mixture. Behavioral studies into the 
pathophysiology of panic in our lab classically involve the use of inhalations of increased concentrations of carbon dioxide (up to 35\%) in oxygen. With this background in mind, a hyperoxic mixture was also used in the present study. Recent data show that this combination of hyperoxia and hypercarbia is likely to dampen the BOLD response (Gauthier et al., 2011). This may have affected the probability of detecting brain activation due to hypercarbia in the present study. However, the results of the current study show a significant between-group difference in BOLD-response in a hypothesis-driven ROI without significant difference between groups in the global BOLD signal increase. Future studies would benefit from multimodal imaging combining arterial spin labeling and BOLD imaging (Chiarelli et al., 2007), to disentangle the physiological effects from actual neural activity. 


\section{References}

Apa., 2000 Diagnostic and Statistical Manual of Mental Disorders. 4th ed. American Psychiatric Association: Washington, DC.

Bailey, J.E., Argyropoulos, S.V., Lightman, S.L., and Nutt, D.J., 2003. Does the Brain Noradrenaline Network Mediate the Effects of the Co2 Challenge? J Psychopharmacol 17, 252-259.

Banzett, R.B., Mulnier, H.E., Murphy, K., Rosen, S.D., Wise, R.J., and Adams, L., 2000. Breathlessness in Humans Activates Insular Cortex. Neuroreport 11, 2117-2120.

Beissner, F., Deichmann, R., and Baudrexel, S., 2011. Fmri of the Brainstem Using Dual-Echo Epi. Neuroimage 55, 1593-1599.

Brannan, S., Liotti, M., Egan, G., Shade, R., Madden, L., Robillard, R. et al., 2001. Neuroimaging of Cerebral Activations and Deactivations Associated with Hypercapnia and Hunger for Air. Proc Natl Acad Sci U S A 98, 2029-2034.

Chen, J.J., Rosas, H.D., and Salat, D.H., 2011. Age-Associated Reductions in Cerebral Blood Flow Are Independent from Regional Atrophy. Neuroimage 55, 468-478.

Chiarelli, P.A., Bulte, D.P., Wise, R., Gallichan, D., and Jezzard, P., 2007. A Calibration Method for Quantitative Bold Fmri Based on Hyperoxia. Neuroimage 37, 808-820.

Colasanti, A., Salamon, E., Schruers, K., Van Diest, R., Van Duinen, M., and Griez, E.J., 2008. Carbon DioxideInduced Emotion and Respiratory Symptoms in Healthy Volunteers. Neuropsychopharmacology: official publication of the American College of Neuropsychopharmacology 33, 3103-3110.

Craig, A.D., 2002. How Do You Feel? Interoception: The Sense of the Physiological Condition of the Body. Nat Rev Neurosci 3, 655-666.

Craig, A.D., 2004. Human Feelings: Why Are Some More Aware Than Others? Trends in Cognitive Sciences 8 , 239-241.

Dagli, M.S., Ingeholm, J.E., and Haxby, J.V., 1999. Localization of Cardiac-Induced Signal Change in Fmri. Neuroimage 9, 407-415.

Del-Ben, C.M. and Graeff, F.G., 2009. Panic Disorder: Is the Pag Involved? Neural Plast 2009,108135.

Delapille, P., Verin, E., Tourny-Chollet, C., and Pasquis, P., 2001. Ventilatory Responses to Hypercapnia in Divers and Non-Divers: Effects of Posture and Immersion. European journal of applied physiology 86, 97-103.

Esquivel, G., Schruers, K., Maddock, R.J., Colasanti, A., and Griez, E., 2009. Acids in the Brain: A Factor in Panic? Journal of Psychopharmacology, 24, 639-647.

Feinstein, J.S., Buzza, C., Hurlemann, R., Follmer, R.L., Dahdaleh, N.S., Coryell, W.H. et al., 2013. Fear and Panic in Humans with Bilateral Amygdala Damage. Nature neuroscience 16, 270-272.

Gauthier, C.J., Madjar, C., Tancredi, F.B., Stefanovic, B., and Hoge, R.D., 2011. Elimination of Visually Evoked Bold Responses During Carbogen Inhalation: Implications for Calibrated Mri. Neuroimage 54, 1001-1011.

Gozal, D., Hathout, G.M., Kirlew, K.A., Tang, H., Woo, M.S., Zhang, J. et al., 1994. Localization of Putative Neural Respiratory Regions in the Human by Functional Magnetic Resonance Imaging. J Appl Physiol 76, 2076-2083.

Griez, E.J., Colasanti, A., Van Diest, R., Salamon, E., and Schruers, K., 2007. Carbon Dioxide Inhalation Induces Dose-Dependent and Age-Related Negative Affectivity. PLoS One 2, e987.

Harper, R.M., Macey, P.M., Woo, M.A., Macey, K.E., Keens, T.G., Gozal, D. et al., 2005. Hypercapnic Exposure in Congenital Central Hypoventilation Syndrome Reveals Cns Respiratory Control Mechanisms. J Neurophysiol 93, 1647-1658.

Hornung, J.P., 2003. The Human Raphe Nuclei and the Serotonergic System. Journal of chemical neuroanatomy 26, 331-343. 
Keren, N.I., Lozar, C.T., Harris, K.C., Morgan, P.S., and Eckert, M.A., 2009. In Vivo Mapping of the Human Locus Coeruleus. Neuroimage 47, 1261-1267.

Klein, D.F., 1993. False Suffocation Alarms, Spontaneous Panics, and Related Conditions. An Integrative Hypothesis. Arch Gen Psychiatry 50, 306-317.

Liotti, M., Brannan, S., Egan, G., Shade, R., Madden, L., Abplanalp, B. et al., 2001. Brain Responses Associated with Consciousness of Breathlessness (Air Hunger). Proc Natl Acad Sci U S A 98, 2035-2040.

Lueken, U., Muehlhan, M., Wittchen, H.-U., Kellermann, T., Reinhardt, I., Konrad, C. et al., 2011. (Don't) Panic in the Scanner! How Panic Patients with Agoraphobia Experience a Functional Magnetic Resonance Imaging Session. European Neuropsychopharmacology 21, 516-525.

Mcnaughton, N. and Corr, P.J., 2004. A Two-Dimensional Neuropsychology of Defense: Fear/Anxiety and Defensive Distance. Neurosci Biobehav Rev 28, 285-305.

Mobbs, D., Yu, R., Rowe, J.B., Eich, H., Feldmanhall, O., and Dalgleish, T., 2010. Neural Activity Associated with Monitoring the Oscillating Threat Value of a Tarantula. Proc Natl Acad Sci U S A 107, 20582-20586.

Naidich, T.P., Duvernoy, H.M., Delman, B.N., Sorensen, A.G., Kollias, S.S., and Haacke, E.M., 2009. Duvernoy's Atlas of the Human Brain Stem and Cerebellum: High-Fieldmri, Surface Anatomy, Internal Structure, Vascularization and 3 D Sectional Anatomy. Springer: Vianna.

Nash, J.R., Sargent, P.A., Rabiner, E.A., Hood, S.D., Argyropoulos, S.V., Potokar, J.P. et al., 2008. Serotonin 5-Ht1a Receptor Binding in People with Panic Disorder: Positron Emission Tomography Study. The British journal of psychiatry : the journal of mental science 193, 229-234.

Nieuwenhuys, R., Voogd, J., and Van Huijzen, F.M.a.A., 2008. The Human Central Nervous System. SpringerVerlag: Berlin.

Pattinson, K.T., Mitsis, G.D., Harvey, A.K., Jbabdi, S., Dirckx, S., Mayhew, S.D. et al., 2009. Determination of the Human Brainstem Respiratory Control Network and Its Cortical Connections in Vivo Using Functional and Structural Imaging. Neuroimage 44, 295-305.

Peiffer, C., Poline, J.B., Thivard, L., Aubier, M., and Samson, Y., 2001. Neural Substrates for the Perception of Acutely Induced Dyspnea. American journal of respiratory and critical care medicine 163, 951-957.

Perna, G., Caldirola, D., Namia, C., Cucchi, M., Vanni, G., and Bellodi, L., 2004. Language of Dyspnea in Panic Disorder. Depress Anxiety 20, 32-38.

Pine, D.S., Klein, R.G., Coplan, J.D., Papp, L.A., Hoven, C.W., Martinez, J. et al., 2000. Differential Carbon Dioxide Sensitivity in Childhood Anxiety Disorders and Nonill Comparison Group. Archives of general psychiatry 57,: 960-967.

Richerson, G.B., 2004. Serotonergic Neurons as Carbon Dioxide Sensors That Maintain Ph Homeostasis. Nat Rev Neurosci 5, 449-461.

Schruers, K., Klaassen, T., Pols, H., Overbeek, T., Deutz, N.E., and Griez, E., 2000. Effects of Tryptophan Depletion on Carbon Dioxide Provoked Panic in Panic Disorder Patients. Psychiatry Res 93, 179-187.

Schruers, K., Van Diest, R., Overbeek, T., and Griez, E., 2002. Acute L-5-Hydroxytryptophan Administration Inhibits Carbon Dioxide-Induced Panic in Panic Disorder Patients. Psychiatry research 113, 237-243.

Severson, C.A., Wang, W., Pieribone, V.A., Dohle, C.I., and Richerson, G.B., 2003. Midbrain Serotonergic Neurons Are Central Ph Chemoreceptors. Nature neuroscience 6, 1139-1140.

Sheehan, D.V., Lecrubier, Y., Sheehan, K.H., Amorim, P., Janavs, J., Weiller, E. et al., 1998. The Mini-International Neuropsychiatric Interview (M.I.N.I.): The Development and Validation of a Structured Diagnostic Psychiatric Interview for Dsm-Iv and Icd-10. J Clin Psychiatry 59 Suppl 20, 22-33;quiz 34-57.

Uhde, T.W., 2000. The Anxiety Disorders. In: Kryger, M.H., Roth, T., and Dement, W., (eds), Principles and Practice in Sleep Medicine, Thrid edition ed. W.B. Saunders Co.: Philadelphia.

Van Der Zande, F.H., Hofman, P.A., and Backes, W.H., 2005. Mapping Hypercapnia-Induced Cerebrovascular Reactivity Using Bold Mri. Neuroradiology 47, 114-120. 
Verburg, K., Perna, G., and Griez, E.J.L., 2001. A Case Study of the 35\% Co2 Challenge. In: Griez, E.J.L., Faravelli, C., Nutt, D.J., and Zohar, J., (eds), Anxiety Disorders: An Introduction to Clinical Management and Research John Wiley \& Sons, Ltd.: Chichester.

Von Leupoldt, A., Sommer, T., Kegat, S., Baumann, H.J., Klose, H., Dahme, B. et al., 2008. The Unpleasantness of Perceived Dyspnea Is Processed in the Anterior Insula and Amygdala. American journal of respiratory and critical care medicine 177, 1026-1032.

Windischberger, C., Langenberger, H., Sycha, T., Tschernko, E.M., Fuchsjager-Mayerl, G., Schmetterer, L. et al., 2002. On the Origin of Respiratory Artifacts in Bold-Epi of the Human Brain. Magn Reson Imaging 20, 575582. 
Brainstem response to $\mathrm{CO}_{2}$ 


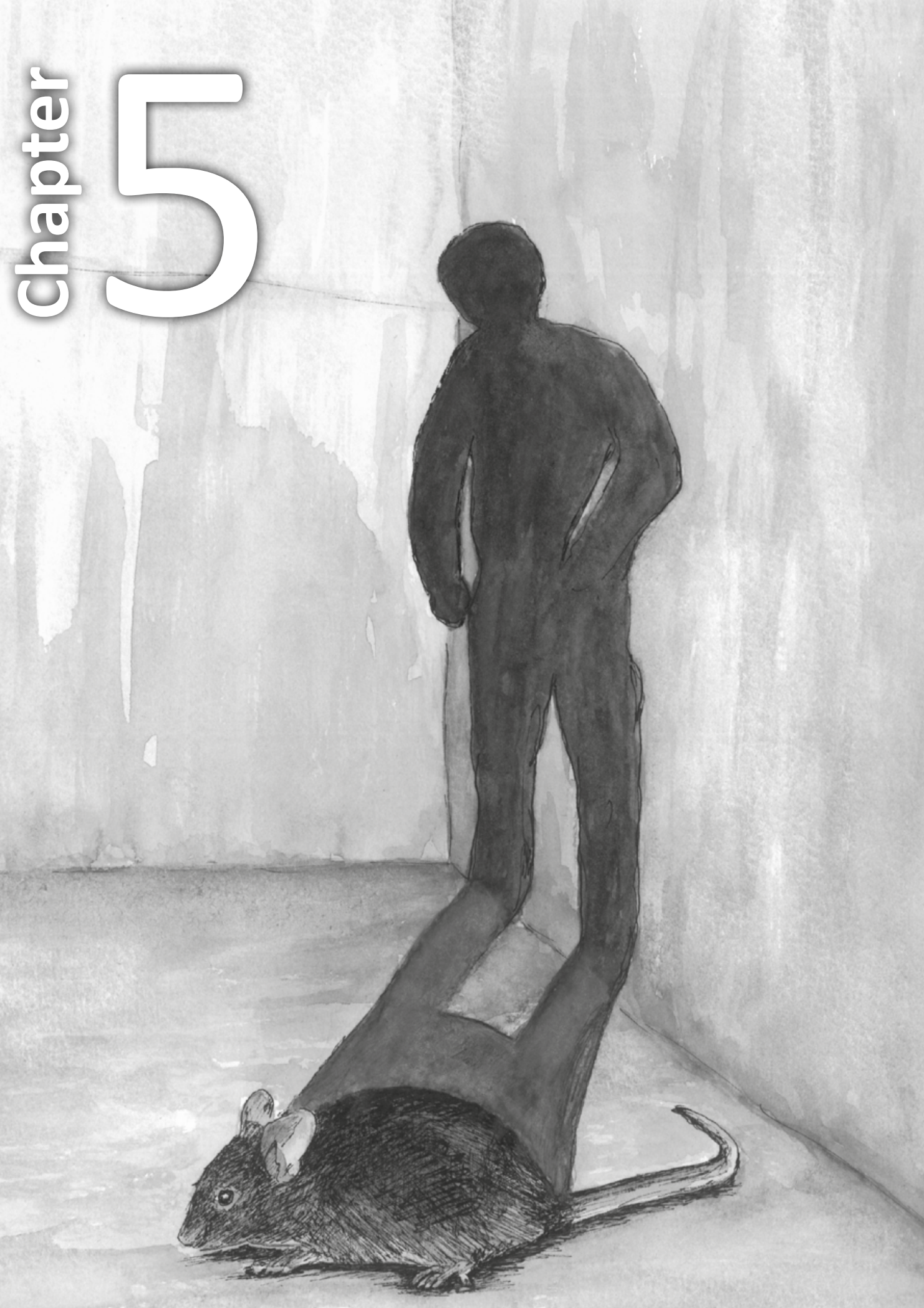

$(x+5)^{2}$ 


\section{Amiloride-sensitive cation channel 2 genotype affects the response to a carbon dioxide panic challenge}

Nicole Leibolda, Daniel van den Hove, ${ }^{a, b}$, Wolfgang Viechtbauer ${ }^{a}$, Gunter Kenis ${ }^{a}$, Liesbet Goossens ${ }^{a}$, Inge Knuts ${ }^{a}$, Hubert Smeets ${ }^{c}$, Inez Myin-Germeys ${ }^{a}$, Harry Steinbuscha, Koen Schruers ${ }^{a}$

a Department of Psychiatry and Neuropsychology, Maastricht University, P.O. Box 616, 6200 MD Maastricht, the Netherlands. School for Mental Health and Neuroscience, Maastricht University. European Graduate School of Neuroscience (EURON), P.O. Box 616, 6200 MD Maastricht, the Netherlands

b Division of Molecular Psychiatry, Laboratory of Translational Neuroscience, Department of Psychiatry, Psychosomatics and Psychotherapy, University of Wuerzburg, Fuechsleinstrasse 15, 97080 Wuerzburg, Germany

Faculty of Health, Medicine and Life Sciences, Genome Center Maastricht, Maastricht University, Maastricht, the Netherlands 


\section{Abstract}

Until recently, genetic research into panic disorder (PD) has had only limited success. Inspired by rodent research, demonstrating that the acid-sensing ion channel (ASIC) $1 \mathrm{a}$ is critically involved in the behavioral fear response to carbon dioxide $\left(\mathrm{CO}_{2}\right)$ exposure, variants in the human homologue gene amiloride-sensitive cation channel (ACCN2) were shown to be associated with PD. However, the relationship between changes in brain $\mathrm{pH}$ and $A C C N 2$, as done in rodents by $\mathrm{CO}_{2}$ exposure, has not been investigated yet in humans. Here, we examined this link between the ACCN2 gene and the response to $\mathrm{CO}_{2}$ exposure in two studies: in healthy volunteers as well as PD patients and using both behavioral and physiological outcome measures. In total, 183 PD patients and 107 healthy volunteers underwent a $35 \% \mathrm{CO}_{2}$ inhalation. Negative affect was assessed using visual analogue scales and the panic symptom list, and, in healthy volunteers, cardiovascular measurements. The single nucleotide polymorphism rs10875995 was significantly associated with a higher emotional response in PD patients and with an increase in systolic as well as diastolic blood pressure in healthy subjects. In all measurements, subjects homozygous for the T-allele showed a heightened reactivity to $\mathrm{CO}_{2}$. Furthermore, a trend towards a rs685012 genotype effect on the emotional response was found in PD patients. We provide the first evidence that variants in the ACCN2 gene are associated with differential sensitivity to $\mathrm{CO}_{2}$ in PD patients as well as healthy volunteers, further supporting ACCN2 as a promising candidate for future research to improve current treatment options. 


\section{Introduction}

Panic disorder (PD) is a highly prevalent and debilitating condition characterized by recurrent, unexpected panic attacks (PAs) (American Psychiatric Association, 2013). Based on clinical and epidemiological data, a division in subtypes is made, with predominant respiratory or cardiovascular symptoms compromising a "core panic type" (Roberson-Nay and Kendler, 2011). PD is associated with high health care costs (Batelaan et al., 2007) and in spite of available treatments, long-term effects are modest and relapse rates are high (Yonkers et al., 2003). Insight into the molecular and genetic mechanisms of the disorder would arguably be beneficial in the search for improved and new treatments.

Until recently, genetic research into PD has been relatively scarce and less successful compared to other psychiatric disorders (Smoller, 2011). Inspired by previous work in mice, attention has been turned to the amiloride-sensitive cation channel (ACCN2), the human homologue to the rodent acid-sensing ion channel 1a (ASIC1a). ASIC1a was shown to play an important role in conditioned fear (Wemmie et al., 2003; Wemmie et al., 2004), but the interest in ASIC1a in relation to PD was boosted by a seminal study (Ziemann et al., 2009) showing that ASIC1a is also essentially involved in the unconditioned behavioral fear response to carbon dioxide $\left(\mathrm{CO}_{2}\right)$ exposure by acting as a chemosensor that detects a decrease in extracellular $\mathrm{pH}$.

Analogues can be drawn to humans, in whom $\mathrm{CO}_{2}$ exposure has been used for many years. Nowadays, the use of low percentages of $\mathrm{CO}_{2}$ (e.g. $5 \%$ ) for prolonged periods of time is considered to relate to generalized anxiety disorder, arousal, and threat processing (Bailey et al., 2011; Garner et al., 2011), while exposure to a high concentration of $\mathrm{CO}_{2}$ has proven to be a reliable experimental model for panic. It is well established that PD patients display a higher fear and panic response to $\mathrm{CO}_{2}$ when compared to healthy volunteers (Griez et al., 1990; Griez et al., 1987). A brief inhalation of 35\% $\mathrm{CO}_{2}$ triggers short lasting, but intense symptoms resembling the ones of a naturally occurring PA in PD patients (Nardi et al., 2006; Schruers et al., 2004). We proposed that an acutely disturbed acid-base homeostasis represents the mechanism underlying the occurrence of PAs (Esquivel et al., 2009). $\mathrm{CO}_{2}$ exposure was shown to cause a decrease in brain $\mathrm{pH}$ in rodents (Schuchmann et al., 2006; Ziemann et al., 2009; Ziemann et al., 2008). While studies investigating the direct effects of breathing $\mathrm{CO}_{2}$ on brain $\mathrm{pH}$ in humans are lacking, indirect evidence for brain acidification comes from a study using intravenous infusion of bicarbonate, which caused a decrease in brain $\mathrm{pH}$ as shown by magnetic resonance spectroscopy (Nakashima et al., 1996). The acid-base homeostasis is tightly regulated within a narrow range and a shift out of the normal range can have fatal consequences (Rhoades and Bell, 2009). Therefore, sensing a change in $\mathrm{pH}$ and triggering adaptive physiological and behavioral responses are of crucial importance for an individual's survival. Hence, genes encoding 
for molecules involved in chemosensation such as ACCN2 present a pivotal link between $\mathrm{pH}$ and panic.

To date, only a few studies investigated the link between ACCN2 and PD. In a first study (Hettema et al., 2008), results were inconsistent given that the replication of a significant association failed in a second larger sample. This is probably due to assessing a group of mixed anxiety disorder patients of whom only a subset had PD. In a recent large casecontrol study, Smoller and colleagues (2014) demonstrated that the C-allele of the single nucleotide polymorphisms rs685012, located in the 5' putative promoter region, and of rs10875995, located in intron 3, was associated with increased probability of having the diagnosis of PD. Moreover, in healthy volunteers, the C-allele was associated with a larger amygdala volume and heightened amygdala reactivity to visual presentation of fearful and angry faces.

The proposed mechanism linking ACCN2 and panic in humans involves an altered threshold for sensing acidosis (Smoller et al., 2014). More specifically, variants in the ACCN2 gene may lead to a lower threshold for detecting a decrease in $\mathrm{pH}$, resulting in a heightened sensitivity to cues from within the body (caused by, e.g., $\mathrm{CO}_{2}$ exposure). This mechanism is highly plausible, but experimental evidence linking differential $\mathrm{CO}_{2}$ reactivity in humans to variants in the ACCN2 gene is currently lacking. For many years it was assumed that, in contrast to PD patients, healthy volunteers are not sensitive to breathing $\mathrm{CO}_{2}$ (Griez et al., 2007). However, by now, a dose-response relationship between $\mathrm{CO}_{2}$ and reported fear and bodily symptoms has been repetitively shown (Griez et al., 2007; Schruers et al., 2011), whereby a double inhalation of $35 \% \mathrm{CO}_{2}$ elicits a response that closely resembles the one reported by PD patients to a single vital capacity inhalation. In addition, twin studies showed that individual differences in the response to $\mathrm{CO}_{2}$ can be, in part, attributed to genetic factors (Battaglia et al., 2007; Battaglia et al., 2009; Roberson-Nay et al., 2013), with a large overlap with the genetic constituents of PD (Battaglia et al., 2009). These observations imply the existence of a $\mathrm{CO}_{2}$-reactivity continuum and that panic symptoms can be provoked in most individuals, depending on the concentration of $\mathrm{CO}_{2}$ used. The findings suggest that $\mathrm{CO}_{2}$ inhalation activates basic fear mechanisms that are present in every individual. This opens the avenue of studying panic-related fear in healthy volunteers, thus bridging the gap between animal models and research in PD patients.

The present study sought to investigate the relationship between the response to $\mathrm{CO}_{2}$ and the ACCN2 gene, with a focus on the two gene variants previously found to be associated with PD and amygdala reactivity. In the first study, we assessed the response to $\mathrm{CO}_{2}$ in healthy individuals. To capture the emotional and the physiological reactivity, we examined the effects of $\mathrm{CO}_{2}$ on self-reported emotions as well as the cardiovascular system. In the second study, in light of clinical relevance, the self-reported emotional response to $\mathrm{CO}_{2}$ 
was evaluated in PD patients. We hypothesized that in both samples the C-allele would be associated with a higher reactivity.

\section{Methods and materials}

\section{Study 1: Healthy individuals}

\section{Subjects}

One-hundred and seven Caucasian adult healthy volunteers participated in this study (mean age 23.76 years, $S D=6.96 ; 27$ males). Subjects were recruited via advertisements at Maastricht University, the Netherlands. Eligibility was confirmed using a standard medical examination and a semi-structured psychiatric interview including the Mini International Neuropsychiatric Interview (M.I.N.I., Sheehan et al., 1998) performed by an experienced psychiatrist or psychologist. Exclusion criteria included current or past cardiovascular or pulmonary disease, hypertension (systolic/diastolic $>170 / 100 \mathrm{mmHg}$ ), familial or personal history of cerebral aneurysm, excessive smoking (>15 cigarettes per day), pregnancy, epilepsy, use of psychotropic medication or adrenergic receptor blockers, and a firstdegree relative with PD. All participants gave written informed consent prior to the study, which was approved by the Medical Ethics Committee of Maastricht University and the Maastricht University Hospital.

\section{$\mathrm{CO}_{2}$ inhalation}

The standardized protocol for $\mathrm{CO}_{2}$ inhalations in healthy volunteers has been described previously (Griez et al., 2007). In brief, subjects were informed that $\mathrm{CO}_{2}$ might cause some effects, ranging from minor sensations up to fear. However, all effects would be short-lasting. Subjects took a double vital capacity breath of $35 \% \mathrm{CO}_{2}$ (premixed gas tanks obtained from Nederlandse Technische Gasmaatschappij B.V., Landgraaf, the Netherlands). All subjects inhaled at least $80 \%$ of their vital capacity as measured using a flowmeter. Subjects were instructed to refrain from caffeine containing beverages on all inhalation days.

\section{Self-reports}

The affective response to $\mathrm{CO}_{2}$ was evaluated in accordance with the DSM-IV criteria for a PA (American Psychiatric Association, 2000). Fear and discomfort were assessed using the Visual Analogue Scale (VAS-F and VAS-D, respectively), consisting of a horizontal line of $100 \mathrm{~mm}$ length and ranging from 0 (not at all) to 100 (the worst imaginable). Panic symptomatology was evaluated using the Panic Symptom List (PSL), a questionnaire listing the 13 DSM PA symptoms such as palpitations, sweating, shortness of breath, dizziness, 
and choking, and ranging from 0 (absent) to 4 (very intense). Self-reports were obtained directly before and immediately after the inhalation.

\section{Cardiovascular recordings}

Blood pressure and heart rate were measured continuously throughout the entire procedure in healthy volunteers using a computerized system (Carbon Dioxide Tolerance Tester, CTT, Maastricht Instruments B.V., Maastricht, the Netherlands). Both parameters were measured by means of a finger cuff that was connected to a cardiovascular monitor (Nexfin, BMEYE B.V., Amsterdam, the Netherlands). All measurements were acquired with custom-made software (IDEEQ, Maastricht Instruments B.V., Maastricht, the Netherlands).

\section{Study 2: Panic disorder patients}

\section{Subjects}

One-hundred and eighty-three Caucasian PD patients (mean age 36.14 years, SD=10.94; 71 men) participated in this study. Patients were recruited from the outpatient setting of the Academic Anxiety Centre, Maastricht, the Netherlands. PD (with or without agoraphobia) as main diagnosis was established via a semi-structured psychiatric interview by an experienced psychiatrist, including the M.I.N.I. (Sheehan et al., 1998) (see Supplementary Table S1 for assessment scores). Patients underwent a standard medical examination to confirm eligibility. Exclusion criteria were current or past cardiovascular or pulmonary disease, hypertension (systolic/diastolic $>170 / 100 \mathrm{mmHg}$ ), familial or personal history of cerebral aneurysm, pregnancy, and epilepsy. In total, 106 patients had one or more comorbid disorders. Patients were free of antidepressant and benzodiazepine treatment for at least four or two weeks, respectively, before taking part in the experiment. Written informed consent was obtained from each subject before participating. The study was approved by the Medical Ethics Committee of Maastricht University and the Maastricht University Hospital.

\section{$\mathrm{CO}_{2}$ inhalation}

In PD patients, $\mathrm{CO}_{2}$ inhalations took place according to a standardized protocol as described previously (Klaassen et al., 1998). Subjects were informed that the subsequent inhalation might cause some effects, ranging from minor sensations up to fear. However, all effects would be short-lasting. Subjects took a single vital capacity breath of $35 \% \mathrm{CO}_{2}$ (premixed gas tanks obtained from Nederlandse Technische Gasmaatschappij B.V., Landgraaf, the Netherlands). Using a flowmeter it was ensured that at least $80 \%$ of their previously measured vital capacity was inhaled. 


\section{Self-reports}

In line with the DSM-IV criteria for a PA (American Psychiatric Association, 2000), experienced fear was evaluated using the Visual Analogue Scale for fear (VAS-F), consisting of a horizontal line of $100 \mathrm{~mm}$ length and ranging from 0 (not at all) to 100 (the worst imaginable). Panic symptoms were assessed by means of the Panic Symptom List (PSL), a questionnaire listing the 13 DSM PA symptoms, and ranging from 0 (absent) to 4 (very intense). Self-reports were obtained directly before and immediately after the inhalation.

\section{Genotyping}

Saliva was collected from all subjects using Oragene ${ }^{\circledR}$ saliva self-collecting kits (DNA Genotek Inc, Ontario, Canada). Genomic DNA was isolated using the AutoGenFlex DNA Isolation system (Autgen, Hilliston, MA, USA) according to manufacturer's instructions and subsequently genotyped using Taqman SNP Genotyping Assays for rs10875995 and rs685012 (Life Technologies). The selection of these particular polymorphisms $\left(D^{\prime}=0.94\right)$ was based on the results of the recent study by Smoller et al. (2014), in which an association with PD and amygdala reactivity was found. Results were independently scored by two experienced technicians.

\section{Data and statistical analysis}

\section{Primary analyses}

Differences in the change of self-reported emotions and symptoms depending on the genotype were analyzed using univariate Analysis of Variance (ANOVA). Six PD patients were excluded from the rs685012 analysis due to genotyping failure (final sample mean age 36.14 years, $\mathrm{SD}=10.94 ; 71$ men).

To analyze physiological measurements in healthy subjects, locally weighted polynomial regression (Cleveland and Devlin, 1988) was used to avoid strong effects of outliers. Based on smoothed data, the area under the curve (AUC), the maximum, and the standard deviation (log transformed) were calculated within the first $60 \mathrm{~s}$ after inhaling $\mathrm{CO}_{2}$. Due to a technical failure, the final sample for physiological analyses consisted of 92 subjects (mean age 23.56 years, $\mathrm{SD}=0.44 ; 24$ men).

\section{Secondary analysis}

Patients with predominantly respiratory symptoms during their panic attacks have been proposed as forming a "core" panic subtype (Roberson-Nay and Kendler, 2011). Smoller et al. (2014) showed a particularly strong relationship between ACCN2 genotype and such a respiratory panic subtype. We have previously demonstrated the existence of a similar respiratory subtype in response to a $\mathrm{CO}_{2}$ challenge (Colasanti et al., 2008). Analysis of 
the respiratory cluster was based on this previous cluster analysis study (Colasanti et al., 2008). The cluster consisted of the symptoms shortness of breath, feeling of choking, dizziness, sweating, palpitations, and chest pain. The effect of genotype on the sum of the change scores of these six symptoms was analyzed by means of univariate ANOVA.

Based on Smoller et al. (2014), C-allele carriers were compared to T/T homozygotes in all analyses for both polymorphisms. Significance was set at $p<0.05$. All analyses were performed using the Statistical Package for the Social Sciences (SPSS 20.0.0.1 for Mac; SPSS Inc., Chicago, IL) or the software R (version 3.1.1, 2014, R Development Core Team, Vienna/Austria).

\section{Results}

Demographical data of healthy volunteers and PD patients are represented in Table 1. The distribution of ACCN2 genotypes was in Hardy-Weinberg equilibrium for both samples. Genotypes did not differ with respect to sex and age and the duration of PD. The linkage disequilibrium for the two variants was $D^{\prime}=84$ in the healthy sample and $D^{\prime}=96$ in PD patients.

Table 1. Demographics of healthy volunteers and panic disorder (PD) patients.

\begin{tabular}{|c|c|c|c|c|c|}
\hline & & \multicolumn{2}{|l|}{ rs10875995 } & \multicolumn{2}{|l|}{ rs685012 } \\
\hline & & $\mathrm{C} / \mathrm{C}$ and $\mathrm{C} / \mathrm{T}$ & $\mathrm{T} / \mathrm{T}$ & $\mathrm{C} / \mathrm{C}$ and $\mathrm{C} / \mathrm{T}$ & $\mathrm{T} / \mathrm{T}$ \\
\hline \multirow{3}{*}{$\begin{array}{l}\text { Healthy } \\
\text { volunteers }\end{array}$} & $\mathbf{N}$ & 55 & 52 & 56 & 51 \\
\hline & Sex (\% male) & 21 & 29 & 20 & 30 \\
\hline & Age (SD) & $23.70(7.02)$ & $23.83(7.22)$ & $24.04(7.17)$ & $23.45(6.78)$ \\
\hline \multirow{4}{*}{ PD patients } & $\mathbf{N}$ & 90 & 93 & 91 & 86 \\
\hline & Sex (\% male) & 40 & 38 & 36 & 42 \\
\hline & Age (SD) & $36.06(11.55)$ & $36.22(10.37)$ & $36.18(11.63)$ & $36.31(10.36)$ \\
\hline & Duration PD (years (SD)) & $11.08(11.30)$ & $8.82(9.84)$ & $11.12(11.31)$ & 9.05 (10.07) \\
\hline
\end{tabular}

\section{Self-reports to $\mathrm{CO}_{2}$ inhalation in healthy volunteers}

In healthy volunteers, no effect of the rs10875995 genotype on the change score regarding VAS-F ( $p=0.264$, Figure $1 a)$, VAS-D ( $p=0.208$, see supplementary Table S2 for all means), and PSL ( $p=0.196)$ was present. No rs685012 genotype effect was found on VAS-F $(p=0.646$, Figure $2 a)$, VAS-D ( $p=0.131$, see supplementary Table S3 for means), and PSL ratings $(p=0.453)$. 
a

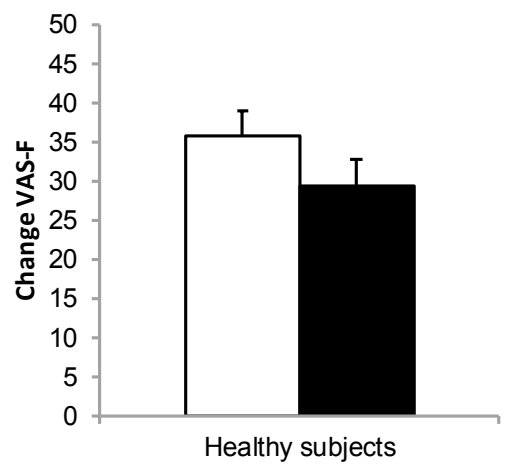

b

a $\mathrm{C} / \mathrm{C}$ and $\mathrm{C} / \mathrm{T}$

- $\mathrm{T} / \mathrm{T}$

Figure 1. Effects of $\mathrm{CO}_{2}$ on the VAS-F ratings depending on the rs10875995 genotype. a) No effect of genotype on the VAS-F was found in healthy subjects. b) In panic disorder (PD) patients, homozygous T-allele carriers scored significantly higher than C-allele carriers. ${ }^{*} p<0.05$. Data represent means + SEM.

a

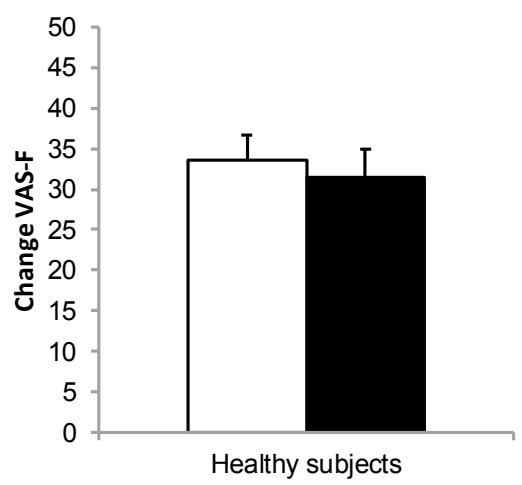

b

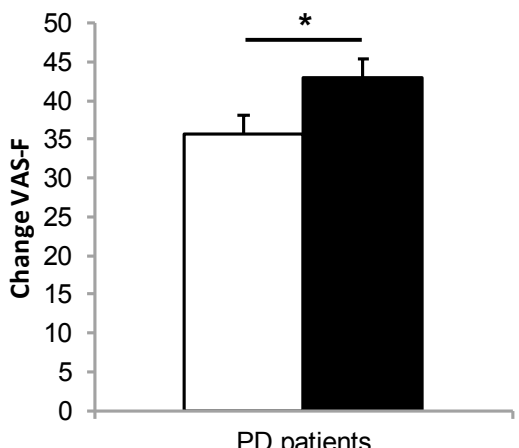

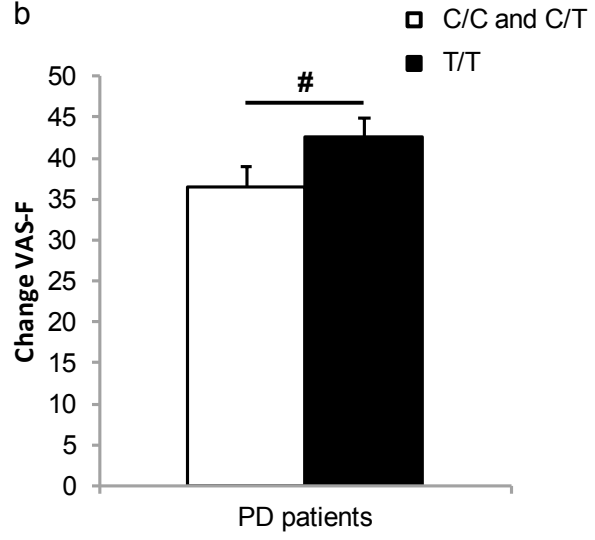

Figure 2. Effects of $\mathrm{CO}_{2}$ on the VAS-F ratings depending on the rs685012 genotype. a) No effect of genotype was present in healthy subjects. b) In panic disorder (PD) patients, a trend towards a higher change score was found in carriers homozygous for the T-allele in comparison with C-allele carriers. $\# 0.05<p<0.1$. Data represent means + SEM.

\section{Cardiovascular response to $\mathrm{CO}_{2}$ inhalation in healthy volunteers}

Healthy subjects homozygous for the T-allele of rs10875995 showed a significantly higher AUC ( $p=0.043$, see supplementary Table S4 for all means) and a tendency towards a higher peak ( $p=0.089$ ) of the systolic blood pressure after the $\mathrm{CO}_{2}$ inhalation. Similarly, also the $\operatorname{AUC}(p=0.049$, Figure $3 a)$ and the peak ( $p=0.030$, Figure $3 b)$ of the diastolic blood pressure were elevated after inhaling $\mathrm{CO}_{2}$ compared to $\mathrm{C}$-allele carriers. No effect was found on any outcome of heart rate (AUC $p=0.357$, peak $p=0.698$ ). With regard to rs685012, no effect was present on any outcome (see supplementary Table S5). 
a

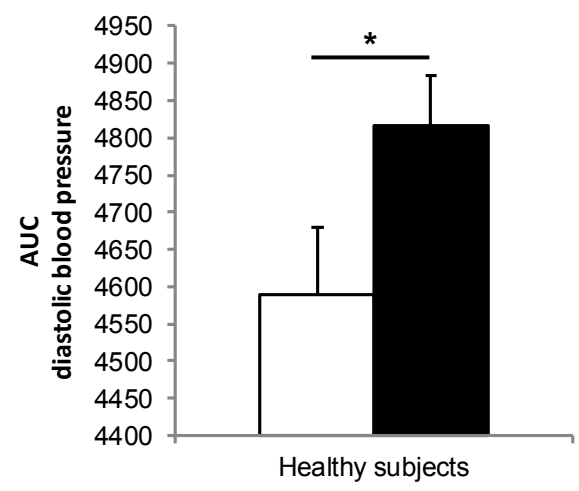

b

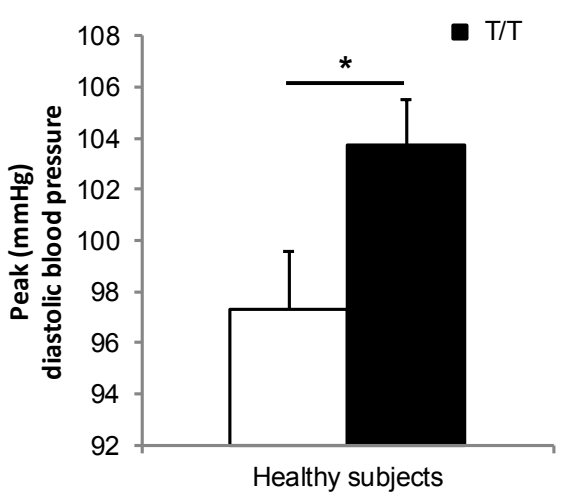

Figure 3. Effects of the rs10875995 genotype on the diastolic blood pressure in response to $\mathrm{CO}_{2}$ in healthy subjects. a) Homozygous T-allele carriers had a significantly higher area under the curve (AUC) after inhaling $\mathrm{CO}_{2}$ compared to subjects of the $\mathrm{C} / \mathrm{C}$ and $\mathrm{C} / \mathrm{T}$ genotype. b) The same effect was observed with regard to the peak after inhaling $\mathrm{CO}_{2} \cdot{ }^{*} \mathrm{p}<0.05$. Data represent means $+\mathrm{SEM}$.

\section{Self-reports to $\mathrm{CO}_{2}$ inhalation in PD patients}

In PD patients, subjects homozygous for the rs10875995 T-allele scored significantly higher on the VAS-F in comparison with C-allele carriers ( $p=0.032$, Figure $1 b)$, whilst no effect of genotype on reported PSL scores was found $(p=0.388)$. With regard to rs685012, there was a trend towards higher VAS- $F$ ratings in subjects with the $\mathrm{T} / \mathrm{T}$ genotype in comparison with C-allele carriers ( $p=0.061$, Figure $2 b$ ). No significant effect of $A C C N 2$ genotype on PSL scores was observed $(p=0.519)$.

\section{Secondary analysis: Respiratory cluster analysis in PD patients}

We next analyzed the effect of genotype on the respiratory symptom cluster in the response to the $\mathrm{CO}_{2}$ challenge, as defined in a previous study. There was no main effect of rs10875995 ( $p=0.659)$ or rs685012 genotype $(p=0.889)$ (see Supplementary Tables S2 and S3 for all means).

\section{Discussion}

The neurobiological mechanisms underlying PAs are not yet fully understood. Here, we show for the first time an association between two genetic variants in the ACCN2 gene, selected based on prior data (Smoller et al., 2014), and $\mathrm{CO}_{2}$ sensitivity in two human samples (PD patients and healthy volunteers) and two types of outcome measures (selfreports and cardiovascular physiology). More specifically, PD patients of the rs10875995 
$T / T$ genotype scored higher on the VAS-F, and healthy subjects of the $T / T$ genotype displayed a higher systolic and diastolic blood pressure response to a $\mathrm{CO}_{2}$ panic challenge than $\mathrm{C}$-allele carriers.

The ACCN2 gene is the human orthologue of the rodent gene encoding the $\mathrm{pH}$-sensitive ion channel ASIC1a, which was shown to be critically involved in conditioned (Wemmie et al., 2003; Wemmie et al., 2004) as well as unconditioned, $\mathrm{CO}_{2}$-induced fear behavior in mice (Ziemann et al., 2009). Therefore, ASIC1a is a prime candidate to be involved in the molecular pathophysiology of panic in humans. To date, two previous human studies investigated an association between the ACCN2 gene and PD. The first study (Hettema et al., 2008) found a significant association, which could not be replicated in a second larger sample. This is unsurprising as the focus of that study was on anxiety spectrum disorders rather than on PD, samples were very heterogeneous and only a subset in fact had PD. More recently, however, in a large case-control study, Smoller et al. (2014) found a significant association between variants in ACCN2 with the diagnosis of PD as well as a larger amygdala volume and heightened functional amygdala reactivity in a sample of healthy C-allele carriers of the rs10875995 genotype. The authors suggested that this observed association might reflect an increased sensitivity to a decrease in $\mathrm{pH}$, secondary to neuronal activity to process the visual emotional stimulus. The elevated sensitivity would be associated with ACCN2 gene variants that contribute to a decreased threshold for sensing acidosis. Furthermore, they speculated that "such activation would clearly be less direct (and less intense) than that induced by a direct $\mathrm{CO}_{2}$ inhalation". Here, we provide the effects of a $35 \% \mathrm{CO}_{2}$ panic challenge, showing an rs10875995 genotype effect on the emotional as well as cardiovascular reactivity. In PD patients, VAS- $F$ ratings were higher in carriers homozygous for the rs10875995 T-allele compared to C-allele carriers, whereas no effect was found in healthy volunteers. Although panic-like sensations can be reliably induced with $35 \% \mathrm{CO}_{2}$ in healthy volunteers (Griez et al., 2007), PD patients on average still show a higher sensitivity to the challenge (Colasanti et al., 2012). We have previously shown that double vital capacity inhalation of $35 \% \mathrm{CO}_{2}$ in healthy volunteers induced a condition complying with the formal criteria of panic in the current psychiatric nosology (Griez et al., 2007). However, this constitutes a qualitative comparison. To date, a direct quantitative comparison is still lacking. This might explain, together with the smaller sample size in the healthy group, why the effect of genetic variation can be detected more easily in patients. Further, in patients, a moderating effect of the ACCN2 genotype on VAS scores, but not on reported bodily symptoms, may be explained by the finding that the VAS is a more specific instrument than the PSL to measure reactivity to a $35 \% \mathrm{CO}_{2}$ challenge (Battaglia and Perna, 1995; Verburg et al., 1998). Similar effects were found for rs685012, which is likely caused by the high correlation and linkage disequilibrium between the two variants. 
Given that PAs are accompanied by profound physiological symptoms, we also included objective cardiovascular measurements in healthy volunteers to complement self-reports. This is also relevant given that ASIC1a interacts with ASIC2, a channel implicated in baroreceptor sensitivity and thus blood pressure regulation (Lu et al., 2009). In addition, interaction of the two channels can shift the $\mathrm{pH}$ sensitivity (Wemmie et al., 2013). Therefore, variants in the ACCN2 gene that potentially increase the $\mathrm{pH}$ sensitivity might be associated with an elevated autonomic response. Consistent with an elevated emotional response in patients of the T/T genotype, we also found a heightened cardiovascular response in healthy T/T carriers. A logical next step would be to apply the validated measurements in PD patients, which we did not obtain in the present study, possibly also in relationship to variants in the human homologue gene encoding ASIC2. A further useful addition would be the inclusion of respiratory measures, given the common respiratory symptoms during PAs. Panic attacks with prominent respiratory symptoms have been proposed as a core panic subtype (Roberson-Nay and Kendler, 2011) and the link between such a subtype and ACCN2 is a logical one. Accordingly, Smoller et al. (2014) showed a particularly strong association between the ACCN2 genotype and the respiratory subtype in a secondary analysis. We could not confirm this in the present study, possibly due to methodological differences between the studies. We based our definition of a respiratory subtype on a cluster of six PSL sub-items in response to the $\mathrm{CO}_{2}$ inhalation, that we previously identified using a principal component factor analysis (Colasanti et al., 2008), whilst Smoller (2014) grouped patients depending on the predominance of certain symptoms during real-life PAs, assessed via diagnostic interview.

Overall, the results of the present study extend previous data (Smoller et al., 2014), although an important difference should be noted, i.e., that the present study showed a stronger response in T/T allele carriers, whereas in the study by Smoller et al. (2014) the $\mathrm{C}$-allele was considered the risk allele. Observing opposite alleles associated with risk disease between studies is a known phenomenon in association studies and is referred to as "flip-flop phenomenon" (Lin et al., 2007). Although the exact cause is unknown it is assumed that it occurs when the focus is on one genetic locus while in fact many genetic variants or environmental factors, and their mutual interaction, contribute to complex phenotypes such as neuropsychiatric disorders. In addition, in spite of similar ethnicities, two populations can differ in terms of linkage disequilibrium between the two genetic loci, leading to differences in the direction of the association between studies (Lin et al., 2007). Moreover, Clarke and Cardon (2010) have calculated that the probability of finding at random flip-flop associations is negligible. Therefore, this phenomenon may have biological implications.

In addition, the examined phenotypes in the present study and in that of Smoller et al. 
(2014) are not entirely similar. In Smoller's study, the C-allele was shown to be associated with the diagnosis of $P D$ and with amygdala volume and function, whereas the present study showed a relationship between the T-allele and experimentally provoked fear/panic sensations. The amygdala has been implicated in rodent (Ziemann et al., 2009) and human (Holmes et al., 2012) fear behavior as well as in enhanced reactivity to emotional threats in humans (Shin and Liberzon, 2010). Furthermore, altered amygdala structure and functioning has been reported in PD patients (Kim et al., 2012). However, PD is a complex disorder and consists of different aspects (PAs, anticipatory anxiety, and avoidance behavior), which are likely subserved by different parts of the brain and not solely by the amygdala. While the amygdala may be most important in the conditioning process leading to avoidance behavior, the nature of PAs might be more related to other structures such as the brainstem (Goossens et al., 2014). Therefore, focusing on a complex disorder (diagnosis of $\mathrm{PD}$ ) or a phenotype (response to $\mathrm{CO}_{2}$ ) might lead to different results.

Previously, we have proposed that PAs are caused by an acute metabolic disturbance of the acid-base homeostasis as can be induced by inhaling $\mathrm{CO}_{2}$ (Esquivel et al., 2009). Neurons intrinsically sensitive to $\mathrm{CO}_{2} / \mathrm{pH}$ are located within many brain structures (Biancardi et al., 2008; da Silva et al., 2011; Dean et al., 1990; Mulkey et al., 2004; Putnam et al., 2004; Ziemann et al., 2009). Some of those structures most likely serve different functions such as breathing as well as defensive behavior (Esquivel et al., 2009). The exact contribution of these brain structures in $\mathrm{CO}_{2}$ sensitivity, sensing changes in $\mathrm{pH}$ and eliciting a fear and panicrelated behavioral response, is still elusive. Rodent research identified the amygdala as an essential brain structure in this process (Ziemann et al., 2009). The association between variants in ACCN2 and amygdala reactivity to visual emotional stimuli reported by Smoller and colleagues (2014) further supports a role of the amygdala. However, that study did not include $\mathrm{CO}_{2}$ exposure. Significant evidence against a crucial role of the amygdala in the behavioral and physiological response to a $35 \% \mathrm{CO}_{2}$ challenge was recently provided by a study in patients with Urbach-Wiethe disease (Feinstein et al., 2013). These patients have bilaterally dysfunctional amygdalae due to infiltration of hyaline. Based on the proposed role of the amygdala, it was expected that these patients would show a reduced response, in terms of self-reported negative affect, to $\mathrm{CO}_{2}$. However, contrary to expectations, Urbach-Wiethe disease patients did experience a panic-like response to inhaling $35 \%$ $\mathrm{CO}_{2}$, thus demonstrating that the amygdala is not required in the $\mathrm{CO}_{2}$-induced response. As this study did not include functional imaging, not other candidate structures could be investigated. We recently (Goossens et al., 2014) performed a functional magnetic resonance imaging (MRI) study, demonstrating stronger brainstem activity in response to inhaling $\mathrm{CO}_{2}$ in PD patients compared to healthy volunteers. These results suggest that, at least in humans, the brainstem is the principal brain area in sensing changes in $\mathrm{CO}_{2} /$ 
$\mathrm{pH}$. The neuronal molecular players that act as brainstem chemosensor have not yet been identified, but as ASIC1a is expressed throughout the entire central nervous system including the brainstem (Price et al., 2014), it is a likely candidate.

Future studies should address the relationship between variants in the ACCN2 gene and the locus of brain activity in response to $\mathrm{CO}_{2}$. The aforementioned study (Goossens et al., 2014) could not address this due to insufficient sample size for genetic analyses. In addition, given the "flip-flop association" in the present study, in the future, other genetic variants should be taken into account to map potential causative loci, and the functional consequences of those variants should be investigated. Further, the exact effects of inhaling $\mathrm{CO}_{2}$ on brain $\mathrm{pH}$ in humans remain to be elucidated. In rodents, it was shown that exposure to $\mathrm{CO}_{2}$ decreases brain $\mathrm{pH}$ (Ziemann et al., 2009). In humans however, direct evidence for such a $\mathrm{CO}_{2}$-induced brain acidosis is lacking. Indirect evidence is available, provided by MRI studies showing that PD patients have a larger brain lactate response to visual stimuli (Maddock et al., 2009) and after lactate infusion (Dager et al., 1999; Dager et al., 1997), compared to healthy controls. Work in rodents showed that an increase in lactate causes a decrease in brain pH (Erlichman et al., 2008), suggesting that a similar effect may occur in humans. Combining $\mathrm{CO}_{2}$ administration and $\mathrm{MR}$ spectroscopy, able to non-invasively detect brain $\mathrm{pH}$ changes, may provide the lacking direct evidence.

The results of this study should be interpreted keeping in mind some potential limitations. First, the different results between our study and Smoller's investigation regarding the direction of the genetic effect might be due to both studies investigating a non-causal variant that is in high linkage disequilibrium with a not yet studied causal variant. Second, in the present study we did not correct for multiple testing. However, given our confirmatory and clear hypothesis-driven approach of two highly correlated variants, this would be overly conservative. Moreover, converging translational and clinical evidence strongly underscores a genuine effect of the gene in PD. Rodent studies showed that ASIC1a is essential in the fear-related behavioral response to $\mathrm{CO}_{2}$ exposure (Ziemann et al., 2009). In line with this, Smoller et al. (2014) demonstrated an association of the ACCN2 gene with the diagnosis of PD, an effect of the gene on amygdala size in healthy volunteers, and an effect of the gene on amygdala function in (a subset of these) healthy volunteers. To that, the present study adds an effect of the gene on physiological response to $\mathrm{CO}_{2}$ in healthy volunteers and an effect on the fear response to $\mathrm{CO}_{2}$ in PD patients. Third, we clustered C-allele carriers into one group instead of a possibly more sensitive quantitative (0-1-2 alleles) approach, due to the low number of subjects homozygous for C. Fourth, family history of PD was an exclusion criterion in the healthy volunteers group. With hindsight, this may have led to the inclusion of a "hyper-normal" group, thereby increasing the possibility of type II error. This might explain the less homogeneous results 
in the healthy group. To increase the sensitivity on outcome measurements, future studies should include samples with a larger variation in anxiety, such as individuals with differential anxiety sensitivity or first-degree relatives of PD patients.

To conclude, the results of the present study extend on those of previous studies into the mechanisms of panic and provide the first evidence for a relationship between the ACCN2 gene and the reactivity to a $\mathrm{CO}_{2}$ panic challenge in humans. Thereby, the association between the ACCN2 gene and PD is strengthened and the importance of investigating both the role of variants in the ACCN2 gene in humans as well as ASIC1a in rodents in the pathophysiology of panic is further supported. In the long-term, ACCN2 may become a potential therapeutic target in the treatment of PD, a suggestion that is also supported by rodent research in which pharmacological inhibition of ASIC1a reduced fear-behavior (Ziemann et al., 2009).

\section{Acknowledgments}

This work was supported by the Deutsche Forschungsgemeinschaft (DFG) Sonderforschungsbereich Transregio (SFB TRR) 58, Sonderforschungsbereich (SFB) 58/A1 and A5 to DvdH. 


\section{References}

American Psychiatric Association, 2000. Diagnostic and Statistical Manual of Mental Disorders: DSM-IV-TR, 4th edn. Washington, DC: American Psychiatric Association.

American Psychiatric Association, 2013. The Diagnostic and Statistical Manual of Mental Disorders (5th ed.). American Psychiatric Publishing, Arlington, VA.

Bailey, J.E., Dawson, G.R., Dourish, C.T., Nutt, D.J., 2011. Validating the inhalation of $7.5 \% \operatorname{CO}(2)$ in healthy volunteers as a human experimental medicine: a model of generalized anxiety disorder (GAD). J. Psychopharm. 25, 1192-1198.

Batelaan, N., Smit, F., de Graaf, R., van Balkom, A., Vollebergh, W., Beekman, A., 2007. Economic costs of fullblown and subthreshold panic disorder. J. Affect. Disord. 104, 127-136.

Battaglia, M., Ogliari, A., Harris, J., Spatola, C.A., Pesenti-Gritti, P., Reichborn-Kjennerud, T., Torgersen, S., Kringlen, E., Tambs, K., 2007. A genetic study of the acute anxious response to carbon dioxide stimulation in man. J. Psychiatr. Res. 41, 906-917.

Battaglia, M., Perna, G., 1995. The 35\% CO2 challenge in panic disorder: optimization by receiver operating characteristic (ROC) analysis. J. Psychiatr. Res. 29, 111-119.

Battaglia, M., Pesenti-Gritti, P., Medland, S.E., Ogliari, A., Tambs, K., Spatola, C.A., 2009. A genetically informed study of the association between childhood separation anxiety, sensitivity to $\mathrm{CO}(2)$, panic disorder, and the effect of childhood parental loss. Arch. Gen. Psychiatry 66, 64-71.

Biancardi, V., Bicego, K.C., Almeida, M.C., Gargaglioni, L.H., 2008. Locus coeruleus noradrenergic neurons and CO2 drive to breathing. Pflugers Arch. 455, 1119-1128.

Clarke, G.M., Cardon, L.R., 2010. Aspects of observing and claiming allele flips in association studies. Genet. Epidemiol. 34, 266-274.

Cleveland, W.S., Devlin, S.J., 1988. Locally weighted regression: An approach to regression analysis by local fitting. J Am Statist Assoc 83, 596-610.

Colasanti, A., Esquivel, G., Schruers, K.J., Griez, E.J., 2012. On the psychotropic effects of carbon dioxide. Curr. Pharm. Des. 18, 5627-5637.

Colasanti, A., Salamon, E., Schruers, K., van Diest, R., van Duinen, M., Griez, E.J., 2008. Carbon dioxide-induced emotion and respiratory symptoms in healthy volunteers. Neuropsychopharmacology 33, 3103-3110.

da Silva, G.S., Giusti, H., Benedetti, M., Dias, M.B., Gargaglioni, L.H., Branco, L.G., Glass, M.L., 2011. Serotonergic neurons in the nucleus raphe obscurus contribute to interaction between central and peripheral ventilatory responses to hypercapnia. Pflugers Arch. 462, 407-418.

Dager, S.R., Friedman, S.D., Heide, A., Layton, M.E., Richards, T., Artru, A., Strauss, W., Hayes, C., Posse, S., 1999. Two-dimensional proton echo-planar spectroscopic imaging of brain metabolic changes during lactateinduced panic. Arch. Gen. Psychiatry 56, 70-77.

Dager, S.R., Richards, T., Strauss, W., Artru, A., 1997. Single-voxel 1H-MRS investigation of brain metabolic changes during lactate-induced panic. Psychiatry Res. 76, 89-99.

Dean, J.B., Bayliss, D.A., Erickson, J.T., Lawing, W.L., Millhorn, D.E., 1990. Depolarization and stimulation of neurons in nucleus tractus solitarii by carbon dioxide does not require chemical synaptic input. Neuroscience $36,207-216$.

Erlichman, J.S., Hewitt, A., Damon, T.L., Hart, M., Kurascz, J., Li, A., Leiter, J.C., 2008. Inhibition of monocarboxylate transporter 2 in the retrotrapezoid nucleus in rats: a test of the astrocyte-neuron lactate-shuttle hypothesis. The Journal of neuroscience : the official journal of the Society for Neuroscience 28, 4888-4896.

Esquivel, G., Schruers, K.R., Maddock, R.J., Colasanti, A., Griez, E.J., 2009. Acids in the brain: a factor in panic? J Psychopharmacol 24, 639-647.

Feinstein, J.S., Buzza, C., Hurlemann, R., Follmer, R.L., Dahdaleh, N.S., Coryell, W.H., Welsh, M.J., Tranel, D., Wemmie, J.A., 2013. Fear and panic in humans with bilateral amygdala damage. Nat. Neurosci. 16, $270-272$. 
Garner, M., Attwood, A., Baldwin, D.S., James, A., Munafo, M.R., 2011. Inhalation of 7.5\% carbon dioxide increases threat processing in humans. Neuropsychopharmacology : official publication of the American College of Neuropsychopharmacology 36, 1557-1562.

Goossens, L., Leibold, N., Peeters, R., Esquivel, G., Knuts, I., Backes, W., Marcelis, M., Hofman, P., Griez, E., Schruers, K., 2014. Brainstem response to hypercapnia: A symptom provocation study into the pathophysiology of panic disorder. J Psychopharmacol.

Griez, E., de Loof, C., Pols, H., Zandbergen, J., Lousberg, H., 1990. Specific sensitivity of patients with panic attacks to carbon dioxide inhalation. Psychiatry Res. 31, 193-199.

Griez, E.J., Colasanti, A., van Diest, R., Salamon, E., Schruers, K., 2007. Carbon dioxide inhalation induces dosedependent and age-related negative affectivity. PLoS One 2, e987.

Griez, E.J., Lousberg, H., van den Hout, M.A., van der Molen, G.M., 1987. CO2 vulnerability in panic disorder. Psychiatry Res. 20, 87-95.

Hettema, J.M., An, S.S., Neale, M.C., van den Oord, E.J., Kendler, K.S., Chen, X., 2008. Lack of association between the amiloride-sensitive cation channel 2 (ACCN2) gene and anxiety spectrum disorders. Psychiatr. Genet. 18, 73-79.

Holmes, A.J., Lee, P.H., Hollinshead, M.O., Bakst, L., Roffman, J.L., Smoller, J.W., Buckner, R.L., 2012. Individual differences in amygdala-medial prefrontal anatomy link negative affect, impaired social functioning, and polygenic depression risk. The Journal of neuroscience : the official journal of the Society for Neuroscience 32, 18087-18100.

Kim, J.E., Dager, S.R., Lyoo, I.K., 2012. The role of the amygdala in the pathophysiology of panic disorder: evidence from neuroimaging studies. Biology of mood \& anxiety disorders 2, 20.

Klaassen, T., Klumperbeek, J., Deutz, N.E., van Praag, H.M., Griez, E., 1998. Effects of tryptophan depletion on anxiety and on panic provoked by carbon dioxide challenge. Psychiatry Res. 77, 167-174.

Lin, P.I., Vance, J.M., Pericak-Vance, M.A., Martin, E.R., 2007. No gene is an island: the flip-flop phenomenon. Am. J. Hum. Genet. 80, 531-538.

Lu, Y., Ma, X., Sabharwal, R., Snitsarev, V., Morgan, D., Rahmouni, K., Drummond, H.A., Whiteis, C.A., Costa, V., Price, M., Benson, C., Welsh, M.J., Chapleau, M.W., Abboud, F.M., 2009. The ion channel ASIC2 is required for baroreceptor and autonomic control of the circulation. Neuron 64, 885-897.

Maddock, R.J., Buonocore, M.H., Copeland, L.E., Richards, A.L., 2009. Elevated brain lactate responses to neural activation in panic disorder: a dynamic 1 H-MRS study. Mol. Psychiatry 14, 537-545.

Mulkey, D.K., Stornetta, R.L., Weston, M.C., Simmons, J.R., Parker, A., Bayliss, D.A., Guyenet, P.G., 2004. Respiratory control by ventral surface chemoreceptor neurons in rats. Nat. Neurosci. 7, 1360-1369.

Nakashima, K., Yamashita, T., Kashiwagi, S., Nakayama, N., Kitahara, T., Ito, H., 1996. The effect of sodium bicarbonate on CBF and intracellular pH in man: stable Xe-CT and 31P-MRS. Acta Neurol. Scand. Suppl. 166, 96-98.

Nardi, A.E., Valenca, A.M., Lopes, F.L., Nascimento, I., Veras, A.B., Freire, R.C., Mezzasalma, M.A., de-MeloNeto, V.L., Zin, W.A., 2006. Psychopathological profile of 35\% CO2 challenge test-induced panic attacks: a comparison with spontaneous panic attacks. Compr. Psychiatry 47, 209-214.

Price, M.P., Gong, H., Parsons, M.G., Kundert, J.R., Reznikov, L.R., Bernardinelli, L., Chaloner, K., Buchanan, G.F., Wemmie, J.A., Richerson, G.B., Cassell, M.D., Welsh, M.J., 2014. Localization and behaviors in null mice suggest that ASIC1 and ASIC2 modulate responses to aversive stimuli. Genes, brain, and behavior 13, 179194.

Putnam, R.W., Filosa, J.A., Ritucci, N.A., 2004. Cellular mechanisms involved in CO(2) and acid signaling in chemosensitive neurons. Am. J. Physiol. Cell Physiol. 287, C1493-1526.

Rhoades, R.A., Bell, D.R., 2009. Medical Physiology: Principles for Clinical Medicine, 3rd Revised Edition ed. Lippincott Williams \& Wilkins, Philadelphia, PA, USA.

Roberson-Nay, R., Kendler, K.S., 2011. Panic disorder and its subtypes: a comprehensive analysis of panic symptom heterogeneity using epidemiological and treatment seeking samples. Psychol. Med. 41, 2411-2421. 
Roberson-Nay, R., Moruzzi, S., Ogliari, A., Pezzica, E., Tambs, K., Kendler, K.S., Battaglia, M., 2013. Evidence for distinct genetic effects associated with response to 35\% CO(2). Depress. Anxiety 30, 259-266.

Schruers, K., Esquivel, G., van Duinen, M., Wichers, M., Kenis, G., Colasanti, A., Knuts, I., Goossens, L., Jacobs, N., van Rozendaal, J., Smeets, H., van Os, J., Griez, E., 2011. Genetic moderation of CO2-induced fear by 5-HTTLPR genotype. J Psychopharmacol 25, 37-42.

Schruers, K.R.J., Van De Mortel, H., Overbeek, T., Griez, E., 2004. Symptom profiles of natural and laboratory panic attacks. Acta Neuropsychiatr. 16, 101-106.

Schuchmann, S., Schmitz, D., Rivera, C., Vanhatalo, S., Salmen, B., Mackie, K., Sipila, S.T., Voipio, J., Kaila, K., 2006. Experimental febrile seizures are precipitated by a hyperthermia-induced respiratory alkalosis. Nat. Med. 12, 817-823.

Sheehan, D.V., Lecrubier, Y., Sheehan, K.H., Amorim, P., Janavs, J., Weiller, E., Hergueta, T., Baker, R., Dunbar, G.C., 1998. The Mini-International Neuropsychiatric Interview (M.I.N.I.): the development and validation of a structured diagnostic psychiatric interview for DSM-IV and ICD-10. The Journal of clinical psychiatry 59 Suppl 20, 22-33;quiz 34-57.

Shin, L.M., Liberzon, I., 2010. The neurocircuitry of fear, stress, and anxiety disorders. Neuropsychopharmacology : official publication of the American College of Neuropsychopharmacology 35, 169-191.

Smoller, J.W., 2011. Who's afraid of anxiety genetics? Biol. Psychiatry 69, 506-507.

Smoller, J.W., Gallagher, P.J., Duncan, L.E., McGrath, L.M., Haddad, S.A., et al., 2014. The Human Ortholog of AcidSensing Ion Channel Gene ASIC1a Is Associated with Panic Disorder and Amygdala Structure and Function. Biol. Psychiatry. 76:902-910.

Verburg, K., Pols, H., de Leeuw, M., Griez, E., 1998. Reliability of the $35 \%$ carbon dioxide panic provocation challenge. Psychiatry Res. 78, 207-214.

Wemmie, J.A., Askwith, C.C., Lamani, E., Cassell, M.D., Freeman, J.H., Jr., Welsh, M.J., 2003. Acid-sensing ion channel 1 is localized in brain regions with high synaptic density and contributes to fear conditioning. $J$. Neurosci. 23, 5496-5502.

Wemmie, J.A., Coryell, M.W., Askwith, C.C., Lamani, E., Leonard, A.S., Sigmund, C.D., Welsh, M.J., 2004 Overexpression of acid-sensing ion channel $1 \mathrm{a}$ in transgenic mice increases acquired fear-related behavior. Proc. Natl. Acad. Sci. U. S. A. 101, 3621-3626.

Wemmie, J.A., Taugher, R.J., Kreple, C.J., 2013. Acid-sensing ion channels in pain and disease. Nature reviews. Neuroscience 14, 461-471.

Yonkers, K.A., Bruce, S.E., Dyck, I.R., Keller, M.B., 2003. Chronicity, relapse, and illness--course of panic disorder, social phobia, and generalized anxiety disorder: findings in men and women from 8 years of follow-up. Depress. Anxiety 17, 173-179.

Ziemann, A.E., Allen, J.E., Dahdaleh, N.S., Drebot, II, Coryell, M.W., Wunsch, A.M., Lynch, C.M., Faraci, F.M., Howard, M.A., 3rd, Welsh, M.J., Wemmie, J.A., 2009. The amygdala is a chemosensor that detects carbon dioxide and acidosis to elicit fear behavior. Cell 139, 1012-1021.

Ziemann, A.E., Schnizler, M.K., Albert, G.W., Severson, M.A., Howard, M.A., 3rd, Welsh, M.J., Wemmie, J.A., 2008. Seizure termination by acidosis depends on ASIC1a. Nat. Neurosci. 11, 816-822. 


\section{Supplement}

Table S1. Clinical assessment in panic disorder patients. MADRS, Montgomery-Asberg Depression Rating Scale; FQA, Fear Questionnaire subscale agoraphobia; PAS, panic and agoraphobia scale.

\begin{tabular}{|ll|}
\hline Assessment & Mean $(S E M)$ \\
\hline MADRS & $13.13(0.61)$ \\
\hline FQA & $17.02(0.95)$ \\
\hline PAS & $22.07(0.81)$ \\
\hline
\end{tabular}

Table S2. Effect of rs10875995 genotype on self-reports in healthy volunteers and panic disorder patients. Data represent means (SEM).

\begin{tabular}{|c|c|c|c|c|c|c|}
\hline & \multicolumn{3}{|c|}{ Healthy volunteers } & \multicolumn{3}{|c|}{ Panic disorder patients } \\
\hline & $\begin{array}{l}C / C \text { and } C / T \\
(n=55)\end{array}$ & $\begin{array}{l}T / T \\
(n=52)\end{array}$ & p-value & $\begin{array}{l}C / C \text { and } C / T \\
(n=90)\end{array}$ & $\begin{array}{l}T / T \\
(n=93)\end{array}$ & $p$-value \\
\hline Change in fear & 35.07 (3.19) & $29.88(3.34)$ & 0.264 & $36.13(2.31)$ & 43.01 (2.19) & 0.032 \\
\hline $\begin{array}{l}\text { Change in } \\
\text { discomfort }\end{array}$ & $46.27(3.36)$ & $40.23(3.38)$ & 0.208 & - & - & - \\
\hline $\begin{array}{l}\text { Change in panic } \\
\text { symptoms }\end{array}$ & $13.45(0.89)$ & $11.79(0.94)$ & 0.196 & $12.80(0.88)$ & $13.84(1.41)$ & 0.388 \\
\hline $\begin{array}{l}\text { Respiratory } \\
\text { cluster }\end{array}$ & - & - & - & $\begin{array}{l}8.13(3.94) \\
(n=75)\end{array}$ & $\begin{array}{l}8.41(3.69) \\
(n=73)\end{array}$ & 0.659 \\
\hline
\end{tabular}

Table S3. Effect of rs685012 genotype on self-reports in healthy volunteers and panic disorder patients. Data represent means (SEM).

\begin{tabular}{|c|c|c|c|c|c|c|}
\hline & \multicolumn{3}{|c|}{ Healthy volunteers } & \multicolumn{3}{|c|}{ Panic disorder patients } \\
\hline & $\begin{array}{l}C / C \text { and } C / T \\
(n=56)\end{array}$ & $\begin{array}{l}T / T \\
(n=51)\end{array}$ & $p$-value & $\begin{array}{l}C / C \text { and } C / T \\
(n=91)\end{array}$ & $\begin{array}{l}T / T \\
(n=86)\end{array}$ & $p$-value \\
\hline Change in fear & 33.57 (3.17) & $31.43(3.41)$ & 0.646 & $36.56(2.32)$ & $42.72(2.30)$ & 0.061 \\
\hline $\begin{array}{l}\text { Change in } \\
\text { discomfort }\end{array}$ & $46.79(3.11)$ & $39.55(3.63)$ & 0.131 & - & - & - \\
\hline $\begin{array}{l}\text { Change in panic } \\
\text { symptoms }\end{array}$ & $13.11(0.88)$ & $12.14(0.94)$ & 0.453 & $12.92(0.92)$ & $13.72(0.84)$ & 0.519 \\
\hline $\begin{array}{l}\text { Respiratory } \\
\text { cluster }\end{array}$ & - & - & - & $\begin{array}{l}8.25(3.82) \\
(n=76)\end{array}$ & $\begin{array}{l}8.34(3.76) \\
(n=71)\end{array}$ & 0.889 \\
\hline
\end{tabular}


Table S4. Effect of rs10875995 genotype on cardiovascular outcome measurements in healthy volunteers. Data represent means (SEM). AUC, area under the curve.

\begin{tabular}{|c|c|c|c|c|}
\hline & & $\mathrm{C} / \mathrm{C}$ and $\mathrm{C} / \mathrm{T}$ & $\mathrm{T} / \mathrm{T}$ & $p$-value \\
\hline \multirow{2}{*}{ Systolic blood pressure } & AUC & 7610 (173.77) & $8068(138.44)$ & 0.043 \\
\hline & Peak & $153(3.01)$ & $162(3.15)$ & 0.089 \\
\hline \multirow{2}{*}{ Diastolic blood pressure } & AUC & 4589 (89.94) & 4816 (68.69) & 0.049 \\
\hline & Peak & $97(2.26)$ & 104 (1.79) & 0.030 \\
\hline \multirow{2}{*}{ Heart rate } & AUC & 4884 (107.67) & $4743(107.84)$ & 0.357 \\
\hline & Peak & $109(2.03)$ & $108(1.98)$ & 0.698 \\
\hline
\end{tabular}

Table S5. Effect of rs685012 genotype on cardiovascular outcome measurements in healthy volunteers. Data represent means (SEM). AUC, area under the curve.

\begin{tabular}{|lllll|}
\hline & & $C / C$ and $C / T$ & $T / T$ & p-value \\
\hline \multirow{2}{*}{ Systolic blood pressure } & AUC & $8015(163.08)$ & $7612(152.61)$ & 0.074 \\
\cline { 2 - 4 } & Peak & $161(33.69)$ & $153(23.08)$ & 0.119 \\
\hline \multirow{2}{*}{ Diastolic blood pressure } & AUC & $4755(73.65)$ & $4621(90.18)$ & 0.249 \\
\cline { 2 - 4 } & Peak & $102(1.96)$ & $99(2.24)$ & 0.281 \\
\hline \multirow{2}{*}{ Heart rate } & AUC & $4694(656.58)$ & $4932(793.43)$ & 0.117 \\
\hline & Peak & $107(14.86)$ & $110(11.77)$ & 0.356 \\
\hline
\end{tabular}


ACCN2 genotype affects the response to $\mathrm{CO}_{2}$ 


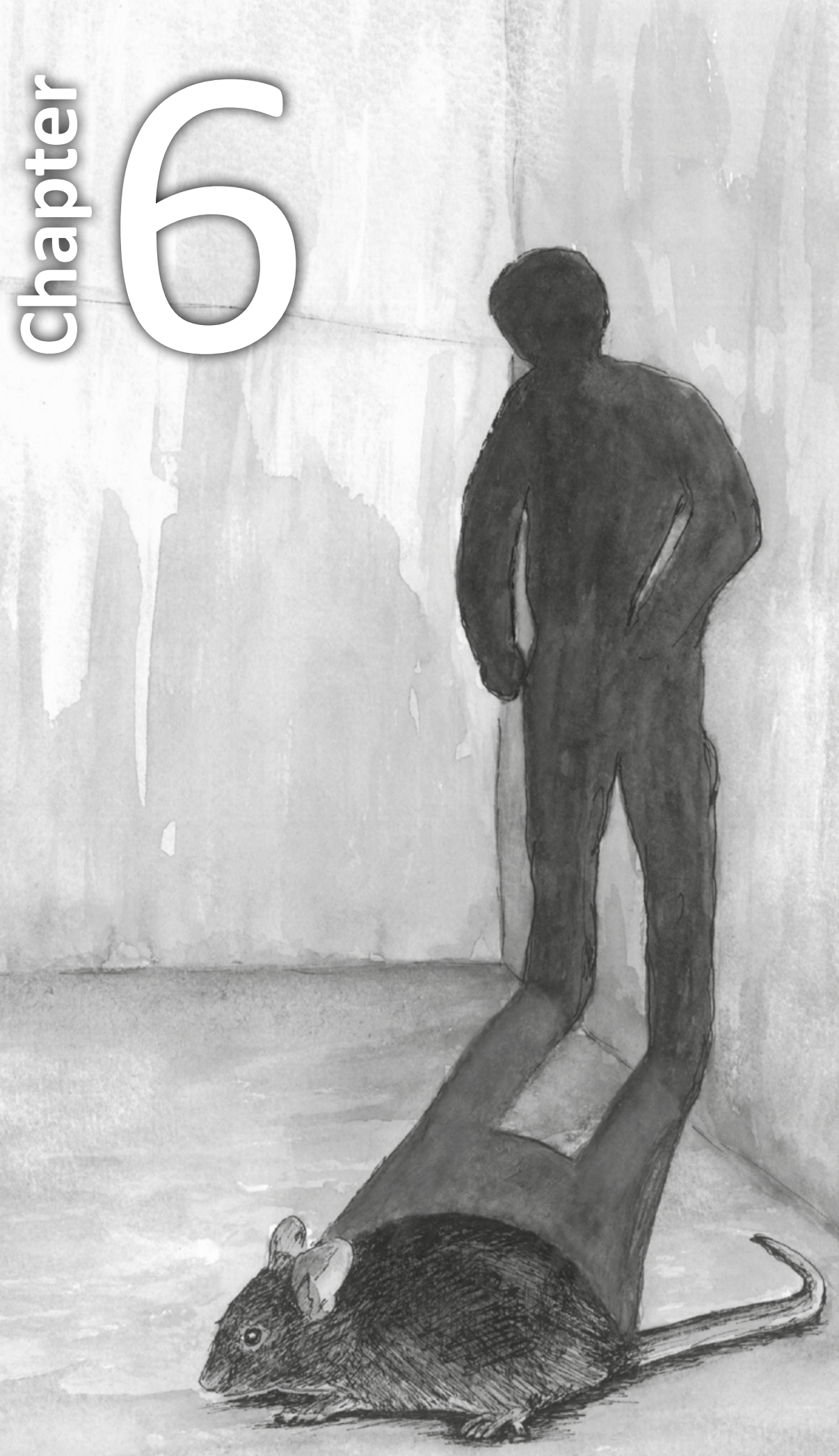

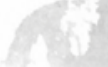




\section{Functional role of the $5-\mathrm{HT}$ system and ASIC1a levels in $\mathrm{CO}_{2}$-induced fear-related behavior in mice}

Nicole Leibold ${ }^{\mathrm{a}, \mathrm{b}}$, Daniel van den Hove ${ }^{\mathrm{a}, \mathrm{b}}$, Magdalena Weidner ${ }^{\mathrm{a}, \mathrm{b}}$, Gordon Buchanan ${ }^{c}$, Angelika Schmitt Gabriela Ortega ${ }^{b}$, Inez Myin-Germeys ${ }^{a}$, Harry Steinbusch ${ }^{a}$, Klaus-Peter Lesch ${ }^{a, b}$, Koen Schruers ${ }^{a, d}$

a Department of Psychiatry and Neuropsychology, Maastricht University, P.O. Box 616, 6200 MD Maastricht, the Netherlands. School for Mental Health and Neuroscience (MHeNS), Maastricht University. European Graduate School of Neuroscience (EURON), P.O. Box 616, 6200 MD Maastricht, the Netherlands

b Division of Molecular Psychiatry, Laboratory of Translational Neuroscience, Center of Mental Health, University of Wuerzburg, Fuechsleinstrasse 15, 97080 Wuerzburg, Germany

c Department of Neurology, Yale University School of Medicine, P.O. Box 208018, 15 York Street, New Haven, Connecticut 06520-8018, USA

d Center for the Psychology of Learning and Experimental Psychopathology, Department of Psychology, University of Leuven, Tiensestraat 102, P.O. Box 3726, 3000 Leuven, Belgium 


\section{Abstract}

Previous research implicated disturbances in the brain acid-base homeostasis and the serotonergic (5-HT) system in the pathophysiology of panic disorder (PD). Inhaling an excess concentration of carbon dioxide $\left(\mathrm{CO}_{2}\right)$ represents a well-validated human experimental model of panic attacks, the core symptom of PD. We previously showed that the fear response to $\mathrm{CO}_{2}$ is moderated by variants in the serotonin transporter (5HTT) gene and the amiloride-sensitive cation channel 2 (ACCN2) gene. ACCN2 is the human homologue of the rodent gene encoding the acid sensing ion channel 1a (ASIC1a), which is essentially involved in the behavioral fear response to $\mathrm{CO}_{2}$ exposure in mice. $A$ missing link is the possibly functional relationship between the sensitivity to $\mathrm{CO}_{2}$, the $5-\mathrm{HT}$ system, and ASIC1a. As a follow-up of those previous studies, we investigated the effects of $\mathrm{CO}_{2}$ exposure on fear-related behavior and the cardio-respiratory response in wildtype, hetero-, and homozygous 5- $\mathrm{Htt}$ knock-out mice. Quantitative real-time polymerase chain reaction (qRT-PCR) was used to assess ASIC1A levels in various brain regions. $\mathrm{CO}_{2}$ exposure resulted in a marked fear-related behavioral response in the open field and the two-chamber test, which was accompanied by a robust freezing response in comparison with air exposure. Furthermore, homozygous 5-Htt knock-out mice showed more anxietyrelated behavior under air exposure in comparison with wildtype and heterozygous $5-\mathrm{Htt}$ mice, while they were less sensitive to exposure to $\mathrm{CO}_{2}$, the behavioral effects of which were particularly observed in wildtype mice. The respiratory system was strongly activated by $\mathrm{CO}_{2}$, whereas heart rate decreased compared to air exposure. No genotype effect was observed at the cardiorespiratory system. ASIC1a levels are currently being assessed and will be related to genotype and the response to air and $\mathrm{CO}_{2}$ exposure. To conclude, $\mathrm{CO}_{2}$ is a robust fear-inducing stimulus, with most pronounced effects in wildtype mice, in line with our previous human study. Ongoing analyses will show whether ASIC1a expression is linked to the extent of fear-related behavior. In the long-term, ASIC1a may become a target for the pharmacological treatment of PD. 


\section{Introduction}

Panic attacks (PAs) are the core symptom of panic disorder (PD) and represent a rare psychopathological phenomenon that can be reliably induced in an experimental setting. Some of the widely used panic provocation procedures acutely disturb the acid-brain homeostasis (Esquivel et al., 2009). One of these is an inhalation with an increased concentration of carbon dioxide $\left(\mathrm{CO}_{2}\right)$. It has been repetitively shown that a heightened $\mathrm{CO}_{2}$-sensitivity is relatively specific for PD (Griez et al., 1990; Kent et al., 2001; Perna et al., 1994; Perna et al., 1999; Talesnik et al., 2007). However, when a higher concentration of $\mathrm{CO}_{2}$ is given, a similar fear response can also be triggered in healthy individuals (Griez et al., 2007). Therefore, insights into the molecular basis of $\mathrm{CO}_{2}$-sensitivity may increase the current understanding of the pathophysiology of PAs.

Important progress was made when rodent research demonstrated that the acid-sensing ion channel 1a (ASIC1a) plays a critical role in the unconditioned behavioral fear response to $\mathrm{CO}_{2}$ exposure (Ziemann et al., 2009), in addition to being involved in acquired fear behavior (Coryell et al., 2008; Wemmie et al., 2003; Wemmie et al., 2004). ASIC1a belongs to the family of degenerin/epithelial sodium channels (for review see Sherwood et al., 2012) and is distributed widely throughout the brain (Price et al., 2014; Wemmie et al., 2003). It is located in dendrites, dendritic spines, neuronal cell bodies (Wemmie et al., 2002; Zha et al., 2009; Zha et al., 2006), as well as glial cells (Lin et al., 2010). Upon activation by a drop in extracellular $\mathrm{pH}, \mathrm{ASIC} 1 \mathrm{a}$ becomes permeable to sodium and calcium (Xiong et al., 2004; Yermolaieva et al., 2004), leading to membrane depolarization and signal transduction (Wemmie et al., 2013). In addition, ASIC1a contributes to synaptic plasticity, likely by interacting with $\mathrm{Ca}^{2+} /$ calmodulin-dependent protein kinase II (CaMKII) (Zha, 2013).

Recently, the human analogue gene to ASIC1a, i.e. the amiloride-sensitive cation channel 2 (ACCN2), has been associated with PD, amygdala volume as well as reactivity to emotional faces (Smoller et al., 2014). As the underlying mechanism, a genetically determined lowered threshold for detecting acidosis was proposed. However, in that study, no direct experimental link to a change in $\mathrm{pH}$ was made. We (Leibold et al., submitted) provided this missing link by using a technique similar to the one applied in rodents, namely a $\mathrm{CO}_{2}$ inhalation in PD patients and healthy individuals. Results showed a differential sensitivity to $\mathrm{CO}_{2}$, depending on the ACCN2 genotype. These data put forward ACCN2 as a new prime candidate for future research and potentially as a therapeutic target in the treatment of PD.

In addition to a critical role of detecting and reacting to changes in $\mathrm{pH}$, the effective clinical use of antidepressants in the treatment of PD implies the involvement of the serotonergic (5-HT) system (Batelaan et al., 2012). For instance, selective serotonin reuptake inhibitors 
(SSRIs) are the first-line pharmacological choice. SSRIs exert their effects by inhibiting the serotonin transporter (5-HTT) (Ravindran \& Stein, 2010), leading to prolonged 5-HT signaling. Other medication includes tricyclic antidepressants, inhibiting both the uptake of 5-HT and norepinephrine, and inhibitors of monoamine oxidase-A, the enzyme that is responsible for the breakdown of 5-HT (Batelaan et al., 2012).

While research supports both a role of chemosensitivity and the 5-HT system in the pathophysiology of PAs, experimental panic studies have also shown a link between both. For instance, tryptophan depletion, a method to reduce brain 5-HT levels, increased the fear response to $\mathrm{C}_{2}$ inhalation in PD patients and healthy individuals (Miller et al., 2000; Schruers and Griez, 2003; Schruers et al., 2000), whereas administration of a 5-HT precursor, leading to increased brain 5-HT levels, reduced the panic response (Schruers et al., 2002). We also showed that the dose-dependent fear reaction to $\mathrm{CO}_{2}$ is moderated by a functional polymorphism in the promoter region of the gene encoding the 5-HTT (5-HTTLPR), with subjects homozygous for the L-allele reporting more fear than S-allele carriers at an intermediate $\mathrm{CO}_{2}$ concentration (Schruers et al., 2011). A remaining questions is which brain structure links $\mathrm{pH}$ detection and the behavioral phenotypes associated with 5-HT system (dys)function? Rodent research showed that several brain regions such as the amygdala (Ziemann et al., 2009), the hypothalamus (Johnson et al., 2012; Williams et al., 2007), and the brainstem (Brust et al., 2014; Richerson, 2004), all of which receive serotonergic innervation, are sensitive to $\mathrm{CO}_{2}$. Recently, we demonstrated that, in humans, inhaling $\mathrm{CO}_{2}$ activates the brainstem (Goossens et al., 2014). In addition, on the molecular level, it was shown that a large proportion of medullary and midbrain 5-HT neurons are highly chemosensitive and tightly juxtaposed to large arteries, allowing an accurate monitoring of arterial blood $\mathrm{CO}_{2}$ levels (Richerson, 2004; Severson et al., 2003). As medullary and midbrain 5-HT neurons are known to regulate respiration and arousal, respectively (Richerson, 2004), which are both associated with the symptomatology during a PA, it is plausible to consider the brainstem as a key neuroanatomical structure in PD.

To date, it remains largely elusive which molecules act as chemoreceptors within the 5-HT brainstem cells. ASIC1a seems a likely candidate for this. Ziemann et al. (2009) demonstrated in their study that the $\mathrm{CO}_{2}$-provoked behavioral fear response was dependent on ASIC1a in the amygdala. However, ASIC1a is widely expressed in the brain (Wemmie et al., 2003), including the brainstem (Price et al., 2014), which was not investigated in the study by Ziemann and colleagues (2009).

The overall aim of the present study was to further explore the relationship between differential chemosensitivity and the 5 -HT system in view of PD. As translational follow-up to our previous human study, showing a moderating effect of the 5 -HTTLPR in $\mathrm{CO}_{2}$-induced fear (Schruers, et al., 2011), wildtype (WT), hetero- (+/-), and homozygous (-/-) 5-Htt 
knock-out mice were exposed to $\mathrm{CO}_{2}$ using an innovative and fully controlled $\mathrm{CO}_{2}$ chamber, allowing live monitoring during $\mathrm{CO}_{2}$ exposure. The response to $\mathrm{CO}_{2}$ was examined in terms of anxiety- and fear-related behavior, and by monitoring the cardio-respiratory response. To study whether behavioral differences were dependent upon ASIC1a, expression levels were analyzed in regions of the fear circuit. Accordingly, we hypothesized that ASIC1a is located within $5-\mathrm{HT}$ brainstem cells, thereby providing a molecule that senses $\mathrm{CO}_{2}$ changes in 5-HT cells.

\section{Experimental procedures}

\section{Assessment of anxiety- and fear-related behavior}

\section{Animals}

In total, 84 male WT, 5- $\mathrm{Htt}+/-$, and 5- $\mathrm{Htt}-/-$ mice (background $\mathrm{C} 57 \mathrm{BL} / 6$ ) were housed individually in ventilated cages within a temperature-controlled environment $\left(21 \pm 1^{\circ} \mathrm{C}\right)$ and under a reversed day/night cycle ( $12 \mathrm{hr}$ light/ $12 \mathrm{hr}$ dark cycle). Standard rodent chow and water were provided ad libitum. From postnatal day 90 onwards, mice were subjected to fear-related behavioral tasks. For this purpose, mice were divided over 6 experimental groups ( $\mathrm{n}=14 /$ group): 1) WT mice exposed to $0 \% \mathrm{CO}_{2}$, 2) $5-\mathrm{Htt}+/-$ mice exposed to $0 \% \mathrm{CO}_{2}$, 3) $5-\mathrm{Htt}$-/- mice exposed to $0 \% \mathrm{CO}_{2}$, 4) WT mice exposed to $10 \% \mathrm{CO}_{2}$, 5) 5 - $\mathrm{Htt}+/-$ mice exposed to $\left.10 \% \mathrm{CO}_{2}, 6\right) 5-\mathrm{Htt}-/-$ mice exposed to $10 \% \mathrm{CO}_{2}$. All procedures of this study were executed according to protocols approved by the Animal Ethics Board of Maastricht University, the Netherlands.

\section{Behavioral tests}

\section{Open field test}

The set-up of the open field chamber was based on a previous study (Ziemann et al., 2009), with several methodological improvements. It consisted of a transparent Plexiglas square $(50 \times 50 \times 40 \mathrm{~cm})$, covered with a clear lid. $\mathrm{CO}_{2}$ or air was infused using a gas infusion port on the upper part of the box to avoid blowing, which may be aversive to mice. Two holes at the opposite site prevented the building of overpressure. In addition, two CPU fans $(5 \times 5 \mathrm{~cm}, 26 \mathrm{~dB})$, fixed to the lid, were used to ensure a homogenous concentration of the infused gas throughout the entire chamber. The $\mathrm{CO}_{2}$ concentration was constantly controlled using a $30 \% \mathrm{CO}_{2}$ Sampling Data Logger ( $\mathrm{CO}_{2}$ meter, Ormond Beach, $\mathrm{FL}$, USA). The floor was subdivided into a $30 \times 30 \mathrm{~cm}$ central zone, $10 \times 10 \mathrm{~cm}$ corners, and $30 \times 10$ $\mathrm{cm}$ walls. Mice were placed in the center of the chamber that was pre-filled with either $10 \% \mathrm{CO}_{2}$ or compressed air (i.e., $0 \% \mathrm{CO}_{2}$; premixed gas tanks obtained from Nederlandse Technische Gasmaatschappij B.V., Landgraaf, the Netherlands) depending on the 
experimental group. Movements were scored automatically with a computerized system (Ethovision Color Pro, Noldus, the Netherlands) for $20 \mathrm{~min}$. Time spent in the different zones and total distance moved were analyzed. All behavioral testing was performed under low light conditions and by an investigator blind to genotype.

\section{Two-chamber test}

The apparatus consisted of two Plexiglas chambers (each $50 \times 25 \mathrm{~cm}$ with $40 \mathrm{~cm}$ high walls) that were connected by an open door $(3.5 \times 3.5 \mathrm{~cm})$ to allow free crossing, whilst limiting mixing of the gasses between the chambers. Each chamber had a gas infusion port, a hole to prevent overpressure, and a CPU fan $(5 \times 5 \mathrm{~cm}, 26 \mathrm{~dB})$ to ensure a homogenous concentration throughout the entire chamber.

For mice subjected to $\mathrm{CO}_{2}$ exposure, one chamber was pre-filled with $10 \% \mathrm{CO}_{2}$ and the other one with air (premixed gas tanks obtained from Nederlandse Technische Gasmaatschappij B.V., Landgraaf, the Netherlands). For mice assigned to air exposure, both chambers were filled with air. The concentration of $\mathrm{CO}_{2}$ was continuously controlled using a $30 \% \mathrm{CO}_{2}$ Sampling Data Logger ( $\mathrm{CO}_{2}$ meter, Ormond Beach, $\mathrm{FL}$, USA; a steady state of $9 \%$ and $2 \%$ was reached in case of $\mathrm{CO}_{2}$ administration). The chamber that was filled with $\mathrm{CO}_{2}$ and the chamber in which mice were placed were randomized. Movements, number of crossings, and time spent in each part were automatically scored with a computerized system across animals (Ethovision Color Pro, Noldus, the Netherlands) for a period of $10 \mathrm{~min}$.

\section{$\mathrm{CO}_{2}$-evoked freezing}

Freezing, defined as absence of any movements apart from respiration, was scored by a trained observer. Freezing is considered to reflect fear-related behavior in rodents (Mongeluzi et al., 2003).

\section{Stress-induced plasma corticosterone secretion}

To assess the hypothalamo-pituitary-adrenal (HPA) axis responsiveness to stress, plasma corticosterone levels were determined. Immediately after taking the mice from the home cage, the first blood sample was drawn via saphenous vein puncture (basal level) using heparinized blood collection tubes (Microvette CB300, Sarstedt, Germany). Then, mice remaining in their home cage - were exposed to $10 \% \mathrm{CO}_{2}$ for $20 \mathrm{~min}$, after which a second blood sample was drawn (stress level). Blood samples were kept on ice and centrifuged at $2000 \mathrm{~g}$ for $10 \mathrm{~min}$ at $4^{\circ} \mathrm{C}$. Plasma was collected and stored at $-80^{\circ} \mathrm{C}$ until further processing. Corticosterone levels were analyzed using radioimmunoassay. An ImmunuChem Double antibody corticosterone ${ }^{125}$ I RIA Kit for rodents (MP Biomedicals, Orangeburg, NY, USA) was used according to the manufacturer's instructions. Per sample 5 ul plasma was 
diluted in steroid diluents (1:100 for basal samples and 1:200 for stress samples). Fifty ul of corticosterone ${ }^{125} \mathrm{I}$ and $100 \mathrm{ul}$ anti-corticosterone were added per $50 \mathrm{ul}$ of diluted sample, after which the tubes were incubated for $2 \mathrm{~h}$ at room temperature. Then, 250 ul precipitant solution was added to each sample and subsequently centrifuged at 2300 rpm for $15 \mathrm{~min}$. After removing the supernatant the precipitation was counted in a Wizard gamma counter 2470 (PerkinElmer, Waltham, MA, USA).

\section{Assessment of the cardio-respiratory response}

\section{Animals}

Based on the results of behavioral testing, and in light of clinical relevance and logistic considerations, male WT and 5- $\mathrm{Htt}+/$ - knock-out mice (background C57BL/6, $\mathrm{n}=20$ / genotype) were housed in pairs of the same genotype within a temperature-controlled environment $\left(25 \pm 1^{\circ} \mathrm{C}\right)$ and under a reversed day/night cycle (12hr light/12hr dark cycle). Animals had access to standard rodent chow and water ad libitum. All procedures were approved by the Institutional Animal Care and Use Committee at Yale University, New Haven, CT, USA.

\section{Breathing and heart rate recordings}

Breathing and heart rate were recorded simultaneously in a custom-made whole body Plexiglas chamber $\left(350 \mathrm{~cm}^{3}\right.$ ), to which mice were habituated for 30 min (with room air infusion) before starting the actual experiment. Measurements were obtained for exposure to air for $20 \mathrm{~min}$, followed by $9 \% \mathrm{CO}_{2}$ for $10 \mathrm{~min}$. Flow rates were controlled with a digital flowmeter (0.4 liter/min; WU-32446-33, Cole-Parmer, Inc., Hoffman Estates, IL, USA). Breathing was measured using a low pressure transducer (DC002NDR5; Honeywell International, Inc.; Minneapolis, USA) that was fitted to the recording chamber. Pressure oscillations induced by breathing were calibrated with 150 pulses/min (300 ul). Heart rate was measured non-invasively using two electrodes placed on the sides of the shaved thorax. The electrodes were connected to an amplifier (Model 440 Instrumentation Amplifier, Brownlee Precision Co., San Jose, USA). Ambient temperature (temperature (BAT-12 microprobe, Physiotemp Instruments, Inc., Clifton, USA) and relative humidity (HIH-4602-A sensor; Honeywell International, Inc., Minneapolis, USA) within the chamber were recorded throughout the entire experiment. Immediately after the experiment, the animal's temperature was measured rectally (BAT-12 microprobe, Physiotemp Instruments, Inc., Clifton, USA). Signals were digitized (PCl-6221 or USB-6008 National Instruments Corp., Austin, TX, USA) and displayed in Matlab (version R2011b, Mathworks Co., Natick, MA, USA) with a custom-written acquisition program. Assessments were made under low-light conditions. 


\section{Brain processing}

At postnatal day 120, mice were sacrificed. Brains were dissected out, freshly frozen, and stored at $-80^{\circ} \mathrm{C}$. Brains of half of the animals per group ( $n=7 /$ group) used for behavioral testing were processed for quantitative ASIC1a expression analyses. For this purpose, the hippocampus, the amygdala, the dorsal raphe nucleus region, and the periaqueductal gray (PAG) were dissected by two investigators. To ensure homogeneity a particular region was done by the same investigator in all mice and the order of mice was randomized.

\section{RNA extraction}

Frozen tissue was incubated with $500 \mathrm{ul}$ QIAzol lysis reagent for $5 \mathrm{~min}$ and homogenized in a Tissuelyser ( $20 \mathrm{~Hz}, 1 \mathrm{~min}$; Qiagen, Hilden, Germany). After subsequent incubation with 100 ul trichlormethan/chloroform (Carl Roth, Karlsruhe, Germany) for 5 min, tubes were centrifuged $\left(5 \mathrm{~min}, 14^{\circ} \mathrm{C}, 12,000 \mathrm{rpm}\right)$. The water phase was mixed with $250 \mathrm{ul} 70 \%$ ethanol. For the following washing steps, and DNase treatment to remove genomic DNA, the protocol of the RNeasy Mini kit (Qiagen, Hilden, Germany) was followed accordingly to the manufacturer's instructions.

For assessing RNA yield and quality, concentrations and $A_{260 / 280}$ and $A_{260 / 230}$ ratios were measured using a Nano-Drop ${ }^{\circledR}$ ND-1000 spectrophotometer (pegLab, Erlangan, Germany). An additional quality check was done using the Experion ${ }^{\mathrm{TM}}$ RNA StdSens Analysis kit and the Experion gel electrophoresis system (Bio-Rad Laboratories, Inc., Munich, Germany) accordingly to the instructions of the manufacturer. RNA integrity was checked by agarose gel electrophoresis, stained with ethidium bromide.

\section{cDNA synthesis and quantitative real-time polymerase chain reaction (qRT-PCR)}

Extracted RNA was converted to cDNA using iScript ${ }^{\mathrm{TM}}$ cDNA Synthesis kit (Bio-Rad Laboratories, Inc., Munich, Germany). ASIC1a expression was quantitatively assessed by means of quantitative real-time polymerase chain reactions (qRT-PCR). For this purpose, $900 \mathrm{ng}$ of cDNA for hippocampus and $450 \mathrm{ng}$ for the amygdala, the dorsal raphe region, and the PAG were analyzed with the use of the SYBR ${ }^{\circledR}$ Select Master Mix (applied biosystems, Carlsbad, USA) in a RT-PCR cycler (Bio-Rad, Munich, Germany). Reactions were performed in duplo and normalized to the following housekeeping genes: CTCF, GDI2, GJA, and SNIP. Specific primers for ASIC1a were designed with the NCBI designing tool Primer-BLAST (http://www.ncbi.nlm.nih.gov/tools/primer-blast/) and produced by metabion international AG (Martinsried, Germany). Primers had the following sequences: sense strand 5'-GAGCAGGGCATGACATTCGA-3' and anti-sense strand 3'-TGGCCCGAGTTGAATGTGTA-5'. Data were analyzed with the qBase Plus2 Software 
(Biogazelle NV, Zwijnaarde, Belgium) and normalized to the two most robust reference genes. Both protocols were in accordance with the manufacturer's instructions.

\section{Statistical analysis}

Data are represented as mean + standard error of the mean (SEM). Behavioral data were analyzed using 3×2-way analysis of variance (ANOVA) to assess interaction effects of genotype (WT, 5- $\mathrm{Htt}+/$ - or $5-\mathrm{Htt}-/-)$ and exposure $\left(\mathrm{CO}_{2}\right.$ or air), which were followed by separate ANOVA and post-hoc Tukey tests. Data of the two-chamber test were additionally analyzed within exposure condition. Corticosterone levels were In-transformed before using repeated measures ANOVA and separate ANOVAs for distinct time points. qRT-PCR data will be linked to the behavioral performance using ANOVA.

With regard to physiological parameters, about 400 breathing-induced pressure changes were analyzed using the second half of each gas exposure. Artifacts due to moving, coughing, sniffing, and sighs were excluded. Animal temperature and body weight were included to calculate tidal volume (amplitude) and ventilation. Heart rate was analyzed in terms of $30 \mathrm{sec}$ of the second half of each gas exposure and the quick peaks gadget in Origin 9.0 (Origin Lab Corp., USA). Data were In-transformed before analyzed using repeated measures ANOVA. Statistical significance was considered as $p<0.05$. All analyses were done using the Statistical Package for the Social Sciences (SPSS 20, Inc., Chicago, IL, USA).

\section{Results}

\section{Anxiety- and fear-related behavior \\ Open field test}

In the open field test, regarding total distance moved, significant overall effects of genotype $(p<0.001)$, exposure $(p<0.001)$, and a genotype $x$ exposure interaction $(p<0.001)$ were observed (Figure 1a). Post-hoc analysis showed that within genotypes, $\mathrm{CO}_{2}$ exposure strongly reduced the distance covered compared to air exposure $(p<0.001)$. In addition, when exposed to air, 5-Htt -/- mice covered less distance in comparison with both WT animals and $5-H t t+/-$ mice $(p<0.001)$, while there was no genotype difference when exposed to $\mathrm{CO}_{2}$ ( $p=0.985$ and $p=0.837$, respectively).

With regard to time spent in center (Figure $1 b$ ), there was no overall genotype effect $(p=0.149)$, but a significant exposure effect $(p=0.008)$ and a genotype $x$ exposure interaction ( $p=0.011)$. Post-hoc follow-up revealed that $\mathrm{CO}_{2}$ exposure decreased the time spent in the center zone within WT mice only $(p=0.003)$. Furthermore, the duration spent was shorter in 5- $\mathrm{Htt}-/$ - air-exposed mice compared to WT air-exposed mice $(p=0.022)$, 
indicative of relatively more anxiety- and fear-related behavior in 5- $\mathrm{Htt}-/-$ mice. However, under $\mathrm{CO}_{2}$ exposure, 5- $\mathrm{Htt}-/-$ and $5-\mathrm{Htt}+/$ - mice showed descriptively less fear-related behavior when compared to WT animals as indicated by spending more time in the center zone $(p=0.884$ and $p=0.603)$, respectively.

Moreover, with regard to freezing, overall analysis showed that there was no overall main effect of genotype $(p=0.933)$, but of exposure $(p<0.001)$. The interaction genotype $x$ exposure was not significant $(p=0.229)$. When exposed to $\mathrm{CO}_{2}$, mice showed a robust freezing response in comparison with air exposure (Figure 1c), reflecting fear-related behavior (Mongeluzi et al., 2003).

a

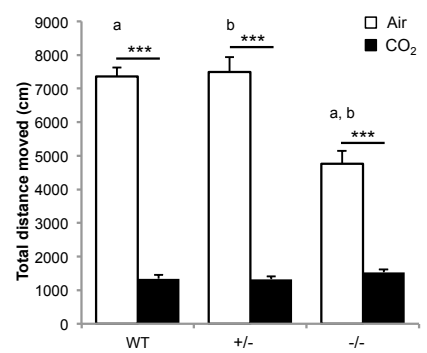

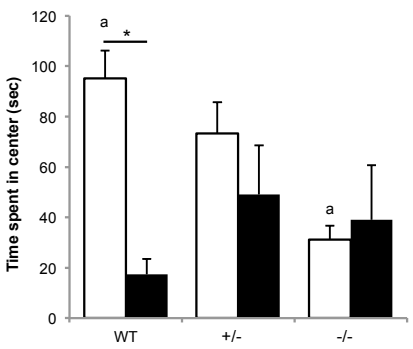

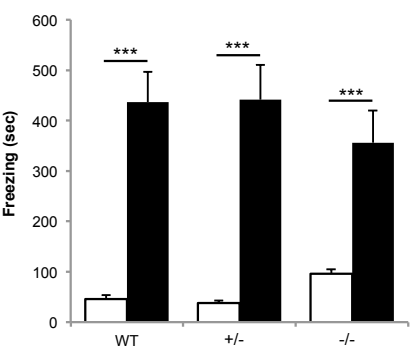

Figure 1. Assessment of the behavioral performance in the open field test. a) While under air exposure, 5-Htt -/- mice covered less distance than the other groups, exposure to $\mathrm{CO}_{2}$ significantly reduced the total distance moved in all genotypes. b) During air exposure, $5-\mathrm{Htt}-/$ - mice spent less time in the center zone in comparison with WT mice. Time spent in center was reduced in WT animals when exposed to $\mathrm{CO}_{2}$ compared to air, whereas exposure to $\mathrm{CO}_{2}$ did not affect time spent in the center in $5-\mathrm{Htt}+/$ - and $5-\mathrm{Htt}-/-$ mice. c) $\mathrm{CO}_{2}$ exposure resulted in a robust freezing response compared to air exposure. Bars represent mean + SEM. WT, wildtype mice; +/-, heterozygous 5-Htt knock-out mice; -/-, homozygous 5-Htt knock-out mice. ${ }^{*} p<0.05,{ }^{* * *} p<0.001$; same letters indicate a difference of $\mathrm{p}<0.001$.

\section{Two-chamber test}

In the two-chamber test, with one chamber filled with $\mathrm{CO}_{2}$ and one with air, or both filled with air, overall effects of genotype $(p=0.005)$, exposure $(p<0.001)$, and an interaction of genotype $x$ exposure $(p=0.043)$ on total distance moved were present (Figure $2 a)$. In line with the open field test, when exposed to $\mathrm{CO}_{2}$, the distance covered was significantly reduced in all genotypes when compared to air exposure $(p<0.001)$. Again, under air exposure, $5-\mathrm{Htt}-/$ - mice travelled less than WT mice $(p=0.006)$ and $5-\mathrm{Htt}+/-$ mice $(p=0.012)$, a difference that disappeared when exposed to $\mathrm{CO}_{2}(p=1.000$ and $p=0.936$, respectively). 
Further, genotype did not significantly affect the number of crossings between the chambers ( $p=0.559$; Figure $2 b)$. There was an overall exposure effect $(p<0.001)$, but not a genotype $x$ exposure interaction $(p=0.549)$. Within all genotypes, the number of crossings was reduced under $\mathrm{CO}_{2}$ exposure compared to air exposure $(p<0.001)$.

Regarding time spent in each chamber, when both chambers were filled with air, there was no overall effect of genotype (e.g., left chamber $p=0.653$ ). Likewise, when one chamber was filled with $\mathrm{CO}_{2}$, there was no genotype difference in the duration spent in the $\mathrm{CO}_{2}$ chamber $(\mathrm{p}=0.253)$.

As in the open field test, overall, there was no genotype effect $(p=0.286)$, but a significant exposure effect $(p<0.001)$, and a genotype $x$ exposure interaction $(p=0.006)$ on the total freezing duration (Figure 2c). Post-hoc analyses showed that within genotype, both WT
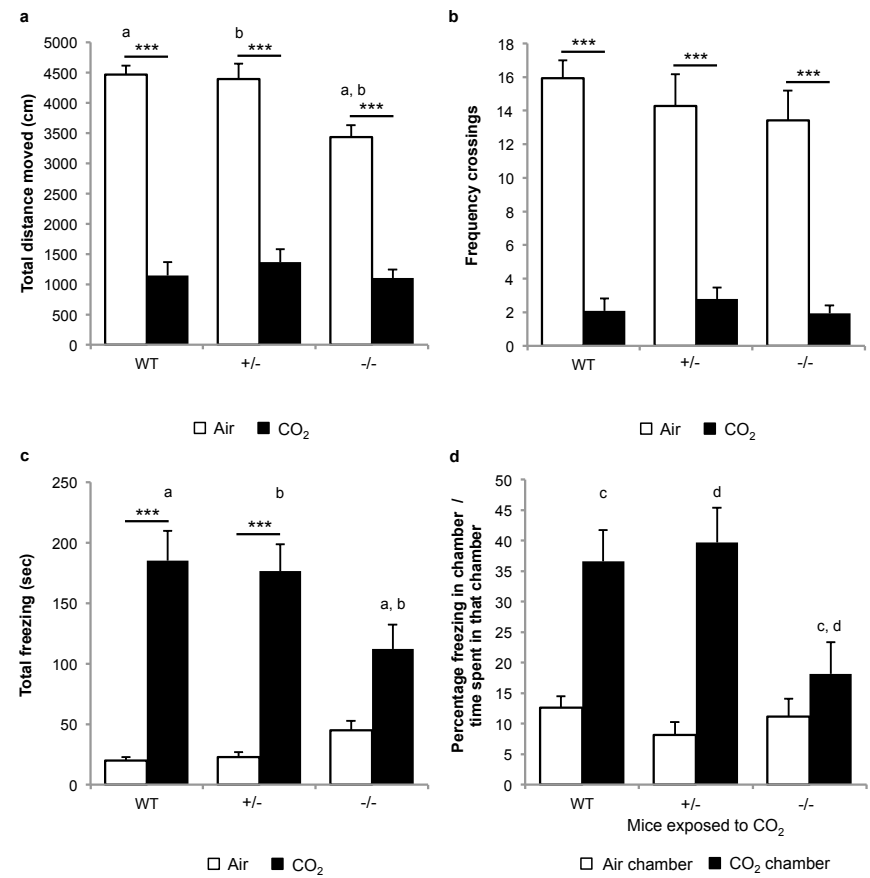

Figure 2. Assessment of the behavioral performance in the two-chamber test. a) The total distance moved was strongly reduced under $\mathrm{CO}_{2}$ exposure. $5-\mathrm{Htt}$-/- mice covered less distance than WT and 5- $\mathrm{Htt}+/$ - mice during air exposure. b) Under $\mathrm{CO}_{2}$ exposure the number of crossings was significantly lower than during air exposure. $\mathrm{c}$ ) When exposed to air, no genotype differences were found. When exposed to $\mathrm{CO}_{2}$, a marked freezing response was observed in WT and 5- $\mathrm{Htt}+/$ - mice only compared to air-exposed mice. d) The percentage of time spent freezing per chamber indicated that WT and $5-\mathrm{Htt}+/$ - mice froze longer in the chamber filled with $\mathrm{CO}_{2}$ than $5-\mathrm{Htt}$ -/- mice. No effect was found within the chamber filled with air. Bars indicate mean + SEM. WT, wildtype mice; +/-, heterozygous 5- $\mathrm{Htt}$ knock-out mice; -/-, homozygous 5- $\mathrm{tt}$ knock-out mice. ${ }^{* * *} \mathrm{p}<0.001$; a, d, difference of $\mathrm{p}<0.05 ; \mathrm{b}, \mathrm{c}$, difference of $0.05<\mathrm{p}<0.1$. 
and $5-\mathrm{Htt}+/$ - mice froze significantly more under $\mathrm{CO}_{2}$ exposure than mice exposed to air $(p<0.001)$, which was marginally not the case for $5-H t t-/-$ mice $(p=0.052)$. When exposed to $\mathrm{CO}_{2}, 5-\mathrm{Htt}-/-$ mice froze less than WT mice $(\mathrm{p}=0.027)$ and displayed a similar tendency compared to $5-\mathrm{Htt}+/-$ mice $(p=0.071)$. Separate analyses for within exposure revealed a genotype effect in the $\mathrm{CO}_{2}$ chamber in animals exposed to $\mathrm{CO}_{2}$ in one chamber and to air in the other $(p=0.029)$. Post-hoc follow-up showed that $5-H t t-/-$ mice froze less than WT mice $(p=0.039)$ and tended to have a shorter freezing duration in the $\mathrm{CO}_{2}$ chamber than $5-H t t+/-$ mice $(p=0.079)$.

Evidently, the freezing duration influences the time spent in a particular chamber. To correct for this, the percentage of time spent freezing per chamber was calculated for mice exposed to $\mathrm{CO}_{2}$ (Figure $2 \mathrm{~d}$ ). Within the $\mathrm{CO}_{2}$ chamber, an overall effect of genotype was found $(p=0.016)$. Post-hoc analysis revealed that the percentage freezing tended to be lower in 5-Htt -/- mice compared to WT ( $p=0.057)$ and was significantly lower than in $5-\mathrm{Htt}$ $+/$ - mice $(p=0.020)$. No overall genotype effect was found in the air chamber $(p=0.469)$.

\section{Stress-induced plasma corticosterone secretion}

Repeated measures ANOVA on plasma corticosterone levels under basal conditions and after $\mathrm{CO}_{2}$ exposure for 20 min showed no genotype effect $(p=0.359)$, but a significant condition effect ( $p=0.002$; Figure 3), with increased levels after $\mathrm{CO}_{2}$ exposure. There was no interaction effect of genotype and condition $(p=0.925)$. Analysis of the distinct time points showed no genotype differences in corticosterone levels (basal $p=0.247$; stress $\mathrm{p}=0.166)$.

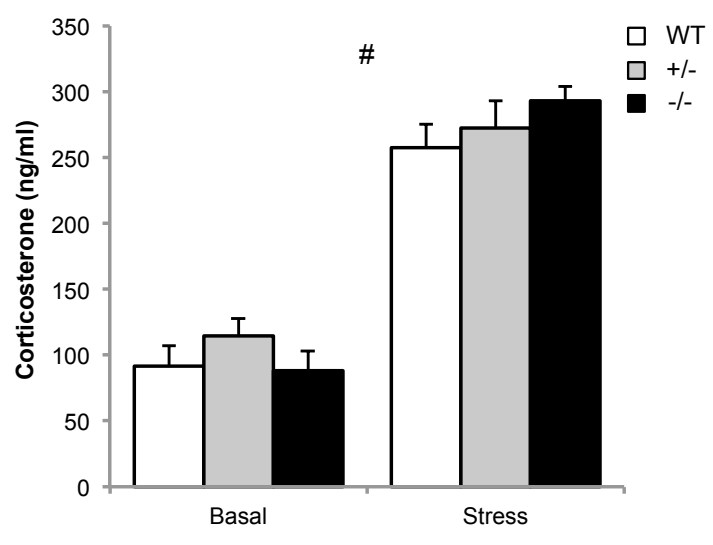

Figure 3. Plasma corticosterone secretion during basal conditions and after exposure to $10 \% \mathrm{CO}_{2}$ for 20 min (stress). $\mathrm{CO}_{2}$ exposure strongly increased corticosterone levels in mice of all genotypes (\#, condition effect $\mathrm{p}=0.002$ ). Bars represent means + SEM. WT, wildtype mice; +/-, heterozygous 5-Htt knock-out mice; -/-, homozygous 5- $\mathrm{Htt}$ knock-out mice. 


\section{ASIC1a expression (in progress)}

qRT-PCR analysis to determine ASIC1a expression is currently in progress. Levels will be linked to genotype and performance during behavioral testing.

\section{Breathing and heart rate recordings}

Analyzing the behavioral response of WT and 5- $\mathrm{Htt}+/-$ mice only, i.e. excluding $5-\mathrm{Htt}-/-$ mice, revealed a significant genotype $x$ exposure interaction $(p=0.047)$ on the time spent in the open field test, with WT animals spending less time in the center when exposed

a Air $\mathrm{CO}_{2}$
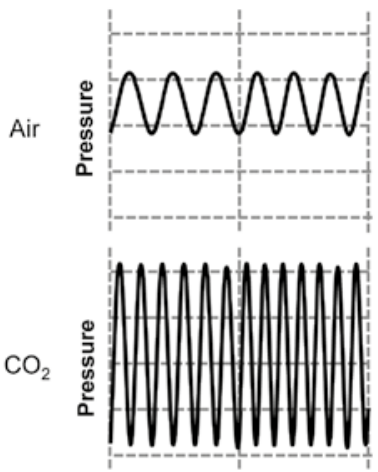

Time (sec)

c

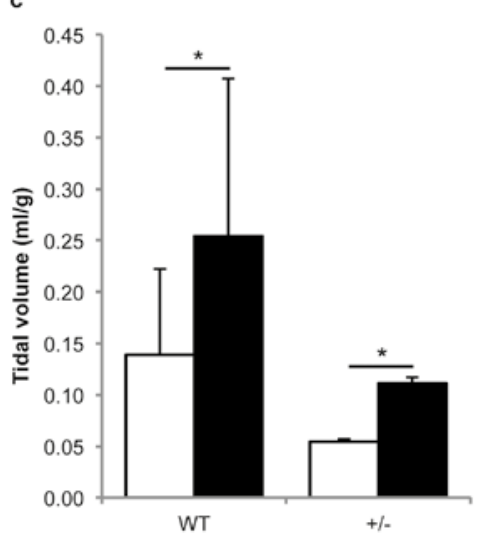

b

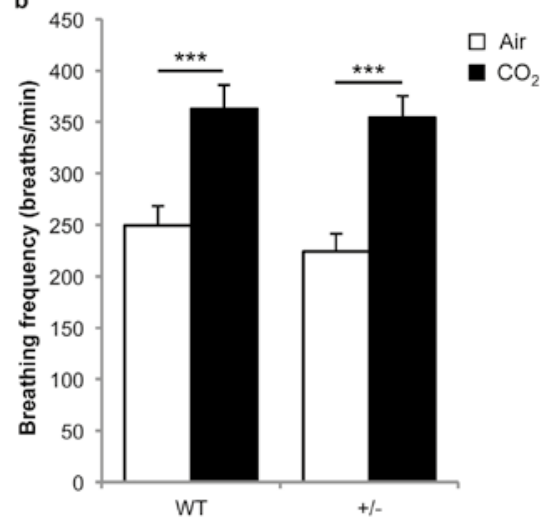

d

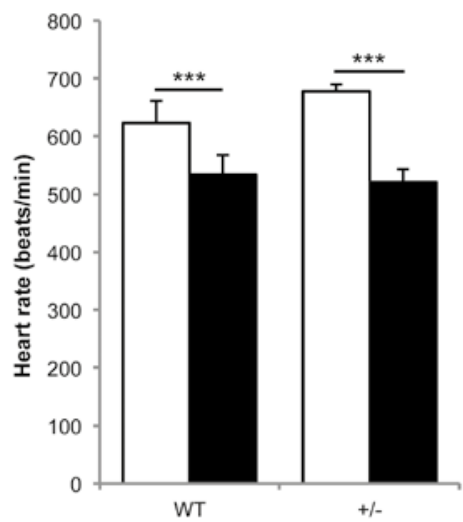

Figure 4. Respiratory and cardiovascular monitoring during exposure to air and $\mathrm{CO}_{2}$. a) Schematic representation of a 2 sec epoch of pressure-induced changes to assess breathing frequency and tidal volume (amplitude) during inhaling air (top) and $\mathrm{CO}_{2}$ (bottom). b, c) $\mathrm{CO}_{2}$ strongly increased breathing frequency (b) and tidal volume (c; corrected for bodyweight) in comparison with air exposure. d) Heart rate decreased during inhaling $\mathrm{CO}_{2}$. $\mathrm{No}$ genotype effect was present in any outcome measurement. Bars represent mean + SEM. WT, wildtype mice; +/-, heterozygous $5-\mathrm{Htt}$ knock-out mice. ${ }^{* * *} \mathrm{p}<0.001$. 
to $\mathrm{CO}_{2}$ compared to air-exposure, while there was no difference in $5-\mathrm{Htt}+/-$ animals. Therefore, and in light of clinical relevance and logistic considerations, the cardiorespiratory response was assessed in WT and $5-\mathrm{Htt}+/$ - mice only.

Repeated measures analysis showed that regarding breathing frequency, no main effect of genotype $(p=0.178)$ and no genotype $x$ exposure interaction were present $(p=0.276$, Figure 4). However, a strong overall exposure effect was observed $(p<0.001)$, with an increased breathing frequency during $\mathrm{CO}_{2}$ compared to air exposure. Similarly, overall, tidal volume was not affected by genotype $(p=0.446)$, but by exposure $(p<0.001)$, and a tendency towards an interaction of both $(p=0.078) . \mathrm{CO}_{2}$ appeared to increase tidal volume in comparison with air exposure. Further, there was no overall effect of genotype $(p=0.295)$ and no genotype $x$ exposure interaction $(p=0.111)$ on ventilation (see Supplement Table 1 for means + SEM). However, a main effect of exposure was present $(p<0.001)$, with increased ventilation when exposed to $\mathrm{CO}_{2}$ compared to air. With regard to heart rate, there was no genotype effect $(p=0.481)$, but overall, $\mathrm{CO}_{2}$ exposure decreased the mean heart rate compared to air exposure $(p<0.001)$. No interaction of genotype $x$ exposure was observed $(p=0.143)$.

\section{Discussion}

In the present study, as translational follow-up to our previous study in humans showing a differential fear response to $\mathrm{CO}_{2}$ depending on the 5-HTTLPR genotype (Schruers et al., 2011), we further investigated the relationship between chemosensitivity and the 5-HT system by exposing WT, 5- $\mathrm{Htt}+/-$, and $5-\mathrm{Htt}-/-$ mice to $\mathrm{CO}_{2}$. In brief, it was shown that $\mathrm{CO}_{2}$ induces a robust fear-related behavioral response, with $5-\mathrm{Htt}+/-$, and particularly $5-\mathrm{Htt}$ -/- mice, showing less fear than WT mice. Analyses regarding ASIC1a are currently ongoing and will be linked to behavioral performance.

\section{$\mathrm{CO}_{2}$ exposure is a stressful stimulus that induces fear-related behavior and a pronounced cardio-respiratory response}

The acid-base homeostasis within the body is tightly regulated. $\mathrm{CO}_{2}$ is continuously produced as end-product of the carbohydrate metabolism, but readily buffered by the bicarbonate system. However, $\mathrm{CO}_{2}$ exposure, causing a robust increase in the $\mathrm{CO}_{2}$ level, has been shown to be associated with a drop in brain $\mathrm{pH}$ in rodents (Schuchmann et al., 2006; Ziemann et al., 2009; Ziemann et al., 2008). Such a shift in the acid-base balance can have life-threatening consequences, leading to emotional and physiological responses. In line with this, exposure to $\mathrm{CO}_{2}$ induced a robust fear-related behavioral response. More specifically, total distance moved and, additionally in the two-chamber test, frequency 
of crossings were strongly decreased in comparison with air exposure. In addition, in the open field test, under $\mathrm{CO}_{2}$ exposure, the duration spent in the center zone, an outcome measurement that is relatively independent on locomotor activity, was strongly reduced in WT mice. Such a $\mathrm{CO}_{2}$-induced behavioral phenotype confirms previous reports in rodents (Johnson et al., 2011; Johnson et al., 2012; Ziemann et al., 2009). In addition with the marked freezing response in all behavioral tests, considered to reflect fear-related behavior (Mongeluzi et al., 2003), this further emphasizes the robust fear-inducing effects of $\mathrm{CO}_{2}$.

Moreover, in the open field test, when exposed to air, 5-Htt -/- mice showed more anxietyrelated behavior concerning distance moved in comparison with WT and 5- $\mathrm{Htt}+/-$ mice. In presence of $\mathrm{CO}_{2}$, however, this difference disappeared. A similar pattern was observed with regard to time spent in center, indicating that $5-\mathrm{Htt}-/$ - mice display more anxiety-related behavior under basal conditions, while they are hyposensitive to $\mathrm{CO}_{2}$ when compared to WT mice. WT mice, in turn, appear to be particularly sensitive to the fear-inducing effects of $\mathrm{CO}_{2}$, as demonstrated by the highly significant reductions in distance moved as well as the time spent in the center zone.

In the two-chamber test, with one chamber being filled with $\mathrm{CO}_{2}$, it is assumed that mice spend more time in the chamber filled with air to avoid the fear-inducing effects of $\mathrm{CO}_{2}$ (Ziemann et al., 2009). Unexpectedly, we did not observe this effect, in contrast with a previous study in mice, in which WT mice spent about $90 \%$ of the time in the chamber filled with air (Ziemann et al., 2009). This discrepancy can be explained by the immense freezing response observed when $\mathrm{CO}_{2}$ was used in one chamber in the present study, which prevented the animals from leaving the $\mathrm{CO}_{2}$ chamber. This notion is also supported by the strongly reduced crossing frequency between both chambers in the presence of $\mathrm{CO}_{2}$. Noteworthy, the total freezing duration was increased under $\mathrm{CO}_{2}$ exposure in WT and $5-H t t+/-$ mice only. Altogether, $5-H t t-/-$ mice seem to perform relatively better under a stressful stimulus such as $\mathrm{CO}_{2}$ compared to the other genotypes.

The observed increase in plasma corticosterone further emphasizes the stressful nature of $\mathrm{CO}_{2}$ exposure. There was no genotype difference, implying that differences in behavioral performance are not primarily dependent on HPA axis reactivity.

Furthermore, the effects of air and $\mathrm{CO}_{2}$ exposure on the cardio-respiratory system were explored. The respiratory system was strongly activated by $\mathrm{CO}_{2}$, while heart rate decreased in comparison to air exposure. In mammals, the partial pressure of $\mathrm{CO}_{2}$ is the main drive for respiration. As an altered $\mathrm{pH}$ within the body can lead to a functional disturbance, the acid-base balance is readily restored by the bicarbonate buffer system and triggering adaptive physiological responses such as increasing the breathing rate to expirate excess $\mathrm{CO}_{2}$. In addition to this effect, in the present study, we observed an elevated tidal volume 
in response to $\mathrm{CO}_{2}$. In the framework of panic, these results are consistent with those previously reported in freely moving rats (Annerbrink et al., 2003) as well as phrenic nerve recordings of anesthetized rats under $\mathrm{CO}_{2}$ exposure (Dumont et al., 2011). Furthermore, we did not observe any genotype difference. Previous studies showed that 5- $\mathrm{Htt}-/-$ mice (Li and Nattie, 2008) and mice lacking more than 99\% of central 5-HT neurons (Zhao et al., 2006) had a blunted breathing response to $\mathrm{CO}_{2}$ compared to WT mice. This contradictory finding (i.e., both an increase as well as absence of extracellular 5-HT associated with a reduced ventilatory response to $\mathrm{CO}_{2}$ ) might be explained by an enhanced negative feedback of 5-HT $1 \mathrm{~A}$ autoreceptors on $5-\mathrm{HT}$ cells in $5-\mathrm{Htt}-/-$ mice, leading to an impaired respiratory response to $\mathrm{CO}_{2}$. In this study, we did not assess breathing in 5- $\mathrm{Htt}-/-$ mice. Possibly, the lack of a genotype difference between WT and $5-H t t+/-$ mice is caused by 5-HT neurons sufficiently acting as chemosensors and initiating an adaptive response (Richerson, 2004), independent of 5-HT availability, or that the difference in extracellular 5-HT availability is functionally not large enough to exert effects in this respect. Moreover, under $\mathrm{CO}_{2}$, a decrease in heart rate was observed, possibly compensatory to an increase in blood pressure, which, however, was not measured in this study as monitoring blood pressure in freely moving animals requires prior surgery.

Overall, $\mathrm{CO}_{2}$ triggered a marked fear-related behavioral response, particularly in WT mice. With regard to several outcome measurements, there was no genotype effect. It might be assumed that a ceiling effect prevented revealing subtle genotype effects and that a lower $\mathrm{CO}_{2}$ concentration would be less intensive. However, for instance, in the twochamber test in both studies presented, a steady state of $9 \% \mathrm{CO}_{2}$ was reached, which is lower than the reached concentration of $15 \% \mathrm{CO}_{2}$ in the study by Ziemann et al. (2009). In addition, care was taken to use an optimized methodological approach, including fans to homogenize the air, continuous measurement of the $\mathrm{CO}_{2}$ concentration, and a randomization regarding side of $\mathrm{CO}_{2}$ administration and side, in which mice were placed at the beginning of the test. A difference to the set-up used by Ziemann et al. is the size of the chamber. Possibly, the larger box in our study in combination with $\mathrm{CO}_{2}$ exposure was too intense. An additional factor that contributes to variability between studies may be the differences in genetic background of the mice.

\section{Integrating the behavioral and cardio-respiratory effects of $\mathrm{CO}_{2}$ exposure in rodents with human $\mathrm{CO}_{2}$ panic studies}

In humans, the use of a $\mathrm{CO}_{2}$ inhalation as experimental panic-stimulus is well established (for review see Leibold et al., accepted). It has been demonstrated that the fear and panic symptoms associated with naturally occurring PAs in PD patients can also be provoked in healthy individuals by an increased concentration of $\mathrm{CO}_{2}$ (Griez et al., 2007), which is 
suggestive of a role of $\mathrm{pH}$ changes in panic as well as the involvement of fundamental neurobiological mechanisms.

Increasing evidence implies a role of the 5-HT system, including the 5-HTTLPR, in chemosensitivity and panic. In human studies, healthy individuals homozygous for the L-allele of the 5-HTTLPR were hyperreactive to a $\mathrm{CO}_{2}$ inhalation (Schmidt et al., 2000; Schruers et al., 2011). Despite that no such association was found in PD patients (Perna et al., 2004), which may be due to a relatively small sample size for such a heterogeneous disorder, the LL genotype may be considered as hypersensitive. In line with this, overall, WT mice showed the most pronounced fear-related behavioral response to $\mathrm{CO}_{2}$.

On the molecular level, the 5-HTTLPR is a functional polymorphism that alters the transcriptional activity of the $5-\mathrm{Htt}$ gene. More specifically, the expression of the $5-\mathrm{HTT}$ is about two times higher in the L-allele compared to the S-allele (Nakamura et al., 2000). A higher expression of 5-HTT leads to a relatively faster 5-HT re-uptake and therefore shorter availability of 5-HT in the synaptic cleft. As it has been proposed that 5-HT exerts inhibitory actions on the brainstem and thereby panic-related responses (Graeff, 1991; Graeff and Zangrossi, 2010), a relatively high expression of 5-HTT, as it is the case in humans of the LL genotype, is associated with less serotonergic inhibition on a panic response. In line with this, $\mathrm{CO}_{2}$ induced a fear-related behavioral response in WT mice, which was more pronounced than in $5-\mathrm{Htt}-/-$ mice that have a relatively longer availability of 5-HT to inhibit panic-like responses. This function of $5-\mathrm{HT}$ is consistent with the repetitively reported clinical effects of 5-HT agents such as SSRIs (Baldwin et al., 2014; Batelaan et al., 2012; Maron and Shlik, 2006) and experimental studies showing that depletion of the 5-HT precursor tryptophan increases the fear response to a $\mathrm{CO}_{2}$ inhalation (Schruers et al., 2000), while administration of a 5-HT precursor blunts the $\mathrm{CO}_{2}$-induced response (Schruers et al., 2002). Therefore, the current data further support a substantial impact of the 5-HT system on panic and show corresponding effects between the animal model used in this study and previous effects reported in humans.

With regard to the cardio-respiratory response, in mice, we observed an increase in respiratory parameters such as breathing frequency and tidal volume, while heart rate was decreased during $\mathrm{CO}_{2}$ exposure. An activation of the respiratory system is in line with previous human experimental studies (Blechert et al., 2010; Bystritsky and Shapiro, 1992; Gorman et al., 1990; Sasaki et al., 1996), although not regarding all aspects due to methodological limitations (e.g., Gorman et al., 1990, not finding an increased breating rate). To date, there is no entirely consistent pattern in the reported cardiovascular response to a $\mathrm{CO}_{2}$ inhalation (Bailey et al., 2005; Martinez et al., 1998; Richey et al., 2010). However, more recent studies using advanced technical equipment showed an immediate activation, with an increase in blood pressure (e.g., Bailey et al., 2005; Leibold et al., 
2013) and a, potentially compensatory, decrease in heart rate (Leibold et al., submitted-a; Verschoor and Markus, 2011). Although blood pressure was not included in this study to the invasiveness nature of commonly used procedures, the reduction in heart rate during $\mathrm{CO}_{2}$ exposure in mice in this study is in line with human reports.

Altogether, behaviorally, WT mice were most reactive to $\mathrm{CO}_{2}$, whilst there was no genotype difference on the physiological level. Overall, the $\mathrm{CO}_{2}$-induced behavior and physiological response in mice reflects the one observed in humans relatively well. Therefore, this rodent study offers the opportunity to complement human research in order to increase the insights into the neurobiological underpinnings of chemosensitivity and panic than cannot be fully studied in humans.

\section{ASIC1a and the link with the 5-HT system in $\mathrm{CO}_{2}$-induced fear}

The interest in ASIC1a in the framework of $\mathrm{CO}_{2}$-sensitivity and panic is based on the seminal study by Ziemann et al. (2009), in which they demonstrated that ASIC1a is a key player in sensing $\mathrm{pH}$ changes and in the subsequent adaptive behavioral fear response to $\mathrm{CO}_{2}$ exposure. In a recent human study, an association between variants in the orthologue gene ACCN2 and the diagnosis of PD as well as amygdala reactivity to the visual presentation of emotional faces was found (Smoller et al., 2014). We complemented that study by showing that the fear response to a $\mathrm{CO}_{2}$ inhalation is moderated by those variants in the ACCN2 gene (Leibold et al., submitted). As previously mentioned, ample evidence supports a role of the 5-HT system in panic. The link with ASIC1a, however, has not been investigated yet. Therefore, integrating these data may provide important insights into the mechanisms underlying differential $\mathrm{CO}_{2}$-sensitivity and the pathophysiology of PD.

As there is no consensus about the neurobiological key structure in $\mathrm{CO}_{2}$-provoked fear, we are currently assessing the localization of ASIC1a and its expression in various regions of the fear circuit. In the study by Ziemann et al. (2009), the amygdala was emphasized as the key player in the behavioral fear response to $\mathrm{CO}_{2}$ in mice. However, in humans, contrary to expectations, Urbach-Wiethe disease patients with a bilaterally dysfunctional amygdala experienced a marked fear response to inhaling $\mathrm{CO}_{2}$ (Feinstein et al., 2013), indicating that the amygdala may not be the sole key structure in the response to $\mathrm{CO}_{2}$. In support of this notion, in a recent study in our lab (Goossens et al., 2014), we demonstrated that inhaling $\mathrm{CO}_{2}$ specifically activates the brainstem, to a greater extent in PD patients than in healthy individuals. As a subset of brainstem 5-HT cells was shown to be highly sensitive to changes in pH (Brust et al., 2014; Richerson, 1995; Severson et al., 2003; Wang et al., 1998) and increases its firing rate about $300 \%$ when the $\mathrm{pH}$ drops about 0.2 units to 7.19 (Wang et al., 1998), the link between pH detection and behavioral phenotypes associated with $5-\mathrm{HT}$ system dysfunction may be the brainstem. An unresolved question is which 
molecule serves as the primary chemoreceptor within 5-HT cells? In this respect, ASIC1a is a candidate: Its expression is not limited to the amygdala, but was observed throughout the brain including brainstem nuclei (Price et al., 2014). Therefore, we will determine whether ASIC1a co-localizes with brainstem 5-HT cells and will correlate expression levels in brainstem nuclei (i.e., dorsal raphe region and PAG) as well as structures of the fear circuit (e.g., amygdala) to genotype and behavioral performance under $\mathrm{CO}_{2}$ and air exposure. ASIC1a and the 5- $\mathrm{Htt}$ genotype may interact to increase proneness to a hypersensitivity to $\mathrm{CO}_{2}$ and PAs.

\section{Future directions and conclusion}

A body of research implicates differential chemosensitivity in the pathophysiology of PAs and PD. Both rodent and human research emphasizes a potential role of ASIC1a and the ACCN2 gene, respectively, in addition to a contribution of the 5-HT system in this respect. To date, in humans, there is no direct experimental evidence whether inhaling $\mathrm{CO}_{2}$ causes a drop in brain $\mathrm{pH}$ as it has been shown in rodents (Ziemann et al., 2009; Ziemann et al., 2008). Magnetic resonance spectroscopy provides a useful and non-invasive tool for this purpose. Furthermore, in the present study, we hypothesized that the brainstem is the key structure in this respect. In a next conceptual step, in humans, it should be assessed whether variants in the ACCN2 gene, possibly in interaction with the 5 - $\mathrm{Htt}$ genotype, are associated with differences in the locus and level of brain activity in response to inhaling $\mathrm{CO}_{2}$. In this respect, it is also important to characterize the genetic variants regarding their functional consequences. Given the limitations in human research to explore the molecular mechanisms in the pathophysiology of a disorder, rodent research can be a useful addition. For instance, exploring whether inhibition of ASIC1a reduces the response to $\mathrm{CO}_{2}$, depending on the $5-\mathrm{Htt}$ genotype, may lead to a more targeted treatment approach in humans in the long-term. As in this study the general direction of the behavioral and physiological response of mice to $\mathrm{CO}_{2}$ resembled the one in humans, with WT mice being most sensitive to $\mathrm{CO}_{2}$, this approach provides the opportunity to further unravel the role of ASIC1a and the 5-HT system in chemosensitivity and the pathophysiology of $P D$, eventually contributing to new potential therapeutic targets and a more personalized treatment strategy in PD.

\section{Acknowledgment}

This work was supported by the Deutsche Forschungsgemeinschaft (DFG) Sonderforschungsbereich Transregio (SFB TRR) 58, Sonderforschungsbereich (SFB) 58/A1 and A5 to K-PL and DvdH. 


\section{References}

Annerbrink, K., Olsson, M., Melchior, L.K., Hedner, J., Eriksson, E., 2003. Serotonin depletion increases respiratory variability in freely moving rats: implications for panic disorder. Int. J. Neuropsychopharmacol. 6, 51-56.

Bailey, J.E., Argyropoulos, S.V., Kendrick, A.H., Nutt, D.J., 2005. Behavioral and cardiovascular effects of $7.5 \% \mathrm{CO} 2$ in human volunteers. Depress. Anxiety 21, 18-25.

Baldwin, D.S., Anderson, I.M., Nutt, D.J., Allgulander, C., Bandelow, B., den Boer, J.A., Christmas, D.M., Davies, S., Fineberg, N., Lidbetter, N., Malizia, A., McCrone, P., Nabarro, D., O’Neill, C., Scott, J., van der Wee, N., Wittchen, H.U., 2014. Evidence-based pharmacological treatment of anxiety disorders, post-traumatic stress disorder and obsessive-compulsive disorder: a revision of the 2005 guidelines from the British Association for Psychopharmacology. J. Psychopharm. 28, 403-439.

Batelaan, N.M., Van Balkom, A.J., Stein, D.J., 2012. Evidence-based pharmacotherapy of panic disorder: an update. The international journal of neuropsychopharmacology / official scientific journal of the Collegium Internationale Neuropsychopharmacologicum 15, 403-415.

Blechert, J., Wilhelm, F.H., Meuret, A.E., Wilhelm, E.M., Roth, W.T., 2010. Respiratory, autonomic, and experiential responses to repeated inhalations of $20 \% \mathrm{CO}(2)$ enriched air in panic disorder, social phobia, and healthy controls. Biol. Psychol. 84, 104-111.

Brust, R.D., Corcoran, A.E., Richerson, G.B., Nattie, E., Dymecki, S.M., 2014. Functional and developmental identification of a molecular subtype of brain serotonergic neuron specialized to regulate breathing dynamics. Cell reports 9, 2152-2165.

Bystritsky, A., Shapiro, D., 1992. Continuous physiological changes and subjective reports in panic patients: a preliminary methodological report. Biol. Psychiatry 32, 766-777.

Coryell, M.W., Wunsch, A.M., Haenfler, J.M., Allen, J.E., McBride, J.L., Davidson, B.L., Wemmie, J.A., 2008. Restoring Acid-sensing ion channel-1a in the amygdala of knock-out mice rescues fear memory but not unconditioned fear responses. J. Neurosci. 28, 13738-13741.

Dumont, F.S., Biancardi, V., Kinkead, R., 2011. Hypercapnic ventilatory response of anesthetized female rats subjected to neonatal maternal separation: insight into the origins of panic attacks? Respir. Physiol. Neurobiol. 175, 288-295.

Esquivel, G., Schruers, K.R., Maddock, R.J., Colasanti, A., Griez, E.J., 2009. Acids in the brain: a factor in panic? J Psychopharmacol 24, 639-647.

Feinstein, J.S., Buzza, C., Hurlemann, R., Follmer, R.L., Dahdaleh, N.S., Coryell, W.H., Welsh, M.J., Tranel, D., Wemmie, J.A., 2013. Fear and panic in humans with bilateral amygdala damage. Nat. Neurosci. 16, $270-272$.

Goossens, L., Leibold, N., Peeters, R., Esquivel, G., Knuts, I., Backes, W., Marcelis, M., Hofman, P., Griez, E., Schruers, K., 2014. Brainstem response to hypercapnia: A symptom provocation study into the pathophysiology of panic disorder. J Psychopharmacol.

Gorman, J.M., Papp, L.A., Martinez, J., Goetz, R.R., Hollander, E., Liebowitz, M.R., Jordan, F., 1990. High-dose carbon dioxide challenge test in anxiety disorder patients. Biol. Psychiatry 28, 743-757.

Graeff, F.G., 1991. Neurotransmitters in the dorsal periaqueductal gray and animal models of panic anxiety, M Briley, SE File (Eds.) ed. MacMillan Press., London.

Graeff, F.G., Zangrossi, H., Jr., 2010. The dual role of serotonin in defense and the mode of action of antidepressants on generalized anxiety and panic disorders. Cent. Nerv. Syst. Agents Med. Chem. 10, 207-217.

Griez, E., Zandbergen, J., Pols, H., de Loof, C., 1990. Response to 35\% CO2 as a marker of panic in severe anxiety. Am. J. Psychiatry 147, 796-797.

Griez, E.J., Colasanti, A., van Diest, R., Salamon, E., Schruers, K., 2007. Carbon dioxide inhalation induces dosedependent and age-related negative affectivity. PLoS One 2, e987.

Johnson, P.L., Fitz, S.D., Hollis, J.H., Moratalla, R., Lightman, S.L., Shekhar, A., Lowry, C.A., 2011. Induction of c-Fos in 'panic/defence'-related brain circuits following brief hypercarbic gas exposure. J Psychopharmacol $25,26-36$. 
Johnson, P.L., Samuels, B.C., Fitz, S.D., Lightman, S.L., Lowry, C.A., Shekhar, A., 2012. Activation of the orexin 1 receptor is a critical component of $\mathrm{CO} 2$-mediated anxiety and hypertension but not bradycardia. Neuropsychopharmacology 37, 1911-1922.

Kent, J.M., Papp, L.A., Martinez, J.M., Browne, S.T., Coplan, J.D., Klein, D.F., Gorman, J.M., 2001. Specificity of panic response to $\mathrm{CO}(2)$ inhalation in panic disorder: a comparison with major depression and premenstrual dysphoric disorder. Am. J. Psychiatry 158, 58-67.

Leibold, N.K., van den Hove, D.L.A., Esquivel, G., De Cort, K., Goossens, L., Strackx, E., Buchanan, G.F., Steinbusch, H.W.M., Lesch, K.P., Schruers, K.R.J., accepted for publication in Prog. Neurobiol. The brain acid-base homeostasis and serotonin: A perspective on the use of carbon dioxide as human and rodent experimental model of panic.

Leibold, N.K., van den Hove, D.L.A., Viechtbauer, W., Kenis, G., Goossens, L., Knuts, I., Smeets, H.J., MyinGermeys, I., Steinbusch, H.W.M., Schruers, K.R.J., submitted. Amiloride-sensitive cation channel 2 genotype affects the response to a carbon dioxide panic challenge.

Leibold, N.K., van den Hove, D.L.A., Viechtbauer, W., Buchanan, G.F., Goossens, L., van Os, J., Knuts, I., Lesch, K.P., Myin-Germeys, I., Steinbusch, H.W., Schruers, K.R.J., submitted-a. The 'humane' nature of euthanizing lab animals using $\mathrm{CO} 2$ : Cross-species panic research.

Leibold, N.K., Viechtbauer, W., Goossens, L., De Cort, K., Griez, E.J., Myin-Germeys, I., Steinbusch, H.W., van den Hove, D.L., Schruers, K.R., 2013. Carbon dioxide inhalation as a human experimental model of panic: the relationship between emotions and cardiovascular physiology. Biol. Psychol. 94, 331-340.

Li, A., Nattie, E., 2008. Serotonin transporter knockout mice have a reduced ventilatory response to hypercapnia (predominantly in males) but not to hypoxia. J. Physiol. 586, 2321-2329.

Lin, Y.C., Liu, Y.C., Huang, Y.Y., Lien, C.C., 2010. High-density expression of Ca2+-permeable ASIC1a channels in NG2 glia of rat hippocampus. PLoS One 5.

Maron, E., Shlik, J., 2006. Serotonin function in panic disorder: important, but why? Neuropsychopharmacology 31, 1-11.

Martinez, J.M., Coplan, J.D., Browne, S.T., Goetz, R., Welkowitz, L.A., Papp, L.A., Klein, D.F., Gorman, J.M., 1998. Hemodynamic response to respiratory challenges in panic disorder. J. Psychosom. Res. 44, 153-161.

Miller, H.E., Deakin, J.F., Anderson, I.M., 2000. Effect of acute tryptophan depletion on CO2-induced anxiety in patients with panic disorder and normal volunteers. Br. J. Psychiatry 176, 182-188.

Mongeluzi, D.L., Rosellini, R.A., Ley, R., Caldarone, B.J., Stock, H.S., 2003. The conditioning of dyspneic suffocation fear. Effects of carbon dioxide concentration on behavioral freezing and analgesia. Behav. Modif. 27, 620636.

Nakamura, M., Ueno, S., Sano, A., Tanabe, H., 2000. The human serotonin transporter gene linked polymorphism (5-HTTLPR) shows ten novel allelic variants. Mol. Psychiatry 5, 32-38.

Perna, G., Battaglia, M., Garberi, A., Arancio, C., Bertani, A., Bellodi, L., 1994. Carbon dioxide/oxygen challenge test in panic disorder. Psychiatry Res. 52, 159-171.

Perna, G., Bussi, R., Allevi, L., Bellodi, L., 1999. Sensitivity to 35\% carbon dioxide in patients with generalized anxiety disorder. J. Clin. Psychiatry 60, 379-384.

Perna, G., di Bella, D., Favaron, E., Cucchi, M., Liperi, L., Bellodi, L., 2004. Lack of relationship between CO2 reactivity and serotonin transporter gene regulatory region polymorphism in panic disorder. Am. J. Med. Genet. B Neuropsychiatr. Genet. 129B, 41-43.

Price, M.P., Gong, H., Parsons, M.G., Kundert, J.R., Reznikov, L.R., Bernardinelli, L., Chaloner, K., Buchanan, G.F., Wemmie, J.A., Richerson, G.B., Cassell, M.D., Welsh, M.J., 2014. Localization and behaviors in null mice suggest that ASIC1 and ASIC2 modulate responses to aversive stimuli. Genes, brain, and behavior 13, 179194.

Richerson, G.B., 1995. Response to CO2 of neurons in the rostral ventral medulla in vitro. J. Neurophysiol. 73, 933-944. 
Richerson, G.B., 2004. Serotonergic neurons as carbon dioxide sensors that maintain pH homeostasis. Nat. Rev. Neurosci. 5, 449-461.

Richey, J.A., Schmidt, N.B., Hofmann, S.G., Timpano, K.R., 2010. Temporal and structural dynamics of anxiety sensitivity in predicting fearful responding to a 35\% CO2 challenge. J. Anxiety Disord. 24, 423-432.

Sasaki, I., Akiyoshi, J., Sakurai, R., Tsutsumi, T., Ono, H., Yamada, K., Fujii, I., 1996. Carbon dioxide induced panic attack in panic disorder in Japan. Prog. Neuropsychopharmacol. Biol. Psychiatry 20, 1145-1157.

Schmidt, N.B., Storey, J., Greenberg, B.D., Santiago, H.T., Li, Q., Murphy, D.L., 2000. Evaluating gene x psychological risk factor effects in the pathogenesis of anxiety: a new model approach. J. Abnorm. Psychol. 109, 308-320.

Schruers, K., Esquivel, G., van Duinen, M., Wichers, M., Kenis, G., Colasanti, A., Knuts, I., Goossens, L., Jacobs, N., van Rozendaal, J., Smeets, H., van Os, J., Griez, E., 2011. Genetic moderation of CO2-induced fear by 5-HTTLPR genotype. J Psychopharmacol 25, 37-42.

Schruers, K., Griez, E., 2003. The effects of tryptophan depletion on mood and psychiatric symptoms. J. Affect. Disord. 74, 305.

Schruers, K., Klaassen, T., Pols, H., Overbeek, T., Deutz, N.E., Griez, E., 2000. Effects of tryptophan depletion on carbon dioxide provoked panic in panic disorder patients. Psychiatry Res. 93, 179-187.

Schruers, K., van Diest, R., Overbeek, T., Griez, E., 2002. Acute L-5-hydroxytryptophan administration inhibits carbon dioxide-induced panic in panic disorder patients. Psychiatry Res. 113, 237-243.

Schuchmann, S., Schmitz, D., Rivera, C., Vanhatalo, S., Salmen, B., Mackie, K., Sipila, S.T., Voipio, J., Kaila, K., 2006. Experimental febrile seizures are precipitated by a hyperthermia-induced respiratory alkalosis. Nat. Med. $12,817-823$.

Severson, C.A., Wang, W., Pieribone, V.A., Dohle, C.I., Richerson, G.B., 2003. Midbrain serotonergic neurons are central pH chemoreceptors. Nat. Neurosci. 6, 1139-1140.

Sherwood, T.W., Frey, E.N., Askwith, C.C., 2012. Structure and activity of the acid-sensing ion channels. Am. J. Physiol. Cell Physiol. 303, C699-710.

Smoller, J.W., Gallagher, P.J., Duncan, L.E., McGrath, L.M., Haddad, S.A., et al., 2014. The Human Ortholog of AcidSensing Ion Channel Gene ASIC1a Is Associated with Panic Disorder and Amygdala Structure and Function. Biol. Psychiatry. 76, 902-910.

Talesnik, B., Berzak, E., Ben-Zion, I., Kaplan, Z., Benjamin, J., 2007. Sensitivity to carbon dioxide in drug-naive subjects with post-traumatic stress disorder. J. Psychiatr. Res. 41, 451-454.

Verschoor, E., Markus, C.R., 2011. Physiological and affective reactivity to a $35 \% \mathrm{CO}(2)$ inhalation challenge in individuals differing in the 5-HTTLPR genotype and trait neuroticism. Eur. Neuropsychopharmacol.

Wang, W., Pizzonia, J.H., Richerson, G.B., 1998. Chemosensitivity of rat medullary raphe neurones in primary tissue culture. J. Physiol. 511 (Pt 2), 433-450.

Wemmie, J.A., Askwith, C.C., Lamani, E., Cassell, M.D., Freeman, J.H., Jr., Welsh, M.J., 2003. Acid-sensing ion channel 1 is localized in brain regions with high synaptic density and contributes to fear conditioning. $J$. Neurosci. 23, 5496-5502.

Wemmie, J.A., Chen, J., Askwith, C.C., Hruska-Hageman, A.M., Price, M.P., Nolan, B.C., Yoder, P.G., Lamani, E., Hoshi, T., Freeman, J.H., Jr., Welsh, M.J., 2002. The acid-activated ion channel ASIC contributes to synaptic plasticity, learning, and memory. Neuron 34, 463-477.

Wemmie, J.A., Coryell, M.W., Askwith, C.C., Lamani, E., Leonard, A.S., Sigmund, C.D., Welsh, M.J., 2004. Overexpression of acid-sensing ion channel $1 \mathrm{a}$ in transgenic mice increases acquired fear-related behavior. Proc. Natl. Acad. Sci. U. S. A. 101, 3621-3626.

Wemmie, J.A., Taugher, R.J., Kreple, C.J., 2013. Acid-sensing ion channels in pain and disease. Nature reviews. Neuroscience 14, 461-471.

Williams, R.H., Jensen, L.T., Verkhratsky, A., Fugger, L., Burdakov, D., 2007. Control of hypothalamic orexin neurons by acid and CO2. Proc. Natl. Acad. Sci. U. S. A. 104, 10685-10690.

Zha, X.M., 2013. Acid-sensing ion channels: trafficking and synaptic function. Mol Brain 6, 1. 
Zha, X.M., Costa, V., Harding, A.M., Reznikov, L., Benson, C.J., Welsh, M.J., 2009. ASIC2 subunits target acidsensing ion channels to the synapse via an association with PSD-95. J. Neurosci. 29, 8438-8446.

Zha, X.M., Wemmie, J.A., Green, S.H., Welsh, M.J., 2006. Acid-sensing ion channel 1a is a postsynaptic proton receptor that affects the density of dendritic spines. Proc. Natl. Acad. Sci. U. S. A. 103, 16556-16561.

Zhao, Z.Q., Scott, M., Chiechio, S., Wang, J.S., Renner, K.J., Gereau, R.W.t., Johnson, R.L., Deneris, E.S., Chen, Z.F., 2006. Lmx1b is required for maintenance of central serotonergic neurons and mice lacking central serotonergic system exhibit normal locomotor activity. J. Neurosci. 26, 12781-12788.

Ziemann, A.E., Allen, J.E., Dahdaleh, N.S., Drebot, II, Coryell, M.W., Wunsch, A.M., Lynch, C.M., Faraci, F.M., Howard, M.A., 3rd, Welsh, M.J., Wemmie, J.A., 2009. The amygdala is a chemosensor that detects carbon dioxide and acidosis to elicit fear behavior. Cell 139, 1012-1021.

Ziemann, A.E., Schnizler, M.K., Albert, G.W., Severson, M.A., Howard, M.A., 3rd, Welsh, M.J., Wemmie, J.A., 2008. Seizure termination by acidosis depends on ASIC1a. Nat. Neurosci. 11, 816-822. 
Chapter 6

\section{Supplement}

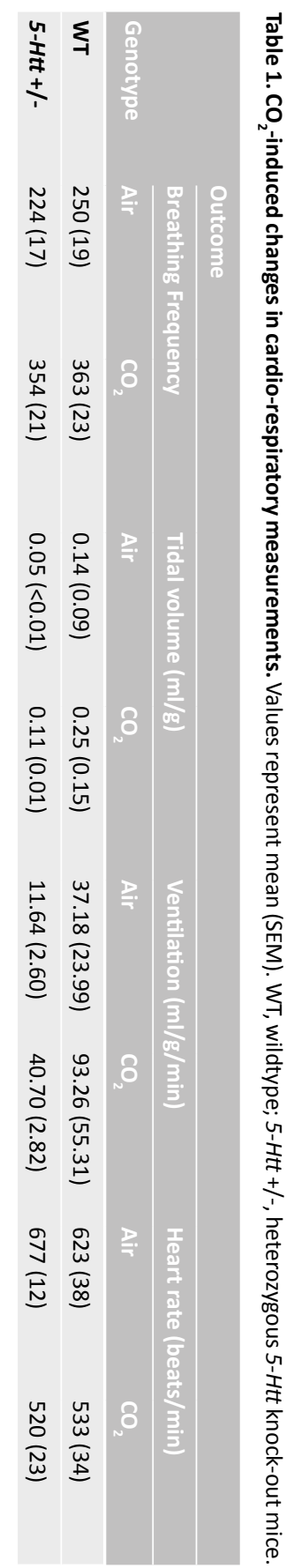


The 5-HT system and ASICla in $\mathrm{CO}_{2}$-induced behavior 


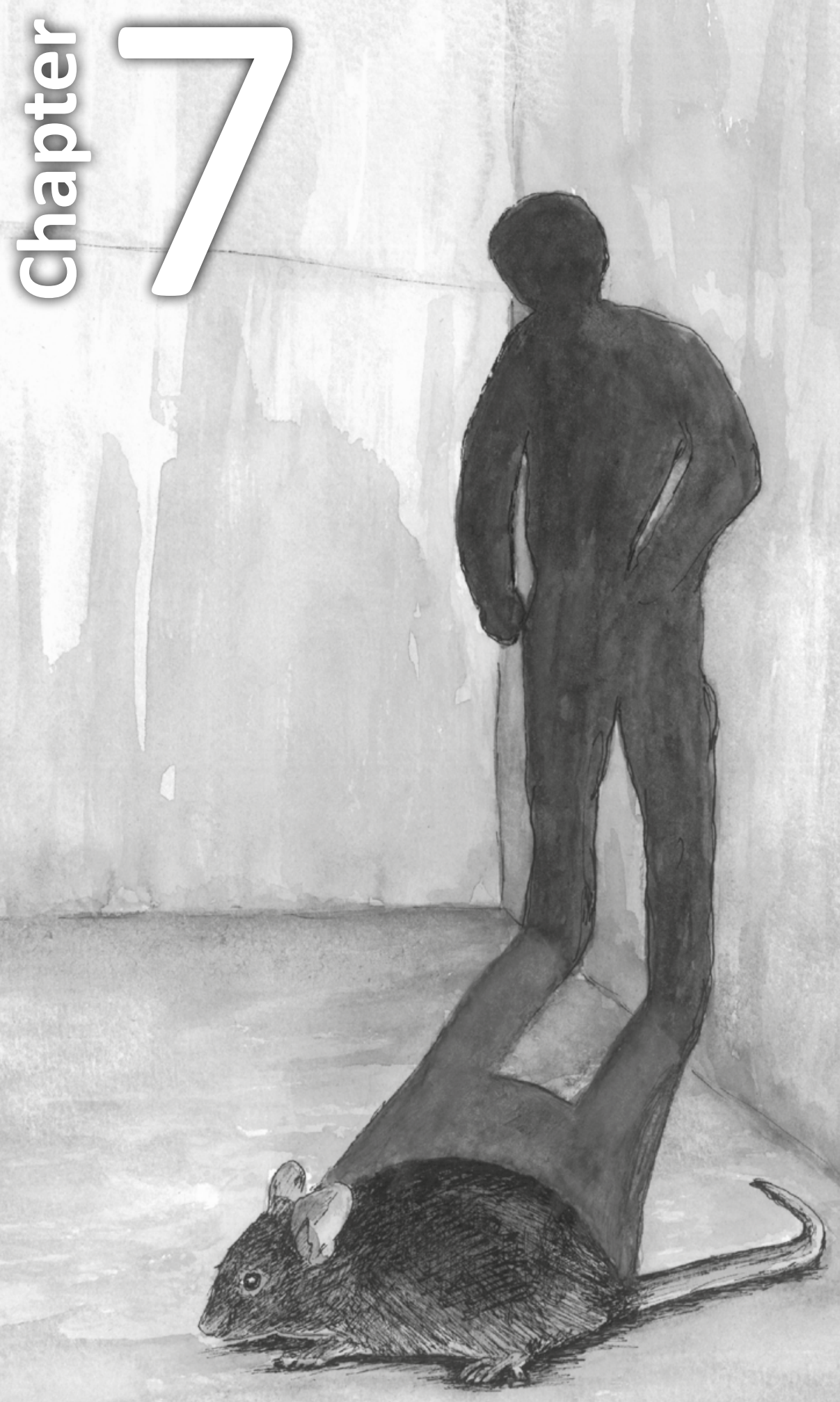




\title{
"humane" nature of euthanizing lab animals using $\mathrm{CO}_{2}$ : Cross-species panic research
}

\author{
Nicole Leibolda, Daniel van den Hove ${ }^{a, b}$, Wolfgang Viechtbauer ${ }^{a}$, Gordon Buchananc, \\ Liesbet Goossens ${ }^{\mathrm{a}}$, Jim van Os ${ }^{\mathrm{a}, \mathrm{d}}$, Inge Knuts ${ }^{\mathrm{a}}$, Klaus-Peter Lesch ${ }^{\mathrm{a}, \mathrm{b}}$, \\ Inez Myin-Germeys ${ }^{\mathrm{a}}$, Harry Steinbusch ${ }^{\mathrm{a}}$, Koen Schruers,
}

a Department of Psychiatry and Neuropsychology, Maastricht University, P.O. Box 616, 6200 MD Maastricht, the Netherlands. School for Mental Health and Neuroscience, Maastricht University. European Graduate School of Neuroscience (EURON), P.O. Box 616, 6200 MD Maastricht, the Netherlands

b Division of Molecular Psychiatry, Laboratory of Translational Neuroscience, Center of Mental Health, University of Wuerzburg, Fuechsleinstrasse 15, 97080 Wuerzburg, Germany

Department of Neurology, Yale University School of Medicine, P.O. Box 208018, 15 York Street, New Haven, Connecticut 06520-8018, USA

d King's Health Partners, Department of Psychosis Studies, Institute of Psychiatry, King's College London, London, UK

e Center for the Psychology of Learning and Experimental Psychopathology, Department of Psychology, University of Leuven, Tiensestraat 102, P.O. Box 3726, 3000 Leuven, Belgium 


\section{Abstract}

Each year, millions of animals are euthanized for scientific research, often by exposure to carbon dioxide $\left(\mathrm{CO}_{2}\right)$ although it remains unclear whether this method can be considered as a "humane" way of sacrifice. Panic research, in which $\mathrm{CO}_{2}$ exposure represents a wellestablished human experimental model, can provide useful information for a better judgment. We show that $\mathrm{CO}_{2}$ exposure causes a robust fear response in terms of behavior in mice and self-reports in healthy volunteers and panic disorder patients. To improve comparability and translation between rodent and human research we next assessed the physiological response to $\mathrm{CO}_{2}$, demonstrating corresponding effects across both species. This similarity on the physiological level implies that mice experience strong aversive effects in response to $\mathrm{CO}_{2}$ exposure comparable to the $\mathrm{CO}_{2}$-induced panic response observed in humans. Hence, the use of $\mathrm{CO}_{2}$ ought to be regarded as a highly stressful rather than a "humane" method of animal sacrifice. 


\section{Introduction}

Each year, millions of animals are euthanized for the purpose of research. In Great Britain alone, 4.11 million experiments on a living animal were started in 2012 (Home Office, 2013). This equates to 11,260 per day. The exact numbers are unknown, but exposure to $\mathrm{CO}_{2}$ is likely the most common method to euthanize laboratory animals (Conlee et al., 2005) despite data showing that $\mathrm{CO}_{2}$ is aversive (Kirkden et al., 2008; Leach et al., 2002; Niel et al., 2008), that the estimated time to death can take up to several minutes (Burkholder et al., 2010; Conlee et al., 2005), and that severe adverse effects such as seizures and nasal hemorrhage can occur prior to death (Conlee et al., 2005). In addition, it is unclear whether tissue damage in the form of hemorrhages and lung edema (Burkholder et al., 2010; Conlee et al., 2005), as revealed by post-mortem analyses, is caused prior or after the loss of consciousness (Conlee et al., 2005). Therefore, to which degree $\mathrm{CO}_{2}$ exposure represents a "humane" practice of euthanasia is a topic of considerable debate (Cressey, 2013; Hawkins et al., 2006). To date, it has been a major problem to "translate" the experience of animals during this procedure into human terms that would allow for a more informed judgment as to its acceptability.

In humans, exposure to $\mathrm{CO}_{2}$ is used in psychiatric research as an experimental model of panic disorder. Similar to how an exercise stress test in cardiology is used to provoke cardiac ischemia, breathing a high concentration of $\mathrm{CO}_{2}$ is used to induce panic attacks, the core symptom of panic disorder. This well-validated human experimental panic model makes use of a brief inhalation of $35 \% \mathrm{CO}_{2}$ (Coryell et al., 2006; Esquivel et al., 2009; Feinstein et al., 2013; Nardi et al., 2006; Perna et al., 2004; Schruers et al., 2011; Schruers et al., 2004) Recently, similar to human studies, exposure with up to $20 \% \mathrm{CO}_{2}$ has been used to investigate the basic mechanisms of fear in rodents (Johnson et al., 2011; Johnson et al., 2012; Johnson et al., 2010; Ziemann et al., 2009). Accordingly, $\mathrm{CO}_{2}$ exposure in rats induces the immediate early gene transcription factor c-fos in various brain structures including the periaqueductal grey (Johnson et al., 2011), similar to the areas activated by unconditioned fear stimuli, such as cat odor (Dielenberg et al., 2001).

The results of the studies using $\mathrm{CO}_{2}$ to provoke fear in humans or animals may be informative for the debate on the use of $\mathrm{CO}_{2}$ for euthanizing laboratory animals. However, the majority of outcome measures used in studies in animals and humans differ widely, hampering the translational validity of results. Animal studies primarily use behavioral assays to assess the fear and distress evoked by $\mathrm{CO}_{2}$, while most human studies rely on self-reports of fear and discomfort levels. In some cases these are complemented by physiological outcome measures (Leibold et al., 2013; Papadopoulos et al., 2010), thus covering representative features of panic symptom spectrum. Here we aimed to bridge the current translational gap between rodents and humans by quantitatively comparing 
data from mice to data collected in healthy volunteers and panic disorder patients. We used the same fear-evoking stimulus, $\mathrm{CO}_{2}$, as well as the same physiological outcome parameters, in addition to common behavioral tests and symptom reports in order to maximize data comparison between species (see Supplementary Figure 1). This crossspecies model provides a unique opportunity to evaluate the "human" use of $\mathrm{CO}_{2}$ to euthanize laboratory rodents.

\section{Methods}

\section{Mice}

\section{Animals}

Twenty male wildtype C57BL/6 mice were housed within a temperature-controlled environment $\left(25 \pm 1^{\circ} \mathrm{C}\right)$ and under a reversed day/night cycle ( $12 \mathrm{hr}$ dark/12hr light cycle). Animals had access to standard rodent chow and water ad libitum. For behavioral testing, mice were assigned to either $\mathrm{CO}_{2}$ exposure $(n=10)$ or air exposure $(n=10)$. The physiological response to room air and $\mathrm{CO}_{2}$ exposure was tested in all animals $(n=20)$. Groups were matched for age and testing was performed from a mean age of 58 days onwards under low light conditions. All procedures and experiments were approved by the Institutional Animal Care and Use Committee at Yale University, New Haven, USA. Animals were handled in accordance with the institutional guidelines.

\section{$\mathrm{CO}_{2}$ exposure and behavioral testing}

Open field test

For the open field test a transparent Plexiglas square chamber $(60 \times 60 \times 40 \mathrm{~cm})$, covered with a clear lid, was used. The floor was subdivided into a $30 \times 30 \mathrm{~cm}$ central zone, $15 \times 15$ $\mathrm{cm}$ corners and 30x15 cm walls. Depending on the experimental group, the chamber was pre-filled with $9 \% \mathrm{CO}_{2}$ or air (compressed air tanks, Airgas East, Cheshire, CT, USA). Gas infusion ports were located on the upper part of the box to avoid blowing, which may be aversive to mice. Two CPU fans ( $21 \mathrm{~dB}$, Ebm papst, St. Georgen, Hungary), fixed to the lid, were used to ensure a homogenous concentration of $\mathrm{CO}_{2}$ throughout the chamber. The concentration of $\mathrm{CO}_{2}$ was constantly controlled using a digital $\mathrm{CO}_{2}$ meter $\left(30 \% \mathrm{CO}_{2}\right.$ Sampling Data Logger, $\mathrm{CO}_{2}$ meter, Ormond Beach, $\mathrm{FL}$, USA). After pre-filling the chamber with gas mice were placed in the center of the chamber and were allowed to explore the chamber for $20 \mathrm{~min}$. Movements were recorded automatically with a computerized system (Ethovision Pro, Noldus, the Netherlands; Fujinon DN camera, Fujinon corporation, China). The number of fecal pellets was scored at the end of each trial by the experimenter. 
Two-chamber test

The testing apparatus consisted of two chambers (each $30 \times 30 \mathrm{~cm}$ with $40 \mathrm{~cm}$ high walls), which were connected by an open door $(3.5 \times 3.5 \mathrm{~cm})$ to allow free crossing. Each chamber had a gas infusion port and a CPU fan ( $21 \mathrm{~dB}$, Ebm papst, St. Georgen, Hun) to ensure a homogenous gas concentration throughout the entire part. For mice subjected to $\mathrm{CO}_{2}$ exposure, one chamber was pre-filled with $\mathrm{CO}_{2}$ and the other one with air. Gas concentrations were controlled continuously using a digital $\mathrm{CO}_{2}$ meter $\left(30 \% \mathrm{CO}_{2}\right.$ Sampling Data Logger, $\mathrm{CO}_{2}$ meter, Ormond Beach, $\mathrm{FL}$, USA; reaching a steady state of $9 \%$ and $2 \% \mathrm{CO}_{2}$, respectively). For mice assigned to air exposure, air was used in both chambers. Side of $\mathrm{CO}_{2}$ administration and side in which a mouse was placed were randomized. Movements were recorded automatically with a computerized system (Ethovision Pro, Noldus, the Netherlands; Fujinon DN camera, Fujinon corporation, China) for a period of $10 \mathrm{~min}$. The number of fecal pellets was scored at the end of each trial by the experimenter.

\section{$\mathrm{CO}_{2}$-evoked freezing}

Freezing was scored in both behavioral tests by a trained observer blind to experimental condition ( $\mathrm{CO}_{2}$ or air exposure). Freezing was defined as absence of any movements apart from respiration.

\section{Breathing and cardiovascular recordings}

Mice were placed into a custom-made whole body recording chamber (Plexiglas, $350 \mathrm{~cm}^{3}$ ). Animals were habituated to the chamber for $30 \mathrm{~min}$ (with room air infusion). Then the physiological response was measured to room air exposure for $20 \mathrm{~min}$ and subsequently to $9 \% \mathrm{CO}_{2}$ for $10 \mathrm{~min}$. Flow rates $(0.4 \mathrm{liter} / \mathrm{min})$ were controlled with a digital flowmeter (WU-32446-33, Cole-Parmer, Inc., Hoffman Estates, IL).

Breathing recordings were obtained non-invasively and simultaneously with cardiovascular recordings. Breathing was assessed using a low volume pressure transducer (DC002NDR5; Honeywell International, Inc.; Minneapolis, USA) that was fitted to the recording chamber. Breathing-induced pressure changes were calibrated with 150 pulses per min, each 300 ul. Relative humidity (HIH-4602-A sensor; Honeywell International, Inc., Minneapolis, USA) and ambient temperature (BAT-12 microprobe, Physiotemp Instruments, Inc., Clifton, USA) were measured continuously within the recording chamber. Electrodes for electrocardiogram (EKG) measurements were placed on both sides of the shaved thorax and connected to an amplifier (Model 440 Instrumentation Amplifier, Brownlee Precision Co., San Jose, a, USA). Blood pressure was not assessed as common methods such as the use of a tail cuff do not allow monitoring in freely moving animals or require prior surgery as it is the case in telemetry. Animal temperature was measured rectally immediately 
after completion of the recording (BAT-12 microprobe, Physiotemp Instruments, Inc., Clifton, USA). All signals were digitized with an analogue-to-digital converter ( $\mathrm{PCl}-6221$ or USB-6008 National Instruments Corp., Austin, TX, USA) and displayed in a custom-written acquisition program in Matlab (version R2011b, Mathworks Co., Natick, MA, USA).

\section{Healthy volunteers}

\section{Participants}

In total, 136 adult healthy volunteers (mean age 22.81 years, SD=8.89, 44 males) were recruited via advertisements at Maastricht University, the Netherlands. Before participating eligibility was confirmed using a medical examination and a semi-structured psychiatric interview (including the Mini International Neuropsychiatric interview (Sheehan et al., 1998)). Exclusion criteria were current or past cardiovascular or pulmonary disease, hypertension (systolic/diastolic $>170 / 100 \mathrm{mmHg}$ ), familial or personal history of cerebral aneurysm, excessive smoking (>15 cigarettes per day), pregnancy, epilepsy, use of psychotropic medication or adrenergic receptor blockers, and a first-degree relative with PD. All participants gave written informed consent prior to the study, which was approved by the Medical Ethics Committee of Maastricht University and the Maastricht University Hospital.

\section{$\mathrm{CO}_{2}$ inhalation and fear/panic symptom scores}

All $\mathrm{CO}_{2}$ inhalations took place according to a standardized protocol as previously described (Leibold et al., 2013). After being seated in an armchair a nasal-oral mask was fixed to the participant's head. The vital capacity of a double breath was measured using a digital flowmeter. All participants were told that the subsequent $\mathrm{CO}_{2}$ inhalation might cause some effects, ranging from vague sensations up to fear. However, all effects would be short lasting. Participants took a double vital capacity breath of four $\mathrm{CO}_{2}$ concentrations according to a double-blind, randomized, cross-over design: $0 \%, 9 \%, 17.5 \%$ and $35 \% \mathrm{CO}_{2}$ in air $\left(21 \% \mathrm{O}_{2}\right.$ and balanced $\mathrm{N}_{2}$, premixed gas tanks obtained from Nederlandse Technische Gasmaatschappij B.V., Landgraaf, the Netherlands). Participants were motivated to inhale at least $80 \%$ of the vital capacity. Inhalations took place on four separate days, each day at the same time for each participant. Participants were instructed to refrain from caffeine containing beverages on the inhalation days.

Presence and intensity of fear and panic symptoms were obtained twice: Immediately before the inhalation patients were asked to rate their sensations at that particular moment and after the inhalation to rate the sensations at the worst moment of the inhalation. Feelings of fear were evaluated using the Visual Analogue Scale for fear (VAS-F), a horizontal line of $100 \mathrm{~mm}$ length that ranges from 0 (not at all) to 100 (the 
worst imaginable). Panic symptoms were assessed using the Panic Symptom List (PSL), consisting of the 13 DSM panic attack symptoms and ranging from 0 (absent) to 4 (very intense).

\section{Breathing and cardiovascular recordings}

Physiological parameters were measured continuously throughout the entire procedure using a computerized system (Carbon Dioxide Tolerance Tester, CTT, Maastricht Instruments B.V. Maastricht, the Netherlands). A soft plastic nasal-oral mask was fixed to the participant's head and was connected to a capnograph device (medair, Delsbo, Sweden) to measure respiration rate. A finger cuff, connected to a cardiovascular monitor (Nexfin, BMEYE B.V., Amsterdam, the Netherlands), was fixed to the middle finger of the non-dominant hand to assess heart rate and blood pressure (sampling rate $2 \mathrm{~Hz}$ ). All measurements were acquired with custom-made software (IDEEQ, Maastricht Instruments B.V., Maastricht, the Netherlands).

\section{Patients with panic disorder Participants}

Ninety-eight adult patients with PD (mean age 35.21 years, SD=11.65, 63 males) from the outpatient setting of the Academic Anxiety Centre, Maastricht, the Netherlands, voluntarily participated in this study. PD (with or without agoraphobia) as main diagnosis was established via a semi-structured psychiatric interview (including the Mini International Neuropsychiatric interview, M.I.N.I.; Sheehan et al., 1998) by an experienced psychiatrist. In addition, a medical examination took place. Exclusion criteria were current or past cardiovascular or pulmonary disease, hypertension (systolic/diastolic $>170 / 100$ $\mathrm{mmHg}$ ), familial or personal history of cerebral aneurysm, pregnancy, and epilepsy. All participants provided written informed consent. The study was approved by the Medical Ethics Committee of Maastricht University and the Maastricht University Hospital.

\section{$\mathrm{CO}_{2}$ inhalation and fear/panic symptom scores}

All $\mathrm{CO}_{2}$ inhalations were performed according to a standardized protocol (Klaassen et al., 1998; Schruers et al., 2004). Patients were seated in an armchair and instructed into the use of a self-administering nasal-oral mask. The vital capacity of a single breath was measured using a digital flowmeter. Then patients were informed that the subsequent $\mathrm{CO}_{2}$ inhalation might cause some effects, ranging from vague sensations up to fear. However, all effects would be short lasting. Patients took a single vital capacity breath of $35 \% \mathrm{CO}_{2}$ (premixed gas tanks obtained from Nederlandse Technische Gasmaatschappij B.V., Landgraaf, the Netherlands) and were motivated to inhale at least $80 \%$ of the previously measured vital 
capacity. Patients were instructed to refrain from caffeine containing beverages on the inhalation day.

Likewise to the assessment in healthy volunteers, fear and panic symptom scores were obtained immediately before and after the $\mathrm{CO}_{2}$ inhalation. The VAS was used to assess fear (ranging from 0 - not at all to 100 - the worst imaginable) and the PSL for assessing the 13 symptoms of a panic attack (ranging from 0 - absent to 4 - very intense).

\section{Breathing and cardiovascular recordings}

A computerized system (Carbon Dioxide Tolerance Tester, CTT, Maastricht Instruments B.V. Maastricht, the Netherlands) was used to record the physiological response continuously throughout the entire procedure. Measuring the respiration rate implies using a mask fixed to the head. This appeared not to be feasible in patients. Heart rate and blood pressure were measured using a finger cuff that was fixed to the middle finger of the non-dominant hand (sampling rate $2 \mathrm{~Hz}$ ). The finger cuff was connected to a cardiovascular monitor (Nexfin, BMEYE B.V., Amsterdam, the Netherlands). All measurements were collected and displayed in custom-made software (IDEEQ, Maastricht Instruments B.V., Maastricht, the Netherlands).

\section{Data and statistical analysis}

\section{Behavioral data}

Rodent behavior was analyzed using univariate analysis of variance. Regarding the twochamber test, within a group, repeated measures analysis was applied. To take the freezing duration into account a ratio was calculated: freezing in the particular chamber divided by the time spent in that chamber. In humans, self-reports were analyzed in terms of change in fear and panic symptoms as calculated by subtracting the rating prior to the $\mathrm{CO}_{2}$ inhalation from the post rating. In healthy volunteers, multilevel models with an unstructured variance-covariance matrix were used to account for the fact that the subjects underwent four $\mathrm{CO}_{2}$ concentrations. A significant overall test was examined in more detail by testing pairwise comparisons using Holm's method to control for the familywise error rate (Holm, 1979). Controls and healthy volunteers were compared using univariate analysis.

\section{Physiological measurements}

In rodents, about 400 breathing-induced pressure oscillations were analyzed of the second half of each gas exposure phase. Moving artifacts, coughing, sighs, and sniffing were excluded. Inter-breath interval, tidal volume, and ventilation were calculated for all mice. The animal temperature obtained immediately after the recording was used to 
calculate tidal volume and ventilation, which were corrected to animal weight in grams. With regard to EKG data, $30 \mathrm{sec}$ were analyzed of the second half of each gas exposure phase. EKG data were further analyzed using the quick peaks gadget in Origin 9.0 (Origin Lab Corp., USA).

In humans, due to technical failure the final sample varied per outcome and $\mathrm{CO}_{2}$ concentration: healthy volunteers - cardiovascular parameters $n=117-136$, respiratory outcomes $n=47-62$; PD patients - cardiovascular parameters $n=98$. Physiological data were averaged to means per second. Ten seconds before the inhalation were taken as baseline and $30 \mathrm{sec}$ after inhaling $\mathrm{CO}_{2}$ (starting after breath holding for $4 \mathrm{sec}$ ) to assess the effects of the exposure.

To be able to compare the effects between mice and humans, effect sizes were calculated for physiological parameters by subtracting the mean value during air exposure from the mean value of the $\mathrm{CO}_{2}$ exposure, which was then divided by the standard deviation of the air exposure. Effect sizes were statistically compared between conditions using z-tests, corrected for multiple testing.

For all analyses, statistical significance was set at $\mathrm{p}<0.05$ (two-tailed). Analyses were done using the software R (version 3.1.1, 2014, R Development Core Team, Vienna/Austria) or the Statistical Package for the Social Sciences (SPSS 20.0.0.1 for Mac; SPSS Inc., Chicago, IL).

\section{Results}

\section{Behavioral response to $\mathrm{CO}_{2}$ exposure}

During open field testing mice exposed to $9 \% \mathrm{CO}_{2}$ for 20 min (Ziemann et al., 2009) covered significantly less distance $(p<0.001$, Figure $1 a)$, spent less time in the center zone ( $p=0.004$, Figure $1 b)$, and spent more time in the corner zones in comparison to airexposed mice ( $p<0.001$, see Supplementary Table 1$)$. Mice also showed a marked freezing response, considered to be a reflection of fear-related behavior in rodents (Mongeluzi et al., 2003), when exposed to $\mathrm{CO}_{2}$ compared to exposure to air ( $p<0.001$, Figure $1 c$ ). Next, we used a 10 min two-chamber test (TCT), with one chamber filled with $\mathrm{CO}_{2}$ and one with air, or both chambers were filled with air. Side of $\mathrm{CO}_{2}$ administration and starting side were randomized. Overall, $\mathrm{CO}_{2}$ exposure decreased the distance moved when compared to air exposure only ( $p<0.001$, Figure $1 d$ ). In addition, the total number of crossings between the two chambers was significantly lower in the group exposed to $\mathrm{CO}_{2}(p=0.011$, see Supplementary Table 1). Time spent did not differ between the chamber filled with $\mathrm{CO}_{2}$ and the one filled with air ( $p=0.891$, see Supplementary Table 1). However, mice showed a marked freezing response when exposed to $\mathrm{CO}_{2}$ in one chamber compared to mice exposed to air only ( $p=0.017$, Figure $1 e$ ). This response was particularly robust in the chamber 

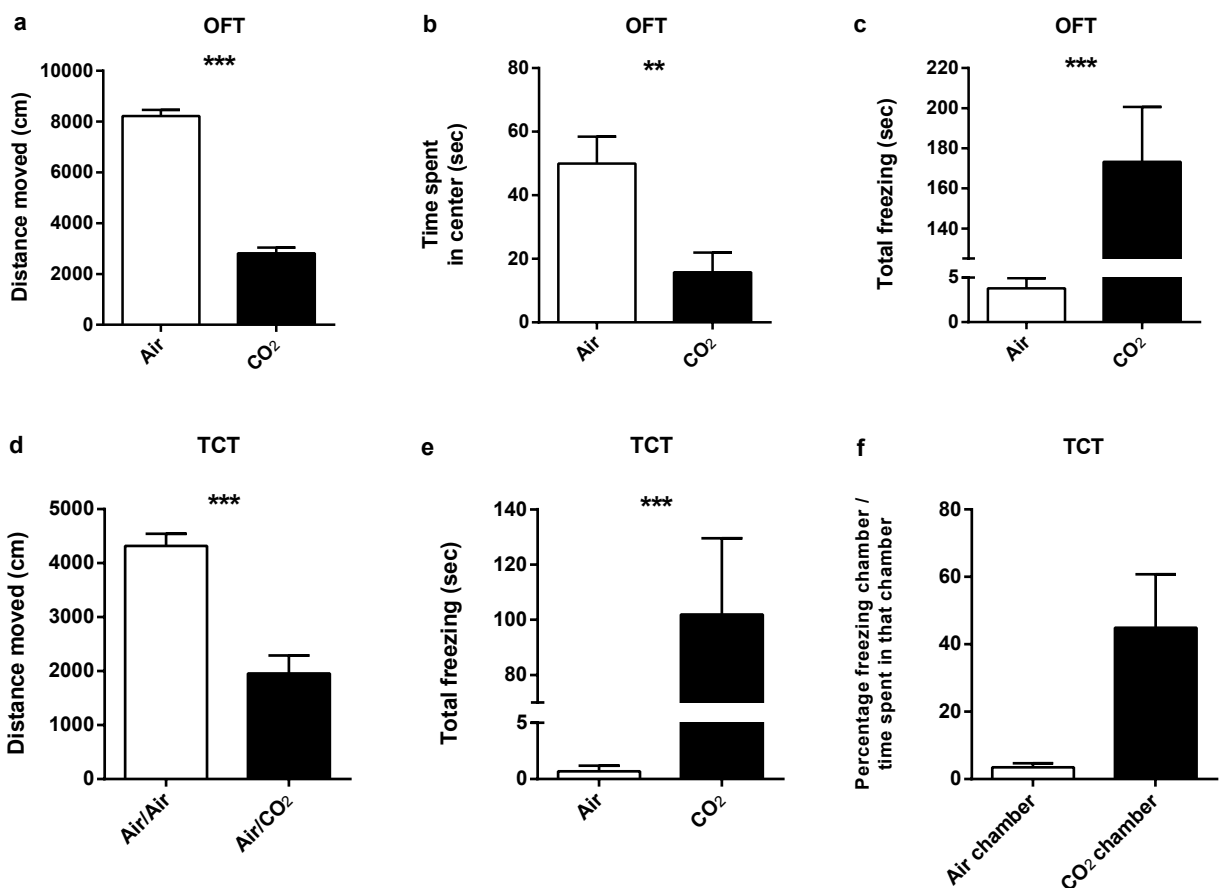

Figure 1. Effect of $\mathrm{CO}_{2}$ exposure on behavior in mice. In the open field test (OFT), $\mathrm{CO}_{2}$ exposure decreased the total distance moved a) and the time spent in the center zone b). c) under $\mathrm{CO}_{2}$ exposure mice froze significantly more than under air exposure. d) in the two-chamber test (TCT), mice exposed to $\mathrm{CO}_{2}$ in one chamber covered less distance than mice exposed to air only. e) $\mathrm{CO}_{2}$-exposed mice froze significantly more than animals exposed to air. f) correcting for the time spent in each chamber confirmed that freezing was strongest in the $\mathrm{CO}_{2}$ chamber. Data represent mean $+\mathrm{SEM} . * * \mathrm{p}<0.01, * * * \mathrm{p}<0.001$

filled with $\mathrm{CO}_{2}$ compared to the air chamber ( $p=0.006$, see Supplementary Table 1$)$. As the freezing duration influences the time spent in the chambers, the ratio of freezing and time spent in a particular chamber was calculated, confirming that the freezing response was most pronounced in the $\mathrm{CO}_{2}$ chamber (Figure 1f). Further, on average, the number of fecal pellets, a relative measure of anxiety/fear in rodents (Hetzel and Rosenkranz, 2014), significantly increased under $\mathrm{CO}_{2}$ exposure $(\mathrm{p}=0.004$, see Supplementary Table 1$)$.

In humans, we first measured the behavioral response to $\mathrm{CO}_{2}$ by means of a visual analogue scale for fear (VAS-F) and the panic symptom list (PSL). In healthy volunteers, taking a double vital capacity breath of four different $\mathrm{CO}_{2}$ concentrations up to $35 \% \mathrm{CO}_{2}$ (Griez et al., 2007; Schruers et al., 2011), VAS-F and PSL ratings increased dose-dependently ( $p<0.001$, Figure $2 \mathrm{a}, \mathrm{b}$ ). PD patients, taking a vital capacity breath of $35 \% \mathrm{CO}_{2}$ (Perna et al., 2004; Schruers et al., 2004), also reported a strong fear and panic symptom response to $\mathrm{CO}_{2}(\mathrm{p}<0.001$, Figure $\mathrm{a}, \mathrm{b})$. 


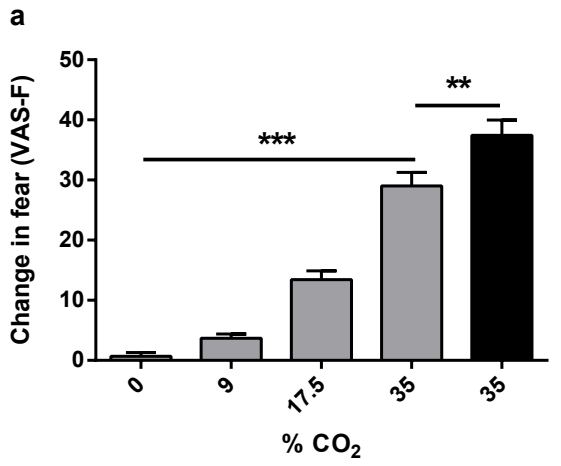

Healthy volunteers

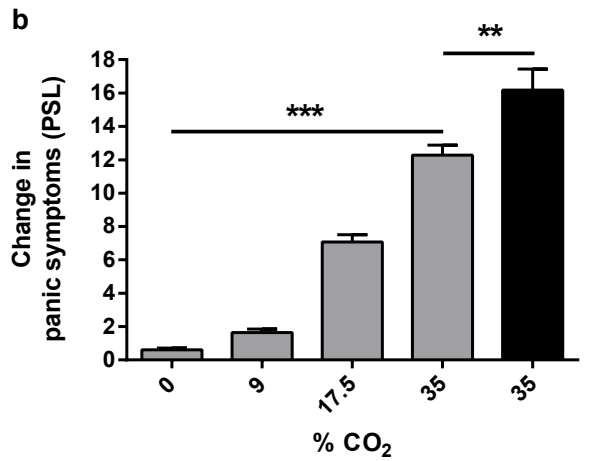

PD patients

Figure 2. Effect of $\mathrm{CO}_{2}$ on self-reported fear and panic symptoms in healthy volunteers and panic disorder (PD) patients. In healthy volunteers (gray), both fear a) and panic symptoms b) increased dose-dependently. Inhaling $35 \% \mathrm{CO}_{2}$ triggered a more robust response in patients (black) when compared to healthy volunteers. VAS-F, visual analogue scale for fear; PD, panic disorder; PSL, panic symptom list. Data represent mean + SEM. $* * p<0.01, * * * p<0.001$.

\section{Physiological response to $\mathrm{CO}_{2}$ exposure}

In a next conceptual step, as a more objective quantitative comparison, we measured the physiological response to $\mathrm{CO}_{2}$ exposure (see Supplementary Table 2 for means \pm $\mathrm{SEM}$ ). In mice, exposure to $9 \% \mathrm{CO}_{2}$ caused a robust increase in respiration rate (Figure 3a, see Supplementary Table 3 for additional respiratory measurements). In healthy volunteers, no difference was found between $0 \%$ and $9 \% \mathrm{CO}_{2}$, as both caused a lower mean respiration rate compared to baseline (Figure 3a). $\mathrm{At}_{2} \mathrm{CO}_{2}$ concentrations of $9 \%$ and higher there was a relative increase in effect size $(p<0.001)$. Only $35 \% \mathrm{CO}_{2}$ caused an increase in mean respiration rate compared to baseline. The increase in respiration rate was more pronounced in mice after prolonged exposure to $9 \%$ than in healthy volunteers after taking a double breath of $35 \% \mathrm{CO}_{2}(\mathrm{p}=0.002)$. Regarding heart rate, a $\mathrm{CO}_{2}$-induced decrease was observed across species, with a particularly strong effect in mice (Figure $3 b$ ). Further, in healthy volunteers, after inhaling $0 \%$ and $9 \% \mathrm{CO}_{2}$, the mean blood pressure decreased, whilst an increase was observed after inhaling an intermediate $(17.5 \%)$ and high (35\%) concentration of $\mathrm{CO}_{2}$. Pairwise comparisons revealed significant differences between all $\mathrm{CO}_{2}$ concentrations regarding the systolic ( $p<0.001$, except for $17.5 \%$ versus $35 \% \mathrm{CO}_{2} \mathrm{p}=0.003$, Figure $3 \mathrm{c}$ ) and the diastolic blood pressure ( $<<0.001$, Figure $3 \mathrm{~d}$ ). On average, the effect size with regard to the systolic blood pressure tended to be higher in PD patients in comparison with healthy volunteers $(p=0.067)$, whilst the effect size of the diastolic blood pressure was lower in patients than in healthy volunteers $(p<0.001)$. 


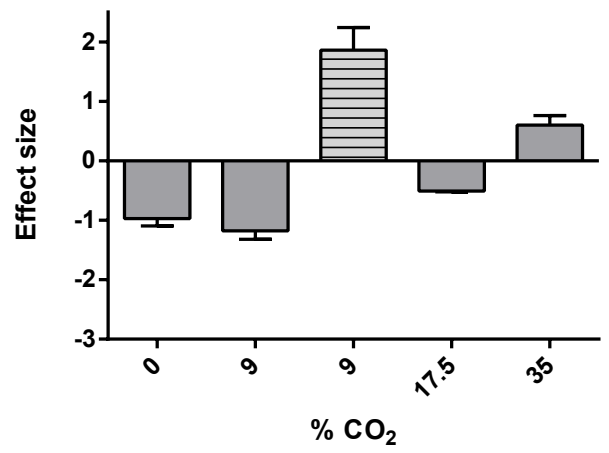

C

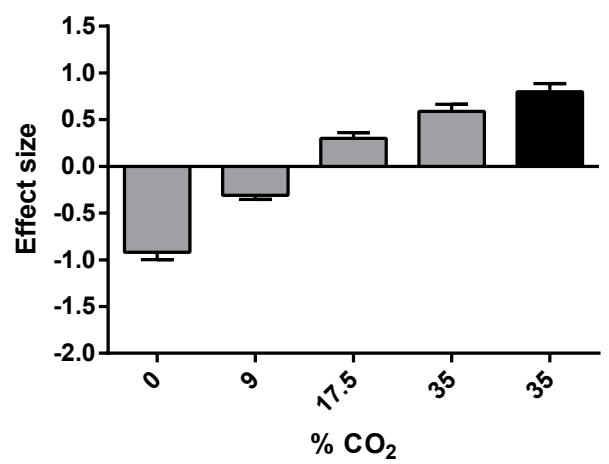

b

Heart rate

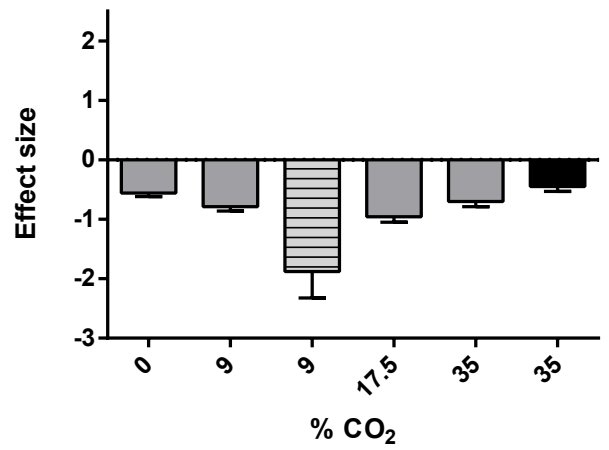

d

Diastolic blood pressure

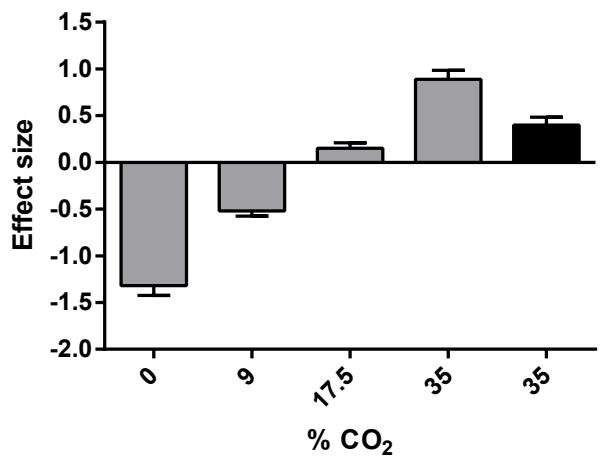

Figure 3. Effect of $\mathrm{CO}_{2}$ on respiration rate, heart rate, and blood pressure in mice, healthy volunteers, and panic disorder (PD) patients. a) In mice (dashed), $\mathrm{CO}_{2}$ strongly increased the respiration rate compared to baseline (yielding a positive effect size), which was also observed in healthy volunteers (gray) after inhaling $35 \% \mathrm{CO}_{2}$. b) $\mathrm{CO}_{2}$ exposure decreased heart rate in all groups, particularly in mice. c, d) in healthy volunteers, $17.5 \%$ and $35 \%$ $\mathrm{CO}_{2}$ increased the blood pressure compared to baseline, which was also the case for PD patients (black) after $35 \% \mathrm{CO}_{2}$. Data represent effect sizes + SD.

\section{Discussion}

The incongruence between rodent and human experiments hampers the translation of knowledge between the two species. In this study, we bridged this gap by applying the same stimulus, i.e. $\mathrm{CO}_{2}$, and obtaining the same physiological outcome parameters in addition to commonly used behavioral phenotypes in mice, healthy volunteers, and PD patients. Using this approach, we showed that in humans, $\mathrm{CO}_{2}$ triggers a marked fear response associated with an increase in respiration rate and blood pressure, and an 
adaptive decrease in heart rate. In mice, a similar fear response associated with a similar physiological response was observed. Based on this similarity between humans and mice, it can be concluded that mice experience a highly aversive response to $\mathrm{CO}_{2}$, comparable to the frightening experience in humans during inhaling a high concentration of $\mathrm{CO}_{2}$ and during naturally occurring panic attacks. In this respect, it has to be noted that we exposed mice to a concentration of $9 \% \mathrm{CO}_{2}$ that is multiple times lower than the $\mathrm{CO}_{2}$ concentrations that are used to euthanize rodents (Conlee et al., 2005). Therefore, the fear experienced during the euthanasia procedure is likely to be even more intense. As it is imperative to euthanize laboratory animals using methods that are as "humane" as possible, the use of $\mathrm{CO}_{2}$ cannot be considered to be in congruence with the assumption of "humane" sacrifice and should be abolished.

\section{Acknowledgments}

N.L. was financially supported by the Boehringer Ingelheim Fonds, Germany. The work was performed as a partial fulfilment towards the International Master in Affective Neuroscience of Maastricht University, the Netherlands and the University of Florence, Italy. This work was also supported by the Deutsche Forschungsgemeinschaft (DFG) Sonderforschungsbereich Transregio (SFB TRR) 58, Sonderforschungsbereich (SFB) 58/A1 and A5 to K-PL and DvdH. 


\section{References}

Burkholder, T.H., Niel, L., Weed, J.L., Brinster, L.R., Bacher, J.D., Foltz, C.J., 2010. Comparison of carbon dioxide and argon euthanasia: effects on behavior, heart rate, and respiratory lesions in rats. Journal of the American Association for Laboratory Animal Science : JAALAS 49, 448-453.

Conlee, K.M., Stephens, M.L., Rowan, A.N., King, L.A., 2005. Carbon dioxide for euthanasia: concerns regarding pain and distress, with special reference to mice and rats. Lab. Anim. 39, 137-161.

Coryell, W., Pine, D., Fyer, A., Klein, D., 2006. Anxiety responses to $\mathrm{CO} 2$ inhalation in subjects at high-risk for panic disorder. J. Affect. Disord. 92, 63-70.

Cressey, D., 2013. Best way to kill lab animals sought. Nature 500, 130-131.

Dielenberg, R.A., Hunt, G.E., McGregor, I.S., 2001. "When a rat smells a cat": the distribution of Fos immunoreactivity in rat brain following exposure to a predatory odor. Neuroscience 104, 1085-1097.

Esquivel, G., Schruers, K.R., Maddock, R.J., Colasanti, A., Griez, E.J., 2009. Acids in the brain: a factor in panic? J Psychopharmacol 24, 639-647.

Feinstein, J.S., Buzza, C., Hurlemann, R., Follmer, R.L., Dahdaleh, N.S., Coryell, W.H., Welsh, M.J., Tranel, D., Wemmie, J.A., 2013. Fear and panic in humans with bilateral amygdala damage. Nat. Neurosci. 16, $270-272$.

Griez, E.J., Colasanti, A., van Diest, R., Salamon, E., Schruers, K., 2007. Carbon dioxide inhalation induces dosedependent and age-related negative affectivity. PLoS One 2, e987.

Hawkins, P., Playle, L., Golledge, H., Leach, M., Banzett, R., Coenen, A., Cooper, J., Danneman, P., Flecknell, P., Kirkden, R., Niel, L., Raj, M., 2006. Newcastle consensus meeting on carbon dioxide euthanasia of laboratory animals (Meeting report). NC3Rs, London.

Hetzel, A., Rosenkranz, J.A., 2014. Distinct effects of repeated restraint stress on basolateral amygdala neuronal membrane properties in resilient adolescent and adult rats. Neuropsychopharmacology 39, 2114-2130.

Holm, S., 1979. A simple sequentially rejective multiple test procedure. Scand J Statist 6, 65-70.

Home Office, 2013. Annual Statistics of Scientific Procedures on Living Animal Great Britain 2012.

Johnson, P.L., Fitz, S.D., Hollis, J.H., Moratalla, R., Lightman, S.L., Shekhar, A., Lowry, C.A., 2011. Induction of c-Fos in 'panic/defence'-related brain circuits following brief hypercarbic gas exposure. J Psychopharmacol 25, 26-36.

Johnson, P.L., Samuels, B.C., Fitz, S.D., Lightman, S.L., Lowry, C.A., Shekhar, A., 2012. Activation of the orexin 1 receptor is a critical component of $\mathrm{CO}$-mediated anxiety and hypertension but not bradycardia. Neuropsychopharmacology 37, 1911-1922.

Johnson, P.L., Truitt, W., Fitz, S.D., Minick, P.E., Dietrich, A., Sanghani, S., Traskman-Bendz, L., Goddard, A.W., Brundin, L., Shekhar, A., 2010. A key role for orexin in panic anxiety. Nat. Med. 16, 111-115.

Kirkden, R.D., Niel, L., Lee, G., Makowska, I.J., Pfaffinger, M.J., Weary, D.M., 2008. The validity of using an approach-avoidance test to measure the strength of aversion to carbon dioxide in rats. Appl. Anim. Behav. Sci. 114, 216-234.

Klaassen, T., Klumperbeek, J., Deutz, N.E., van Praag, H.M., Griez, E., 1998. Effects of tryptophan depletion on anxiety and on panic provoked by carbon dioxide challenge. Psychiatry Res. 77, 167-174.

Leach, M.C., Bowell, V.A., Allan, T.F., Morton, D.B., 2002. Aversion to gaseous euthanasia agents in rats and mice. Comp. Med. 52, 249-257.

Leibold, N.K., Viechtbauer, W., Goossens, L., De Cort, K., Griez, E.J., Myin-Germeys, I., Steinbusch, H.W., van den Hove, D.L., Schruers, K.R., 2013. Carbon dioxide inhalation as a human experimental model of panic: the relationship between emotions and cardiovascular physiology. Biol. Psychol. 94, 331-340.

Mongeluzi, D.L., Rosellini, R.A., Ley, R., Caldarone, B.J., Stock, H.S., 2003. The conditioning of dyspneic suffocation fear. Effects of carbon dioxide concentration on behavioral freezing and analgesia. Behav. Modif. 27, 620636. 
Nardi, A.E., Valenca, A.M., Lopes, F.L., Nascimento, I., Veras, A.B., Freire, R.C., Mezzasalma, M.A., de-MeloNeto, V.L., Zin, W.A., 2006. Psychopathological profile of 35\% CO2 challenge test-induced panic attacks: a comparison with spontaneous panic attacks. Compr. Psychiatry 47, 209-214.

Niel, L., Stewart, S.A., Weary, D.M., 2008. Effect of flow rate on aversion to gradual-fill carbon dioxide exposure in rats. Appl. Anim. Behav. Sci. 109, 77-84.

Papadopoulos, A., Rich, A., Nutt, D.J., Bailey, J.E., 2010. The effects of single dose anxiolytic medication on the CO2 models of anxiety: differentiation of subjective and objective measures. J Psychopharmacol 24, 649656.

Perna, G., Bertani, A., Caldirola, D., Di Pasquale, D., Migliarese, G., Bellodi, L., 2004. Modulation of hyperreactivity to $35 \% \mathrm{CO} 2$ after one week of treatment with paroxetine and reboxetine: a double-blind, randomized study. J. Clin. Psychopharmacol. 24, 277-282.

Schruers, K., Esquivel, G., van Duinen, M., Wichers, M., Kenis, G., Colasanti, A., Knuts, I., Goossens, L., Jacobs, N., van Rozendaal, J., Smeets, H., van Os, J., Griez, E., 2011. Genetic moderation of CO2-induced fear by 5-HTTLPR genotype. J Psychopharmacol 25, 37-42.

Schruers, K.R.J., Van De Mortel, H., Overbeek, T., Griez, E., 2004. Symptom profiles of natural and laboratory panic attacks. Acta Neuropsychiatr. 16, 101-106.

Sheehan, D.V., Lecrubier, Y., Sheehan, K.H., Amorim, P., Janavs, J., Weiller, E., Hergueta, T., Baker, R., Dunbar, G.C., 1998. The Mini-International Neuropsychiatric Interview (M.I.N.I.): the development and validation of a structured diagnostic psychiatric interview for DSM-IV and ICD-10. The Journal of clinical psychiatry 59 Suppl 20, 22-33;quiz 34-57.

Ziemann, A.E., Allen, J.E., Dahdaleh, N.S., Drebot, II, Coryell, M.W., Wunsch, A.M., Lynch, C.M., Faraci, F.M., Howard, M.A., 3rd, Welsh, M.J., Wemmie, J.A., 2009. The amygdala is a chemosensor that detects carbon dioxide and acidosis to elicit fear behavior. Cell 139, 1012-1021. 


\section{Supplement}

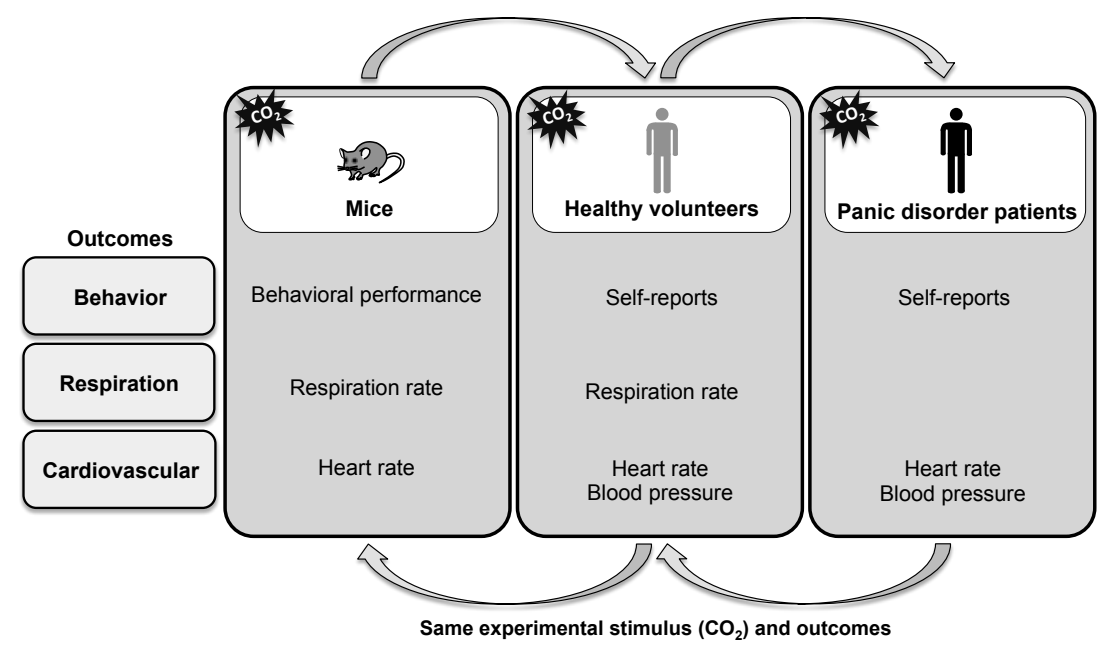

Figure 1. Overview of the translational approach used in the present project. The same experimental stimulus (carbon dioxide, $\mathrm{CO}_{2}$ ) was applied and the same cardio-respiratory outcome measurements were obtained in addition to the commonly used behavioral ones.

Table 1. Effect of $\mathrm{CO}_{2}$ on various outcomes of the open field test and the two-chamber test. Data represent mean values ( \pm SEM).

\begin{tabular}{|c|c|c|c|c|}
\hline & Outcome & Air & $\mathrm{CO}_{2}$ & p-value \\
\hline \multirow{2}{*}{ Open field test } & Time spent in corners (sec) & $682.63 \pm 14.85$ & $913.24 \pm 31.84$ & 0.001 \\
\hline & Fecal pellets & $5.60 \pm 0.98$ & $6.2 \pm 0.59$ & 0.607 \\
\hline \multirow{11}{*}{ Two-chamber test } & $\begin{array}{l}\text { Distance moved per chamber } \\
\text { (mice exposed to } \mathrm{CO}_{2} / \text { air; } \mathrm{cm} \text { ) }\end{array}$ & $1317.89 \pm 318.33$ & $635.78 \pm 105.04$ & 0.078 \\
\hline & Number of crossings & $7.3 \pm 1.37$ & $2.56 \pm 0.88$ & 0.011 \\
\hline & $\begin{array}{l}\text { Time spent in each chamber } \\
\text { (mice exposed to } \mathrm{CO}_{2} / \text { air; sec) }\end{array}$ & $304.02 \pm 72.49$ & $283.13 \pm 74.94$ & 0.891 \\
\hline & $\begin{array}{l}\text { Freezing per chamber } \\
\text { (mice exposed to } \mathrm{CO}_{2} / \text { air; sec) }\end{array}$ & $96.89 \pm 29.08$ & $5.00 \pm 2.29$ & 0.017 \\
\hline & Fecal pellets & $1.8 \pm 0.76$ & $5.22 \pm 0.68$ & 0.004 \\
\hline & $\begin{array}{l}\text { Fecal pellets per chamber } \\
\text { (mice exposed to } \mathrm{CO}_{2} / \text { air) }\end{array}$ & $2.5 \pm 0.79$ & $2.7 \pm 0.85$ & 0.891 \\
\hline & & Left air chamber & Right air chamber & p-value \\
\hline & $\begin{array}{l}\text { Distance moved per chamber } \\
\text { (mice exposed to air only; } \mathrm{cm} \text { ) }\end{array}$ & $2402.92 \pm 211.77$ & $1912.58 \pm 345.21$ & 0.376 \\
\hline & $\begin{array}{l}\text { Time spent in each chamber } \\
\text { (mice exposed to air only; sec) }\end{array}$ & $326.80 \pm 41.57$ & $249.39 \pm 43.17$ & 0.385 \\
\hline & $\begin{array}{l}\text { Freezing } \\
\text { (mice exposed to air only; sec) }\end{array}$ & $0.50 \pm 0.40$ & $0.20 \pm 0.13$ & 0.394 \\
\hline & $\begin{array}{l}\text { Fecal pellets per chamber } \\
\text { (mice exposed to air only) }\end{array}$ & $1.10 \pm 0.52$ & $0.70 \pm 0.33$ & 0.399 \\
\hline
\end{tabular}


Table 2. Effect of $\mathrm{CO}_{2}$ on respiration rate, heart rate, and blood pressure. Data represent mean values ( \pm SEM).

\begin{tabular}{|c|c|c|c|c|c|c|c|}
\hline \multirow[b]{2}{*}{ Outcome } & \multirow[b]{2}{*}{$\% \mathrm{CO}_{2}$} & \multicolumn{2}{|l|}{ Mice } & \multicolumn{2}{|c|}{ Healthy volunteers } & \multicolumn{2}{|c|}{ Panic patients } \\
\hline & & Baseline & $\mathrm{CO}_{2}$ & Baseline & $\mathrm{CO}_{2}$ & Baseline & $\mathrm{CO}_{2}$ \\
\hline \multirow{4}{*}{ Respiration rate } & 0 & & & $16 \pm 0.62$ & $11 \pm 1.34$ & & \\
\hline & 9 & $263 \pm 14.64$ & $382 \pm 13.68$ & $16 \pm 0.56$ & $11 \pm 1.47$ & & \\
\hline & 17.5 & & & $16 \pm 0.60$ & $14 \pm 1.80$ & & \\
\hline & 35 & & & $16 \pm 0.50$ & $18 \pm 2.38$ & & \\
\hline \multirow{4}{*}{ Heart rate } & 0 & & & $91 \pm 1.43$ & $82 \pm 3.37$ & & \\
\hline & 9 & $661 \pm 13.47$ & $554 \pm 20.16$ & $91 \pm 1.37$ & $78 \pm 3.25$ & & \\
\hline & 17.5 & & & $91 \pm 1.43$ & $76 \pm 2.72$ & & \\
\hline & 35 & & & $90 \pm 1.27$ & $80 \pm 3.30$ & $95 \pm 1.97$ & $86 \pm 1.66$ \\
\hline \multirow{4}{*}{$\begin{array}{l}\text { Systolic blood } \\
\text { pressure }\end{array}$} & 0 & & & $129 \pm 1.43$ & $115 \pm 4.17$ & & \\
\hline & 9 & & & $134 \pm 1.58$ & $128 \pm 4.70$ & & \\
\hline & 17.5 & & & $131 \pm 1.61$ & $136 \pm 5.15$ & & \\
\hline & 35 & & & $125 \pm 1.76$ & $137 \pm 5.52$ & $137 \pm 1.97$ & $153 \pm 2.50$ \\
\hline \multirow{4}{*}{$\begin{array}{l}\text { Diastolic blood } \\
\text { pressure }\end{array}$} & 0 & & & $78 \pm 0.77$ & $67 \pm 3.03$ & & \\
\hline & 9 & & & $80 \pm 0.92$ & $75 \pm 3.30$ & & \\
\hline & 17.5 & & & $79 \pm 0.94$ & $81 \pm 3.48$ & & \\
\hline & 35 & & & $76 \pm 0.78$ & $84 \pm 3.70$ & $83 \pm 0.99$ & $87 \pm 1.12$ \\
\hline
\end{tabular}

Table 3. Effect of $\mathrm{CO}_{2}$ on inter-breath interval, tidal volume, and ventilation in mice.

Data represent mean values ( \pm SEM; tidal volume and ventilation corrected for body weight).

\begin{tabular}{|llll|}
\hline Outcome & Baseline & $\mathrm{CO}_{2}$ & p-value \\
\hline Inter-breath interval (s) & $0.26 \pm 0.01$ & $0.16 \pm 0.01$ & $<0.001$ \\
\hline Tidal volume (ml/g) & $0.06 \pm 0.00$ & $0.10 \pm 0.00$ & $<0.001$ \\
\hline Ventilation $(\mathrm{ml} / \mathrm{g} / \mathrm{min})$ & $13.37 \pm 1.29$ & $37.97 \pm 2.63$ & $<0.001$ \\
\hline
\end{tabular}




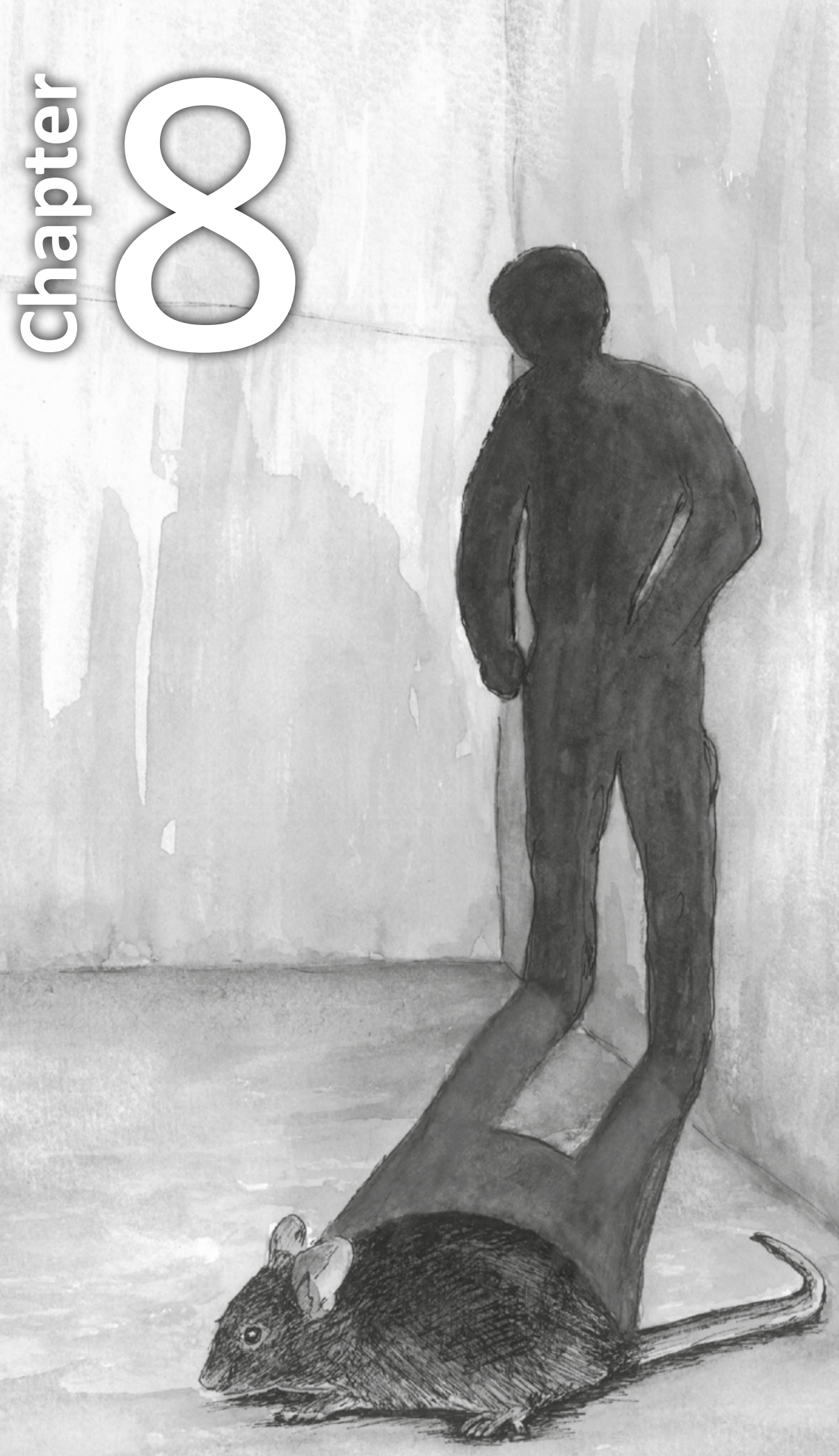

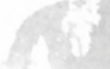


General discussion 
Chapter 8 
In spite of important progress of insight into the pathophysiology of panic attacks (PAs) over the past few years, the neurobiological underpinnings are still not fully understood. Therefore, it is challenging to improve current pharmacological treatment options, which are accompanied by many side effects and high relapse rates. The present thesis aimed to increase the current understanding of PAs by starting in humans (i.e., healthy individuals as well as panic disorder (PD) patients) using an experimentally provoked threat inducing acute physiological changes in the body and expanding this paradigm to rodents to eventually combine these very different research domains. The results of these studies and implications for future research and clinical applications are discussed here.

\section{The road to understanding panic in humans}

The spontaneous nature of naturally occurring PAs makes it challenging to study them in real-life. However, PAs are a unique and rare example of a psychopathological phenomenon that can be reliably provoked in an experimental setting, which has led to a long-standing history of panic research. Among the various models, those that acutely disturb the brain acid-base homeostasis are the most effective ones: inhalation of an increased concentration of carbon dioxide $\left(\mathrm{CO}_{2}\right)$, hyperventilation, and lactate infusion. Particularly $\mathrm{CO}_{2}$ inhalation is a well-validated technique with a number of advantages in comparison with the other two as reviewed in Chapter 2. Valuable aspects include the non-invasive administration and the reliability to trigger the intense fear and panic symptoms resembling real-life PAs in PD patients. For several years, it was believed that the hypersensitivity to $\mathrm{CO}_{2}$ is specific for PD patients. However, by increasing the dosage, a similar effect can be provoked in healthy individuals, indicating that a fundamental mechanism is involved in the sensitivity to $\mathrm{CO}_{2}$ and thus changes in the acid-base homeostasis. PD patients often suffer from comorbid psychiatric disorders and have received current or past treatments, both of which obscure the search for basic mechanisms underlying panic. The possibility to evoke PAs in healthy people opens the avenue of studying those basic mechanisms first in healthy individuals before involving PD patients.

PAs consist of intense fear and/or discomfort accompanied by various physiological symptoms such as palpitations and breathing difficulties. Traditionally, panic studies rely on self-reports about the presence and intensity of the symptoms. As an emotional response is highly variable between individuals and in fact a subjective experience, it can be, indeed, best reported and rated by the individual itself. However, to entirely capture all aspects of a PA and thus also the physiological response, monitoring parameters such as heart rate and respiration rate are a useful addition to self-reports. A number of studies explored the cardio-respiratory response to a $\mathrm{CO}_{2}$ inhalation, with inconsistent results however, mainly due to small sample sizes and technical limitations. 
In light of this background, in Chapter 3, we addressed the methodological drawbacks of previous studies and assessed the emotional as well as cardiovascular response to four $\mathrm{CO}_{2}$ concentrations in a large sample of healthy individuals. For cardiovascular monitoring, a novel computerized system was used, in which previously validated physiological parameters were incorporated. We replicated a previous study in our lab showing a dosedependent increase in self-reported panic symptomatology. In addition, we demonstrated an immediate, profound activation of the cardiovascular system in response to $\mathrm{CO}_{2}$. In particular, the diastolic blood pressure was a highly sensitive parameter in reflecting the degree of fear and panic symptoms and may therefore represent a biomarker (i.e., an objective, measurable, and reproducibly indicator of a biological state) for the reactivity to $\mathrm{CO}_{2}$. Therefore, the combination of self-reports and the diastolic blood pressure response may provide the most sensitive and powerful assessment of (experimentally induced) PAs. This opens the opportunity for a refined diagnosis of PD as explained later (see section "Roads into the future").

Another avenue in human research is the identification of specific genes that increase the risk of developing a disease or are related to, for instance, symptom severity, prognosis or treatment outcome. With regard to PD, genetic association studies yielded a variety of potential susceptibility loci, of which the functional polymorphism 5-HTTLPR in the serotonin transporter (5-HTT) gene and variants in the ACCN2 gene are of relevance for this thesis (Chapters 5 and 6 ). The 5 -HTTLPR represents a functional polymorphism in the promoter region of the 5-HTT gene, with a 43 base pairs deletion/insertion, yielding either a short S-allele or a long L-allele, respectively. The expression levels of 5-HTT are about two times lower in the S-allele in comparison with the L-allele. Regarding chemosensitivity, a first study in healthy volunteers showed that the reactivity to a $\mathrm{CO}_{2}$ inhalation was higher in individuals homozygous for the L-allele compared to S-allele carriers (Schmidt et al., 2000). This, however, could not be replicated in PD patients (Perna et al., 2004). Possible explanations are the sample size that may have been too small for revealing subtle differences in such a heterogeneous disorder and the presence of a third genetic variant, which was later discovered, leading to 5-HTT expression levels comparable to the S-allele. A study by our own group, also taking the third variant into account, replicated in a large sample of healthy individuals that the LL-genotype was hyperreactive to $\mathrm{CO}_{2}$ compared to the SS-genotype, particularly at an intermediate dosage of $17.5 \%$ (Schruers et al., 2010). No significant difference was found after inhaling $35 \% \mathrm{CO}_{2}$, which may be due to a ceiling effect. Further, in PD patients, a more favourable treatment response to paroxetine, an SSRI targeting the 5-HTT, was reported in carriers of one or two L-alleles (Perna et al., 2005). In disagreement to these data, it was reported that the low expressing 5-HTTLPR genotype was related to more severe panic symptoms in PD patients (Lonsdorf et al., 
2009). However, methodological drawbacks limit the generalizability of these results: the study sample was rather small with less than 75 patients and the use of medication may have influenced symptom severity in a genotype-dependent manner.

The second gene of interest in this thesis concerns the ACCN2, which is the human homologue of the rodent gene encoding the acid-sensing ion channel 1a (ASIC1a). Only recently, an association between variants in the ACCN2 gene and PD was reported (Smoller et al., 2014). More specifically, an association was found with the diagnosis of PD in a casecontrol study as well as with amygdala volume in a sample of more than 1000 patients. In addition, another significant relationship was found with the amygdala reactivity to visual emotional stimuli in a sample of 103 healthy individuals. It was proposed that specific genetic variants would cause a decrease in the threshold for sensing acidosis. However, no direct experimental link to changes in $\mathrm{pH}$ was included. We provided precisely this missing link using a $\mathrm{CO}_{2}$ inhalation in PD patients and healthy individuals (Chapter 4). We concluded that the ACCN2 gene is a new and prime candidate to be further investigated in the pathophysiology of PD.

In general, genetic research on anxiety disorders, including PD, is relatively scarce and has been less successful compared to other psychiatric disorders. Reasons include the complex and heterogeneous phenotype and gender-specific effects, leading to the necessity of large sample sizes. Moreover, differences in ethnicity-dependent allele frequencies emphasize the need for homogeneous samples. Despite these methodological challenges, gaining more insights into the genetic basis of PD may significantly move forward the identification of molecular targets and may contribute to a more personalized treatment in the future.

\section{The road to appropriate rodent models of panic}

In general, the primary outcome measurement in rodent research is the behavioral response to a stimulus, which is often related to neurobiological mechanisms of interest. Despite that both lactate administration and exposure to $\mathrm{CO}_{2}$ have been applied, rodent studies in direct relation to PD are relatively scarce (Chapter 2). With regard to the use of lactate, a major drawback is the invasive nature of the administration, which might cause stress that interferes with the behavioral response. In contrast, exposure to $\mathrm{CO}_{2}$ can be done non-invasively using flow chambers or hermetically closed boxes. In a few studies, anxiety- and fear-related behavior has been studied immediately after exposure, while assessment during exposure has only been applied recently in a seminal study by Ziemann and colleagues (2009). In that study, the activity in the center zone of the open field was strongly reduced by $\mathrm{CO}_{2}$, indicating increased anxiety- and fear-related behavior. In addition, depending on the used concentration, $\mathrm{CO}_{2}$ caused robust freezing, 
which is generally accepted to reflect fear. Although this study boosted the interest in panic research and provided a molecular substrate involved in $\mathrm{CO}_{2}$-induced fear-related behavior, the question that remains is how to progress from here in light of PD in humans?

\section{Facing roadblocks: Is there a need for translational research?}

Nowadays, many different research disciplines exist, among which human research and basic research including studies in rodents. Each area has advantages, but there are also limitations regarding the extent each discipline can contribute to increase the insights into the complex mechanisms and interactions underlying mental disorders such as PD.

Human research, for instance, is particularly suitable for assessing the emotional components of a disorder. In PD, the intense fear during a PA can best be reported and evaluated by the individual itself. In addition, the disease does not need to be modeled and obtained knowledge can immediately be applied to humans. On the other hand, drawbacks include the common comorbidities, making it necessary to study large groups, and the considerable variation in factors that may potentially affect the development of a disorder. For instance, environmental factors can hardly be assessed in complete detail in retrospect. For such an assessment prospective, longitudinal studies are needed. However, following a large sample of healthy individuals for many years in order to assess which factors are related to disease development is very time consuming and costly. A major roadblock in human research is the limited potential to study the neurobiological molecular mechanisms of a disease to identify new therapeutic targets. Although experimental models may indicate a direction for which system is altered, they have not yet provided any specific target for treatment.

At the point at which the limits of human research are reached, rodent research becomes of particular importance. Main advantages consist of the access to brain tissue, controlled environmental conditions, a fast reproduction, and a lifespan of about two years that make it feasible to study (the development of) a psychopathological phenomenon in a relatively short time period. Further, the generation of genetically modified animals gives the opportunity to investigate the function of a particular gene and related proteins in a disease. Moreover, safety concerns also forbid testing new drugs and dosages in humans, which is therefore addressed in animals first. In spite of these advantages, the incapability to model complex diseases in rodents, and instead shifting the focus to specific symptoms, often limits the use of rodent studies.

Facing roadblocks: Is there a need for translational research? In the past few decades, pivotal progress has been made in understanding health and disease and many molecular targets with therapeutic potential have been identified. However, many discoveries of basic research have not been translated back successfully to clinical practice yet. What 
is the main obstacle that hinders and slows down this process? The most likely answer may be the gap between basic research in the lab and research in humans and the daily clinic. The outcome measurements vary widely between studies in rodents and humans. In rodent experiments, the behavioral response to a stimulus is often primarily explored in relation to neurobiological alterations, while, for instance, in human panic research, selfreports about the experienced emotions and symptoms are evaluated. Evidently, observed behavioral responses in animals and self-reports by humans are not interchangeable. This difference in outcome measurements hampers the translation of knowledge between the two species and decreases, for example, the likelihood of discovering a drug that is not only effective in rodents but also in humans. This is not limited to pharmacological medication, but to therapeutic strategies in general. Knowledge obtained in basic research needs to be applicable in humans to have beneficial health effects. To increase the efficacy of current treatment strategies and to get closer to a more personalized medicine, we do need translational, cross-species research, in which aspects of fundamental science and human (clinical) research are combined and experimental stimuli as well as outcome measurements are as similar as possible in rodents and humans.

\section{Translational research hits the road: moving towards a bi-directional roundabout}

As highlighted in the last section, the need for translational, cross-species research is evident. The concept of translational research emerged already years ago with the approach "from bench to bedside and back". The implementation, however, is challenging and still in need of improvement. In this thesis, inspired by both human and rodent research, we aimed to go beyond the classical roads and to move towards a bi-directional roundabout.

A groundbreaking series of studies by Ziemann and colleagues (2009) provided a molecular substrate that senses a change in $\mathrm{pH}$ and triggers the fear-related behavioral response to $\mathrm{CO}_{2}$ exposure. These rodent studies put forward ASIC1a in the amygdala as prime candidate for future panic research. In light of this, as mentioned previously, as it was recently shown that two genetic variants in the human orthologue gene ACCN2 are associated with PD, i.e. with a diagnosis of PD and amygdala activity to the visual presentation of emotional faces (Smoller et al., 2014). It was proposed that the genetic variants cause a decreased threshold to sense a drop in $\mathrm{pH}$. However, direct experimental evidence was lacking. We provided this missing evidence by showing an association between those two genetic variants and the fear response to a $\mathrm{CO}_{2}$ inhalation in PD patients (Chapter 5). In addition, the same relationship was found with regard to the cardiovascular response in healthy individuals. Thereby, a role of the $\mathrm{pH}$-sensitive ion channel system in human chemosensitivity and PD is supported. A remaining question is which brain area represents the key structure in PD 
and panic-related chemosensitivity? In the rodent study by Ziemann et al., the amygdala was highlighted as the main player. However, a potential contribution of other brain structures was not investigated. In contrast to this study, Urbach-Wiethe patients, having a bilaterally dysfunctional amygdala, unexpectedly experienced a strong fear response to a $\mathrm{CO}_{2}$ inhalation in another study (Feinstein et al., 2013), indicating that in humans the amygdala may not be the sole brain center in detecting changes in $\mathrm{pH}$ and triggering a behavioral response. As this latter study did not include functional imaging, no other candidate structures were proposed. In Chapter 3, we showed that inhaling $\mathrm{CO}_{2}$ causes brainstem, and not amygdala, activation in humans. This effect was more pronounced in PD patients than in healthy volunteers. Therefore, we assume that, in humans, the brainstem plays a primary role in panic-related chemosensitivity.

In addition to detecting and reacting to changes in $\mathrm{pH}$, evidence supports a role of the 5-HT system in PD. For instance, many of the clinically effective pharmacological treatments are antidepressants. The first-line medical compounds are selective serotonin reuptake inhibitors (SSRIs) that target the 5-HTT and thereby prolong 5-HT neurotransmission. Similarly, tricyclic antidepressants inhibit the 5-HTT and additionally act as norepinephrine reuptake inhibitors. 5-HT is broken down by the enzyme monoamine oxidase-A (MAO-A). Pharmacological inhibition of this enzyme also enhances 5-HT signalling, suggesting that 5-HT exerts inhibitory effects on PAs. Moreover, imaging studies showed a reduced brainstem $5-\mathrm{HT}_{1 \mathrm{~A}}$ receptor binding in PD patients, possibly a compensatory effect in order to increase the extracellular availability of 5-HT as antidepressants do.

A growing body of research thus suggests that both a disturbed acid-base homeostasis and the 5-HT system are involved in the pathophysiology of PD, and beyond that, there is also evidence for a link between both. Panic provocation studies showed that a reduction in brain 5-HT levels, caused by depletion of the 5-HT precursor tryptophan, increased the panic response to a $\mathrm{CO}_{2}$ inhalation (Schruers et al., 2000), while increasing brain 5-HT levels, by means of administration of a 5-HT precursor, decreased the response (Schruers et al., 2002). In addition, in our lab, it was also shown that the 5-HTTLPR, a functional polymorphism in the 5-HTT gene, moderates the emotional response to a $\mathrm{CO}_{2}$ inhalation (Schruers et al., 2011). More specifically, carriers of the LL genotype, having a relatively high number of 5-HTT, were most reactive at an intermediate dosage of $\mathrm{CO}_{2}$. Taken together, the $\mathrm{pH}$ detection system and the 5-HT system seem to interact in PD, although the exact molecular link between both remains largely to be elucidated. Therefore, in the framework of translational research, in Chapter 6, we expanded on those previous studies and used the same experimental stimulus that is used in human panic provocation studies: $\mathrm{CO}_{2}$ exposure. As taking vital capacity breaths of $\mathrm{CO}_{2}$ is not feasible in mice, we used a custom-made, innovative, and fully controlled $\mathrm{CO}_{2}$ chamber, allowing live monitoring of 
freely moving animals during the exposure. As direct follow-up of the previously shown 5-HTTLPR moderation in human $\mathrm{CO}_{2}$-induced fear, wildtype, hetero-, and homozygous 5-Htt knock-out mice were used. Likewise to self-reports in human studies, behavioral assessment showed a marked fear response in different tests under $\mathrm{CO}_{2}$ exposure. Overall, wildtype mice were most reactive, while hetero- and in particular homozygous knock-out mice were relatively hyposensitive to $\mathrm{CO}_{2}$, thereby further confirming the fear-reducing effects of 5-HT. In contrast, trait anxiety scores, assessed during normal air exposure, were more pronounced in homozygous 5 - $\mathrm{Htt}$ knock-out mice. Further, previous chemosensitivity research showed that brainstem 5-HT neurons are tightly juxtaposed to large arteries, making them ideally situated for sensing changes in arterial blood $\mathrm{CO}_{2}$ levels (Richerson, 2004). In addition, a subset of these neurons is highly sensitive to $\mathrm{pH}$ and strongly increases the firing rate in response to a drop in $\mathrm{pH}$. Inspired by those experiments, it is currently assessed whether ASIC1a is expressed within 5-HT neurons in the brainstem. If confirmed that ASIC1a is located on the cell membrane of 5-HT neurons, possibly only on a subset of those, this study would provide a molecular substrate how 5-HT neurons sense and react to changes in $\mathrm{pH}$. In addition, assessment of expression levels of ASIC1a in the dorsal raphe region, PAG, and amygdala are ongoing and will be related to genotype and the behavioral response to $\mathrm{CO}_{2}$.

Up to this point, we applied the same experimental stimulus to humans and rodents and incorporated previous knowledge. However, as mentioned in the previous section, obtaining similar outcome measurements is of equally essential importance to be able to translate the knowledge more efficiently and faster, and to bridge the gap between basic science and the clinical setting. To maximize comparability between rodents and humans, physiological parameters that can be measured in both species would be highly valuable. With this in mind, we monitored the cardio-respiratory response to $\mathrm{CO}_{2}$ in the next rodent study (Chapter 6), similar to the way we did in healthy individuals and PD patients (Chapters 3, 5, and 6). Very few studies have done this in the direct framework of panic research and none did it within one large cross-species project. We measured all parameters non-invasively in freely moving animals. The results show that, similar to human studies, respiration rate and tidal volume strongly increased to $\mathrm{CO}_{2}$ in mice. In addition, heart rate decreased during the $\mathrm{CO}_{2}$ exposure. This effect has been reported before and may be compensatory to an increased blood pressure. In this rodent study, we did not include blood pressure measurements, as commonly used methods either require restraining the animals or prior surgery. Furthermore, no genotype effect was found in mice with regard to any physiological outcome parameters, indicating that $\mathrm{CO}_{2}$ exerted similar effects in all genotypes. An explanation might be that the difference in extracellular 5-HT levels was not large enough between genotypes to cause differential 
effects or that 5-HT neurons act as chemosensors and induced a physiological response, independent of the 5-HT availability. Moreover, the lack of a genotype effect is relevant for interpreting the behavioral results, as a lack of a genotype difference indicates that all animals received the same stimulus and that the behavioral differences are not caused by, for instance, inhaling different amounts of $\mathrm{CO}_{2}$. No direct comparison with humans can be made as the 5-HTTLPR genotype has not yet been assessed in relation to the $\mathrm{CO}_{2}$-induced cardio-respiratory changes. However, these results indicate that though the stimulus and the physiological response are comparable between genotypes, the emotional response is not the same. As mentioned above, a differential expression of ASIC1a may be associated with the degree of fear-related behavior and may further shed light onto whether ASIC1a could be a potential therapeutic target in the treatment of PD.

To conclude, in this thesis, we combined knowledge of previous rodent and human studies to perform a cross-species project that we consider an important advance in psychiatric research to date, as it forms a "bi-directional roundabout". In addition to applying the same experimental stimulus, we obtained the same physiological outcome measurements in humans to make the translation between species more efficiently. In this interdisciplinary approach, the reactivity to $\mathrm{CO}_{2}$ in mice represents a model for the reactivity in humans, and the reactivity in healthy volunteers serves as a model for the $\mathrm{CO}_{2}$ reactivity in PD patients. The potential of new medication can thus be tested in a $\mathrm{CO}_{2}$ model in rodents first before further assessing promising compounds in healthy volunteers and eventually in PD patients. Thereby, patients do not need to undergo assessing the effects of drugs that may not yet work efficiently in humans. In addition, new insights obtained in patients as for instance by genetic association studies can be directly translated to the field of basic research to further examine the molecular effects and potential treatment options.

\section{A side path to a more "humane" use of laboratory animals}

In spite of that the focus of this doctoral thesis on PD, the used cross-species approach also provides unique insights into another direction, in which $\mathrm{CO}_{2}$ exposure is used: euthanasia of lab animals (Chapter 6). Biomedical research often relies on animal research as alternatives such as cell culture do not have the potential to study, for instance, behavior in relation to neuroanatomical alterations. Millions of animals are euthanized for this purpose worldwide each year. It is imperative to take care of the animals' welfare and to perform the euthanasia in a "humane" way. One of the most commonly used methods is exposure to $100 \% \mathrm{CO}_{2}$, likely because of the ease of use and its relative safety for the investigator. A number of studies showed behavioral aversion and severe side effects such as nasal hemorrhages and seizures to $\mathrm{CO}_{2}$ exposure. Observations like these led to a considerable, still ongoing, debate whether $\mathrm{CO}_{2}$ euthanasia can be considered as a 
"humane" method of sacrifice (Cressey, 2013). A major challenge in this respect is to judge what animals' experience during this procedure. As mentioned earlier, the incongruence in outcome measurements between rodent and human studies, that is primarily behavior compared to self-reports, restricts the direct translation between the two species. In Chapter 6 , we overcame this major roadblock by directly and quantitatively comparing the behavioral and the cardio-respiratory response to $\mathrm{CO}_{2}$ exposure assessed in mice, healthy individuals, and PD patients, thereby allowing a comparison across species and thus "giving the mice a voice". In addition to a profound fear-related behavioral response, mice showed a physiological response similar to that of healthy individuals and PD patients when experiencing an experimental PA. The similarity on the physiological level implies that $\mathrm{CO}_{2}$ causes a similar, highly aversive, and frightening experience in mice. In light of animal welfare and ethical handling of lab animals, our study strongly suggests that the use of $100 \% \mathrm{CO}_{2}$ exposure ought to be regarded as highly stressful. Therefore, this way of euthanasia should be urgently reconsidered and replaced by alternative procedures.

\section{The road to the future}

The studies in the present thesis represent a basis for several roads into the future, keeping the roundabout of translational cross-species research in mind. A few directions are elaborated here.

PAs are highly emotional arousing periods that occur "out of the blue". When a person experiences the first PAs, he or she often seeks help at first heart aid departments. However, as the bodily symptoms such as chest pain, palpitations, and breathing difficulties do not occur exclusively in the context of PD, PAs are often not recognized as such immediately and other conditions such as heart-related disorders are assumed. Being physically healthy and not obtaining a medical explanation for the frightening episode is highly unsatisfactory and frustrating for the individuals. Therefore and to be able to provide treatment, it is important to refine the diagnostic options, which are currently based on self-reports. In Chapter 3, we showed that, in healthy individuals, the diastolic blood pressure might represent a biomarker for the reactivity to $\mathrm{CO}_{2}$. To be implemented in the clinical setting, this result needs to be replicated in PD patients first. Once the value is confirmed, incorporating $\mathrm{CO}_{2}$ inhalation and monitoring the diastolic blood pressure in the clinic could be a beneficial addition to selfreports to support and accelerate the diagnosis. In this respect, future research should also further study the respiratory response to $\mathrm{CO}_{2}$ and potentially reveal additional biomarkers. In our studies, we made use of a facial mask and it did not appear to be feasible to obtain respiratory parameters in PD patients due to the inability of supporting the mask against the face long enough. Equipment with a better tolerability, smaller in size for example, may contribute to an improved assessment. 
Inhalation of an excess concentration of $\mathrm{CO}_{2}$ has been used in human panic research for the past three decades and represents a well-validated experimental model. It is assumed that $\mathrm{CO}_{2}$ acutely disturbs the brain acid-base homeostasis as $\mathrm{CO}_{2}$ exposure in rodents decreases brain $\mathrm{pH}$ (Ziemann et al., 2009). In humans, indirect evidence from lactate studies points into the same direction, but direct experimental evidence is lacking. Magnetic resonance spectroscopy combined with inhaling $\mathrm{CO}_{2}$ would allow non-invasive mapping of brain $\mathrm{pH}$ in humans and show whether inhaling $\mathrm{CO}_{2}$ indeed causes a drop in brain $\mathrm{pH}$ in humans and is associated with negative affect. Further support for a role of a $\mathrm{pH}$ disturbance in PD is provided by our study presented in Chapter 5 . In that study, we found an association between variants in the ACCN2 gene and the reactivity to a $\mathrm{CO}_{2}$ inhalation in healthy volunteers and PD patients. Our study in combination with the recent case-control study by Smoller et al. (2014), finding a significant association with PD, emphasizes the need for building further on those results. Smoller and colleagues suggested that the variants are related to alterations in the threshold of sensing acidosis. In light of this notion, a further step could be to explore whether the degree of brainstem activation to inhaling $\mathrm{CO}_{2}$ (Chapter 4 ) is dependent on the ACCN2 genotype. This would be interesting to investigate in both healthy individuals and in PD patients, but it might not be readily feasible in the latter group. For genotyping a large sample is required and patients may not be easily willing to inhale $\mathrm{CO}_{2}$, causing discomfort, whilst lying in a noisy scanner that is often associated with the experience of claustrophobia to some extent. Furthermore, the functionality of those genetic variants is currently not known and should be assessed first. If there is a difference in expression levels of the $\mathrm{pH}$-sensitive ion channel and a correlation with $\mathrm{CO}_{2}$-sensitivity, in the long-term, inhibition of the channels might become a treatment option.

At the first stages of new potential pharmacological interventions, animal research is of particular importance. As mentioned earlier, to maximize knowledge transfer, the resemblance of stimulus and outcome measurements between animal and human research should be as close as possible. Testing the efficacy and dosages in such an animal model would significantly contribute to improve the current process of knowledge translation and application. This thesis provides a unique example of combining rodents, healthy individuals, and patients within one large project. We used $\mathrm{CO}_{2}$ exposure as experimental stimulus, and obtained cardio-respiratory outcome measurements in addition to the commonly used behavioral ones. However, a methodological consideration is that it was not feasible to obtain all parameters in all groups. As patients did not tolerate the mask for a prolonged period of time, parameters such as respiration rate and tidal volume could not be monitored. Breathing, however, is relatively easy to measure in rodents. Further, we managed to measure heart rate non-invasively in all groups, while blood pressure 
was only assessed in humans as in rodents restraining or prior surgery (e.g., in case of telemetry) is required. Although a surgery is an invasive and expensive procedure, blood pressure measurements may be an important addition based on our human data in Chapter 3, showing that particularly the diastolic blood pressure might be a biomarker for the $\mathrm{CO}_{2}$-reactivity.

To get closer to a more personalized treatment approach, genetic research aims to identify susceptibility alleles. However, in general, genetic research in PD has not been overly successful to date (Smoller, 2011). A relatively new field that may explain part of the inconsistencies is epigenetics, a system that regulates whether a gene is actually transcribed into messenger RNA or "silenced", without changing the nucleotide sequence of the DNA (Narayan and Dragunow, 2010; Stahl, 2010). One of the main forms of epigenetic modifications is DNA methylation. DNA methylation occurs at the 5-carbon position of cytosine residues, often in highly concentrated regions of CG dinucleotides, referred to as CpG islands. By adding a methyl group, the enzyme DNA methyltransferase (DNMT) promotes the conversion of cytosine to 5-methylcytosine, which in turn attracts binding of repressor complexes. In addition, the chromatin structure becomes more compact, thereby preventing the binding of transcription factors. Thus, generally, high methylation is associated with a decreased gene transcription. Removing a methyl group generally leads to a more open chromatin structure and gene expression. DNA methylation is accomplished by the family of DNMTs: DNMT1 is required for maintenance of the current methylation pattern, while DNMT2 and DNMT3 are involved in de novo methylation. Methylation states can be inherited and altered by environmental factors such as stress and diet, leading to "unwanted" changes in the methylation pattern. Therefore, epigenetics potentially contribute to making an individual prone to develop a certain disorder and may act as a mediator in the pathophysiology. Future studies should not only investigate genes $x$ environment interactions, but also epigenetic patterns should be taken into account. With regard to PD, few epigenetic studies have been performed to date. The MAO-A gene, encoding the enzyme that breaks down 5-HT, was reported to be hypomethylated in female PD patients (Domschke et al., 2012). Negative life events were related to a relatively decreased methylation, whilst the opposite effect was observed with increased methylation. The exact functionality of the methylation pattern is not known, but assuming that hypomethylation is associated with increased gene transcription, the observed hypomethylation could be related to an increased expression of MAO-A, leading to a relatively faster $5-\mathrm{HT}$ breakdown. As mentioned earlier, $5-\mathrm{HT}$ is believed to exert panicolytic effects, thus an association between faster 5-HT breakdown and PD seems to be plausible. Future studies could address whether the methylation state of genes such as 5-HTT are related to symptom severity, $\mathrm{CO}_{2}$-sensitivity, treatment response, and 
relapse. In the long-term, this may lead to new and better treatment options and to more personalized medicine. If relapse could be predicted, for instance identified by a too small change in the methylation state before and after treatment, additional pharmacological approaches could be added.

\section{Concluding remarks}

In the past few years, both rodent and human research had a tremendous contribution in understanding the pathophysiology of psychiatric disorders. Yet, the progress is hindered by the differences in outcome measurements between the two domains. As highlighted in this thesis, most powerful would be the combination of the different areas and to use experimental stimuli and outcome parameters that are as similar as possible. In such a translational, cross-species approach, mice can serve as a model for humans, and healthy individuals as a model for patients. In that way, we may be able to minimize the burden for patients as new discoveries in rodents can be verified in healthy individuals first. Viewed from the other side, once insights of associations between genetic variants and the diagnosis of PD or epigenetic methylation states and treatment prediction/relapse are made in PD patients, interventions can be investigated in mice and then, again, tested in healthy individuals first.

To conclude, more research still has to be done. The use of translational, crossspecies projects can however significantly accelerate the progress of understanding the pathophysiology of a disorder like PD. In the long-term, this might lead to a new classification of the diagnostic criteria based on symptomatology and neurobiological etiology, and to a more individual treatment strategy. The focus of the present thesis was on PD, but this approach is likely to be highly beneficial for a large number of other research areas. 


\section{References}

Cressey, D., 2013. Best way to kill lab animals sought. Nature 500, 130-131.

Domschke, K., Tidow, N., Kuithan, H., Schwarte, K., Klauke, B., Ambree, O., Reif, A., Schmidt, H., Arolt, V., Kersting, A., Zwanzger, P., Deckert, J., 2012. Monoamine oxidase A gene DNA hypomethylation - a risk factor for panic disorder? The international journal of neuropsychopharmacology/official scientific journal of the Collegium Internationale Neuropsychopharmacologicum 15, 1217-1228.

Feinstein, J.S., Buzza, C., Hurlemann, R., Follmer, R.L., Dahdaleh, N.S., Coryell, W.H., Welsh, M.J., Tranel, D., Wemmie, J.A., 2013. Fear and panic in humans with bilateral amygdala damage. Nat. Neurosci. 16, $270-272$.

Lonsdorf, T.B., Ruck, C., Bergstrom, J., Andersson, G., Ohman, A., Schalling, M., Lindefors, N., 2009. The symptomatic profile of panic disorder is shaped by the 5-HTTLPR polymorphism. Prog. Neuropsychopharmacol. Biol. Psychiatry 33, 1479-1483.

Narayan, P., Dragunow, M., 2010. Pharmacology of epigenetics in brain disorders. Br. J. Pharmacol. 159, $285-303$.

Perna, G., di Bella, D., Favaron, E., Cucchi, M., Liperi, L., Bellodi, L., 2004. Lack of relationship between CO2 reactivity and serotonin transporter gene regulatory region polymorphism in panic disorder. Am. J. Med. Genet. B Neuropsychiatr. Genet. 129B, 41-43.

Perna, G., Favaron, E., Di Bella, D., Bussi, R., Bellodi, L., 2005. Antipanic efficacy of paroxetine and polymorphism within the promoter of the serotonin transporter gene. Neuropsychopharmacology: official publication of the American College of Neuropsychopharmacology 30, 2230-2235.

Richerson, G.B., 2004. Serotonergic neurons as carbon dioxide sensors that maintain $\mathrm{pH}$ homeostasis. Nat. Rev. Neurosci. 5, 449-461.

Schmidt, N.B., Storey, J., Greenberg, B.D., Santiago, H.T., Li, Q., Murphy, D.L., 2000. Evaluating gene x psychological risk factor effects in the pathogenesis of anxiety: a new model approach. J. Abnorm. Psychol. 109, 308-320.

Schruers, K., Esquivel, G., van Duinen, M., Wichers, M., Kenis, G., Colasanti, A., Knuts, I., Goossens, L., Jacobs, N., van Rozendaal, J., Smeets, H., van Os, J., Griez, E., 2011. Genetic moderation of CO2-induced fear by 5-HTTLPR genotype. J Psychopharmacol 25, 37-42.

Schruers, K., Klaassen, T., Pols, H., Overbeek, T., Deutz, N.E., Griez, E., 2000. Effects of tryptophan depletion on carbon dioxide provoked panic in panic disorder patients. Psychiatry Res. 93, 179-187.

Schruers, K., van Diest, R., Overbeek, T., Griez, E., 2002. Acute L-5-hydroxytryptophan administration inhibits carbon dioxide-induced panic in panic disorder patients. Psychiatry Res. 113, 237-243.

Smoller, J.W., 2011. Who's afraid of anxiety genetics? Biol. Psychiatry 69, 506-507.

Smoller, J.W., Gallagher, P.J., Duncan, L.E., McGrath, L.M., Haddad, S.A., et al., 2014. The Human Ortholog of AcidSensing Ion Channel Gene ASIC1a Is Associated with Panic Disorder and Amygdala Structure and Function. Biol. Psychiatry. 76, 902-910.

Stahl, S.M., 2010. Methylated spirits: epigenetic hypotheses of psychiatric disorders. CNS Spectr 15, 220-230.

Ziemann, A.E., Allen, J.E., Dahdaleh, N.S., Drebot, II, Coryell, M.W., Wunsch, A.M., Lynch, C.M., Faraci, F.M., Howard, M.A., 3rd, Welsh, M.J., Wemmie, J.A., 2009. The amygdala is a chemosensor that detects carbon dioxide and acidosis to elicit fear behavior. Cell 139, 1012-1021. 
A $\left.10^{3}\right)^{3}$ 


\section{Summary}

Samenvatting

Valorization

Acknowledgments

Curriculum vitae

Publication list 
Anxiety, fear, and panic represent emotions with two opposite effects: on the one hand they serve to protect us from (potential) danger, but on the other hand when dysregulated they also bear the risk of evolving into mental disorders. One of these disorders is panic disorder (PD) with its core feature panic attacks (PAs). PAs are a unique and rare example of a psychopathological phenomenon that can be reliably provoked in the laboratory. One of the most established techniques is an inhalation with an increased concentration of carbon dioxide $\left(\mathrm{CO}_{2}\right)$. The present thesis aimed to further investigate the link between differential $\mathrm{CO}_{2}$ sensitivity and PAs using a translational, cross-species approach that is unique in psychiatric research to date. We present a series of studies, in which PD patients, healthy individuals, and mice were exposed to $\mathrm{CO}_{2}$. In addition to the use of the same experimental stimulus, we aimed to use comparable outcome measurements. In doing so, various genetic and molecular approaches were applied.

Chapter 2 presents a critical literature review on the relationship between the brain acidbase homeostasis and PAs. Three experimental panic-inducing techniques that acutely disturb the acid-base homeostasis are described, with a particular focus on $\mathrm{CO}_{2}$ inhalation. Methodological approaches to expose humans and rodents to $\mathrm{CO}_{2}$, and the effects on the cardio-respiratory as well as the endocrine system in humans are summarized. Human and animal data are integrated to discuss the relationship between a change in $\mathrm{pH}$ and adaptive responses. Accordingly, it can be concluded that $\mathrm{CO}_{2}$ inhalation is an easy, noninvasive, reliable, and well-validated human experimental model, while rodent studies using $\mathrm{CO}_{2}$ exposure in the direct framework of panic are still relatively scarce. Yet again, over the past few years, important progress has been made regarding the molecular mechanisms underlying chemosensitivity. There is a growing body of evidence that the brainstem is a key structure in sensing acidosis and that the 5 -HT system plays an important role in this respect. However, it is not yet fully known which molecular players serve as chemoreceptors within 5-HT cells. To further increase the insights into the mechanisms underlying chemosensitivity and the pathophysiology of PD, we suggest that combining human and animal research would be most powerful. However, currently, the translation of knowledge between the two domains is often hampered by differences in outcome measurements. Human panic studies classically rely on self-reports about experienced fear and panic symptoms, while animal studies focus on the behavioral performance. To maximize comparability, additional outcome parameters that can be obtained in both species should be included. For instance, monitoring the cardio-respiratory response to $\mathrm{CO}_{2}$ exposure may be a useful addition to the presently used outcomes. We concluded that using the same experimental stimulus and obtaining the same outcome measurements in humans and mice will significantly improve the translation of knowledge between the two 
domains and the application of it. Eventually, such a translational approach will contribute to the development of new therapeutic options for PD.

The study presented in Chapter $\mathbf{3}$ sought to examine the emotional and cardiovascular response to $\mathrm{CO}_{2}$-induced fear. Previous attempts to include physiological measures in human panic studies yielded inconclusive results, mainly due to methodological shortcomings. We addressed these shortcomings and used a novel customized computerized system to continuously record the cardiovascular effects induced by four $\mathrm{CO}_{2}$ inhalations, with concentrations ranging from $0 \%$ to $35 \%$, in 120 healthy individuals. Results showed that self-reported fear, discomfort, and panic symptoms increased dose-dependently. Various outcomes such as the peak of the systolic and diastolic blood pressure increased with rising $\mathrm{CO}_{2}$ concentration, but particularly the diastolic blood pressure appeared to reflect the dose-dependent emotional response. Therefore, it is concluded that the diastolic blood pressure is the most sensitive parameter and may represent a putative biomarker to assess the reactivity to $\mathrm{CO}_{2}$.

It is well known that PD patients are more sensitive to a $\mathrm{CO}_{2}$ inhalation than healthy individuals. Two decades ago, it was proposed that every individual is equipped with an evolutionarily evolved suffocation alarm system that senses metabolic threats from bodily origin, signals vital danger, and leads to a profound emotional and behavioral response. PAs are proposed to be caused by a dysfunctional suffocation system that erroneously triggers an alarm without the presence of a real vital threat. The neurobiological basis for this system is not yet fully understood. Animal research suggests a role of the brainstem in the response to hypercapnia. To investigate whether the brainstem is activated by $\mathrm{CO}_{2}$ Chapter 4 presents a functional magnetic imaging (fMRI) study with 15 PD patients, 12 healthy controls, and 15 experienced divers, representing three groups with declining $\mathrm{CO}_{2}$ sensitivity. The reactivity was assessed to inhaling $7 \% \mathrm{CO}_{2}$ in blocks of $2 \mathrm{~min}$. As expected, self-reported fear scores were higher in PD patients than in healthy controls and divers. In addition, inhaling $\mathrm{CO}_{2}$ resulted in brainstem activation, an effect that was more pronounced in PD patients compared to controls and divers. These results provide further support for an increased sensitivity to $\mathrm{CO}_{2}$ in PD patients, possibly caused by an increased neural sensitivity at the brainstem level.

Rodent research demonstrated that the $\mathrm{pH}$-sensitive ion channel ASIC1a plays an important role in sensing changes in $\mathrm{pH}$ and triggering the fear-related behavioral response to $\mathrm{CO}_{2}$ exposure. Based on this work, two variants in the human homologue gene amiloridesensitive cation channel 2 ( $A C C N 2)$ were shown to be associated with PD and amygdala 
reactivity to the presentation of emotional faces. The proposed mechanism was a lowered threshold for sensing acidosis, leading to a heightened sensitivity. However, that study did not include any direct link to a change in $\mathrm{pH}$. Therefore, in Chapter $\mathbf{5}$, we investigated the effects of those two variants in the ACCN2 gene on the response to a $35 \% \mathrm{CO}_{2}$ challenge in 107 healthy individuals and 183 PD patients. The reactivity to $\mathrm{CO}_{2}$ was measured using selfreports about fear/discomfort and panic symptoms, and, in healthy volunteers, additional continuous blood pressure measurements. Results showed that patients homozygous for the T-allele reported more fear than C-allele carriers. Healthy individuals homozygous for the T-allele had a higher area under the curve of the systolic and diastolic blood pressure as well as a higher peak of the diastolic blood pressure after the $\mathrm{CO}_{2}$ inhalation in comparison with C-allele carriers. At first sight, these results differ from the ones reported in the previous study that found an association between the $\mathrm{C}$-allele and the diagnosis of $P D$ as well as amygdala volume and function. However, our study had a different focus, namely the relationship between ACCN2 and experimentally induced fear/panic using $\mathrm{CO}_{2}$ and this so-called flip-flop phenomenon is not uncommon in association studies. In conclusion, we provided the first evidence that variants in the ACCN2 gene are associated with differential sensitivity to $\mathrm{CO}_{2}$ in PD patients and in healthy volunteers. Therefore, ACCN2 is a promising candidate as potential target in the treatment of PD.

As the potential to study molecular mechanisms in humans is limited, Chapter 6 expands on the studies in humans by exposing mice to $\mathrm{CO}_{2}$. As a follow-up on a previous human study within our lab, showing that the reactivity to $\mathrm{CO}_{2}$ is moderated by the 5-HTTLPR polymorphisms, male wildtype, hetero-, and homozygous $5-\mathrm{Htt}$ knock-out mice were exposed to either $10 \% \mathrm{CO}_{2}$ or normal air using an innovative, fully controlled, and noninvasive $\mathrm{CO}_{2}$ chamber. The response was evaluated in terms of the behavioral performance in anxiety- and fear-related tasks. $\mathrm{CO}_{2}$ appeared to be a robust fear-stimulus, as indicated by a decrease in distance moved in the open field test and the two-chamber test, in which one chamber was filled with $\mathrm{CO}_{2}$ and one with air, compared to air exposure. In addition, the number of crossings between the two chambers was lower than when exposed to air in the latter test. Between genotypes, homozygous knock-out mice showed more anxiety-related behavior when exposed to air, but performed equally or even relatively better in presence of $\mathrm{CO}_{2}$, indicative of an adaptive acid-base homeostasis. Furthermore, evaluating the freezing response showed the same pattern with regard to the effects of $\mathrm{CO}_{2}$ and between-genotype differences. Subsequently, the cardio-respiratory response was assessed in response to air and $\mathrm{CO}_{2}$ in WT and heterozygous 5- $\mathrm{Htt}$ knock-out mice, showing a strong activation of the respiratory system and a decreased heart rate to $\mathrm{CO}_{2}$ exposure. No genotype effect was found. 
Currently, immunohistochemical stainings and quantitative real-time polymerase chain reaction (qRT-PCR) analyses are ongoing to examine levels of ASIC1a in various brain regions including brainstem nuclei such as the dorsal raphe. Levels will be linked to behavioral performance. As ASIC1a was shown to be an essential player in both conditioned and unconditioned fear-related behavior, based on the observed under $\mathrm{CO}_{2}$ exposure a higher expression may be expected in wildtype mice compared to homozygous knock-out mice. In addition, it is hypothesized that ASIC1a is located within 5-HT cells in the brainstem, thereby providing a molecule substrate for $5-\mathrm{HT}$ cells to sense changes in $\mathrm{pH}$.

In Chapter 7, data obtained from PD patients, healthy individuals, and mice are combined to judge the acceptability of euthanizing lab animals using $\mathrm{CO}_{2}$. Each year, millions of lab animals are sacrificed for science using $\mathrm{CO}_{2}$. It remains unclear how aversive animals find being exposed to $\mathrm{CO}_{2}$. As $\mathrm{CO}_{2}$ is a well-validated panic-provoking stimulus in humans, we question the "humane" nature of $\mathrm{CO}_{2}$ euthanasia in animals. We simultaneously examined, for the first time, $\mathrm{CO}_{2}$ exposure and behavioral as well as the same cardiorespiratory outcomes in 20 mice, 136 healthy volunteers, and 98 PD patients, allowing a comparison across species. Mice showed robust fear-related behavior in all employed tests and a physiological response similar to humans, who reported intense fear and panic symptoms. This study thus strongly suggests that euthanasia in animals using $\mathrm{CO}_{2}$ is highly stressful rather than a "humane" method and hence should be abolished.

In Chapter 8, the studies included in this thesis are discussed and human and animal work is integrated to provide clinical implications and directions for future research. The stimulation of translational approaches as in this case is of particular importance to enable a useful combination of human and animal research, which eventually will improve current therapeutic options. Despite that the focus of the present thesis is on panic, the translational, cross-species approach of this thesis is likely to be relevant for many other research areas. 
A $\left.10^{3}\right)^{3}$ 


\section{Summary}

Samenvatting

Valorization

Acknowledgments

Curriculum vitae

Publication list 
Angst, vrees en paniek zijn emoties met twee tegenovergestelde effecten: aan de ene kant beschermen ze ons voor (mogelijk) gevaar, aan de andere kant, wanneer ze ontregeld zijn, vormen ze ook een risico voor psychische stoornissen. Eén van deze aandoeningen is een paniekstoornis met als kenmerkend symptoom paniekaanvallen (PA). PA zijn een uniek en zeldzaam voorbeeld van een psychopathologisch verschijnsel dat betrouwbaar kan worden opgewekt in het laboratorium. Eén van de meest gevalideerde technieken is een inhalatie met lucht die beduidend meer $\mathrm{CO}_{2}$ bevat dan normale lucht. Dit proefschrift is gericht op het verband tussen de gevoeligheid voor $\mathrm{CO}_{2}$ en PA, waarbij we gebruik maken van een zogenaamd translationeel model, dat tot op heden uniek is in psychiatrisch onderzoek. Wij presenteren een reeks van studies, waarin patiënten met een paniekstoornis, gezonde vrijwilligers en muizen werden blootgesteld aan $\mathrm{CO}_{2}$. Naast het gebruik van dezelfde experimentele stimulus, beoogden we vergelijkbare uitkomstmaten te gebruiken. Daarbij werden verschillende genetische en moleculaire benaderingen toegepast.

Hoofdstuk 2 is een kritisch literatuuroverzicht waarin we de relatie tussen de zuur-base $(\mathrm{pH})$ balans in de hersenen en PA bespreken. De focus is op $\mathrm{CO}_{2}$ inhalaties. De manier waarop mensen en knaagdieren aan $\mathrm{CO}_{2}$ worden blootgesteld, en de effecten op het cardio-respiratoire en endocriene systeem worden samengevat. Onderzoeken in mensen en knaagdieren worden geïntegreerd om de relatie tussen een $\mathrm{pH}$ verandering en adaptieve responsen te bespreken. Op basis hiervan concluderen wij dat een $\mathrm{CO}_{2}$ inhalatie een eenvoudig, niet-invasief, betrouwbaar en goed gevalideerd experimenteel model in mensen is. In knaagdieren daarentegen wordt blootstelling aan $\mathrm{CO}_{2}$ nog niet vaak toegepast in het kader van paniekonderzoek. Desondanks werden in de afgelopen jaren belangrijke inzichten verkregen in de moleculaire mechanismen die een rol spelen bij het detecteren van en reageren op $\mathrm{pH}$ veranderingen ("chemosensitiviteit"). Uit onderzoek blijkt dat hierbij de hersenstam en het serotonerge $(5-\mathrm{HT})$ systeem een belangrijke rol spelen. Het is echter nog niet volledig bekend welke moleculen in 5-HT cellen als receptoren dienen om een $\mathrm{pH}$ verandering te detecteren. Om de biologische basis van chemosensitiviteit en paniekstoornis nader te onderzoeken stellen wij voor studies in mensen en in knaagdieren te combineren. Tegenwoordig is de vertaling van kennis tussen de twee groepen steeds moeilijk omdat de uitkomstmaten verschillen. In mensen worden meestal rapportages van de patiënt of proefpersoon gebruikt over hoe veel vrees en panieksymptomen werden ervaren, terwijl in dierstudies het gedrag wordt bekeken. Om de vergelijkbaarheid te verbeteren moeten uitkomstmaten worden gebruikt die in mensen zowel als in muizen kunnen worden gemeten, bijvoorbeeld de respons van het cardio-respiratoire systeem. Wij concludeerden dat het gebruik van dezelfde experimentele stimulus en dezelfde uitkomstmaten de vertaling van kennis tussen mens en dier sterk kan verbeteren. Een 
dergelijke translationele aanpak zal uiteindelijk bijdragen aan de ontwikkeling van nieuwe therapeutische mogelijkheden voor paniekstoornis.

In de studie beschreven in Hoofdstuk 3 onderzochten wij de emotionele en cardiovasculaire reactie op een $\mathrm{CO}_{2}$ inhalatie in gezonde vrijwilligers. Studies die in het verleden poogden de fysiologische respons op $\mathrm{CO}_{2}$ te bepalen leverden geen duidelijk resultaat, voornamelijk als gevolg van methodologische tekortkomingen. Daarom hebben wij een nieuw systeem gebruikt om de effecten van vier $\mathrm{CO}_{2}$ inhalaties, tussen $0 \%$ tot $35 \% \mathrm{CO}_{2}$, op het hart- en vaatstelsel in 120 gezonde vrijwilligers te bestuderen. De resultaten toonden aan dat het gevoel van vrees, ongemak en panieksymptomen heviger was naarmate de $\mathrm{CO}_{2}$ concentratie toenam. De piek van de systolische en diastolische bloeddruk nam ook toe met toenemende $\mathrm{CO}_{2}$-concentratie, maar vooral de diastolische bloeddruk bleek de dosisafhankelijke emotionele reactie te weerspiegelen. Derhalve werd geconcludeerd dat de diastolische bloeddruk de meest gevoelige uitkomstmaat is en mogelijk een biomarker vormt voor de reactiviteit op een $\mathrm{CO}_{2}$ inhalatie.

Het is bekend dat patiënten met een paniekstoornis sterker reageren op een $\mathrm{CO}_{2}$ inhalatie dan gezonde mensen. Reeds twee decennia geleden werd voorgesteld dat elk individu is voorzien van een ingebouwd alarmsysteem dat als functie heeft het individu te waarschuwen voor verstikken. Het detecteert bedreigingen vanuit het lichaam (bijvoorbeeld afkomstig van de stofwisseling) en is verantwoordelijk voor het tot stand komen van een emotionele en gedragsmatige reactie. De hypothese is dat PA worden veroorzaakt door een alarmsysteem dat ontregeld is en geactiveerd wordt terwijl er geen sprake is van een reëel gevaar. De neurobiologische basis voor dit systeem is nog niet volledig bekend. Onderzoek in knaagdieren duidt op een rol van de hersenstam in de respons op $\mathrm{pH}$ veranderingen. Om te onderzoeken of de hersenstam bij de mens wordt geactiveerd door het inademen van $\mathrm{CO}_{2}$ presenteren wij in Hoofdstuk 4 een functionele magnetische beeldvorming ( $\mathrm{fMRI}$ ) studie met 15 paniekstoornis patiënten, 12 gezonde vrijwilligers en 15 ervaren duikers, drie groepen met dalende $\mathrm{CO}_{2}$-gevoeligheid. ledereen ademde $7 \% \mathrm{CO}_{2}$ voor $2 \mathrm{~min}$. Zoals verwacht rapporteerden paniekstoornis patiënten meer vrees dan gezonde controles en duikers. Inademen van $\mathrm{CO}_{2}$ activeerde de hersenstam, een effect dat sterker was in paniekstoornis patiënten dan in gezonde controles en duikers. Deze resultaten ondersteunen de hypothese dat de hevigere reactie van patiënten met paniekstoornis op $\mathrm{CO}_{2}$, wat mogelijk veroorzaakt wordt door een verhoogde gevoeligheid in de hersenstam. 
Onderzoek in proefdieren heeft aangetoond dat het $\mathrm{pH}$-gevoelige ionkanaal ASIC1a een belangrijke rol speelt bij het detecteren van $\mathrm{pH}$ veranderingen en het uitlokken van een gedragsmatige vreesrespons gedurende blootstelling aan $\mathrm{CO}_{2}$. Op basis van die studie werden twee varianten in het menselijke homoloog gen "amiloride-sensitive cation channel 2" (ACCN2) geassocieerd met paniekstoornis en met amygdala reactiviteit op de visuele presentatie van emotionele gezichten. Het voorgestelde mechanisme is een verlaagde drempel voor de detectie van een verlaagde $\mathrm{pH}$, wat dus leidt tot een verhoogde gevoeligheid. Waarvoor was er echter voorlopig geen experimenteel bewijs. Daarom onderzochten wij in Hoofdstuk 5 de effecten van die twee varianten in het ACCN2 gen op de respons op een $35 \% \mathrm{CO}_{2}$ inhalatie in 107 gezonden en 183 paniekstoornis patiënten. De reactiviteit op $\mathrm{CO}_{2}$ werd gemeten met behulp van zelf-rapportages over het gevoel van vrees/ongemak en panieksymptomen, en bij gezonden additioneel met bloeddruk- en hartslagmetingen. De resultaten toonden aan dat patiënten homozygoot voor het T-allel meer angst rapporteerden dan mensen met één of twee C-allelen. Gezonde vrijwilligers homozygoot voor het T-allel hadden een hogere "area under the curve" van de systolische en diastolische bloeddruk en een hogere piek van de diastolische bloeddruk na de $\mathrm{CO}_{2}$ inhalatie in vergelijking met gezonden met één of twee $\mathrm{C}$-allelen. Het verschil tussen de resultaten van onze studie en het vorige onderzoek, dat een verband tussen het $\mathrm{C}$-allel en de diagnose van paniekstoornis en amygdala functie had gevonden, komt mogelijk door een verschillende focus. Wij hebben niet paniekstoornis als geheel bekeken maar de respons op een fenotype, namelijk experimenteel geïnduceerde vrees/paniek met behulp van een $\mathrm{CO}_{2}$ inhalatie. Verder is dit omgekeerde effect een bekend fenomeen in genetische associatie studies en wordt "flip-flop fenomeen" genoemd. Samengevat, wij leveren het eerste bewijs dat de varianten in de ACCN2 gen geassocieerd zijn met een verschillende gevoeligheid op $\mathrm{CO}_{2}$, in paniekstoornis patiënten en in gezonde vrijwilligers. ACCN2 lijkt dus een veelbelovende kandidaat voor mogelijke toekomstige farmacologische interventies in het kader van behandeling van paniekstoornis.

Omdat moleculaire mechanismen niet helemaal in mensen kunnen worden bestudeerd, wordt in Hoofdstuk 6 een vervolgstudie in muizen beschreven. Wij hebben eerder in ons lab aangetoond dat een functionele variant in het "serotonine transporter gen" (5-HTTLPR) de mate van ongemak en panieksymptomen, opgewekt door een $\mathrm{CO}_{2}$ inhalatie, beïnvloedt in mensen. Als vervolg werden mannelijke "wildtype", hetero- en homozygote 5- $\mathrm{Htt}$ "knockout" muizen blootgesteld aan ofwel $10 \% \mathrm{CO}_{2}$ of normale lucht. Hierbij werd gebruikt gemaakt van een innovatieve, volledig gecontroleerde, en niet-invasieve box. De respons werd geëvalueerd op basis van het gedrag in angst- en vrees-gerelateerde taken. $\mathrm{CO}_{2}$ bleek een sterke vrees stimulus te zijn, wat duidelijk werd door een afname in de gelopen 
afstand in de "open field test" en de "two-chamber test", waarbij één kamer was gevuld met $\mathrm{CO}_{2}$ en één met lucht, vergeleken met blootstelling aan lucht. Bovendien was het aantal verplaatsingen heen en weer tussen de twee kamers lager dan onder blootstelling aan lucht in de laatste test. Uit een vergelijking tussen genotypen bleek dat homozygote "knock-out" muizen meer angstgedrag vertoonden onder blootstelling aan lucht, terwijl zij relatief beter presteerden in aanwezigheid van $\mathrm{CO}_{2}$. Hetzelfde patroon was te zien met betrekking tot de "freezing" respons. Vervolgens werd de cardio-respiratoire respons gemeten in "wildtype" en heterozygote 5 - $\mathrm{Htt}$ "knock-out" muizen. Hieruit bleek dat $\mathrm{CO}_{2}$ het ademhalingsstelsel sterk activeerde, terwijl hartslag verminderd was ten opzichte van de effecten gedurende blootstelling aan lucht. Geen genotype effect werd gevonden.

Momenteel vinden immunohistochemische kleuringen en "quantitative real-time polymerase-chain reactions" (qRT-PCR) analyses plaats om het niveau van ASIC1a in verschillende hersengebieden (waaronder hersenstamkernen) te bepalen. Expressie levels worden gekoppeld aan het geobserveerd gedrag onder lucht en $\mathrm{CO}_{2}$ blootstelling. Vermits ASIC1a een essentiële rol in zowel geconditioneerde en ongeconditioneerde vrees heeft en "wildtype" muizen relatief gezien meer vreesgedrag vertoonden, verwachten wij dat de expressie hoger is in "wildtype" muizen vergeleken met homozygote "knock-out" muizen. Bovendien is de hypothese dat ASIC1a in 5-HT cellen in de hersenstam zit en het molecuul is dat een verlaging in $\mathrm{pH}$ detecteert.

In Hoofdstuk 7 worden de data verkregen in paniekstoornis patiënten, gezonde vrijwilligers, en muizen gecombineerd om de aanvaardbaarheid van $\mathrm{CO}_{2}$ euthanasie in lab dieren te beoordelen. Elk jaar worden miljoenen proefdieren opgeofferd voor de wetenschap met behulp van $\mathrm{CO}_{2}$. Het blijft onduidelijk hoe aversief de blootstelling aan $\mathrm{CO}_{2}$ is voor deze dieren. $\mathrm{CO}_{2}$ is een goed gevalideerde stimulus om paniek uit te lokken in mensen. Daarom ondervragen wij de "humane" aard van $\mathrm{CO}_{2}$ euthanasie bij dieren. Voor het eerst hebben wij gelijktijdig onderzocht wat de effecten van blootstelling aan $\mathrm{CO}_{2}$ op gedrag en dezelfde cardio-respiratoire uitkomstmaten zijn in 20 muizen, 136 gezonde vrijwilligers en 98 paniekstoornis patiënten. Daardoor kan een vergelijking tussen mens en dier plaatsvinden. Muizen hadden een sterke gedragsmatige vrees respons in alle taken en een fysiologische reactie vergelijkbaar met die van mensen, die een sterk gevoel van vrees en panieksymptomen rapporteren. Uit deze studie blijkt dat euthanasie bij dieren met behulp van $\mathrm{CO}_{2}$ waarschijnlijk zeer stressvol is, in plaats van een "humane“ wijze, en wellicht beter moet worden afgeschaft.

In Hoofdstuk 8 worden de studies uit dit proefschrift besproken en geïntegreerd om klinische implicaties en mogelijk vervolgonderzoek te bespreken. De stimulatie van 
translationele modellen (vergelijkbaar onderzoek in mensen en proefdieren) is belangrijk om op lange termijn de therapeutische opties op lange termijn te verbeteren. Hoewel de focus van dit proefschrift op paniekstoornis ligt, is het waarschijnlijk dat de translationele aanpak ook relevant is voor vele andere onderzoeksgebieden. 
Samenvatting 
A $\left.10^{3}\right)^{3}$ 


\section{Summary}

\section{Samenvatting}

\section{Valorization}

Acknowledgments

Curriculum vitae

Publication list 


\section{Individual and socio-economic relevance}

Panic disorder (PD) is a prevalent condition that affects about $4 \%$ of the general adult population (Weissman et al., 1997). The recurrent, unexpected nature of its core feature, panic attacks (PAs), is highly frightening and stressful for patients. Before PD is being diagnosed, patients typically associate the symptoms (e.g., shortness of breath, choking, dizziness, chest pain, palpitations) with heart attacks and seek help in emergency departments (Fleet et al., 1996), without receiving a solid explanation for their problem. Over time, patients often develop concerns about future attacks and eventually avoid places and situations, in which previous attacks occurred, in which it may be difficult to get help (e.g., being outside alone) or in which a PA might be embarrassing (e.g., in a restaurant). Consequently, patients are often confined to their homes, unable to participate in social activities or to go to work, leading to financial problems for the patient as well as the employer and a marked decrease in quality of life (Davidoff et al., 2012; Mendlowicz and Stein, 2000). In addition, available treatments are associated with many side effects (Batelaan et al., 2012) and relapse rates are high (Craske and Zucker, 2001). Therefore, the costs associated with an individual with PD are substantial in terms of medical care and decreased productivity such as missed working days. At the population level, the annual societal costs of $€ 226$ million equal the range of the combined costs of general anxiety disorder, social phobia, and simple phobia (Batelaan et al., 2007).

\section{Refining the diagnosis of PD}

As the symptoms of a PA such as chest pain and breathing difficulties closely resemble those of a heart attack or acute asthma, patients commonly seek help at emergency or heart departments (Fleet et al., 1996). Often costly tests such as angiography are performed (Zaubler and Katon, 1998), however without finding a medical explanation. In fact, up to $25 \%$ of patients with chest pain and visiting hospital emergency departments have been shown to fulfil the diagnostic criteria of PD (Huffman and Pollack, 2003). This observation emphasizes the need for a better and fast diagnosis of PD, which to date is based on selfreports during clinical interviews. It is evident that the presence and intensity of emotions (e.g., fear of dying) and some symptoms such as dizziness experienced during a PA can only be evaluated by the individual itself. However, PAs are also accompanied by marked physiological symptoms. Therefore, in the first study of this thesis, we went beyond the traditional approaches and included physiological measurements to complement selfreports. We showed that in healthy subjects particularly the diastolic blood pressure was a sensitive parameter that reflected the degree of self-reported emotions and panic symptoms, and might therefore represent a suitable biomarker. The next conceptual steps are to confirm the potential of the diastolic blood pressure as biomarker in PD patients 
and, when validated, incorporation in the daily clinic. When no heart- or asthma-related explanation can be found, patients could take a vital capacity breath of $\mathrm{CO}_{2}$, whilst blood pressure is measured. The combination of a high emotional response and assessing the diastolic blood pressure could support the clinical diagnosis. The incorporation in the clinic is relatively easy in terms of methodology: blood pressure can be measured using a non-disturbing finger cuff connected to a cardiovascular monitor. Such devices are commercially available and costs are relatively low. To disseminate this application, we published the study addressing the inclusion of physiological measurements to complement self-reports in an international peer-reviewed journal and present the results in lectures and at (inter)national conferences for scientists. In addition, we work together with national health centers to inform clinicians about the potential use. In the mid-term, including the diastolic blood pressure might be a highly value addition for diagnosing PD and providing the patients the right medical explanation and treatment.

\section{Improving current pharmacological treatments in PD and other disorders}

In PD, the two main treatment options are pharmacotherapy and cognitive behavioral therapy. Despite that the current pharmacological drugs are effective in general, many patients remain symptomatic or do not respond to the first-line choice of treatment (Baldwin et al., 2014). In addition, the many side effects such as sexual dysfunction, weight gain, sleeplessness, and nausea (Cascade et al., 2009) often lead to a low acceptability of the drug by the patient. After drug discontinuation relapse rates are high, with up to $70 \%$ (Craske and Zucker, 2001). Therefore, to improve the current treatment options and to find new neurobiological targets, it is important to make progress in gaining more insights into the molecular mechanisms underlying PAs. Human experimental models are limited in their potential to investigate molecular mechanisms. However, in contrast to the longstanding use of panic-provoking agents such as $\mathrm{CO}_{2}$ inhalation in humans, relatively little research has been done in rodents in the direct framework of PD. In addition, human panic provocation studies rely on self-reports, while in rodent studies the main outcome parameter is the animal's behavior, two outcomes that are difficult to compare. This divergence between human and animal models hampers the translation of the results and is one of the reasons why drugs that proved to be promising in animals frequently fail in the clinical phase.

To optimally compare the aspects of human and animal research, it is important to perform experiments and use outcome measures that are as similar as possible. Although some studies already applied $\mathrm{CO}_{2}$ exposure to rodents as experimental stimulus, the field would greatly benefit from adding outcome variables that can be obtained in both research domains, for instance cardio-respiratory parameters, as we did in the present 
thesis. When using the same stimulus and outcome measures in both species, the likelihood of obtaining an effective drug in humans based on a promising compound in the rodent model strongly increases. In addition, given the spectrum of $\mathrm{CO}_{2}$-reactivity and to reduce the burden for patients with PD, the potency of new therapeutics can be evaluated in healthy subjects and then followed by first-degree relatives of PD patients, who show an intermediate vulnerability to $\mathrm{CO}_{2}$ when compared to healthy participants and PD patients. Eventually promising drugs can be tested in patients, in collaboration with pharmaceutical companies. Given that the pathophysiology of PD is not yet fully understood, more research is needed and potential molecular targets have to be studied in detail in order to have value for patients in the future. In the present thesis, we further put forward $\mathrm{pH}$-sensitive ion channels as promising candidates. Future studies could elucidate the effects of, for instance, drugs selectively inhibiting those channels. Starting in rodents, with making use of a combined behavioral-physiological approach established in the course of this PhD project, and extending to humans might lead to better treatment strategies in the mid-term.

Despite that the focus in the present thesis is on PD, going beyond the commonly used methods is likely to be highly beneficial for all research disciplines, in which data from rodent research are applied in humans and in which drug development is involved. More effective drugs and with less side effects, and decreasing the time to test them is of pivotal importance for patients to return to a normal daily life, which also has a large impact on society and economics.

\section{$\mathrm{CO}_{2}$ inhalation in exposure therapy in PD}

A further application of the results of the present thesis may be in light of exposure therapy in PD, a form of cognitive behavioral therapy. Exposure therapy is based on the repeated exposure to the frightened stimulus until patients have learned that there are no lifethreatening consequences, associated with a reduction in discomfort to a tolerable level that does not hamper daily life anymore. In case of PAs, the arousing bodily sensations are provoked by, for instance, intentional hyperventilation (Meuret et al., 2005), spinning in a chair, and running on the spot (Ito et al., 2001). However, only a fraction of the symptoms of a full-blown PA are provoked using these approaches (Antony et al., 2006; Lee et al., 2006). In contrast, $\mathrm{CO}_{2}$ inhalation triggers the fear and bodily response resembling naturally occurring PAs. The response to a few $\mathrm{CO}_{2}$ inhalations is relatively consistent (Coryell and Arndt, 1999; Verburg et al., 1998), but repeated exposures were shown to cause desensitization to some extent (Beck et al., 1997; van den Hout et al., 1987). Therefore, $35 \% \mathrm{CO}_{2}$ is a promising tool for exposure therapy in patients with PD. It is commonly used in the daily practice at the Academic Anxiety Hospital, Maastricht, and 
receives modest interest from other centers as well. To become an addition or alternative to pharmacological treatment that is frequently accompanied by considerable side effects (Cascade et al., 2009), it has to be investigated how many inhalations are required to obtain relevant effects in PD patients. Patients can be recruited in the clinical setting when seeking treatment. By systematically assessing the required number and frequency of $\mathrm{CO}_{2}$ exposure sessions, application guidelines can be provided to clinicians in a few years. Clinicians can be reached via national health centers and large conference such as the annual meeting of the American Psychiatric Association (APA) and the European College of Neuropsychopharmacology (ECNP).

To date, it is largely unknown what the biological basis of exposure therapy is, as is the case regarding the observed desensitization to repeated $\mathrm{CO}_{2}$ exposure. To further elucidate the involved mechanisms, monitoring the physiological response in terms of respiratory and cardiovascular parameters, as we did in the studies presented in this thesis, represents an easy to implement and relatively inexpensive starting point. Thereby, we could obtain insights in whether the effects of $\mathrm{CO}_{2}$ exposure therapy are associated with personal perception or also with physiological alterations. The relevance in this regard is twofold: First, to potentially offer an add-on therapy if changes on the physiological level are essential for relevant effects or exert an additional beneficial effect. This could be in form of, for instance, relaxation or breathing training in patients. Second, to possibly identify patients at risk for relapse in order to intervene in time by, for instance, scheduling earlier appointments with the clinician. Furthermore, in the future, the effects of $\mathrm{CO}_{2}$ exposure therapy might also be boosted by augmentation with pharmacological drugs. To test the therapeutic potential of drugs, a combination of repeated $\mathrm{CO}_{2}$ exposure and assessing the behavioral as well as physiological response could be tested in rodents. In addition, animal research might also reveal new neurobiological targets. Overall, there is a high potential of $\mathrm{CO}_{2}$ inhalations in the framework of treatment options for PD, however much research has still to be done before clinical applications can be expected.

\section{Decreasing the stigmatization in mental disorders}

Despite that mental disorders are highly prevalent, the field of psychiatry is still perceived as having a negative connotation. Patients have a double burden, suffering from severe symptoms of the illness and experiencing stigmatizing attitudes from society. Patients are often negatively judged by other people as being dangerous (Whalen, 2006) or crazy. These beliefs lead to discrimination, avoidance, and reluctance to provide support and help. It is apparent that this additionally affects the patients' life in a negative manner, on an emotional level as well as in terms of daily life activities and willingness to seek treatment at psychiatry wards (Prasko et al., 2011; Whalen, 2006). Frequently, patients 
start to internalize believes of their environment, stigmatize themselves, and loose selfesteem and confidence into the future (Corrigan and Watson, 2002).

In contrast to the belief that mental disorders are due to a weak character (Corrigan and Watson, 2002), there is a large body of scientific evidence that mental disorders have a biological origin in form of vulnerability factors that interact with environmental factors. The present thesis contributes to extending our understanding of PD by showing that, for instance, genetic variants are associated with a heightened reactivity in an experimental model of PAs. By raising awareness for a biological basis of mental disorders, de-stigmatization could be achieved. Target groups include the community residents, patients, relatives, and health insurances that often reimburse treatment of psychiatric disorders to a smaller extent than of physical illnesses. Performing educational campaigns, in collaboration with health care providers, patient organizations, and the media, could provide information to a broad audience and clarify misunderstandings based on scientific evidence. In addition, it has been shown that interpersonal contact with patients is associated with less stigmatization (Corrigan and Watson, 2002). Therefore, it is important to actively involve patients in activities, for instance in discussion meetings, in which they tell about their personal experiences. Moreover, education should start early, for instance at school, as it was shown that young adults with an age of 16-19 years are more likely to have negative attitudes towards mental disorders than older people (Crisp et al., 2005). This could significantly increase the patients' quality of life and give them a more positive future.

\section{Conclusion}

The present thesis went beyond the commonly used methods by using a unique approach in psychiatric research to date, thereby providing promising opportunities for future thriving applications in the framework of PD as well as mental disorders in general. Multi-disciplinary scientific collaborations and interacting with various stakeholders may accelerate the endeavors of science to positively impact on patients' lives, which, in turn, could reduce the socioeconomic costs related to mental disorders. Money saved could then be spent on research again to further push forward discoveries in the same or other disciplines, to disseminate applications, and to decrease stigmatization by doing campaigns. Thereby, we may be able to make a significant step towards bringing together science, society, and clinic, and to perform research that benefits the patient in the shortterm. 


\section{References}

Antony, M.M., Ledley, D.R., Liss, A., Swinson, R.P., 2006. Responses to symptom induction exercises in panic disorder. Behav. Res. Ther. 44, 85-98.

Baldwin, D.S., Anderson, I.M., Nutt, D.J., Allgulander, C., Bandelow, B., den Boer, J.A., Christmas, D.M., Davies, S., Fineberg, N., Lidbetter, N., Malizia, A., McCrone, P., Nabarro, D., O’Neill, C., Scott, J., van der Wee, N., Wittchen, H.U., 2014. Evidence-based pharmacological treatment of anxiety disorders, post-traumatic stress disorder and obsessive-compulsive disorder: a revision of the 2005 guidelines from the British Association for Psychopharmacology. J. Psychopharm. 28, 403-439.

Batelaan, N., Smit, F., de Graaf, R., van Balkom, A., Vollebergh, W., Beekman, A., 2007. Economic costs of fullblown and subthreshold panic disorder. J. Affect. Disord. 104, 127-136.

Batelaan, N.M., Van Balkom, A.J., Stein, D.J., 2012. Evidence-based pharmacotherapy of panic disorder: an update. The international journal of neuropsychopharmacology/official scientific journal of the Collegium Internationale Neuropsychopharmacologicum 15, 403-415.

Beck, J.G., Shipherd, J.C., Zebb, B.J., 1997. How does interoceptive exposure for panic disorder work? An uncontrolled case study. J. Anxiety Disord. 11, 541-556.

Cascade, E., Kalali, A.H., Kennedy, S.H., 2009. Real-World Data on SSRI Antidepressant Side Effects. Psychiatry $6,16-18$

Corrigan, P.W., Watson, A.C., 2002. Understanding the impact of stigma on people with mental illness. World Psychiatry 1, 16-20.

Coryell, W., Arndt, S., 1999. The 35\% CO2 inhalation procedure: test-retest reliability. Biol. Psychiatry 45, 923-927.

Craske, M.G., Zucker, B.G., 2001. Consideration of the APA practice guideline for the treatment of patients with panic disorder: strengths and limitations for behavior therapy. Behav. Ther. 32, 259-281.

Crisp, A., Gelder, M., Goddard, E., Meltzer, H., 2005. Stigmatization of people with mental illnesses: a follow-up study within the Changing Minds campaign of the Royal College of Psychiatrists. World Psychiatry 4, 106113.

Davidoff, J., Christensen, S., Khalili, D.N., Nguyen, J., IsHak, W.W., 2012. Quality of life in panic disorder: looking beyond symptom remission. Quality of life research: an international journal of quality of life aspects of treatment, care and rehabilitation 21, 945-959.

Fleet, R.P., Dupuis, G., Marchand, A., Burelle, D., Arsenault, A., Beitman, B.D., 1996. Panic disorder in emergency department chest pain patients: prevalence, comorbidity, suicidal ideation, and physician recognition. The American journal of medicine 101, 371-380.

Huffman, J.C., Pollack, M.H., 2003. Predicting panic disorder among patients with chest pain: an analysis of the literature. Psychosomatics 44, 222-236.

Ito, L.M., de Araujo, L.A., Tess, V.L., de Barros-Neto, T.P., Asbahr, F.R., Marks, I., 2001. Self-exposure therapy for panic disorder with agoraphobia: randomised controlled study of external v. interoceptive self-exposure. The British journal of psychiatry: the journal of mental science 178, 331-336.

Lee, K., Noda, Y., Nakano, Y., Ogawa, S., Kinoshita, Y., Funayama, T., Furukawa, T.A., 2006. Interoceptive hypersensitivity and interoceptive exposure in patients with panic disorder: specificity and effectiveness. BMC Psychiatry 6, 32.

Mendlowicz, M.V., Stein, M.B., 2000. Quality of life in individuals with anxiety disorders. Am. J. Psychiatry 157, 669-682.

Meuret, A.E., Ritz, T., Wilhelm, F.H., Roth, W.T., 2005. Voluntary hyperventilation in the treatment of panic disorder-functions of hyperventilation, their implications for breathing training, and recommendations for standardization. Clin. Psychol. Rev. 25, 285-306.

Prasko, J., Mainerova, B., Diveky, T., Kamaradova, D., Jelenova, D., Grambal, A., Latalova, K., Sigmundova, Z., Silhan, P., 2011. Panic disorder and stigmatization. Activitas Nervosa Superior Rediviva 53, 194-201. 
van den Hout, M.A., van der Molen, G.M., Griez, E., Lousberg, H., Nansen, A., 1987. Reduction of CO2-induced anxiety in patients with panic attacks after repeated CO2 exposure. Am. J. Psychiatry 144, 788-791.

Verburg, K., Pols, H., de Leeuw, M., Griez, E., 1998. Reliability of the $35 \%$ carbon dioxide panic provocation challenge. Psychiatry Res. 78, 207-214.

Weissman, M.M., Bland, R.C., Canino, G.J., Faravelli, C., Greenwald, S., Hwu, H.G., Joyce, P.R., Karam, E.G., Lee, C.K., Lellouch, J., Lepine, J.P., Newman, S.C., Oakley-Browne, M.A., Rubio-Stipec, M., Wells, J.E., Wickramaratne, P.J., Wittchen, H.U., Yeh, E.K., 1997. The cross-national epidemiology of panic disorder. Arch. Gen. Psychiatry 54, 305-309.

Whalen, D., 2006. The stigma associated with mental Illness. Canadian Mental Health Association. Accessed Online: http://www.cmhanl.ca/pdf/Stigma.pdf.

Zaubler, T.S., Katon, W., 1998. Panic disorder in the general medical setting. J. Psychosom. Res. 44, 25-42. 
Valorization 
A $\left.10^{3}\right)^{3}$ 


\section{Summary}

Samenvatting

\section{Valorization}

Acknowledgments

Curriculum vitae

Publication list 
Here it is, my book, my "scientific driver's licence". Many said it before and I have to repeat it: It would not have been possible without the help of so many people. Where to start... this may not be only the most read chapter, but also one of the few opportunities to finally express gratitude and say what we thought all the time, but often did not literally say. Every time you start a new project or do a work visit, there is the potential it will become an unforgettable time, if you end up in the right environment. I am very grateful that I worked together with bright and passionated colleagues, and that I met many great people during my work visits, who all they deserve a few personal words. Grap a cup of coffee and a cookie, it is going to take a bit longer...

Professor Harry Steinbusch, ik wil u bedanken dat u als promotor mijn PhD project hebt begeleid. $U$ gaf mij de vrijheid om binnen twee divisies te werken en mezelf te ontplooien in het lab. Ik waardeer de interesse die u gedurende de afgelopen jaren toonde, bijvoorbeeld in het verloop van de huidige studie of de plannen voor de toekomst. Uw vooruitdenkend vermogen heeft mij altijd geholpen.

\section{Mijn co-promotoren, Dr. Koen Schruers en Dr. Daniël van den Hove}

Mijn Yoda's, hoe moet ik jullie in een alinea bedanken? In de afgelopen jaren voelde ik mij alsof ik in een oceaan zwom. Zo veel richtingen, zo veel mogelijkheden. Soms zwom ik goed vooruit, soms was ik de oriëntatie kwijt of moest ik door sterke golven heen. Ik bleek stressbestendig te zijn, maar dit komt vooral ook door jullie. Kinderen springen het water in zonder bang te zijn, zolang ze maar weten dat er iemand is om hen omhoog te trekken wanneer de golven te sterk worden of wanneer ze niet meer weten waar ze naartoe moeten. En deze 'iemand' zijn jullie voor mij. Heel erg bedankt! Ik heb veel van jullie geleerd en zo veel steun ervaren. Ik hoop ooit een gedeelte hiervan terug te kunnen geven, misschien in de vorm van een publicatie, die ons beroemd maakt ;).

Koen, King of $\mathrm{CO}_{2}$, King of wine. Hoeveel aandacht heb ik gevraagd... bedankt voor het geduld, ook wanneer ik de 10e keer in één week binnenliep. Ik bewonder jouw vermogen het bos door de bomen te zien en dass du immer die Kernaussagen in meinen langen, durch Komma getrennten Sätzen, die für mich, aber nicht unbedingt für andere, deutlich waren, verstanden hast.

Daniël, bedankt dat je altijd te bereiken bent en voor je humor. Ik zat vaak lachend achter de computer om vervolgens een antwoord te bedenken (ook een manier om de creativiteit van je Aios te stimuleren). Ik kan steeds nog niet geloven dat je met een foto in je hand op de SfN bent rondgelopen en hem ook nog hebt gevonden. Don't Hassel The Hove! 
The evaluation committee, thank you for taking the time to read my thesis.

\section{Vijverdal}

Ik begin eens in de kelder, waar ik het eerste half jaar zat. Ten eerste, alle deelnemers van mijn studies, heel erg bedankt voor jullie inzet en tijd! Sara, het was fijn met u samen aan de eerste studie te werken. Toen ik begon was alles nieuw voor mij en met z'n tweeën was het toch een heel stuk leuker. Julien, wat ik ook moest hebben, jij hebt echt alles samengeknutseld, bedankt. Anouk, Jojanneke, Suzanne, Inge L., Louis, en Rudy, ik denk graag terug aan de korte, maar gezellige, babbeltjes tussendoor. Inge K., dank je wel dat ik gebruik mocht maken van uw prachtige dataset, enorm waardevol. Gabriel en Klara, bedankt voor jullie adviezen tussendoor en de tijd om met een ander perspectief naar mijn papers te kijken. Jos, wij begonnen pas iets later als directe collega's samen te werken. Telkens als ik kwam opdagen of een mail van mij binnenkwam, betekende het extra werk voor jou. Bedankt dat je het altijd met een glimlach hebt geaccepteerd (je had toch geen andere keuze, hè). Bedankt ook aan alle andere AAC leden die op de ene of andere manier betrokken waren.

Nu de 2e verdieping. Mijn Aio-lichting: Dennis, kamergenoot voor meer dan twee jaar. Te warm, te koud, fijn dat we samen mochten verhuizen. Jij hebt mij zo vaak geholpen wanneer ik met mijn fruit-computer vast zat, bedankt voor je tijd. Jessica, "koekje gegen koffie?" - wie oft haben wir das gesagt und in Taten umgesetzt, es war gezellig dich am Ende in Vijverdal zu haben, bis bald in Oz hoffentlich! Claudia, wie du alles unter einen Hut gekriegt hast ist unglaublich. Christine, toen jij begon werden we kamergenoten voor een tijdje en nu gaan we in dezelfde week promoveren. Misschien moeten wij van tevoren weer zo veel koekjes samen eten, dan komt het goed;). Martine, jij bent een van de mensen die slachtoffer was van mijn 1 op 1 vertalingen. Weet jij nog toen ik enthousiast tegen jou zei "jij bent aangekomen", ik bedoelde het in de context van een $10 \mathrm{~km}$ run die je had gehaald. Binnen een fractie van een seconde kon ik aan jouw gezicht zien dat er iets helemaal mis was (de Nederlandstalige Duitsers knikken nu waarschijnlijk met empathie), sorry :-D. Feikje, Petra, Mayke en Catherine, het was leuk met jullie in de lunchpauzes of tussendoor van gedachten te wisselen. 
Lies, één van de twee Belgen in mijn naaste omgeving en toch zo veel invloed op mij dat ik meer Vlaams spreek dan sommige Nederlanders. Mercikes voor de tijd die je altijd hebt genomen wanneer ik inspiratie nodig had, voor de gezelligheid (lunchpauze ;)), en je kritische kijk op mijn papers.

Wolfgang, wenn man zu dir ins Büro läuft, gibt es nur zwei Optionen. Entweder man bekommt eine klare Antwort oder einen Termin um eine Antwort zu bekommen. Danke, dass du ein Statistiker bist, der Probleme löst und nicht noch 10 weitere verursacht (oder diese dann zumindest gleich wieder löst).

Ron, het is zo fijn te weten dat wij met elk computerprobleem bij jou kunnen binnenlopen. Wanneer jij een dagje vrij hebt wordt iedereen op de afdeling onrustig ("Ron heeft verlof? Ja, dan moeten wij ook allemaal vrij pakken, zonder hem kunnen we toch niet werken."). Met een glimlach denk ik aan de dag terug dat je toevallig binnenkwam toen ik probeerde te achterhalen hoe je een CD uit een fruit-computer haalt ("Rooon, die heeft geen knop"). Bedankt!

Onze secretaresses, Trees, Jolanda en len, waar zouden wij zonder jullie zijn. Ruimtes reserveren, pennen, jullie wisten altijd waar ik iets kon vinden of wie ik moest benaderen. Bedankt voor al het werk dat jullie op de achtergrond doen. Truda en Debora, bij jullie kan altijd iedereen terecht, bedankt. Zeker in het begin leerde ik snel "Wat Truda zegt is wet" ;).

Mijn studenten, Manon, Angela, Jamie en Roman, jullie hebben een pak werk van mij weggenomen. Dank jullie, ik hoop dat jullie een fijne tijd hadden. Yori, gezellig je op onze werkvloer te hebben. Ik wens je veel succes met je promotietraject, niet vergeten: Ook met de stenen die je weg versperren kun je iets moois bouwen. Nele V. en Sanne S., ook hebben wij nooit samengewerkt toch hadden jullie altijd even tijd voor een babbeltje. De research retreat was gezellig toen. Inez en Jim, bedankt voor jullie kritische blik en bijdrage aan mijn papers. Jullie zijn onderzoekers met zo veel inspiratie. Ed, ik vond het altijd erg attent van jou om aan mij te denken wanneer je iets onderzoeksrelevant in de krant had ontdekt of gewoon je interesse toonde hoe het met mij ging. Alle andere (oud-)collega's, ik heb van de gezelligheid in de keuken, de dagjes uit en research retreats genoten. Het was een fijne tijd! Nieuwe Aio's, ik wens jullie veel succes en plezier met jullie trajecten. Progress is when every mistake is a new one ;).

Bedankt voor jullie geduld en begrip wanneer ik weer een taalfout maakte ("ijsklontertjes", "gewist") of nieuwe woorden had uitgevonden. Ik ben steeds nog van mening dat het woord "onderdrijven" ("Dit is wel onderdreven") een nuttige toevoeging aan jullie taal zou zijn. 


\section{Randwyck}

My roommates: Mark en Roy, zie ik jullie misschien volgend jaar terug in de VS? Het was leuk met jullie over kleuringen en onderwijsdingen te brainstormen. Op naar de volgende papers! Ehsan, thank you for your support, when I needed help to get started with something. I wish you all the best for your defence (go Ehsan, go Ehsan). Artemis, when you came the number of organized events suddenly increased. Let's go for the first place at the next pubquiz! Caroline en Rianne, bedankt dat jullie bij mijn eerste studie in de kelder naast mij stonden en voor jullie input tussendoor.

De TNP groep: Gunter, "The big G", "The Gene Hunter", jij verdient deze namen terecht. Dank je wel dat ik altijd met vragen bij jou terecht kon. Het was fijn dat je altijd hebt meegedacht. Bart, Julie, Fabien, Leonidas, Shahed, and all others, thanks to all of you, the meetings were very productive and interesting.

Wat had ik gedaan zonder de analisten (dat zegt iedereen, maar het is gewoon waar). Hellen, Marjan, Denise, en Barbie, hoe vaak heeft jullie advies me verder geholpen, hoe vaak waren jullie aan mijn zijde of hebben iets voor mij "op de achtergrond" gedaan. Bedankt!

Mijn studenten, Dean, Renzo, Anneke, Gerben, en Jay. Ik heb veel van jullie geleerd en jullie hopelijk ook van mij. Bedankt voor jullie hulp in het lab.

Jo en Lisa, mede-FNers, ongelofelijk maar het is tijd om te promoveren. Veel succes met het afronden van jullie projecten. Jos, het is zo ver, de eerste lichting wordt "volwassen". Wat we voor het leven hebben geleerd: A mouse is not a small rat and a rat is not a small human, hè.

Jochen, ook jij bent altijd heel behulpzaam met advies, bedankt. Celine, my "stereo park pilot" partner, we were so efficient - as long as we beeped in the same rhythm. Melanie, thanks for your supporting words here and there. Daan en Maria, partners in crime aka practical training for students, how many sessions did we supervise together. Nick, João, Maartje, and Pim, thanks for the nice courses. Marlies, dank je wel voor jouw ondersteuning toen ik mijn eerste stapjes in het $\mathrm{CO}_{2}$ veld zette. Wiel, bedankt voor al de klussen met de laptop, software programma's, of de server. Bedankt aan alle andere collega's voor de leuke samenwerking (onderzoek en onderwijs).

Medewerkers van de CPV en de Facilitaire Dienst, bedankt, zonder jullie hadden de experimenten nooit op die manier kunnen plaatsvinden, heel erg bedankt.

Rachelle, Marie-Thérèse, en Lisa P., bedankt dat jullie deuren altijd open stonden. Ankie en Laurent, voor alle financiële vragen komen wij bij jullie terecht. Dank voor jullie hulp. Laurent, had $\mathrm{u}$ niet zo hard getrapt om een tandem met baggage van $1.58 \mathrm{~m}$ grootte achterop vooruit te bewegen, had ik het waarschijnlijk nooit gehaald de Cauberg op te fietsen. Nicole Senden, bedankt voor de goede organisatie van al de cursussen. 


\section{Master in Affective Neuroscience}

I met many great people during the master's program, but I want to particularly thank a few of them. Brad and Björn, whenever I did one of the courses, at least one of you was there, too. It was so nice going out for dinner and to watch the world cup games (thanks Björn that at least one person was happy for me when Germany won 7:1). Hope to see you soon.

Leni, jij was niet enkel bij de master betrokken maar ook in het dagelijkse leven op Vijverdal. Het was zo gezellig met jou. Ik zou het liefst zeggen dat jij vaak zo'n familiaire sfeer creeërde dat ik je als oma wou adopteren, maar daarvoor ben je veel te jong!

Wendy, je bent een waardige opvolgster. Geen taak te veel, altijd goed gezind. Bedankt voor al het organisatorisch werk dat je doet. Ik kijk uit naar goed weer in Firenze dit jaar (nadruk ligt op goed, maar ik zal toch een trui inpakken).

\section{New Haven, USA}

Dr. Gordon Buchanan, dear Gordon, thank you for not running away when a tall Dutch guy with your picture in his hand approached you at the SfN meeting. I am very thankful that I could come to your lab, it was a great time. Thank you for all the opportunities you offered me and your support. I am looking forward to our future collaborations, including the lunch tradition. And remember that only one thing helps, when you get sick next time: vinegar!

Dan, you were my best lab colleague. Even if there would have been a second lab colleague, you would have had realistic chances to get the title. Your jokes often made my day. Thanks for helping me, when necessary, and figuring out things together. Do you remember "Okay, Nicole, you can let it go" - "I... can't"... we laughed tears... one of my first experiences with superglue. Thanks, also to your family, for inviting me over for Hanukkah/Thanksgiving, it was a very special evening.

My friends, it was so much fun, every one of you made my time special: Leonie, es began im international office mit einem Bundesatler auf dem Reisepass. Du wurdest ein wichtiger Teil von so vielen Erlebnissen. Danke! Danke für die vielen kurzen Treffen abends bevor es zurück ins lab ging. Ich freu mich auf unsere weiteren Ausflüge. Barbara, you gave the warmest welcome I could have wished for. Although neuroscience and literature do not have a lot in common, we never ran out of topics to talk about. Thank you for being there and grazie per avermi mostrato la bella Roma! Sam and Bryan, thanks for the nice chats after a long day. Lisa and Pieter, somehow I immediately think of pizza and muffins, when I think about you. I am wondering why... You two always make me laugh "Braai! BBQ is a flavour!" Ek hoop dat ek julle gou kan besoek vir 'n ware braai. Kasey, hit by a car on one 
of your first days was not the best start in New Haven, but I hope that you, in the end, keep the time in good memory. Thank you for my first Halloween with pumpkin carving and candy corn. I enjoyed being part of your first experience to take a bus (really?!). George, Rob, and Shamano, thank you for showing me the real American culture and my birthday party. Only guys can come up with the idea to decorate a cake with as many tealights as possible ;). Clarice and Ruaidhri, it was a lot of fun. Rory, you brought back so many memories of my time in Ireland, thanks!

\section{Würzburg, Deutschland}

Professor Klaus-Peter Lesch, ich danke Ihnen für die Zusammenarbeit und all die Möglichkeiten, die Sie mir geboten haben. Ich habe viel in Ihrem Labor gelernt und bewundere, dass Sie so viele verschiedene Projekte betreuen und doch die Zeit finden auf dem neusten Stand zu bleiben.

Judith, vielen Dank für die Unterstützung bei allen Formalitäten und für die leckeren gebackenen Sachen, die du öfters mitgebracht hast.

Magda, wie gern denke ich an die Zeit und deinen Humor zurück ("Du benimmst dich wie ein echter LLer"). Danke, dass du tagelang an meiner Seite warst und dass du Ruslan mit mir geteilt hast. Ruslan, mit was für einer Geduld du pipettieren geübt und mit mir RNA extrahiert hast. Ab und zu hast du bestimmt mal nachgedacht, ob du nicht Dinge ins oberste Regalfach legen sollst, so dass ich ohne dich nicht dran komme ;). Gabi, du arbeitest mit einer bewundernswerten Effizienz und Geschwindigkeit, so dass wir oft nur an der Staubwolke erkennen konnten, in welche Richtung wir laufen mussten um dich zu finden (im übertragenen Sinne natürlich, in unserem Labor gibt's keinen Staub!). Danke für deine Hilfe. Karla, Frühjahr 2013, zwei Doktoranden und eine straff geplante Verhaltensstudie... Tigerenten, XXL Maleranzug, Licht und Sucroseflaschen (ohne Worte). Danke auch für all deine Hilfe bei meiner eigenen Studie. Christiane, danke für deine detailierten Antworten auf all meine Fragen. Ich hoffe, wir können das Kind noch schaukeln. Sarah S. und Miriam, wisst ihr noch: Kekse/Schokolade oder der Test meiner "Stressbeständigkeit" (da wird mir schon wieder ganz flau, Sarah ist einfach viel tougher ;) ). Kathrin und die Julias, von Statistik bis Lederjacken, euch war keine Frage zu lästig, danke.

Allen anderen, von Angelika, Inge, den Nicole's, Carola, Thomas, Marion, Jonas, Ben, über Charlotte bis zum Rest in der Bib: danke! Ich danke euch allen für die lehrreiche Zeit und Geduld, wenn ich alle Sprachen durcheinander geworfen hab. Ihr habt mich mit offenen Armen empfangen und seid der beste Beweis, dass die Deutschen gar nicht so kalt sind wie immer behauptet wird. 
Nach der Arbeit sorgte meine WG für Abwechslung. Jan, du warst der erste, der mich in Würzburg willkommen geheißen hatte. Ich danke dir für die vielen WG Abende, deine (gnadenlose ;) ) ehrliche Meinung, und dass du mich sofort integriert hast. Marie, es war schön, dass du so oft vorbei gekommen bist. Wer hätte sich sonst so kindisch mit mir gefreut, als ich Jan das erste Mal beim Durak spielen besiegt habe... Sarah, danke für die Spieleabende, das leckere Essen und deine Hilfsbereitschaft und Unterstützung am Ende, obwohl du selbst im Stress warst! Oli, wie gern würde ich mal wieder eine Pizza mit euch essen.

Edel, and Frank, the first time that I left home, my first flight... you welcomed me like a family member, you made me feel home, you introduced me to the Irish culture. Fintan and Jude, you were only 3 months old, just discovering the world, and yet able to teach me so many lessons. It was a great and unforgetable time that made me the "adventureous" person I am today. Go raibh mile maith agath!

'54, '74, '90, 2014: Sommermärchen 2014, der vierte Stern. Danke, Jungs! Danke, Jogi!

Hans Peeters, ik vind het erg fijn dat $u$ bereid was het coverplaatje voor mijn boekje te tekenen. Ik vind het geweldig, super bedankt! Bedankt Leny voor het lekkere avondeten. Leuk dat jullie ons tijdens Maastricht's Mooiste hebben ondersteund.

Suzanne, team "bridge to bridge". Jij en Sanne hebben ervoor gezorgd dat ik met hardlopen ben begonnen. Gelukkig zijn de bruggen in Maastricht niet zo ver uit elkaar ;).

Sebastian, danke für deine Unterstützung, den ein oder anderen Schubs in die richtige Richtung und für deine Gelassenheit, wenn eine Nachricht mit "Das Wichtigste ist doch, dass wir gesund sind" begann.

Andi, für die relativ kurze Zeit haben wir doch schon einiges erlebt, was uns zusammenschweißt. Lustig war's. Auf dass es weiterhin so bleibt, in Sulzfeld, Würzburg, Maastricht oder wo auch immer.

Tobias, der harte Kern in der Heimat. Schön, dich immer da zu wissen, wenn ich mal wieder vorbei schaue. Und durch deine Pflanzen warst du doch auch irgendwie bei mir in Maastricht.

Elina, my crazy and lovely roommate. Two people who went to Yale coincidentally end up as roomies in Maastricht. It was fun to talk about life and my (a)typical German personality traits (no, I would never give away my fridge or write notes on the wall ;)). Thanks for making me laugh so often.

Nicole, Kekse, Kuchen, Spinning und Skaten... Obwohl du alle Hände voll zu tun hast, freue 
ich mich, dass du zu den Menschen gehörst, die einfach mal anrufen statt zu schreiben und ist es nur für $5 \mathrm{~min}$ ! Sibren, thanks for the lovely dinners, also when I unexpectedly show up at dinner time. Jamie and Ando, thanks for your flirty eyes that always make me smile.

Sanny, wij hebben zo veel gedeeld in de afgelopen vier jaar. Jij was er toen ik mijn een, twee... tegenslagen had. Niet minder belangrijk, jij was er ook op de goede dagen en nu promoveren wij in dezelfde week. Bedankt dat jij zo'n "Sonnenschein" bent, mijn Nederlands naar echt Nederlands vertaalt ("zij bedoelt..."), maar toch accepteert dat ik vaak beter ben in de Nederlandse $d / t$ spelling. Fijn dat je altijd een open deur hebt (altijd?! Nou, af en toe is die toch dicht en jij zorgt ervoor dat dicht ook inderdaad dicht is :-p). Graag denk ik terug aan al die dingen die wij hebben gedaan. Het is fijn je aan mijn zijde te hebben!

Iris, toen jij ons klein angstteam kwam versterken werd het nog leuker, op de werkvloer maar ook in de vrije tijd. Wij hebben nooit aan hetzelfde project gewerkt en toch had ik door jou leuke ervaringen, waaraan ik graag terug denk: Was het Annie beter te kunnen leren kennen of de 7T scanner in te mogen. Onze plank challenge in de namiddag, carnaval, zelfgemaakte cocktails, en de lekkere etentjes tijdens de cursussen in Firenze en Maastricht ("Ik zit zo vol" - "Ik ook" - "Toetje?" - "Oké!") zal ik altijd blijven herinneren. Bedankt voor de gezelligheid en dat jij tijdens mijn promotie naast mij staat!

Mirjam, meine liebe Mir-Jam, danke für die vielen Telefonate über bis zu Tausenden von Kilometern. Ich kenne wenige Menschen, die sich so offen und ehrlich für einen mitfreuen können. Danke, dass du dir immer Zeit nimmst und fürs Händchenhalten im 80m hohen Kettenkarussel (ich nie wieder in das Ding und du dafür nicht mehr in die Achterbahn Deal?)! Danke, dass es dich gibt, wir uns gefunden haben und du in allen Lebenslagen an meiner Seite bist.

Oma, danke, für die vielen Bleche Kuchen, die ich importieren durfte und die mir über Monate jedes Wochenende ein Stückchen Heimat gebracht haben. Es wird Zeit, dass du den neuen Backofen endlich mal richtig einweihst (und das ist kein kleiner Wink mit dem Zaunpfahl, sondern mit dem Scheunentor... los geht's, du bist Rentner, du hast Zeit!).

Markus, so gut wie nichts, was ich dir kaputt gegeben habe, kam unrepariert zurück. Danke, dass du so viel Geduld hast und auch das letzte Reiskorn im Handy gefunden hast (komm, die Idee an sich war net schlecht).

Mama und Papa, ich habe euch in all den Jahren sicher das eine oder andere graue Haar beschert ("Amerika?! Gibt's nichts in der Nähe?"), aber hoffentlich auch ab und zu ein Schmunzeln ins Gesicht gezaubert, wenn ich z.B. auf der Golden Gate Bridge stand und angerufen habe um euch zumindest am Lärm teilhaben zu lassen. Danke, dass ihr mir die 
Freiheit gebt meinen Weg zu gehen und immer bedingungslos hinter mir steht. Danke für die unendlich vielen kleinen Dinge, die ihr tut. Als Kind denkt man hin und wieder, dass man nie so werden möchte wie seine Eltern. Wenn ich aber jetzt Markus und mich angucke, dann muss ich sagen, dass ihr es doch ganz gut gemacht habt ;) (ich würde meinen erwachsenen Kindern auch noch einen Adventskalender kaufen)!

Thanks to everyone who was part of my big adventure. I hope that many of you will also be part of my future.

$\mathrm{NiCO}_{2} \mathrm{le}$ 
A $\left.10^{3}\right)^{3}$ 


\section{Summary}

Samenvatting

Valorization

Acknowledgments

Curriculum vitae

Publication list 
Nicole Leibold was born on November 20th, 1984 in Schlüchtern, Germany. After graduating from secondary school (Ulrich-von-Hutten Gymnasium, Schlüchtern), she spent 9 months in Dublin, Ireland, as au pair. In 2006, she moved to Maastricht to study Molecular Life Sciences. After obtaining the bachelor degree in 2009, she continued with the twoyear research master program Cognitive and Clinical Neuroscience and specialized in Fundamental Neuroscience. During her master's internship at the Department of Psychiatry and Neuropsychology, Nicole became familiar with experimental fear provocation. After graduating (cum laude) in 2011 and obtaining a Kootstra Fellowship for talented aspirant PhD students, she worked on a translational project to study the pathophysiology of panic disorder under the supervision of Dr. Koen Schruers and Dr. Daniël van den Hove at the School of Mental Health and Neuroscience (MHeNS), Maastricht University. During this time, she spent four months at Yale University, USA, and four months at the University of Würzburg, Germany. Moreover, Nicole received grants awarded by the Van Leersumfonds (Koninklijke Nederlandse Akademie van Wetenschappen, KNAW, the Netherlands) and the Boehringer Ingelheim Fonds (Germany), and won several prices, including the "Koninklijke Nederlandse Maatschappij tot bevordering der Geneeskunst (KNMG) Consolidation Prize". The results of her PhD project are described in this doctoral thesis. In addition to working on her PhD project, Nicole obtained the International Master in Affective Neuroscience degree by Maastricht University and the University of Florence, Italy. 
A $\left.10^{3}\right)^{3}$ 


\section{Summary}

Samenvatting

Valorization

Acknowledgments

Curriculum vitae

Publication list 


\section{Scientific publications in international peer-reviewed journals}

Leibold, N.K., van den Hove, D.L.A., Esquivel, G., De Cort, K., Goossens, L., Strackx, E., Buchanan, G.F., Steinbusch, H.M.W., Lesch, K-P., Schruers, K.R.J. The brain acid-base homeostasis and serotonin: A perspective on the use of carbon dioxide as human and rodent experimental model of panic. Accepted for publication in Prog. Neurobiol. doi:10.1016/j.pneurobio.2015.04.001.

Knuts, I.J., Esquivel, G., Kenis, G., Leibold, N.K., Goossens, L., Overbeek, T., Schruers, K.R., 2014 Therapygenetics: 5-HTTLPR genotype predicts the response to exposure therapy for agoraphobia. Eur Neuropsychopharmacol. 24, 1222-1228.

Goossens, L., Leibold, N.K., Knuts, I.J., Esquivel, G., Schruers, K.R.J, 2014. Brainstem response to hypercapnia: A symptom provocation study into the pathophysiology of panic disorder. J Psychopharmacol. 28, 449-456.

Leibold, N.K.*, Van den Hove, D.L.*, Strackx, E., Martinez-Claros, M., Schruers, K.R., Lesch, KP., Steinbusch, H.W., Prickaerts, J. (*contributed equally), 2014. Prenatal stress and subsequent exposure to chronic mild stress in rats; interdependent effects on emotional behaviour and the serotonergic system. Eur Neuropsychopharmacol. 24, 595-607.

Leibold, N.K., Viechtbauer, W., Goossens, L., Myin-Germeys, I., Steinbusch, H.W.M., Van den Hove, D.L.A., Schruers, K.R.J., 2013. Carbon dioxide inhalation as a human model of panic: The relationship between emotions and cardiovascular physiology. Biol Psychol. 94, 331-340.

\section{Submitted}

Leibold, N.K., van den Hove, D.L.A., Viechtbauer, W., Kenis, G., Goossens, L., Knuts, I., Smeets, H.J., Myin-Germeys, I., Steinbusch, H.M.W., Schruers, K.R.J. Amiloridesensitive cation channel 2 genotype affects the response to a carbon dioxide panic challenge. 
